\title{
Repression and Realism in Postwar American Literature 1945-1955
}

By

Erin Mercer

\author{
A thesis \\ submitted to the Victoria University of Wellington \\ in fulfilment of the requirements for the degree of \\ Doctor of Philosophy \\ in English
}

Victoria University of Wellington

2010 


\section{Abstract}

This thesis focuses on the uncanny in literature produced in America during the first decade following World War II. The period between 1945 and 1955 was marked by repressive socio-political forces such as McCarthyism and cultural conformity which complicated the representation of what Philip Roth refers to as "demonic reality." I explore the ways in which the avoidance and minimisation of the unpleasant created a highly circumscribed version of postwar American life while also generating a sense of objectless anxiety.

According to the theories of Sigmund Freud, repression inevitably stages a return registered as the "uncanny." Animism, magic, the omnipotence of thoughts, the castration complex, death, the double, madness, involuntary repetition compulsion, live burial and haunting are all deemed capable of provoking a particular anxiety connected to what lies beneath the surface of accepted reality. Although it is common to argue that fantasy genres such as science fiction and gothic represent the return of what is repressed, this thesis explores several realist novels displaying uncanny characteristics. The realist novels included here are uncanny not only because they depict weird automaton-like characters, haunting, and castration anxieties, thus exhibiting a conscious use of Freudian theory, but because the texts themselves act as the return of the repressed. Norman Mailer referred to this unsettling phenomenon when he described writing as the "spooky" art; spooky because although a writer might sit down to consciously write a particular story, another unwilled story might very well appear. 


\section{Acknowledgements}

My most heartfelt thanks go to my supervisors Charles Ferrall and Anna Jackson whose tireless efforts in reading innumerable drafts, offering suggestions and editing manuscripts was only matched by their generous willingness to provide letters of support for financial assistance and job opportunities. Over the four years it has taken to complete my $\mathrm{MA}$ and $\mathrm{PhD}$, they have never once failed to make time for me, regardless of the significant demands posed to them by teaching, research and family. Their expertise and intelligence has been invaluable; so too has their encouragement and humour - I doubt that other postgraduate students enjoy such lively supervisor meetings! The best parts of this study must be attributed to their insight and support, while any deficiencies are entirely my own.

I would also like to thank the staff in the School of English, Film, Theatre and Media Studies at Victoria University of Wellington, particularly Harry Ricketts, who took time from his busy schedule to share his expertise in the poetry of World War I, and Mark Williams, whose advice was eagerly sought and generously given. His cheery "Good Morning" at the start of each day was much appreciated. Thanks to Helen O'Sullivan, who patiently guided me through various administrative duties and never once laughed at my inability to work the fax machine. Special thanks go to Peter Whiteford, who kindly took the time to advise me on writing a curriculum vitae and who was nothing but encouraging during the fraught process of looking for employment.

My studies were generous funded by Victoria University of Wellington, both through a PhD Scholarship and faculty funding enabling me to conduct research in Auckland, Sydney and New York. The New Zealand Education Postgraduate Study Abroad Award enabled me to deliver a paper based on my research at the 2008 
Australian and New Zealand Association of American Studies, which was an invaluable experience. I am extremely grateful to the J.L. and Kathleen Stewart Postgraduate Research Experience Travel Award, which allowed me to conduct research at New York Public Library's Berg Collection. This award enabled me to access manuscripts and unpublished letters, primary resources I would not have been able to utilise without financial support.

There are of course innumerable other people who assist in various ways over the period it takes to complete a $\mathrm{PhD}$ thesis. I am particularly indebted to Eluned Summers-Bremner at the University of Auckland, who generously allowed a perfect stranger to attend one of her graduate workshops on post-World War II British fiction. Her class provided me with valuable insight as to what was occurring in Britain during the period I was focusing on in American literature and her continuing mentorship has been invaluable. Thanks also to Richard Nicholson at the University of Auckland who organised the opportunity for me to deliver a seminar to the Faculty of Arts based on my research. I am particularly grateful to Anne Garner at the New York Public Library's Berg Collection whose suggestions as to what papers to look at during my period of research at the collection proved very fruitful.

Lastly, thanks always to my mother Pamela Mercer, whose care packages and unwavering support are the foundation of everything I do, and to Zhenya, whose name is always last on the list and first in my heart. Your love and light make forays into darkness possible, so this is for you. 


\section{Contents}

\section{Introduction}

Missing in Action:

Repression, Return, and the Postwar Uncanny

\section{Chapter One}

Automatons and the Atomic Abyss:

Norman Mailer's The Naked and the Dead

$50-82$

Chapter Two

Haunting and Race:

Ralph Ellison's Invisible Man

$83-120$

Chapter Three

The Sacred Other:

Flannery O'Connor's Wise Blood

$121-155$

Chapter Four

The Dubious Double:

Saul Bellow's The Victim

$156-194$

Chapter Five

The Familiar Made Strange:

Paul Bowles' The Sheltering Sky

$195-226$

Chapter Six

Repression and Confession:

Jack Kerouac's On the Road

$227-246$

Conclusion

The Concealment that Fails to Conceal

$247-259$

Works Cíted

$260-292$ 


\section{Missing in Action:}

\section{Repression, Return, and the Postwar Uncanny}

Repression: c. Psychol. The action, process, or result of suppressing into the unconscious or keeping out of the conscious mind unacceptable memories or desires.

During the first decade following 1945, America was dealing with the effects of a war with a casualty toll of an estimated fifty million people, as well as grappling with a new Cold War reality that threatened complete annihilation, yet even the most cursory glance over literature produced between 1945 and 1955 reveals a widespread avoidance of what Philip Roth terms "demonic reality" (Reading Myself 90). While there is little reason to expect Americans to write novels about the actual war, given that conflict occurred at a distance and that information regarding the personal impact of the Holocaust and the bomb was so difficult to obtain, it is reasonable to expect writers of realism to engage with a postwar reality quite different than that of previous decades. The end of World War II might have been the start of an invigorated literary tradition, such as occurred following the First World War, but this was not to be the case. Early war novels such as James Gould Cozzens' Guard of Honor (1948) and Herman Wouk's The Caine Mutiny (1950) studiously avoid both the Holocaust and the atomic bomb, even managing in many cases to completely avoid depictions of combat, and popular novels such as The Hucksters (1946) and The Man in the Gray Flannel Suit (1955) purport to deal with the new difficulties facing the postwar American, but imply that the most pressing threat to existence is conformity and corporatisation. One critic disappointedly observed that "Since 1945, when all signs 
pointed to a literary revival comparable to that after World War I, our literature has actually been in a state of decline" (Geismar 53).

Although some critics were vocal in registering their discontent with a literature that seemed banal and lifeless when compared with that of recent decades, this banality was not linked to the exclusion of disturbing subject matter. In fact, critics frequently expressed gratitude at the avoidance of disturbing material. In a 1952 review of Ralph Ellison's Invisible Man, Irving Howe describes the famous battle royal scene and then reassures the reader that "Nothing, fortunately, in the rest of the novel is quite so harrowing" (454). As Richard Bessel and Dirk Schumann point out that "there can be little doubt that the social and cultural effects of the mass experience of violence and death during the 1940s were profound and colored all aspects of life during the postwar decades, even when this was not necessarily articulated explicitly", but what these effects actually were and what constitutes the connections between the violence of the 1940s and the normality of the 1950s remains “extremely speculative" (7).

The first four decades of the twentieth century saw American culture far more willing to acknowledge the more disquieting aspects of modern life. Literature from the 1890s was marked by social protest, particularly in the works of naturalist writers such as Stephen Crane and Theodore Dreiser, and later writers such as Sinclair Lewis, John Steinbeck and John Dos Passos. Lewis' novel Main Street (1920), Steinbeck's The Grapes of Wrath (1939) and Clifford Odets's play Waiting for Lefty (1935) are all examples of early twentieth century American literature engaged with social inequality, economic disparity and the need for reform. Difficult economic conditions following the First World War and intellectual currents such as Freudian psychology and Marxism contributed to the breakdown of traditional values and young Americans 
of the 1920s were deemed "the lost generation." One result of the turbulence of these years was a rich literary movement spearheaded by writers such as William Faulkner, T.S. Eliot, Gertrude Stein, Ezra Pound, Ernest Hemingway, F. Scott Fitzgerald and the writers of the Harlem Renaissance.

The very richness of American literature produced before World War II only served to highlight the failings of novels written in its aftermath. American fiction since World War II, according to R.W.B. Lewis, "has been rich enough in quantity, but its quality has been somewhat puzzling and contradictory" (144). There have been many novels of "clear artistic competence", but despite using the war as a marker of a new era and referring to a writer known for his writing on the first global conflict, Lewis was unable to explain the absence of "the decisive power of a Faulkner, or a Hemingway, or even a Scott Fitzgerald" (144). Postwar literature was defined as "superior entertainment best embodied in the New Yorker school of writers; writers who are always leading up to something that never happens" (Geismar 54). Edmund Wilson was especially dismissive, saving his most biting comments for bestsellers such as The Turquoise (1946), the crudity of which "has not even the rankness of the juicier trash" (318). Jack Kerouac summed up the situation in a 1951 letter to Alfred Kazin by stating that "fiction is become FETID."

Although the vitality of writing by the Lost Generation was frequently linked to World War I, and although critics seemed dimly aware of the "something that never happens" (Geismar 54) in American writing following World War II, no one appears to have pointed to an avoidance of the unpleasant aspects of a postwar reality for the era's literary banality. John Aldridge came close when he pointed out that "the novels of this war simply do not have the impact that those of the first war had - nor, for that matter, do the novels that have been written so far about the aftermath" ("Search for 
Values" 42). He suggested it is "as if they had been written too easily and their authors had too painless an apprenticeship" ("Search for Values" 43). Utilising common concerns about mass production, Aldridge described the era's literature as "machine-made," more a "prefabricated product" than a finely wrought piece of craftsmanship, "the sort that can be obtained if more problems are avoided than are met and overcome" ("Search for Values" 43).

Like the majority of the era's critics, Aldridge turned away from this brief identification of the absence of painful problems to focus on what came to be a continually reiterated theme in literary discourse. The increasing move towards mass culture and the perceived failure of liberalism meant that the postwar writer had inherited what Aldridge described as "a world without values," the engagement with which "can never form the basis of successful literature" (Devil in the Fire 9). ${ }^{1}$ Critics even justified literary banality by pointing out that it was hardly the writer's fault if the materials they were obliged to work with lacked meaning. Marcus Klein suggested that the era had "no Puritanism, no Babbitry, no Booboisie, no Comstockery. No tyranny of ideology, no ideology at all in the proper sense, no hollow patriotism, no evangelical Christianity. No Prohibition, and scarcely any prohibitions, no prudery, no social complacency, no somnolent insularity" (American Novel 13). To suggest a lack of cultural material as responsible for postwar reticence is startlingly disingenuous given that Klein made this claim only a few years after the Holocaust, a devastating world war, the first combat use of nuclear weapons and the start of a cold war that threatened complete annihilation. This popular line of reasoning saw critics ignoring "demonic reality" in favour of a version of American life much more manageable: one that positioned bland suburban complacency as the

\footnotetext{
${ }^{1}$ Sociologists such as Daniel Bell declared the fifties "the end of ideology." World War II and the Cold War were seen as discrediting both the right and the left, leaving political ideas generally exhausted.
} 
cause of mediocre literature rather than as another symptom of the avoidance of the unpleasant.

\section{Reality and War}

Following the long and difficult years of global conflict Americans were naturally eager to put it all behind them and focus on the good things in life. This was relatively easy, for unlike Europe's devastated landscape America bore little physical sign of the conflict. With no arduous task ahead of rebuilding shattered cities and with initial fears regarding the postwar economy soon put to rest, ${ }^{2}$ there was little reason for America to focus on the nightmares of the recent past and the nation settled into a period of unparalleled prosperity in which citizens could rest secure in the knowledge that they were both the moral victors of the war against fascism and the new global superpower. Increased affluence meant Americans could focus on building homes, acquiring goods and raising families. ${ }^{3}$ The American middle-class expanded dramatically during these years and the availability of consumer items after years of deprivation encouraged a frenzy of materialism with newly developed credit cards put to use purchasing cars, televisions sets and household appliances. Alan Brinkley points out that in 1956, for the first time in American history, workers in white-collar jobs outnumbered those in blue-collar employment; homeownership rose from 40 percent in 1945 to 60 percent in 1960; and by the end of the fifties 75 percent of all families owned cars, 87 percent owned televisions and 75 percent owned washing machines (66).

\footnotetext{
${ }^{2}$ Many thought that the economic downturn after World War I would be repeated after World War II. After a few rocky years following 1945, however, America's economy strengthened and continued to grow throughout the 1950s.

${ }^{3}$ Elaine Tyler May argues that the Cold War ideology of containment and the domestic revival were "two sides of the same coin: postwar Americans' intense need to feel liberated from the past and secure in the future" (10).
} 
Popular art that sprang from the "happy days" vision of postwar culture were sunny portrayals of domestic life such as television sitcoms Leave it to Beaver and Father Knows Best, sentimental melodramas such as Douglas Sirk's Technicolor All that Heaven Allows (1955) and humorous bestsellers such as Edward Streeter's Father of the Bride (1949). Although films and novels frequently acknowledged anxiety, they did so by aligning uncertainty with solvable issues deemed relevant to the period. In Frederick Wakeman's bestseller The Hucksters (1946), for example, the anxious advertising executive acknowledges "the Fear" which pervades the offices of Wall St as well as the paranoia which sees his colleague warn, "Somebody's going to hear you talking like that one of these days and report you. I wouldn't be surprised if he had spies planted in the agency" (Wakeman 90), but the protagonist's "dark and gloomy" feelings about the future are alleviated when he predictably runs into the beautiful woman whose love will facilitate his redemption. Although Vic has witnessed "the children of that harsh parent, Europe, lose all faith in the men who led them, the gods who once comforted them, and finally, and oh, how inevitably, in themselves" (Wakeman 96), it only takes a few outings with Kay (who unfortunately is married) to transform an alienated cynic into a fully engaged idealist who stands up to the bullying Beautee soap executive and who affirms the status quo by sacrificing his illicit love for the sake of Kay's socially-sanctioned marriage. Wakeman's protagonist is rewarded with a promotion and a new sense of psychic ease, which the reader has little doubt will facilitate a more successful domestic pairing in the near future.

Dwight Eisenhower summed up the era's optimism in 1949 when he claimed during a commencement address at Columbia University that there "is nothing wrong with America that the faith, love of freedom, intelligence and energy of her citizens 
cannot cure." The most popular authors of the period adhered to this outlook and were categorised by novelist Harvey Swados as "curative" writers whose reassuring tomes offered "aid in the quest for security" (190). Laura Z. Hobson's Gentleman's Agreement (1947), John P. Marquand's Point of No Return (1949) and Herman Wouk's Marjorie Morningstar (1955) all admit to a certain amount of unease, but clearly link the difficulties facing the postwar individual to acceptable social and political issues, particularly the effects of corporatisation and conformity. ${ }^{4}$ Richard $\mathrm{H}$. Pells observes that the primary dangers of the first postwar decade were identified as standardisation, uniformity and the moral consequences of abundance rather than the social inequality and economic exploitation that concerned America during the years of the Great Depression (187). Curative novels presented acceptable anxieties in manageable form and offered reassurance through the eventual defeat of any threat. So while Hobson's bestseller Gentleman's Agreement might appear to be an engagement with the horrors of anti-Semitism, its focus is on a manageable version of prejudice which sees Jews snubbed at parties and barred from country clubs and never even mentions, let alone depicts, the orchestrated murder of approximately six million European Jews. The novel presents a sanitised version of a "topical issue" and suggests that the American version of anti-Semitism is far less troubling than that of Europe. $^{5}$

\footnotetext{
${ }^{4}$ Andrew Hoberek points out that by the end of World War II there were over 500, 000 fewer small businesses than at its start and over 1,600 mergers had taken place, about one-third of which involved corporations worth $\$ 50$ million or more taking over smaller enterprises (7).

${ }^{5}$ Deborah E. Lipstadt describes a 1953 episode of This is Your Life devoted to the story of Hanna Kohner, a Holocaust survivor whose husband, father and mother were all killed at Auschwitz. She settled in America with her second husband who escaped from Germany prior to the war. Lipstadt points out that this show was one of the earliest treatments by American television of the Holocaust and its portrayal "eschewed gloom and doom and ended on a note of 'good overcomes all' - particularly if that good is American in origin." The episode ends with the host's reassuring conclusion: "The neverto-be-forgotten tragic experiences of your life, Hanna, have been tempered by the happiness you've found here in America. . . This is your life, Hanna Block Kohner. To you in your darkest hour America held out a friendly hand" (Lipstadt 197).
} 
Similarly, films such as Duck and Cover (1952) seem to point to an engagement with the horror of the atomic bomb, but its buoyant depictions of methods for surviving atomic attack completely avoid the fact that such an attack would mean either immediate death from the blast, lingering death from the effects of radiation or, at best, existence in a radically altered, post-apocalyptic world. Meant as an instructional film and shown in schools across America, Duck and Cover begins with an animated sequence starring a turtle named Bert whose pleasant stroll is accompanied by the jaunty Duck and Cover theme:

There was a turtle by the name of Bert and Bert the turtle was very alert. When danger threatened him he never got hurt, he knew just what to do...He ducked! And covered! Ducked! And covered! He did what we all must learn to do, you, and you, and you, and you! Duck and cover!

Although Bert is suddenly attacked by a monkey wielding a firecracker, he survives the resulting explosion by adhering to the duck and cover strategy. What is particularly striking about the film, which then switches to live action, is the obvious fact that strategies such as ducking under a desk, lying in a gutter or shielding one's face with a newspaper would have little or no effect on the chances of survival during nuclear attack. The fact that so many Americans accepted the officially sanctioned view of survivability just a few years after the devastation of Hiroshima and Nagasaki points to how well the realities of atomic horror were avoided.

A 1946 letter to Time magazine acknowledged the editors' claims about the repression of the bomb's horror and wondered how a better world could be created "when the people of a democracy just sit back and try to repress their anxiety?" (Purcell, "People are Afraid"). Although there was a large body of civil defense literature and educational films, and although Life magazine was filled with advice on how to build, stock, even interior decorate a bomb shelter, the massive devastation of atomic attack was consistently bypassed in order to emphasise the preferred scenario 
of survivability. The official U.S. Government booklet Survival Under Atomic Attack (1950) assured readers of the ease with which they could live through an atomic bomb raid since “you won't have to have a Geiger counter, protective clothing, or special training in order to do it" (3). The booklet stresses the unlikely odds of being one of the "unlucky people" right under the bomb and points out that for the majority of people at least two miles away, "the explosion will cause practically no deaths at all" (3).

Thomas Doherty notes that when the first footage of the H-bomb was aired via newsreels it was superimposed upon a skyline of New York City for what the narrator described as "dramatic effect." Although the voiceover ominously pointed out that "the heart of the metropolis would be instantaneously transformed into an inferno while shock waves devastated the rest of the city," the effect of this frightening scenario was immediately diluted by the upbeat "Hollywood Fashion Holiday" which immediately followed. Starlets Mamie Van Doren, Ruth Hampsen and "other lovelies" countered the vision of nuclear annihilation by modelling what the narrator described as "an eye-appealing array of summer styles, ranging from travel suits to swim wear, a lovely picture" (qtd. in Doherty 11).

This goes some way towards explaining the strange results reported by Paul Boyer, who cites a 1946 survey by Leonard S. Cottrell, Jr. and Sylvia Eberhart for the Social Science Research Council which revealed both a common assumption of atomic war to come and a low level of acknowledged anxiety about this eventuality. The study's conclusion was that either respondents were unwilling to admit their atomic anxieties or that fear had been repressed (Boyer 23). A similar survey was carried out in the early 1950s by the American Institute of Public Opinion, which discovered that half of people living in the largest American cities believed that there was a distinct 
likelihood of an atomic attack on their city in the event of another war; a further quarter thought there was a "fair chance"; while only 17 percent responded that they thought it unlikely. Yet despite belief that attack was likely, only 7 percent of those interviewed felt compelled to be involved in a civil-defence programme (Boyer 23). It was not until the 1960s that the survivability of atomic attack was openly questioned. In November 1961, Newsweek ran an anonymous article entitled "Survival: Are Shelters the Answer" which admitted that the facts of nuclear war, fallout and shelter life were "far more complex and sobering" than previously admitted (19).

The "happy days" concept of American reality sits strangely alongside a darker version comprising tranquilisers, increasing juvenile crime, blacklists and HUAC subpoenas. Father Knows Best, which began as a NBC radio show in 1949 and moved to CBS television in 1954, suggests a postwar life of domestic stability and safety in which the most pressing concerns for the Anderson children are attending dance lessons for the first time and learning how to cook and clean. William Tuttle's study of the experiences of children during the war and its aftermath presents a reality far more troubling. Including over two thousand letters from respondents who were children during the war, Daddy's Gone to War: The Second World War in the Lives of America's Children (1995) reveals the profound anxieties provoked by the bombing of Pearl Harbour, the revelation of the Holocaust and the detonation of the atomic bomb over Japan, all of which had deep and long-lasting psychological effects.

While most historians focus on privileging either paranoid Cold War culture or a more idyllic version of the postwar years, it is the uneasy combination of anxiety and complacency that most clearly defines the period. In 1945, a Time editorial by James Agee identified "a new age in which all thoughts and things were split" ("The Bomb"), suggesting that the anxious decade depicted in Douglas Field's study 
American Cold War Culture (2005) co-exists with Martin Halliwell's description in American Culture of the 1950s (2007) of a period that "gave rise to Elvis, high-school romances, Tupperware, the Peanuts comic strip, Hollywood blondes, 3-D cinema, and black baseball star Jackie Robinson" (3). 1946, for example, saw the publication of William Saroyan's fatuously optimistic novel The Adventures of Wesley Jackson, as well as Edmund Wilson's sexually frank Memoirs of Hecate County. If the bestseller lists were filled with frothy historical romances, the existentialist fictions of Sartre and Camus were also highly fashionable, and cinemas screened Technicolor adventures as well as the dark world of film noir. Vladimir Nabokov wrote fiction on extremely unpleasant and disconcerting subject matter such as suicide, insanity and paedophilia, but he also earned a position in the New Yorker stable of writers and initial sales higher than any novel since Gone With the Wind for the highly unsettling Lolita. Margot A. Henriksen identifies the oddly schizophrenic nature of postwar America by suggesting it "revealed two cultural personalities in conflict"; beneath the surface serenity and security of the mainstream American mind was an "unstable and paranoid underground American psyche in a state of panic" (85).

Cultural alarm was potent and persistent, but was frequently shifted to and controlled by the implications of the Cold War which combined an ideology perceived as alien with the threat of atomic attack. Communism's threat was not simply external, however, and even more troubling was the danger it seemed to pose from within. Just two months after the end of World War II, J. Edgar Hoover warned that the "fight against fascism continues." Actual combat may have ceased, but "espousers of dictatorships still exist, and they have been too well entrenched to become converts of democracy overnight." Hoover ominously pointed out that to the "Fascist foe must be added another, the American Communist" (qtd. in Fried 17). 
Cardinal Spellman confessed his fear in 1946 that "we may fail or refuse to realize that Communists, who have put to death thousands of innocent people across the seas, are today digging deep inroads into our own nation" (qtd. in Goldman 130). Spellman need not have worried. The fear of internal subversion saw 6.6 million people investigated between March 1947 and December 1952 under President Truman's loyalty review programme, and, although not a single case of espionage was uncovered, hundreds of people lost their jobs because of "questionable loyalty" (Miller and Nowak 10). This "orgy of repression" (Fried 4) began several years prior to Senator McCarthy's appearance, and the events of 1949 and 1950 - the trial of Alger Hiss, the Soviet atomic bomb test, the "fall of China" - served to intensify fears about internal subversion and external threat, paving the way for McCarthy's speech at Wheeling, Virginia on February 9, 1950, in which he claimed to have the names of over two hundred Communists in the US State Department.

According to Eric Goldman, the anti-Communism which defines the period between 1947 and 1954, which reached a hysterical peak during the years of the Korean War, resulted in "a tendency to denounce anything associated with the different or disturbing as part of a Communist conspiracy" (122). The most characteristic and ominous fact of life in America during this period was identified by Hugo Ernst as the "fear of speaking out" (447). It mattered little whether a person's views were actually subversive; what mattered was deviation from consensus. In 1953 syndicated columnist George Sokolsky explained that in the radio and television industries, a category had been devised known as "the controversial person," meaning "an actor, writer, commentator, etc., who has at some time in his life taken a position on a public question which has attracted attention" (qtd. in Doherty 31). 
Although McCarthyism was described as a virus which "chills the heart and stills the tongue" (H. Ernst 447), what makes the ten year period following the end of the war so fascinating is that "the climate of repression did not originate with or depend on the ravings of a single demagogue" (Pells 262) but was spread throughout almost every aspect of American life. The repressive forces which took McCarthy's name in the popular imagination were the result of actions undertaken not just by the Senator but by various government committees, private organisations and special interest groups which both pre-dated and post-dated McCarthy's short reign. ${ }^{6}$ In a 1949 letter from novelist John Clellon Holmes to Jack Kerouac held in the New York Public Library's Berg Collection, Holmes describes the treatment Allen Ginsberg received from Columbia University following his arrest in connection with stolen goods. Ginsberg's lawyer approached Columbia University's Mark Van Doren for assistance in his client's defence, but before Van Doren would agree to help his young student, he posed the question, "Do you believe in this society?" After Ginsberg gave the expected reply, "Of course", Van Doren agreed to help in any way possible since he was assured that Ginsberg was "not an anarchist." Holmes' letter describes Ginsberg's distraught telephone call following this encounter in which he claimed, "They treated me as though I were a Communist!"7

The fact that fears regarding internal subversion were almost completely unjustified suggests that the success of anti-Communist rhetoric lay in its ability to sanction cultural silence and give shape to diffuse anxiety. According to Arthur

\footnotetext{
${ }^{6}$ For an in-depth discussion of postwar anti-Communism see Ellen Schrecker, "McCarthyism: Political Repression and the Fear of Communism," Social Research 71, no. 4 (Winter 2004): 1041-86.

${ }^{7}$ In the same letter, Holmes relates: "A friend who works in the record department at Columbia comes to me and tells me this little vignette. As soon as word reached the busy little archivists in this department, word that Allen had been arraigned with some 'unsavoury characters', his file-folder was taken from the drawer with two careful fingers, as though it was contagious, and dropped into the 'deadfile.' My friend protested: 'After all, he hasn't been tried yet, it hasn't been proved. Isn't this a bit hasty?' His colleagues look askance at him, a sign of sympathy with the rebel casts suspicion on him as well. 'From now on,' they tell him, 'Columbia University denies that Allen Ginsberg exists. For us, he is a dead issue!"”
} 
Miller, "with remarkable speed conformity became the new style of the hour" (262), and Edward R. Murrow perceptively suggested in his March 9, 1954 episode of See It Now spotlighting the Senator from Wisconsin, that McCarthy "didn't create this situation of fear; he merely manipulated it - and rather successfully."8 McCarthy's manipulations created a manageable externalisation of fear, with Red Scare discourse providing a site in which diffuse anxiety could be harnessed, worked through and dispelled. Despite scathing critical reviews which labelled the film I was a Communist for the FBI (1951) crude and mechanical, Americans eagerly flocked to cinemas to see its Communist baddies vanquished. ${ }^{9}$ The success of Mickey Spillane's pulpy detective novel One Lonely Night (1954) relied on a similar paradigm. Tough guy Mike Hammer explains, "I had one good, efficient, enjoyable way of getting rid of cancerous Commies. I killed them" (Spillane 175).

Morris Dickstein argues that too much emphasis on McCarthyism and repression results in "a skewed picture of the period" (8), but censorship, control and conformity were undeniably a major part of American life during the forties and fifties. Although the American Civil Liberties Union announced in 1945 "the almost complete absence of repression" during World War II, the authors of The Home-Front War point out that repression during the war years simply took "subtler and more unexpected forms" (O'Brian and Parson 16). Liberal fear of subversion saw right-wing publications attacked; Henry Luce (publisher of Time and Life) was denied credentials to visit China as a war correspondent; and in 1942 Japanese Americans living on the West

\footnotetext{
${ }^{8}$ This explains the often ludicrous forms anti-Communism took. In West Virginia a vigilant policeman discovered tiny candies bearing geography lessons, and to his horror some of these lollies bore the hammer-and-sickle Soviet Flag and the information that the U.S.S.R. was the largest country in the world. When brought to the attention of City Manager Robert L. Plummer, the horrified response was: "This is a terrible thing to expose our children to." Measures were swiftly taken to protect American children from this geographical knowledge (Goldman 213).

${ }^{9}$ For an excellent discussion of this film see Dan Leab, "I was a Communist for the FBI," History

Today 46, no. 12 (1996): 42-7.
} 
Coast were rounded up and shifted to internment camps. Following the war, the TaftHartley Act of 1947 outlawed picketing, sympathy strikes and boycotts; William F. Buckley's God and Man at Yale (1951) argued that Ivy League alumni should have control over university syllabi in order to restrict academic freedom; and in $1954 \mathrm{~J}$. Robert Oppenheimer lost his security clearance as a result of questioning the wisdom of developing the H-Bomb and his association with members of the Communist Party. Blacklisting became a very real threat with life-shattering repercussions, not just for Hollywood professionals whose high profile made them the most visible victims, but also for countless technicians working behind the scenes, government employees, teachers and academics. $^{10}$

Dickstein argues convincingly that the 1950s were the seed of the next decade's radicalism, but the categorisation of literature as countercultural solely because of its author's status as social outsider overlooks the intense ambivalence many writers expressed between accommodation and dissent. Marcus Klein identified the social progress of the postwar hero as being "from a position of alienation toward accommodation", by which he meant "an impossible reconciliation, a learning to live with, and at the same time a learning to deny, what has been plainly there: the happy middling community of these years, the suffocating suburbs, the new wealth, the fat gods, the supermarket, the corporate conscience, and also one's own conscience" (After Alienation 33). Leslie Fiedler similarly warned that increased opportunities for publishing brought about by the rise of paperback formats and an affluent, educated and leisured society were accompanied by "pressures toward accommodation" (875).

\footnotetext{
${ }^{10}$ For an in-depth analysis of the era's anti-Communism see Richard M. Fried, Nightmare in Red: The McCarthy Era in Perspective (Oxford: Oxford University Press, 1990); Albert Fried, McCarthyism: The Great American Red Scare (New York and Oxford: Oxford University Press, 1997); and Robert Griffith, The Politics of Fear: Joseph R. McCarthy and the Senate, $2^{\text {nd }}$ ed. (Amherst: University of Massachusetts Press, 1970).
} 
Such pressures were also accompanied by intense censorship which inevitably toned down literary revolt. In 1953, for example, drama publisher Samuel French announced a playwriting contest in which one of the conditions was that the sponsor "reserves the right at any time to declare ineligible any author who is, or becomes publicly involved, in a scholastic, literary, political, or moral controversy" (qtd. in Goldman 258). Even a film about Henry Wadsworth Longfellow, surely an unlikely candidate for un-American subversion, was not safe from McCarthy-inspired paranoia. In 1951 Monogram Pictures cancelled its planned film because of the studio's fear that Hiawatha's peace-brokering might be construed "as propaganda for the Communist Peace offensive" (qtd. in Goldman 213). Censorship did not just come from the right, however. Vladimir Nabokov was one of only a few writers in America to tackle the subject of the Holocaust. In an episode of his novel Pnin written in 1955 , Nabokov describes a young woman who "had been brought in a cattle car to an extermination camp and killed by an injection of phenol into the heart ... the only certain thing was that being too weak to work (though still smiling, still able to help other Jewish women), she was selected to die and was cremated only a few days after her arrival in Buchenwald" (Pnin 135). The chapter from which this passage comes would have been published in The New Yorker, as previous chapters had, were it not for censorship from the left demanding that Nabokov remove the phrase "medieval tortures in a Soviet jail” (Pnin 116).

Philip Roth declared that his generation "belong to what may have been the most propagandized generation of young people in American history" and suggested that the generation known in its college years as "silent" was in actuality "straitjacketed" (Reading Myself 88). Writer Philip Wylie observed the profound mistrust provoked by the critical attitude, which was thought "to border on subversion," especially when 
intellectual enquiry became critical of popular American attitudes (qtd. in Halliwell 24). In 1952, playwright George S. Kaufman was fired from his role as regular panellist on CBS's This is Show Business because of a flood of angry letters protesting his criticism of the incessant playing of "Silent Night" on Christmas specials. The era's dislike of controversy was matched by its adherence to majority consensus, since, when CBS was inundated with an equally passionate flood of letters protesting Kaufmann's termination, he was quickly reinstated (Doherty 65).

The furore over Kaufmann's comment reveals something of the era's increasing distrust of the academic and the "highbrow." A 1954 Fortune article by Charles Murphy states that among businessmen who approve of McCarthy's war on subversion "there is satisfaction, subconscious perhaps but very strong, over his incidental licks at all longhairs, eggheads, professors and bright young men of the 1930s and 1940s" (qtd. in Rogin 223). President Eisenhower's popularity relied on his “common man" persona. At a breakfast given by the Republican Groups of Southern California in 1954, he famously defined an intellectual as a "man who takes more words than necessary to say more than he knows." Even canonical writers were not free from this mistrust. In 1950 Sydney Hook blamed international anti-American sentiment on the false impressions derived from reading novels of social protest. $\mathrm{He}$ suggested that Europeans were "shockingly ignorant" of American reality because of the portraits of national "degeneracy" and "inanity" promulgated by writers such as Faulkner and Sinclair Lewis (qtd. in Pells 125).

In a culture that deemed dissent, controversy, even independent thought as undesirable or subversive, the writer's role was obviously rather fraught. In 1951, C. Wright Mills argued that the postwar intellectual had

ceased to be in any sense a free intellectual, he has joined the expanding world of those who live off ideas, as administrator, idea-man, and good-will 
technician. In class, status, and self-image, he has become more solidly middleclass, a man at a desk, married, with children, living in a respectable suburb, his career pivoting on the selling of ideas, his life a tight little routine, substituting middle-brow and mass culture for direct experience of his life and his world, and, above all, becoming a man with a job in a society where money is supreme. (156)

The "curative" writers of the period, whose reassuring novels swelled the bestseller lists, had little to say regarding the strange cultural climate (perhaps because it suited them so well), but more academic writers voiced numerous, if somewhat perplexed, complaints. Critic Dwight Macdonald felt there was "something alarming in the craving of contemporary Americans for reassuring, soothing messages" (386); Saul Bellow suggested the era was controlled by "invisible powers" ("Recent American Fiction" 161); and Roth described America as "crooked and unreal." If "one feels less and less power in the face of this unreality", Roth wondered, and if the inevitable end for civilisation is destruction, "why in God's name is the writer pleased?" ("Writing American Fiction” 158).

Why indeed? With tens of millions recently killed and with the atomic bomb posing pressing questions regarding the survival of the human race, the ebullience of mainstream fiction is indeed perplexing. Bellow blamed a new "modern disorder" impelling the writer to "live by an image of themselves created by papers, television, Broadway, Sardi's, gossip, or the public need for celebrities" (Writers at Work 185), revealing how writers struggled with their own conformist impulses while facing intense pressure to deliver the reassuring message consensus culture demanded. The need for literary reassurance was so strong it even saw critics and reviewers overlooking aspects of novels which on closer inspection might be worrying. While J. D. Salinger's The Catcher in the Rye was the most censored book in high schools and libraries between 1961 and 1982 due to its obscene language and perceived ability to promote deviant behaviour, its favorable reception upon publication in 1951 points 
less to a liberal acceptance of its subversive elements than to studious avoidance. Nash K. Burger's review in the New York Times comfortably suggests there is nothing wrong with the protagonist "that a little understanding and affection, preferably from his parents, couldn't set right" (19). Rather than being a poor role model, “you'll look a long time before you'll meet another youngster like Holden Caulfield, as likable and, in spite of his failings, as sound." The review complacently concludes, "though he's still not out of the woods entirely, there at the end, still we think he's going to turn out all right' (19). In an era when subversion was located in the most trifling comments, the urge to hunt out dissent was matched by an urge to ignore or minimise threat. It is little wonder, Bellow concluded, that the powerful figures in postwar society held writers and poets "in contempt. They do it because they get no evidence from modern literature that anybody is thinking about any significant question" (Writers at Work 185).

In a 1952 Partisan Review symposium the editors suggested that writers "have ceased to think of themselves as rebels" and "now believe that their values, if they are to be realized at all, must be realized in America and in relation to the actuality of American life" ("Our Country and Our Culture" 284). Lewis Mumford argued that America needed the help of the artist "to rally, by his example and effective demonstration, the forces of life, the passionate commitments of love, to recall to us all the qualities we have violated this last century in the untrammelled pursuit of power" (174). Nestled inside a culture that looked to artists for an effective demonstration of morality yet which also held intellectualism in suspicion, many writers struggled with a paradoxical desire to be both inside and outside consensus culture, a dilemma well-illustrated by John Cheever whose stories both criticise and defend suburban lifestyles. In the Saturday Review Cheever suggested there was "too 
much criticism" of the suburban way of life and insisted that life "can be as good and rich there as anyplace else" (qtd. in Wilhite 215). Just two years later, however, he proclaimed the suburbs "a cesspool of conformity" (qtd. in Wilhite 220). Cheever's insistence that suburban life is one of "indescribable dreariness" coupled with his declaration that the "truth is that I'm crazy about the suburbs, and I don't care who knows it" (qtd. in Wilhite 220) reveals a profound tension between conformity and dissent. $^{11}$

In 1949, Michigan Republican Representative George Dondero outlined just how easy it was for an artist to court accusations of subversion when he stated that

Modern art is Communistic because it is distorted and ugly, because it does not glorify our beautiful country, our cheerful and smiling people, and our great material progress. Art which does not portray our beautiful country in plain, simple terms that everyone can understand breeds dissatisfaction. It is therefore opposed to our government, and those who create it and promote it are our enemies. (qtd. in Ninkovich 18)

Dondero clearly outlines the perceived relationship between "ugly" art and unAmerican beliefs, a conflation which acted as a powerful deterrent for those contemplating disturbing subject matter. Robert Lowell's famous description of the "tranquilised fifties" is seconded by a speech made by Edward R. Murrow in 1958 for the Radio and Television News Director's Association in which he diagnosed the era's "built-in allergy to unpleasant or disturbing information." The era's denial of a post-1945 reality defined by mass death relied on the avoidance of Roth's "demonic reality" and the confirmation of "happy days" America by novelists whose "deep affirmations for those who admire the editorials in Life" produced a literature enabling the reader to believe "I'm safe, I really am, and I'm pleased about it!" (Gold 100). Yet despite the prevalence of those who were convinced by supermarkets,

\footnotetext{
${ }^{11}$ Cheever's comments also reveal the changing cultural climate since he is more eager to denounce suburbia in 1960 than he was during the fifties.
} 
superhighways and suburbia, there were some people increasingly aware of something strange in postwar life, something hidden, something vaguely threatening, something profoundly weird...

\section{The Return of the Repressed}

The repression of disturbing reality resulted in a sense of something dark at the heart of American life, an apprehension so vague and shadowy that the diffuse anxiety it caused resulted in one out of every three prescriptions during the 1950s being for tranquilisers (Cuordileone 103). In 1952, Louis B. Seltzer of the Cleveland Press published an editorial which expressed something of this unsettling feeling:

What is wrong with us? It is in the air we breathe. The things we do. The things we say. Our books. Our papers. Our theater. Our movies. Our radio and television. The way we behave. The interests we have. The values we fix. We have everything. We abound with all the things that make us comfortable. We are, on average, rich beyond the dreams of kings of old. Yet something is not there that should be - something we once had. Are we our own worst enemies? Should we fear what is happening among us more than what is happening elsewhere? No one seems to know what to do to meet it. But everybody worries. (qtd. in Goldman 218)

This dim recognition of something "not there that should be" and the pervasive objectless anxiety this absence causes reveals a postwar climate defined by the return of the repressed. Seltzer's editorial struck such a chord that he reported being contacted by over one thousand people in the week following its appearance, and it was subsequently reprinted in forty publications across the nation.

While the relationship between "happy days" reality and postwar literature minimising threat and celebrating the American way of life is reasonably clear, the relationship between "demonic reality" and the literature it inspired is significantly more complicated. Freud's theories on repression, which posit the inevitable return of what is repressed, have encouraged critics of the era's culture to search for instances 
of "the uncanny" in which to locate denied or buried material. The majority of these studies identify science fiction and gothic as uncanny genres capable of provoking the particular anxiety Freud identifies with the return of the repressed. According to the authors of The Fifties: The Way We Really Were (1977), sci-fi films featuring mutants and aliens "confirmed the viewer's repressed suspicions about reality", ${ }^{12}$ and Margot A. Henriksen similarly suggests that postwar films such as Invaders from Mars and Invasion of the Body Snatchers "dramatised the culture of dissent's recognition of the dangers menacing Americans in the atomic age" (144).

The perception of science fiction and gothic as vexing genres which offer "significant resistance to canonisation" (Punter ix) is frequently interpreted as a sign of an essentially subversive nature, hence Rosemary Jackson's Fantasy: The Literature of Subversion (1981). Although gothic in particular is a much-contested genre, critics have tended to agree that its crypts, haunted houses and returning dead indicate its inherent uncanniness, an assumption which David Punter identifies as having rendered gothic "one of the major sites on which reinvestigation of Freud and reinstitution of psychoanalysis can take place" (ix). Hélène Cixous sums up the elusiveness of the uncanny when she observes that it is a concept "whose entire denotation is a connotation" (528), but while it remains an often frustratingly broad topic most critics adhere to Freud's definition of the uncanny as something familiar made strange. ${ }^{13}$

\footnotetext{
${ }^{12}$ Miller and Nowack, The Fifties, 66.

${ }^{13}$ Freud's article on the uncanny remains a seminal text, but in recent years it has been popular to approach the topic via the works of postmodern thinkers such as Jean-Francois Lyotard and Jacques Derrida. For a discussion of the uncanny as a trope of deconstruction see Nicholas Royle, The Uncanny (Manchester: Manchester University Press, 2003). The uncanny's boundlessness has seen it also become a trope of postcolonialism; see Homi Bhabha, The Location of Culture (London and New York: Routledge, 1994); and Julia Kristeva, Strangers to Ourselves, trans. Leon S. Roudliez (New York: Columbia University Press, 1991); feminism; see Hélène Cixous, "Fiction and Its Phantoms: A Reading of Freud's Das Unheimlich," New Literary History 7, no. 3 (Spring 1976); and psychoanalysis; see Ernst Jentsch, "On the Psychology of the Uncanny," trans. Roy Sellars, Angelaki 2, no. 1 (1995); and Sigmund Freud, "The Uncanny," trans. James Strachey, New Literary History 7, no.
} 
Although much enlightening criticism has been conducted on the subversive aspects of gothic, the genre is not always revolutionary. Analyses of "female gothic" have frequently provided illuminating insights into the genre's ability to subvert gender norms, ${ }^{14}$ but Kate Ferguson Ellis reveals the contradictory nature of gothic when she suggests that in addition to the presentation of the female subject as "individual and inviolable", which made "available to women possibilities for action outside the code of female passivity and sublime helplessness", are the happy endings of female gothic which serve to contain female subversion (221). The gothic as a phenomenon is commonly identified as beginning with Horace Walpole's novel The Castle of Otranto (1764), which was followed by Clara Reeve's The Old English Baron (1778), the romances of Ann Radcliffe, and Matthew Lewis' The Monk (1796). The nineteenth century gothic was characterised by "penny dreadfuls" (pulp horror) and novels such as Mary Shelly's Frankenstein (1818) and Bram Stoker's Dracula (1897). Frequently dismissed as pulpy and populist, the gothic genre has experienced a critical revival in recent decades, beginning with the feminist revisionism of the 1970s. ${ }^{15}$ With the appearance of studies such as David Punter's The Literature of Terror (1980), gothic literature became a reputable field of enquiry, with critics identifying suburban gothic, imperial gothic, postcolonial gothic and various national gothics. Yet what constitutes gothic as a genre has never remained static and it is a

3 (Spring 1976). For other significant studies of the uncanny see Terry Castle, The Female Thermometer: $18^{\text {th }}$ Century Culture and the Invention of the Uncanny (New York: Oxford University Press, 1995); Anthony Vidler, The Architectural Uncanny: Essays in the Modern Unhomely (Cambridge: MIT Press, 1994); Hal Foster, Compulsive Beauty (Cambridge, Mass.: MIT Press, 1993); Gordon Slethaug, The Play of the Double in Postmodern American Fiction (Carbondale: Southern Illinois University Press, 1993); and Paul Coates, The Double and the Other (New York: St Martin's Press, 1998).

${ }^{14}$ See Katherine Ellis, "Charlotte Smith's Subversive Gothic," Feminist Studies 3, no. 3/4 (SpringSummer 1976), 51-55; and Susan Becker, Gothic Forms of Feminine Fictions (Manchester: Manchester University Press, 1999).

${ }^{15}$ See Ellen Moers, Literary Women (London: The Women's Press, 1980); and Sandra M. Gilbert and Susan Gubar, The Madwoman in the Attic: The Woman Writer and the Nineteenth-Century Literary Imagination, $2^{\text {nd }}$ ed., (New Haven: Yale University Press, 2000). 
modality characterized by change. As has been recently pointed out, gothic "is both temporally and culturally inflected - what terrified the eighteenth-century reader will not frighten the twenty-first century cyberspace surfer" (Horner and Zlosnik 2).

Gothic changes over time, responding to particular cultural needs. The fact that gothic seems to appear at times of crisis certainly implies a relationship with cultural norms, but in addition to interrogating the status quo, gothic frequently conserves the norm by providing an outlet in which to safely engage with deviant material. Although in 1807 the Marquis de Sade identified the gothic genre as the "inevitable product of the revolutionary shocks with which the whole of Europe resounded" during the late eighteenth century (qtd. in Mulvey-Roberts 204), the first gothic novels preceded the revolution by several decades and appeared in England, which did not actually experience a revolution. ${ }^{16}$ Anne Williams highlights the conservative nature of early "male gothic" (written by authors such as William Beckford and Matthew Lewis) by identifying its primary concern as threats posed to patriarchy and established class boundaries. Eighteenth-century gothic was also a predominantly Protestant genre which conserved the status quo through fictional depictions of Catholicism as medieval and barbaric. ${ }^{17}$ Furthermore, while nineteenth-century gothic articulated fears regarding industrialization and new forms of science and technology, it also frequently presented these new forms of knowledge as antidotes to various threats. Mary Shelley's Frankenstein is a horrifying vision of modern science gone terribly wrong, but Bram Stoker's Dracula features an ancient threat vanquished by a psychiatrist who uses up-to-date equipment such as the phonograph, and a professor whose scientific knowledge is referred to as "advanced" (147).

\footnotetext{
${ }^{16}$ Horace Walpole's The Castle of Otranto is generally considered to be the first gothic novel and was published in 1764. The French Revolution began in 1789.

${ }^{17}$ M. G. Lewis' The Monk (1796) concerns a pious monk and the various transgressions he commits, including rape and murder. The story also includes a woman's torture by Catholic nuns.
} 
The mutability of gothic means that "it is no longer adequate - if it ever was - to consider Gothic solely under the rubric of the counter-cultural or subversive; Gothic is now canonical in many different ways" (Punter and Bronfen 7). This was certainly true during the 1940s and 1950s in America when the most popular form of gothic was lurid comic books such as Adventures in the Unknown, Marvel Tales, Crypt of Terror, Nightmare, and Vault of Horror, the illustrations of which, while frequently gory, were more likely to provoke titillation than dread. Fredric Wertham's infamous study Seduction of the Innocent (1954), which effectively silenced the comic book industry, identified sexual content and gruesome imagery as the main dangers posed to youth rather than the ability of gothic-inspired material to reify taboo. In a 1951 Tales from the Crypt story entitled "The Living Death" for example, the grisly illustration of a death scene is accompanied by a description designed to thrill:

His skin shrivelled, and turned from pink to blue to a sickening brown! His eyes sunk deep into his head! Then they became hollow black sockets! The flesh...rotted and stinking...fell from his bones! Soon, the bed was covered with nothing but a seething, oozing mass of putrefied and decayed flesh. (qtd. in Wright 151)

Even in its more literary manifestations, the era's gothic imagination provokes little real dread. Shirley Jackson's The Haunting of Hill House (1959) concerns a group of people who attempt a scientific investigation of a reputedly haunted house standing "against its hills, holding darkness within" (3). This potentially threatening darkness is made manageable by the novel's insistence on rational solutions to mystery. The ghastly appearance of the house and the way its doors close as if by an invisible hand are explained by the fact that it was built intentionally with tiny distortions in its structure, and the apparently supernatural manifestations that occur around the protagonist Eleanor Vance are given a psychological, if somewhat paranormal, explanation. 
Although the novel's theme of haunting suggests the return of the repressed, Jackson clearly outlines a manageable past trauma implicating only Eleanor. As Jackson's figure of scientific rationality Dr Montague points out, threat is both caused and controlled by Hill House's "contained illwill” (82). When Eleanor hears "the little babbling murmur" that seems to have no source, she wonders, "Am I doing it ... is that me?" (202). Jackson utilises popular understandings of Freudian theory to describe Eleanor's psychological breakdown, which is related to guilt over her mother's death and her repressed sexual desire. The reader's familiarity with such popularised psychology makes Hill House a sort of haunted funhouse where we anticipate and receive with pleasure the various spooky manifestations that occur. What returns in Jackson's novel is not really the repressed at all, but everything the reader already knows.

The Haunting of Hill House is a continuation of Ann Radcliffe's "supernatural explained" in which ghostly apparitions and mysterious occurrences are given rational explanation and the potential threat of the return of the repressed is controlled. Even the rather macabre ending of Jackson's novel in which Eleanor is killed in a car crash suits the conservative purposes of the postwar gothic. What happens to the protagonist is indeed scary but her rather repellent personality and obvious fragility suggests Eleanor's reassuring distance from "normal" psychology. In terms of postwar femininity, Eleanor is a deviant; unattractive, unmarried, unsocial, and with unnaturally cold feelings towards her family, her unhappy end can be read as an example of what happens to those outside the norm and thus reaffirms the status quo rather than threatening it through the depiction of repressed material.

Science fiction of the era such as Jack Finney's The Body Snatchers (1955) and Robert A. Heinlein's The Puppet Masters (1951) focuses on the threat of invasion and 
nuclear war and clearly provided a site where audiences could engage with issues relevant to the Cold War and new forms of scientific technology. Cynthia Hendershot argues that science fiction's "lowbrow" status gave it more freedom to deal with horror than the era's realistic dramas, but her suggestion that the non-realistic framework of science fiction allowed it to create a space for Atomic Age paranoia overlooks the familiarity of this fantasy space. While it is certainly correct that the giant mutant ants in the film Them! (1954) represent anxiety about nuclear threats, such figures are symptomatic less of an engagement with repressed fears than with the processes through which Americans minimised fears which were acknowledged. ${ }^{18}$

Discourse surrounding atomic attack never denied the possibility of its occurrence in America, but what was denied were the catastrophic results of future attack and the awful effects actually experienced in Japan. Survival Under Atomic Attack explains that an atom bomb "holds more death and destruction than man has ever before wrapped in a single package" but stresses that "its total power is definitely limited" (4). In fact, the booklet reassuringly notes that thousands of survivors in Hiroshima and Nagasaki live in new houses where their old ones stood; the war "may have changed their way of life, but they are not riddled with cancer. Their children are normal. Those who were temporarily unable to have children because of radiation now are having children again" (4). In the case of attack on America, the chances of making a complete recovery from injury "are much the same as for everyday accidents" (Survival 5) and even if a serious dose of radioactive poisoning was

\footnotetext{
${ }^{18}$ Science fiction can, of course, be profoundly disturbing but was rarely so during this period in America. When Jack Finney's novel The Body Snatchers (1955) was made into its first film version in 1956, screenwriter Daniel Mainwaring changed Finney's happy ending by concluding the script with the protagonist yelling into the camera, "They're already here! You're next!" The studio deemed this ending too pessimistic and demanded a framing device be added that suggests the novel's happy conclusion. In the 1978 film version the happy ending was completely abandoned and the alien vanquishes the hero. There is also a decidedly uncanny moment in which Donald Sutherland's character smashes his replica's face whilst it sleeps.
} 
received, sufficient to cause hair loss and make you feel "feel below par" for a little while, "in spite of it all, you would still stand better than an even chance of making a complete recovery, including having your hair grow in again" (Survival 12).

Richard Matheson's novel I am Legend (1954) engages with the era's preoccupations with invasion and apocalypse by depicting its hero's existence as the sole survivor of a biological plague that transforms humans into vampires. The novel illustrates the way science fiction of the era controlled anxieties even while seeming to engage with taboo material. ${ }^{19}$ Although the novel makes a clear distinction between the "living infected" and the un-dead, Matheson's protagonist Neville ruthlessly disposes of both beings by staking them through the heart. Matheson's protagonist justifies his murdering sprees by explaining that "If I didn't kill them, sooner or later they'd die and come after me. I have no choice; no choice at all" (146). Faced with the eventual domination of the new vampire hybrids, however, Neville realises that his actions, which are both preservative and conservative, have turned him into a menacing other. He admits, "I'm the abnormal one now. Normalcy was a majority concept, the standard of many and not the standard of just one man" (170). As he looks over "the new people of the earth" he realises that like the vampires, he is "anathema and black terror to be destroyed." This epiphany causes Neville to commit suicide and his dying thought is "I am legend" (170).

Neville's obsessive study of the vampire bacteria and his desperate efforts to identify, prevent and cure contamination reflect his desire to restore the social order of

\footnotetext{
${ }^{19}$ Jörg Hienger argues that the uncanny can occur in science fiction when there are three prerequisites: an occurrence of the fantastic must remain incomprehensible to all those affected; the viewpoint of the narrator must be identical to that of the characters; and the unexplained event must awaken a doubt as to its explicability. Hienger is correct in pointing out the uncanny nature of events in some science fiction stories of the period, but his suggestion that the resolution of the horror at the end of an uncanny tale has a function similar to that of the disturbance of a closed society at the end of a satirical tale fails to take into account the triumph of the canny over the uncanny in such reassuring endings. See Hienger, "The Uncanny and Science Fiction," Science Fiction Studies 18, no. 6 (July 18, 1979): http://www.depauw.edu/sfs/backissues/18/hienger18art.htm.
} 
his lost world and clearly adheres to what Priscilla Wald calls the "outbreak narrative." Although viruses became visible to scientists in the early 1930s, it was not until the 1950s that new developments in technology enabled a clear view of their mysterious workings. Wald points out that accounts of viruses (encouraged by the mid-twentieth century polio epidemic) "frequently shared the page with another topic of particular interest: the allegedly emerging global threat of communism" (158). As viruses became "increasingly sinister and wily, sneaking into cells and assuming control of their mechanisms, external agents, such as Communists, became viral, threatening to corrupt the dissemination of information as they infiltrated the nerve center of the state" (Wald 159).

Although Matheson's story seems to involve a return of repressed fears regarding threats to human survival, the novel is not as subversive as critics might like to think. ${ }^{20}$ While it is true that Neville initially represents the norm, his eventual defeat is not a defeat of the status quo since Matheson is careful to position the hybrids as the new representatives of a normalised majority. Neville's ruthless violence towards the living infected, his cruelty towards women on whom he performs experiments and his narrow minded prejudice contribute to the reader's growing alienation until by the end of the novel it is Neville who has become the real danger. His death is not a hero's disturbing defeat but a punishment for violent crimes against the majority. The fact that the vampire menace is scientifically verifiable certainly plays into fears regarding biological threat, but it also reassures the reader that science and technology will in turn provide an antidote. Even though civilisation as we know it has been destroyed, Matheson's post-apocalyptic vision is actually infused with profound optimism since Americans survive and prevail over their new conditions. It is up to this new breed of

\footnotetext{
${ }^{20}$ For an interesting discussion of the political aspects of I am Legend see Kathy David Patterson, "Echoes of Dracula: Racial Politics and the Failure of Segregated Spaces in Richard Matheson's I Am Legend," Journal of Dracula Studies 7 (2005): 19-27.
} 
American to rebuild civilisation, an eventuality that recalls Georgia Senator Richard Russell's proclamation that "If we have to start over again with another Adam and Eve" in a post-apocalyptic world, "then I want them to be Americans and not Russians, and I want them on this continent and not in Europe" (qtd. in Winkler 129). Although Mark Jancovich convincingly argues that not all horror and science fiction of the period is conservative, noting that it is often concerned with critiquing American ideology rather than simply that considered "alien", he acknowledges that the common feature is "a preoccupation with the modern world", particularly the processes of social development and modernisation (3). Although individual films and books might engage with the anxieties provoked by rationalisation within America, Jancovich's study highlights the way that the majority of 1950s "monster movies" conclude with the successful vanquishing of that threat. Gothic's supernatural manifestations and science fiction's monsters, like the Communist baddies of Red Scare propaganda, are externalisations of fear which the majority of postwar examples of these genres control and ultimately vanquish. Rather than forcing a confrontation with the return of the repressed, the era's fantasy genres render fears manageable by the eventual reinstatement of the status quo. Edmund Wilson notes that the "only real horror in most of these fictions is the horror of bad taste and bad art", singling out H.P. Lovecraft's work for particular ridicule. Wilson argues that when the revelation to which a long story has been building turns out to be a race of ten foot tall, scaly, iridescent beings shaped like giant cones who slide along on a viscous foot like snails, "you may laugh or you may be disgusted, but you are not likely to be terrified" (288). As Freud points out, ghosts, vampires and monsters are potentially uncanny but when a writer chooses a setting "which though less imaginary than the world of fairy tales, does yet differ from the real world by admitting superior spiritual beings such as 
daemonic spirits or ghosts of the dead", as long as they "remain within their setting of poetic reality, such figures lose any uncanniness which they might possess" (“Uncanny” 640).

Freud describes the unheimlich (roughly translated as "uncanny") as something which is secret, hidden and unfamiliar that inspires dread. Complicating this definition, however, is that fact that the unheimlich's opposite heimlich has amongst its expected antonyms of the familiar, cosy, known and domestic, the rather unexpected meanings of secrecy and concealment. From the idea of a private domestic space comes the idea of something hidden from the eyes of strangers, an ambiguity which implies that rather than acting as simple binary opposites, unheimlich and heimlich are strangely intertwined. When we turn to the Oxford English Dictionary for definitions of "uncanny" we discover that it does not usually operate as the opposite of "canny." 21 The definitions of "uncanny" include malicious, unreliable, untrustworthy, dangerous, unsafe, mysterious, weird, uncomfortably strange, unfamiliar and partaking of a supernatural character. Among the definitions of "canny" we discover shrewd, clever, artful, worldly-wise, quiet, snug, pleasant, homely and somewhat surprisingly, "supernaturally wise, endowed with occult or magical power." Just as unheimlich and heimlich both imply something hidden and secret, the uncanny and the canny both imply an association with the supernatural. The uncanny is thus not frightening solely because of its association with the supernatural, but because of the threat posed by its weirdness and mystery. The canny is a knowing, worldly and familiar magic; the uncanny is an obscure supernaturalism not to be trusted.

\footnotetext{
${ }^{21}$ For a discussion of the intersections between the unheimlich and the heimlich in children's fiction see Anna Jackson, "Uncanny Hauntings, Canny Children," The Gothic in Children's Literature: Haunting the Borders, ed. Anna Jackson, Karen Coats, and Roderick McGillis (New York: Routledge, 2008): 157-76.
} 
While often resembling accepted reality, the worlds of gothic and science fiction differ from the "real" world in that ghosts, aliens and monsters are not only admitted but are expected. A reader approaches a genre with knowledge and expectation gleaned from previous experiences and like any genre gothic works "within a set of conventionalized parameters which constrain it towards a norm" (Grixti 5). Each spooky novel renders the conventions, themes, plot devices and structure of its genre more familiar; the differences and developments to be found in each successive example do not defamiliarise us and take us into the uncanny, but further ground the reader in a fictional world that remains recognisable. The reassurance of familiarity combined with the frisson provoked by ghosts and monsters results in the pleasurable shudders which have guaranteed fantasy literature's continuing success. Horror writer Stephen King points out that fantasy genres reaffirm "the virtues of the norm by showing us what awful things happen to people who venture into taboo lands" (368).

The conflation of fantasy genres with the uncanny is largely the result of confusion regarding a text's representation of the return of the repressed and its ability to evoke an uncanny response. As The Haunting of Hill House and I am Legend illustrate, it is possible for literature to depict haunted houses and vampires without the texts provoking any lasting feeling of unease. It is important to keep in mind that the uncanny is an affect; despite Freud's difficulties in pinning down the notoriously slippery concept, his final conclusion is that an uncanny experience involves a profound dread provoked "either when infantile complexes which have been repressed are once more revived by some impression, or when primitive beliefs which have been surmounted seem once more to be confirmed" ("Uncanny" 639). A ghost in a gothic novel may indeed represent the uncanny, but might not elicit the response defined as uncanny. 
This seeming paradox relies on generic familiarity as well as the similarities Freud notes between jokes and the uncanny. In Jokes and their Relation to the Unconscious (1905), Freud explains how tendentious jokes begin as unconscious material deemed transgressive which then undergo a revision similar to that of dreams to take on a guise acceptable to the conscious mind. Such jokes are spontaneous and involve "a sudden release of intellectual tension" when the psychic barrier restraining censored material is broken. Both jokes and the uncanny thus involve the return of the repressed, a similarity Stephen LeDrew notes in his discussion of the manner in which horror films can provoke laughter. Freud clearly states, however, that the uncanny is not related to pleasure but is "undoubtedly related to what is frightening - to what arouses dread and horror" ("Uncanny" 619). While both jokes and the uncanny do indeed spring from repressed material, Martin Grotjahn makes an important distinction: jokes are actively made by a subject who then experiences the pleasure of released inhibition; the uncanny is an experience forced upon the subject by an external stimulus which provokes fear. Jokes involve an internally activated return of material deemed acceptable by the conscious mind whereas the uncanny involves a subject's helpless confrontation with material that has not yet undergone revision.

The pleasure provoked by the coming to light of revised material leads directly to genres which enable what Freud describes as the liberation of psychic energy. The pleasure produced by the controlled release of unconscious material through a joke is also experienced by the joke's audience, whom Freud suggests receives even more pleasure than the joke's maker since no psychic energy has been expended in unconscious revision. The audience for revised unconscious material thus receives all the pleasure of the liberation of psychic energy without any of the work necessary to render unconscious material acceptable. According to the Oxford English Dictionary, 
"tendentious" is defined as being composed or written with a tendency or aim, recalling the artful cunning of the canny which has increasingly come to mean "a cleverness that is not just about knowing things, but is about a particular sort of capability, the capability to manipulate people and events in your own self-interest" (A. Jackson 159). Horror and fantasy texts are thus best thought of as canny genres artfully constructed to elicit pleasure through the release of psychic tension via the reification of revised unconscious material. Though such texts might represent the uncanny, they are not necessarily experienced as uncanny.

The canniness of genres representing the return of the repressed explains the surprising popularity of Freudian theory in a period defined by reluctance to acknowledge what lies beneath. Although Freud suggests that the ability of psychoanalysis to reveal "hidden forces" renders it potentially uncanny ("Uncanny" 636), postwar American culture was replete with depictions of Freudian analysis with little indication they provoked unease. By the 1940s, Freudian theory was part of the common parlance, a fact which Nathan G. Hale accounts for by Freudian theory's ability to provide strategies through which individuals might strengthen their defences against instinctual drives such as sexuality and aggression. ${ }^{22}$ Alfred Hitchcock's 1941 film Suspicion reveals just how familiar the American audience was with Freudian symbols. The first scene of the film depicts a train going through a tunnel to the accompanying sound of a woman's gasp in the dark and a man's query wondering where her leg is. Of course this all turns out to be perfectly innocent, but Hitchcock

\footnotetext{
${ }^{22}$ The link made during the 1950s between psychoanalysis and normalisation was critiqued by Norman O. Brown in Life Against Death: The Psychoanalytical Meaning of History (1959). For Freud and his orthodox adherents, sublimation was key in terms of relieving neurotic suffering, whereas Brown argues for a radical desublimation involving a reunification of the life and death instincts, a cessation of repression, and a reinstatement of the natural Dionysian body-ego. Brown suggests a return to the polymorphously perverse body, as well as a rejection of goal-oriented culture in favor of living in the moment. Not surprisingly, his ideas found particular popularity during the 1960s and 1970s among leftist intellectuals and countercultural movements.
} 
was obviously relying on audience familiarity with Freud's interpretation of symbols to give this scene its double entendre. In the same scene, the prudish female character responds to Cary Grant's attempts to kiss her by snapping shut her purse, an action similarly indicating Hitchcock's confidence of the viewer's familiarity with the psychoanalytical interpretation of the purse as a symbol for female genitalia.

This conscious use of Freudian theory is canny in two ways: firstly, concepts such as repression and castration anxiety are familiar and understood, even if often only on a superficial level; and secondly, these familiar theories are reassuring in that they attempt to make known the workings of the psyche. The era's Freudianism is thus strangely akin to McCarthyism: both were deemed capable of exposing and neutralising hidden threats via verbal confession. McCarthy's exact lists of subversive elements were like the therapist's notepad in that both gave order to disorder. Containment has become the byword for the Cold War period and Dwight Macdonald linked the era's mania for how-to books to the fact that "as world issues appear increasingly hopeless of solution, people console themselves with efforts in spheres where solutions are more manageable - the practical and the personal" (365).

Freud's "talking cure" is predicated on identifying the causes of neurosis in order to diminish its power. By labelling previously mystifying behaviour as stemming from "oral fixation" or "castration anxiety" the patient can be relieved of troubling symptoms. Even if the patient is not cured, there is some comfort to be found in diagnosis. While the process for people actually undergoing psychoanalysis was sometimes quite different, reading about Freud's theories in the diluted form of selfhelp manuals did not necessarily involve any reflection on the unplumbable depths of the unconscious. In fact, self-help fiction often discouraged self-examination. In The Age of Happy Problems (1962) Herbert Gold suggested, "We need to give up the 
fashion of having 'insights,' which, in a society delighted by psychology because it is undelighted by most other things, has become a repulsive game of one-upmanship" (xi).

Freudian theory was so popular that EC Comics were inspired to start a new series in 1955 titled Psychoanalysis, depicting an array of variously troubled individuals such as young Freddy Carter who is caught stealing from his best friend and Ellen Lyman who is troubled by a recurring dream. The series, which only lasted for four issues, follows each character's visits to the therapist whose superficial use of Freudian theory immediately diagnoses their trouble and cures their unease. When popular fiction and non-fiction did represent the Freudian subject as prey to inner tensions and driven by deep impulses not fully understood, these depictions paradoxically created the illusion of a knowable self. The concept of buried unconscious urges was presented only in the most superficial way in the majority of popular literature and was frequently a way to understand the psyche without too much painful investigation. The determinism of unconscious urges assisted the abdication of personal responsibility and psychoanalysis was seen by many as a quick cure-all guaranteeing - as the title of rabbi-psychoanalyst Joshua Liebman's 1947 bestseller promised - Peace of Mind. ${ }^{23}$

Irving Schneider points out that most of the era's numerous films about Freudian analysis "were shallow, trashy romances or suspense dramas that emphasised lurid symptoms and dramatic cures" (62). In the 1957 film The Three Faces of Eve, which was based on a non-fiction case study by Corbett Thigpen and Hervey M. Cleckley of a woman with Multiple Personality Syndrome published that same year, a prim young woman turns up in the therapist's office complaining of memory loss and headache.

\footnotetext{
${ }^{23}$ For an excellent summary of the advice of the bestselling self-help books of the period see Irene Taviss Thomson, "Individualism and Conformity in the 1950s vs. the 1980s," Sociological Forum 7 , no. 3 (September 1992): 497-516.
} 
In fact, these symptoms turn out to hide a much more serious problem: alternative personalities which engage in behaviour Eve White cannot control. Yet the potentially horrifying effects of this possession by unknown selves are mitigated by the story's emphasis on locating the trauma causing Eve's self-fracture. In true Freudian fashion, hypnosis uncovers a buried past which once named and made familiar facilitates the merging of Eve's separate personalities. Hitchcock's Spellbound (1945) opens with a statement dedicating the film to psychoanalysis' ability to cure mental illness and restore reason. The plot is both a murder mystery and a mystery of a traumatised psyche: through the tireless investigations of Ingrid Bergman's Dr Constance Peterson, Gregory Peck's Dr Anthony Edwardes is relieved of the suspicion of murder and his trauma-induced amnesia. Both mysteries are solved by the interpretation of a heavy-handed dream sequence designed by Salvador Dali, filled with Freudian symbols such as eyes, curtains, scissors, playing cards and a man with no face.

The canniness of popular art utilising Freudian theory also relies on the way repression appears only as subject matter. In Ross Macdonald's novel The Galton Case (1959), written after the author underwent therapy, the detective figure is a sort of hardboiled Freudian whose method of uncovering hidden family secrets is remarkably similar to psychoanalysis. The Galton Case utilises themes taken directly from the Oedipus legend and although its plot depicts the uncovering of secret crimes, these "returns" evoke no sense of anxiety since they are devoid of any repressed content. The rational deductions of the detective figure are designed to neutralise the irrational and provide an antidote to mysterious threat. ${ }^{24}$

\footnotetext{
${ }^{24}$ For a discussion of the relationship between the detective figure and the psychiatrist see Allan Beveridge, "The Detective, the Psychiatrist and Post-modernism," Psychiatric Bulletin 22 (1998): 5734; S. Marcus, Freud and the Culture of Psychoanalysis (Boston: George Allen and Unwin, 1984); and M. Shepherd, Sherlock Holmes and the Case of Dr Freud (London: Tavistock, 1985).
} 
It is perhaps not surprising that Freud's own investigation into the uncanny occasionally lapses into a kind of canny Freudianism. Although Freud admits that Ernst Jentsch's prior exploration of the uncanny is "fertile" ("Uncanny" 619), he is adamantly opposed to his predecessor's emphasis on intellectual uncertainty. In fact, Freud chooses to explicate Hoffmann's story "The Sandman" (1816) rather than his novel The Devil's Elixir (1815) because the longer work, although containing "a whole mass of themes" connected with the uncanny, is "too obscure" ("Uncanny" 629). Freud's discomfort with obscurity sees him deny the uncanniness of Hoffmann's automaton Olimpia since acknowledging it as uncanny would require accepting Jentsch's theory. Instead, Freud insists that the more striking instance of the uncanny in "The Sandman" is the idea of being robbed of one's eyes, which he suggests has been linked by the scientific study of dreams and myths to the dread of being castrated.

While "The Sandman" certainly involves castration anxiety, Nathanael's horror of the Sandman is far more complex than Freud's diagnosis might suggest. As several critics have noted, Freud's interpretation of Hoffmann's tale completely bypasses the importance of the female protagonists. ${ }^{25}$ Freud suggests that Nathanael's fear of the Sandman is really his fear of "the dreaded father at whose hands castration is expected" (628), but it is Nathanael's nurse who first tells him about the grotesque bogeyman who plucks out children's eyes, and it is his mother who uses the Sandman to hurry her child into bed at night. Nathanael's resentment of the mysterious figure who appears at night to enter his father's rooms relies on the fact that it "always

\footnotetext{
${ }^{25}$ Both Susan E. Linville and Maureen Molloy point out Freud's neglect of the female figure in his analysis of the uncanny. See Linville, History Films, Women and Freud's Uncanny (Austin: University of Texas Press, 2004) and Molloy, "Death and the Maiden: The Feminine and the Nation in Recent New Zealand Films," Signs 25, no. 1 (1999): 153-70. For a marvellous discussion of the role of women in Freud's essay see Jean-Marie Todd, "The Veiled Woman in Freud's Das Unheimlich," Signs 11, no. 3 (1986): 519-28.
} 
chases us away from papa" (86), and as Nathanael grows older the "sinister happenings" (87) in his father's room increasingly occupy his imagination. He is prevented from asking his father about the Sandman "and his relation to us children" (86) because of "an unconquerable timidity" (87), so he resolves to make the Sandman's acquaintance by more devious means. Interestingly, Nathanael then describes how "when my mother had gone past, I would slip out of my bedroom into the corridor, but I never managed to discover anything; for the Sandman had always entered the room before I reached the spot at which he would have been visible' (88). This conflates the threat of the Sandman with the feminine as well as the masculine, since the ambiguous passage seems to describe Nathaniel's mother as the Sandman.

Nathanael's anxiety about the Sandman thus involves childish horror inspired by the nurse's story and pre-adolescent fascination regarding what happens in his parents' room at night and its relationship to children. When he is discovered spying by his father's unpleasant friend, Nathanael's anxieties are reinforced by the cruel beating he receives and the long illness that follows. The complicated mesh of fears from which Hoffmann's protagonist suffers as a youth returns upon his engagement to be married, reinforcing the sense that the Sandman represents a sexualised threat. Yet Freud insists on bypassing the role played by Nathanael's fiancée Clara and the automaton he falls in love with. When summarising the story's events, Freud suggests that after Clara points out a curious bush she spies from the top of a tower, Nathanael "looks at this thing through Coppola's spy-glass" ("Uncanny" 627), which then causes him to fall into a fit of madness. In fact, Hoffmann clearly writes that while Nathanael intends to look at the bush, it is in fact Clara who "was standing before glass" (117). Nathanael's fit of madness is not due, as Freud suggests, to his seeing the approach of Coppelius (whom Nathanael is convinced is the Sandman) through 
the glass, but to the sight of his fiancée through the telescope, which recalls his first view of the automaton Olimpia.

Freud's explication of "The Sandman" seems intent on avoiding what he himself finds most discomforting. At the start of "The Uncanny" he pleads guilty to "a special obtuseness" (620) in the matter of the uncanny, which rather than springing from a natural immunity seems to be the result of avoidance. Freud's insistence on exemption to the uncanny is possibly linked to Jentsch's assertion that while abnormal psychological states might provoke anxiety in a subject confronted with insanity or epileptic fits, in "the case of an expert, the corresponding emotion will occur only rarely or perhaps be completely lacking, for to him the mechanical processes in the human mind are no longer a novelty" (15). In order to maintain "expert" status, Freud must deny his own vulnerability to the unheimlich and he reacts with hostility to writers who manipulate narrative conventions in order to "trick" him into experiencing it, describing his response as "a kind of grudge" ("Uncanny" 641). When narrating his sole encounter with the return of the repressed, it is the threatening female figure which features predominantly as Freud returns time and time again to a foreign street full of "painted women" ("Uncanny" 631). Although he insists on involuntary repetition as the cause of his anxiety, it is the nature of the street that Freud kept returning to that undoubtedly contributed to his feelings of dread. It is no coincidence that the essay's final example of the uncanny is the suggestion that for some neurotic men, female genital organs are profoundly disturbing. Freud thus returns to what he cannot completely repress as the source of his own feelings of anxiety. 


\section{Uncanny Realism}

Freud's use of Hoffmann's story to explore the uncanny obviously provides a clue as to where we might locate the return of the repressed in literature, but it also sends some critics off in false directions. In Uncanny American Fiction (2004) Allan Lloyd Smith suggests that the psychoanalytical perspectives opened by Freud are useful in understanding gothic literature because "Freud himself drew on Gothic texts in reaching his conclusions" (140). He goes on to argue that Freud's reading of "The Sandman" reveals gothic's dependency "on the production of a sense of the uncanny" (Smith 137). But the text Freud chooses as a prime example of the uncanny in literature is not really a gothic text. British gothic certainly influenced German Romanticism, but the fantastic settings, frenetic pacing and melodramatic plots of gothic novels contemporaneous with Hoffmann's work, such as Matthew Lewis' The Monk (1796), Lady Caroline Lamb's Glenarvon (1816) and Charles Robert Maturin's Melmoth the Wanderer (1820), are at odds with the German Romantic focus on evil beneath normality. Cynthia Chalupa argues that the reduction of Hoffmann's fantastic subject matter to simply the "bizarre" and the "demonic" somewhat misleadingly places "the fantastic before the everyday, the poetic before the prosaic" (13). The events of "The Sandman" occur in an everyday world of an urban centre, not in a realm of haunted houses, crypts or deserted moors; the protagonist is not doomed by a supernatural curse but by the failure of his own psychology; and his psychic disintegration is caused by the products of modernity rather than being cured by them, an inversion of gothic's depiction of the past as barbaric and haunting.

Freud is correct in pointing out the story's "quite unparalleled atmosphere of uncanniness" ("Uncanny" 625), which springs largely from the inability to privilege one particular interpretation of events. Unlike gothic, which Tzvetan Todorov 
identifies as either "supernatural explained" or "supernatural accepted," Hoffmann's tale hovers in a realm of indeterminacy in which it is questionable whether there is anything supernatural about the events at all. Hoffmann is particularly careful to distance himself from gothic hyperbole by using a narrator intent on providing a reasonable narrative persuading the reader of "The Sandman" that "nothing can be stranger or weirder than real life, and that the poet can do no more than capture the strangeness of reality" (98-9). The story is uncanny precisely because it is not gothic. Its depiction of a realistic world governed by laws adhering to a reality we recognise as our own makes the reader's suspicion that Nathanael's story involves something more than meets the eye especially disturbing. The events depicted in "The Sandman" manage to adhere to notions of accepted reality while also threatening to disrupt them. Hoffmann's story is not an example of supernatural explained or supernatural accepted, but of supernatural suspected.

Freud points out that many fictional occurrences, such as the reanimation of the dead Snow White, are not experienced by the reader as uncanny but would certainly be so if they occurred in real life. The writer can fashion the fictional world so it either coincides with or departs from the reality the reader is familiar with; in fairy tales, fantasy or science fiction "virtually everything is uncanny, so that nothing is experienced as uncanny" (Krell 60). The situation is altered as soon as fictional events are set in a world that gives the appearance of common reality with an adherence to natural laws. In this case, the reanimation of the dead is much more likely to evoke an uncanny response. When writing realistic fiction, Freud notes that the writer accepts "all the conditions operating to produce uncanny feelings in real life; and everything that would have an uncanny effect in reality has it in his story" ("Uncanny" 641). The uncanny in literature depends upon a semblance of recognisable reality in order for its 
disrupting effects to have their full power, rendering realism the true "home" of the return of the repressed.

As we might expect in a period so intent on avoiding the unpleasant, realism was generally neglected in America during the late forties and fifties in favour of genres better described as escapist. The most popular films were lush Technicolor romances, biblical epics, science fictions, musicals and westerns. A quick look at the bestseller list reveals Western novels such as Gwen Bristow's Jubilee Trail (1950), Frank Yerby's historical Southern romance A Woman Called Fancy (1951), Thomas B. Costain's Grail legend The Silver Chalice (1951) and Samuel Shellabarger's eighteenth-century romp Lord Vanity (1953). While realist novels did appear in the bestseller lists, notably the very popular "social problem" novels such as Peyton Place (1956), Marjorie Morningstar (1955) and Gentleman's Agreement (1947), realism was by no means the dominant popular mode. Furthermore, novels such as Grace Metalious' Peyton Place were less a close exploration of social reality than part of what Dwight Macdonald refers to as a trivial culture that avoids the "deep realities" of "sex, death, failure, tragedy" because they are "too real" (71).

However, realism is the dominant mode in what we might term canonical or "high culture" literature such as Norman Mailer's The Naked and the Dead (1948), Arthur Miller's Death of a Salesman (1949), J.D. Salinger's The Catcher in the Rye (1951), James Baldwin's Go Tell it on the Mountain (1953), Saul Bellow's The Adventures of Augie March (1953) and the short stories of John Cheever. Clearly, not all realism is uncanny; in fact, most of it is not. There is a certain paradox about uncanny realism since the disrupting effects of the uncanny in fiction rely upon a semblance of recognisable reality, but these effects necessarily render this fictional reality strange. Uncanny realism might best be described as a mode of fiction involving moments of 
estrangement from its own generic conventions. The reader enjoys a depiction of a fictional reality similar to their own surroundings and invests in a cast of characters who adhere to common understandings of psychological motivation, but at certain moments in the text fictional reality admits a ghostly figure or a realistically rendered protagonist suddenly becomes oddly mechanical.

What differentiates "serious" writers of postwar literature from the writers of bestsellers is their articulation of disturbances between the familiar and the unfamiliar, and their awareness of absences and elisions between the consensus vision and disturbing reality. Mary McCarthy declared the era "inaccessible to common sense" and identified the novel as the form "least adapted to encompass the modern world, whose leading characteristic is irreality" (qtd. in Schaub 66). Cultural critic Benjamin Demott admitted a "deeply lodged suspicion" that events and individuals were "unreal" and suggested that the era displayed a "universal descent into unreality" (qtd. in Roth, "American Fiction" 145). In an unpublished letter written to Jack Kerouac in 1949, John Clellon Holmes similarly suggested that "There is something irrational to our world today" and admitted that "I can't recognise the land or the people anymore and I look at everything as though I had never seen it before.” Novelist James Jones also came close to identifying uncanniness as the chief characteristic of life in America following World War II when he explained,

I don't think people like to read about themselves or about others as they really are. It would be too horrifying. After all, we have to give ourselves a little of the feeling that we're human beings with a capital $\mathrm{H}$ and $\mathrm{B}$. so we do that, and every now and then the real truth surges up to plague us from that limbo to which we've suppressed it. (Writers at Work 248)

Philip Roth describes the struggle between "the benign national myth of itself that a great power prefers to perpetuate, and the relentlessly insidious, very nearly demonic reality" (Reading Myself 90) that refuses to be banished, singling out the Holocaust as 
something 'simply there, hidden, submerged, emerging, disappearing, unforgotten' (Reading Myself 136).

The obscure recognition of something concealed beneath the surface of postwar life that these writers articulate contributes to a peculiarly tense literature, and, in a period so intent on promulgating a strictly circumscribed vision of reality, literary realism struck some critics as strange. John Aldridge suggested that the new writers of the period such as Truman Capote, display an elaboration of technique "in excess of the demands of their raw material." It is as if,

in their confusion before the exact implications of that material, they have tried to create a false reality of words alone that would give it an appearance of life and truth which it did not by itself possess. They have dealt with a thin substance and managed to make it rich by perfecting their manner of presenting it; and in the process they have made the obvious obscure and the familiar overly strange. ("Search for Values" 55)

The duplicity of elaborately constructed fiction suggesting something both real and unreal is symptomatic of the ambiguity plaguing American life as well as American letters. The awareness of a "false reality" created by language only emphasises the suspicion of something unknown lurking beneath. What was once familiar reality has become profoundly strange.

Aldridge's comments recall Freud's suggestion that towards the end of Hoffmann's novel The Devil's Elixir, "the reader is told the facts, hitherto concealed from him, from which the action springs; with the result, not that he is at last enlightened, but that he falls into a state of complete bewilderment" ("Uncanny" 629). Hoffmann "has piled up too much material of the same kind. In consequence one's grasp of the story as a whole suffers, though not the impression it makes" ("Uncanny" 629). The uncanny thus relies on uncertainty, over-elaboration, excess and a sense of reality destabilised by a sense of something unreal. Furthermore, if Freud is correct in stating that "an uncanny effect is often and easily produced when the distinction 
between imagination and reality is effaced", and through "the over-accentuation of psychical reality in comparison with material reality" (“Uncanny" 636), then not only literature but the act of reading itself is potentially uncanny.

The relationship between the uncanny and literary realism is complicated not only by the fact that unhomeliness guarantees estrangement from any genre, but that the uncanny might cause genre itself to become estranged from its own conventions. It is this ability to confound definition that enables the uncanny to behave subversively by disrupting the psychic boundaries of self and other, life and death, reality and unreality. The familiar made strange relies on uncertainty between what is present and what is absent, between the acknowledged and the silenced. Wolfgang Iser goes so far as to suggest that the comprehension of a text is only possible through its blanks and negations, that a text's meaning emerges as the reverse side of what the text has depicted. The gap between what was spoken and what was silenced was particularly large during the early postwar period and writers who expressed awareness of this chasm and who struggled to negotiate awareness with the pressures of consensus culture frequently found themselves in the realm of the uncanny.

By arguing for the countercultural elements of postwar uncanny realism this study goes against prevailing criticism during the 1980s aligning elite art forms with conservative, dubious, even fascist politics. Andreas Huyssen points out that "Modernism constituted itself through a conscious strategy of exclusion, and anxiety of contamination by its other: an increasingly consuming and engulfing mass culture" (vii). Modernism's perceived elitism, desire for order and traditionalism, along with the dubious politics of several of its leading figures - Ezra Pound's support of Mussolini, T.S. Eliot's reputed anti-Semitism and Wyndham Lewis' right-wing politics - have seen recent critics such as Roger Griffin cast it in a less than flattering 
light. Yet one of modernism's most important figures, James Joyce, held liberal views and was even active for some time with socialist politics. ${ }^{26}$ Similarly, Virginia Woolf married a left-wing journalist and moved in liberal social circles.

There is little reason to conflate modernism's elite dogma with that of postwar American "high" culture. While modernism did linger on into the fifties, its influence was mainly seen in visual arts movements such as Abstract Expressionism, with American literature of the period exhibiting little modernist influence. ${ }^{27}$ While postwar critics certainly displayed the fear of contamination that Huyssen attributes to modernism, these critics were also concerned with distancing themselves from the elitist ideology that was popularly seen as contributing to the rise of fascism. Marcus Klein wondered, "After Auschwitz, who would want to be D.H. Lawrence?" (American Novel 14). Klein's suggestion that the "modernist revolution leads on the one hand to middle-class bohemianism and on the other hand to horrors" (American Novel 14) reflects the era's attempt to discover what Martin Halliwell describes as "a middle way between high modernism and popular tastes" (54). Although twentiethcentury "high" culture has always adopted adversarial positions, it displayed an overwhelmingly liberal rather than rightwing character during the postwar years in America, with leading intellectuals such as Miller, Mailer, Bellow, Irving Howe and Mary McCarthy holding decidedly leftwing views.

György Lukács argues against the perception of realism as politically and aesthetically conservative by suggesting that because it creates apparently subjective

\footnotetext{
${ }^{26}$ For a discussion of Joyce's involvement in socialist politics see James Fairhall, James Joyce and the Question of History (Cambridge: Cambridge University Press, 1995), 49-54.

${ }^{27}$ Ralph Ellison's use of modernist strategies in Invisible Man was highly unusual for the period and is partly the reason it provoked so much controversy. In denouncing Ellison's novel, Ernest Kaiser argued that "Good fiction has to be experienced and lived. It cannot be contrived and created from symbols and myths." See Kaiser, "A Critical Look at Ellison's Fiction and at Social and Literary Criticism by and about the Author," The Literature and Culture of the American 1950s, University of Pennsylvania Center for Programs in Contemporary Writing, http://www.writing.upenn.edu/ afilreis/50s/kaiser-onellison.html. Ellison's focus on Western traditions of tragedy and art has been seen as a betrayal to a politicized African American fiction.
} 
experiences that demonstrate social realities, realism is the only valuable literary school of the early twentieth century. Another defender of realism is Ian Watts, who points out that the novel as it appeared in the eighteenth century is the form of literature which most fully reflects the modern reorientation towards individualism and innovation. Literary forms prior to the Enlightenment had, according to Watts,

reflected the general tendency of their cultures to make conformity to traditional practice the major test of truth: the plots of classical and renaissance epic, for example, were based on past history or fable, and the merits of the author's treatment were judged largely according to a view of literary decorum derived from the accepted models in the genre. (13)

For Watts, this literary traditionalism was first and most fully challenged by the realist novel, "whose primary criterion was truth to individual experience - individual experience which is always unique and therefore new" (13). The novel is thus the "logical literary vehicle of a culture which, in the last few centuries, has set an unprecedented value on originality, on the novel; and it is therefore well named" (Watts 13). Watts stresses the radical elements of the realist novel's origins, a radicalism which was reinstated, admittedly in heavy disguise, during the first postWorld War II decade in America.

The texts covered in this study exemplify repression and illustrate the different forms of literary reaction to the avoidance of the uncomfortable in the America of 1945-55. Realist novels such as Mailer's The Naked and the Dead and Paul Bowles' The Sheltering Sky not only depict automaton-like characters, insanity and haunting, thus suggesting a conscious use of Freudian theory, but the texts themselves act as the return of excluded or denied material. Bowles' novel includes a character who represses the traumatic experience of her husband's death and becomes insane, but this conscious use of a Freudian concept is destabilised by the obscure sense of a second hidden story existing beneath the obvious narrative. While Bowles' novel can 
be read as an illustration of the bad end that comes to individuals who transgress boundaries both geographical and ideological, there is something else going on that inspires considerable discomfort: moments when the text appears to bend back upon itself; when one character suddenly ceases and another takes over as the main protagonist; when we feel that the text itself is a sheltering sky that only tenuously guards us from something menacing behind. Mailer referred to this unsettling phenomenon when he described writing as the "spooky" art (qtd. in Lennon 142), spooky because although a writer might sit down to consciously write a particular story, another unwilled story might very well appear. Such doubling is profoundly unsettling for the reader, who is faced not only with the depiction of uncanny objects and events, but who is also confronted with the knowledge that somehow these novels and the psyches that created them are ultimately unknowable, perhaps even dangerously out of control. 


\section{Automatons and the Atomic Abyss: \\ Norman Mailer's The Naked and the Dead.}

For the first time I became powerfully aware of the fact that I had an unconscious, which seemed to have little to do with me.

Norman Mailer, "The Art of Fiction No. 32"

Mailer's The Naked and the Dead (1948) adheres to the practise of the era's war novels by focusing on acceptable social and political issues, but it is unusual in its inclusion of uncanny automatons, strangely malevolent environments and superstitions regarding death. It was Mailer's first novel and proved to be a bestseller. In a period fascinated with psychology, the detailed portraits of the numerous characters provided a sense of reality lauded for its grittiness but which was also a familiar aspect of literature depicting war. There is little in the way of plot, with much of the long novel painstakingly recording the mundane details of military life: the digging of foxholes; the waiting for command; the building of roads; the transportation of materials; the eating of rations. There are numerous flashback scenes detailing the soldiers' lives prior to the platoon's arrival on the Pacific Island, and the dénouement is a disastrous reconnaissance mission which turns out to be unnecessary, since when the survivors return to base they discover the island has been successfully taken by the Allied forces in a separate manoeuvre.

Yet despite the emphasis on conventional psychology and the quotidian aspects of war, and despite what David Dempsey's 1948 review in the New York Times describes as the novel's depiction of "the blood if not the guts" (6) of battle, Mailer 
discovered that a period of Cold War is "obviously equal to greater censorship" (qtd. in Lyle 23). America was not prepared for a military that indulged in four letter words and Mailer was forced by his publishers to replace his soldiers' expletives with the single word "fug." The lesson learned by the budding author was "if good writers write novels which are conventionally obscene or exceptionally radical, you can be sure that they would have one hell of a time getting their books published" (qtd. in Lyle 23).

Before looking in-depth at the uncanniness of Mailer's novel, it is worth taking a brief look at the ways the censorship he identified affected the era's representation of World War II. Marianna Torgovnick notes that such morally ambiguous aspects of America's role in the war as internment camps for Japanese and Japanese Americans, incendiary bombing of cities in Germany and Japan, and the atomic bombing of Hiroshima and Nagasaki, while part of the public record, "have never registered in America's image of World War II or in America's image of itself' (4). Following long years of hardship and loss, America wanted a celebration of its heroic part in the conflict, and while this necessarily included violence and death, without which heroism would be impossible, only rarely was this depicted in any detail. Hollywood films such as The Best Years of Our Lives (1946) might include a flashback scene of combat, there might be a corpse or two, even an actual killing, but there was no civilian death, no mass destruction, no real contemplation of the Holocaust and no exploration of the moral implications of the deployment of the atomic bomb. ${ }^{28}$

\footnotetext{
${ }^{28}$ Christian G. Appy points out that the use of World War II as frame, setting or flashback in the era's popular films provided "a blanket of moral certitude and nostalgia" under which Cold War militarization was concealed, justified or comforted. While the aftermath of the war did involve the grim representations of American life found in film noir, Appy suggests that "it would be hard to exaggerate the power and persistence of sentimentality in American culture." See Appy, "'We'll Follow the Old Man': The Strains of Sentimental Militarism in Popular Films of the Fifties," Rethinking Cold War Culture, ed. Peter J. Kuznick and James Gilbert (Washington and London: Smithsonian Institution Press, 2001): 74-105.
} 
Admiral Gene LaRocque expressed his frustration with popular renderings of the war by pointing out that in "all those films, people get blown up with their clothes and fall gracefully to the ground. You don't see anybody being blown apart. You see only an antiseptic, clean, neat way to die gloriously" (qtd. in Adams 100). Michael C.C. Adams' The Best War Ever relates the story of a combat photographer who recorded the murder of SS soldiers by their American guards only to be informed that the film could not be screened because of "technical difficulties" (9). When one reporter attempted to broadcast descriptions of faceless, limbless American soldiers in military hospitals, the censors instructed him to write about new miracle drugs and medical instruments instead. Known for his social realist fiction of the 1930s, John Steinbeck admitted that as a war reporter he deliberately slanted stories to omit anything that might shock civilians (Adams 9).

Consensus regarding the representation of World War II was widespread, with most writers of war novels avoiding depictions of the end of the war since this could complicate the Allied victory through unsavoury descriptions of how that victory was won. Many writers even avoided depictions of combat, a rather tricky feat given the subject matter. ${ }^{29}$ James Gould Cozzens' Guard of Honor (1948) solves these problems by setting the action on a Florida Army Air Forces base. The novel focuses on the social issues facing an institution coping with racial integration, a potentially controversial subject which merely acts as a catalyst designed to facilitate action by the admirably efficient military professionals. There are other bureaucratic issues that

\footnotetext{
${ }^{29}$ Torgovnick describes Movietonenews reportage of D-Day and cites reassurance and control as the main aspects of what purports to be actual footage from the invasion, but which is really a reenactment. The soldiers neatly exit the landing craft and show no signs of panic or hurry, nor are any wounded or killed. The D-Day invasion is made to look "routine and tidy. Almost like a barracks inspection; the troops might almost dust and clean the craft before they disembark." Closer inspection of the newsreel shows that the lighting does not match previous shots; it is night rather than day and klieg lights are just discernable. There was no acknowledgement of the re-enactment and Torgovnick suggests that Movietonenews recreated the unloading to "reassure and buoy the folks back home" (27).
} 
arise over the weekend in which the novel is set, such as a troublesome alcoholic colonel and a disastrous parade, all of which serve Cozzens' focus on the depiction of the quotidian affairs of the stateside Army Air Forces. It is interesting to note that Cozzens' own role in the Air Force during the war was working in the USAAF Office of Information Services, a liaison between the military and the civilian press responsible for creating a censored image of the Air Force deemed suitable for the civilian population. Given this training ground, it is perhaps not surprising that Guard of Honor won the Pulitzer Prize for Fiction in 1949.

James Jones' From Here to Eternity (1951) proved just as popular. It received the National Book Award for Fiction in 1951 and was adapted into a screen version in 1953. As in Cozzens' novel, Jones avoids unsavoury violence by setting his story on a military base in Hawaii prior to the bombing of Pearl Harbour. Jones' focus is also on acceptable social issues relevant to the postwar period, particularly the effects on the individual of a powerful organisation demanding subservience. Prior to the bombing there is little need for the novel's protagonists to deal with death or destruction, and Maggio even admits that he has never seen a dead person aside from his grandfather in his casket. Just as Jones avoids the more disturbing aspects of war, his characters are similarly compelled to turn away. When one soldier commits suicide in the barracks, his comrades react with anger at being confronted with his corpse. They "all looked like if The Warden had not been there holding them at bay they would have swarmed on Bloom, dead or not, and beaten him with their fists for having reminded them of this thing they spent the best years of their lives trying to forget" (J. Jones $665)$.

Jones' leading protagonist Prew experiences his own fear as something "flapping from the depths like a giant mantra ray" and concludes that "there were things in 
themselves that men should not look at, just as there were things in the very deep bottom of the sea that it was better men did not know about" (446). This justification recalls Jones' statement cited in the previous chapter that realism in literature is often "too horrifying" for many readers. Although he acknowledges that "the real truth surges up to plague us from that limbo to which we've suppressed it" (Writers at Work 248), there is no such return within his novel. Prew succeeds in overcoming the limitations of his impoverished background and his constant fear in order to stand up for the American ideals he so firmly believes in. Although his death is tragic, it is not disturbing since it adheres to familiar literary conventions of heroic self-sacrifice. In fact, although Prew absolves himself by returning from being AWOL to defend his country against attack, his murder of a fellow American and his abandonment of military duty actually necessitates his final punishment in order to reaffirm ideals of patriotism, idealism and courage.

Herman Wouk's Pulitzer Prize winning novel The Caine Mutiny (1951) displays similar conservative traits. Selling three million copies within three years, it was translated into seventeen languages, made into a successful Broadway play and turned into a film starring Humphrey Bogart. The plot of the novel concerns Philip Queeg, a mentally unbalanced and increasingly incompetent skipper, and explores whether mutiny by his sailors is justifiable. Although the lawyer hired to defend the mutineers succeeds in winning an acquittal, the novel ends with his condemnation of his clients thus rendering the mutineers (who saved both the ship and the lives of all onboard) villains and Queeg a hero. As Wouk himself suggested, the novel's main theme is the conflict between authority and responsibility, and he hoped that the crux of the tale would reveal "that the mutiny was a mistake even though Maryk was acquitted" (qtd. in Whitfield 61). Not surprisingly given the strong consensus regarding the military in 
the postwar years, Wouk takes the side of authority and suggests that losing a ship and the lives aboard is preferable to mutiny, a message at odds with that of the books that received comparable popularity following the Great War, such as Hemingway's $A$ Farewell to Arms (1929), Dos Passos' Three Soldiers (1921) and Remarques' All Quiet on the Western Front (1929). The success of The Caine Mutiny, according to Stephen Whitfield, proves "how smoothly popular taste could accommodate an authoritarian ideology, justifying submission to a demented superior" (61). The novel clearly illustrates Cold War antipathy towards individual conscience and individual judgement.

One of the few American war novels of the period set in Europe was Irwin Shaw's The Young Lions (1948). Shaw seems aware of the complicated mix of attraction and repulsion engendered by the war experience and his characters experience a compulsion to look as well as an unwillingness to see. Before he enlists, the American protagonist Michael Whitacre is unable to cease scanning the newspaper for reports on the war, but he turns away from "the blood on the Volga, the drowned men of the Atlantic, the sand-blinded troops of Egypt, from the rumours of rubber and the flames in France and the restrictions on roast beef, to the sporting page" (Shaw 230-1). Although the novel's Nazi protagonist passes through a concentration camp during his retreat to Germany, Shaw exhibits a similar avoidance strategy to the one he attributes to Whitacre. While the foul odour of the camp and the emaciated appearance of the prisoners are described, the exact nature of the camp and the identity of its inmates are avoided. In a 1953 interview in the Paris Review, Shaw suggested that war "has now been taken out of all human contact. We can hardly conceive or bear to think of the faculties now achieved for mass destruction.” The killing of World War II “isn't even the kind of killing with regret, with compassion, that I tried to write about in The 
Young Lions" (18-19). Shaw implies that despite its realistic detail, his literary depiction of war is in fact a censored version of something too difficult or too unpleasant to represent. ${ }^{30}$

Unlike early American literature about World War II, the writers of the First World War did not hesitate to fill their texts with depictions of filth, rotting corpses, mangled limbs and suicidal soldiers. Many of the British war poets were impelled to write not only as a way of articulating their own war experience, but as a way to counter what they saw as false patriotic propaganda. ${ }^{31}$ Siegfried Sassoon's philosophy of "no truth unfitting" illustrates the belief of many World War I writers whose choice of the poetic form gave their work, often composed on the battle field, a visceral immediacy. Margot Norris observes that artists such as Sassoon and Wilfred Owen responded to the Great War by attempting to develop new forms of expression capable of portraying the unprecedented violence of the trenches, while intellectuals of the period engaged in creating "theoretical and institutional controversies over the priorities of aesthetics and pity" (99).

The ability of First World War writers to engage with a version of war opposed to an officially sanctioned one was in large part engendered by the conflict's perceived morality. A generation later, American writers of the next global conflict found the "no truth unfitting" philosophy difficult to embrace. After all, it was a very different war. While many considered the first conflict avoidable and of dubious necessity, the

\footnotetext{
${ }^{30}$ Shaw's deviance from the literary consensus in depicting a concentration camp was matched by his atypical response to anti-Communism. In 1951 Shaw published his second novel The Troubled Air, which chronicles the rise of McCarthyism. He signed the petition for a review of John Howard's and Dalton Trumbo's convictions for contempt of Congress that resulted from HUAC hearings and was falsely accused of being a Communist. After being blacklisted by Hollywood, Shaw left America in 1951 for Europe where he resided mostly in Paris.

${ }^{31}$ In "Remorse" Siegfried Sassoon writes: "Remembering how he saw those Germans run/Screaming for mercy among the stumps of trees: /Green-faced, they dodged and darted: there was one/Livid with terror, clutching at his knees. . . /Our chaps were sticking 'em like pigs . . 'O hell!'/He thought 'there's things in war one dare not tell/Poor father sitting safe at home, who reads/Of dying heroes and their deathless deeds"” (War Poems 44).
} 
second was the "good war" fought not simply by nations but by representatives of a binarised moral code. Violence was not restricted to the front during the 1939-45 conflict; regimes murdered entire populations and bombs obliterated whole cities. The bafflement over how to express the horror of the Second World War's mass destruction was further compounded by doubts as to whether such horror could, or should, be expressed.

Mailer had little to say regarding the cultural imperatives of writing about the war, but he was particularly vocal in complaining about a postwar literary climate in which it was "almost impossible ... for anyone to do anything individual without being crucified in those very mediocre and dreary salons which pop up like mushrooms all over New York" (qtd. in Wolheim 68). But Mailer's desire for rebellious individuality co-existed with an equally strong desire for popular success, making him the American writer who perhaps most clearly straddles the divide between the artistic and the commercial. His literary output was frequently overshadowed by appearances on television talk shows and his involvement in prize fighting, politics, bar room brawls, social scandals and literary feuds. Although he proclaimed that an "artist follows his own nature" whereas "commercial talents do what they are obliged to do, and say what they are obliged to say" (qtd. in Lyle 25), Mailer seemed uncertain about his own place. He described himself both as the American writer most fit to run for president of the literary world and as a professional hack writing to fulfil publishing contracts and magazine deadlines.

In an unpublished letter written to Alfred Kazin in 1959, Mailer explained his dilemma regarding publishing part of a novel in progress in a collection of short writing to appear that year. Although Putnam publisher Walter Minton "has a welldeserved reputation for being not without courage ... he feels that The Time of Her 
Time is certain to be prosecuted, even banned, unless there is in advance a reasonably impressive critical support." Mailer's pride at having written something which the publisher of Nabokov's Lolita (1955) baulked at was accompanied by a desire for popular success. Consequently he sent out the manuscript "to eight or ten critics whose word would have influence", even though he admitted to finding it unattractive "to solicit a critic with unpublished work."

When asked in a 1961 interview whether he believed that people want to "look into the abyss," Mailer responded, "No, I don't. I think it's very hard. I think people are petrified of it" (qtd. in Auchincloss 45). Mailer's paradoxical desires, particularly his awareness of the abyss and his acceptance of the reluctance to look into it, create a war novel that appears to focus on military detail but which also harbours hidden concerns. The Naked and the Dead was described by its author as "the book of a young engineer" written "mechanically", and his description of its "sturdy" (qtd. in Marcus 13) working plan utilising extensive character dossiers and charts implies its consciously controlled construction. Several years after the book's publication, however, Mailer described his increasing awareness of a division in his mind between a "conscious intelligence" engaged with political issues and an unconscious mind "much more interested in other matters: murder, suicide, orgy, psychosis" (qtd. in Marcus 15). This gulf between the conscious and the unconscious, according to Mailer, is "vast and quite resistant to any quick literary coupling" and is the reason for the "unearthly" focus of 1951's Barbary Shore (qtd. in Marcus 16). Mailer's sense of this psychic divide, of which he only became aware after writing The Naked and the Dead, posed difficulties he identified as "haunting" him in all his subsequent work (qtd. in Marcus 16). 
In his first novel, Mailer's unacknowledged fascination with the dark areas of the unconscious co-exists with a strong reluctance to look into its shadows and an equally strong narrative strategy designed to keep repressed content at bay. The story written by Mailer's "conscious intelligence" concerns acceptable political issues affecting both the military organisation and civilian life. Mailer's platoon contains one of almost every representative American type, asides from African Americans since the military was racially segregated. There is the patrician General Cummings; the Harvard-educated Lieutenant Robert Hearn; the cynical Czienwicz (known as Polack); working-class Bostonian Gallagher; two Jews; one Mexican American; a Mississippi farmer; a happy-go-lucky Georgian; and the sensitive Buddy Wyman who dreams of heroism and of one day being able to support his mother. These carefully chosen representative figures are placed in a situation guaranteed to result in personal conflict and Mailer's determinist vision sees his characters behaving in ways dictated by their socio-economic backgrounds.

The novel displays close ties with the naturalistic work of writers such as Stephen Crane and John Dos Passos, but as much as individual powerlessness is a part of the naturalistic worldview, much of this concern springs from Cold War sociological concerns regarding the corporate-controlled "organisation man." Mailer's interest in the effects on individual psychology of socio-political structures focuses on the ways in which the war against fascism potentially involves the Allied forces operating in similarly totalitarian ways. David Dempsey's New York Times review reveals just how carefully Mailer handled this potentially subversive theme when he stated that "Mr. Mailer obviously doesn't like war, or the people who fight it" (6), but concluded that the author was attempting to show that much of its unpleasantness comes from the 
nature of the participants rather than from any implicit problem with the American military.

The conscious theme of the novel can be summarised as power: "the power of man over man, the power of military force, the power of political thought and polemic, the inexorable power of events on the lives of men" (P. Jones 87). Yet as Mailer himself points out, writing is "a very odd, spooky activity" (qtd. in Canby 142), and surging through the conscious delineation of political and social issues are darker unconscious themes. Mailer's haunting problem - the unbridgeable gap between his conscious and unconscious concerns - creates a realistic war novel strangely peopled with automatons, which critics going back to Jentsch and Freud have identified as particularly uncanny. Jentsch suggests that doubt as to whether an apparently living being is really animate, or whether a lifeless object may actually be alive, is one of the most potent psychic uncertainties, a doubt which is intensified when it "only makes itself felt obscurely in one's consciousness" (11). Freud disagrees with Jentsch's emphasis on intellectual uncertainty and dismisses the uncanny effects of Hoffmann's automaton, but as the previous chapter has shown this was part of Freud's avoidance of disturbing material rather than a denial of the automata's ability to invoke the uncanny. ${ }^{32}$

\footnotetext{
${ }^{32}$ Roboticists working in the field of humanoid robots have investigated the relationship of what they refer to as "the uncanny valley" with the degree of the robot's human likeness. An unpleasant reaction is reported when the robot has an extremely realistic human appearance, and interestingly, this unpleasant reaction is increased when an unrealistic feature, such as bizarre eyes, are added to the robot. A perfect human likeness is disturbing in an artificial creature, but the uncanniness of this encounter between real and unreal is increased when there is some indication of the artificiality of the unreal. On the history of automata see Richard D. Altick, The Shows of London (Cambridge, Mass.: Harvard University Press, 1978): 64-76; and Jean-Claude Beaune, "The Classical Age of Automata: An Impressionistic Survey from the Sixteenth to the Nineteenth Century," Zone: Fragments for a History of the Human Body, ed. Michel Feher 3, no. 1 (1989): 430-80.
} 
As Hal Foster points out, the machine has often been seen as somehow demonic, an obscure threat disruptive of traditional social practice, but it is the machine's relationship to the human that makes it particularly uncanny:

In the premodern instance the machine is thought to mimic the organic movements of the body; in the modern instance, however, the machine becomes the model, and the body is disciplined to its mechanistic specifications. Like the commodity, the machine is uncanny because it assumes our human vitality and because we take on its deathly facticity. Both forms draw out human labor and will, animation and autonomy, and return them in alien guises; both are other yet not-other, strange yet familiar. (Foster 51)

The replacement of human labour by machines, which intensified during the Industrial Revolution, created an increasingly mechanistic society in which humanity is supplanted by technology. According to Siegfried Giedion, the machine's ability to affect not just industry but the private realm impinges "upon the very center of the human psyche" (41), a process which obviously has a profound effect on human experience during war, especially the 1939-45 conflict in which mass death was meted out by advanced forms of technology.

Mailer saw the dissolving boundaries between the human and the inhuman as a theme not only in war but in American life following the conflict. He suggested that It was as if back in the late Forties and early Fifties a great many people unconsciously began to sense that they were getting further and further away from themselves. There was something funny in the scheme of things. The whole apparatus of the buildings about us, the things we read, the things we eat, the things we see for entertainment, the philosophies about us, the faiths everything was making it harder and harder for someone to have a sense of identity. (qtd. in Bragg 199-200)

Mailer's apprehension of something wrong in postwar life defies clear expression and his grammatical errors between the past and present tense reveal something of the troubling vagueness of this estrangement. Loss of individual identity is linked with an obscure dread, suggesting that the loss of self in an era of conformity registers as uncanny. 
Mailer's confused articulation of this loss of self is an early example of a line of thought that would culminate in William Whyte's sociological study The Organization Man (1956), which identified one of the major aspects of postwar American life as the belief in the individual's need to belong. Individual existence was largely perceived as meaningless without collaboration with social groups, which obviously resulted in enormous value being placed on acceptance and conformity, a trend exemplified in much contemporary literature. While it was acceptable to discuss the effects on the individual of increasing corporatisation and conformity, the majority of these discussions were couched in reassuring terms, illustrating what Whyte identified as the dominant strain in popular culture: adjustment to the system. In Sloan Wilson's The Man in the Gray Flannel Suit (1955) for example, the protagonist is rewarded for his adjustment to the system by a happy suburban existence and a lucrative financial inheritance. Mailer, however, does not present the subservience of the individual as an acceptable fact of life nor does he reward his characters for observing such subservience. Instead, he utilises an acceptable theme and imbues it with the dread inherent in the return of the repressed, rendering his automatons a disturbing manifestation of the loss of humanity.

Mailer's soldiers are repeatedly referred to as automatic entities stripped of emotion, autonomy and free will. General Cummings has become so alienated from what is human that he even lacks recognisable expressions, merely displaying "a certain vacancy in his face" (81). When this strangely inhuman commander attempts a rare smile, the only result is that his face looks "numb" (129). Yet this vacant cipher commands his troops with an absolute power they have little choice but to obey. Ordered out on patrol and lit up by the light of a flare, the soldiers become a mass of "black cutouts moving past a spotlight" (129), two-dimensional figures obeying 
orders "with no consciousness any longer of what they were doing" (131). Even in extreme situations they are unable to react as humans. When a Japanese soldier is caught in a rain of bullets, he remains standing with "no expression on his face; he looked vacant and surprised even as the bullets struck him in the chest" (153).

Susan Bernstein points out that dislocation and loss of control are lapses of consciousness frequently thematised in uncanny texts. One of Mailer's soldiers is unable to integrate his war experience because everything feels "unbelievable" (188). He claims it "always seemed impossible he would move or fire his gun, expose his life, and yet he always advanced" (188). Plagued by his lack of agency and profoundly estranged from his own perceptions, the only solace the soldier has is the "certainty that none of it was real" (189). Even the bodies of dead soldiers are not really human, with one swollen corpse merely resembling "a doll whose stuffing had broken forth" (211).

The soldiers know "very little about what was happening in the campaign" and the days repeat themselves until they are "no longer able to distinguish between things which had happened a few days before" (252). They "stand guard at night, awaken a half hour after dawn, eat breakfast, wash their mess kits, shave, and load onto trucks" which take them to their daily duties. They "return at noon, go out again after chow, and work until late afternoon when they would come back for supper, take a bath perhaps in the stream just outside the bivouac, and then go to sleep soon after dark" (252). These minutely observed details should intensify the fictional reality, but obscurely felt doubt regarding the soldier's humanity complicates the necessary suspension of disbelief. Mailer's elaborate details are strangely countered by reminders of the text's fictional status; while the reader might initially feel on familiar ground, the known conventions of realism are rendered increasingly strange. All 
writing attempts to "double" reality, but this illusion becomes threatening when it forces a confrontation with the tenuous nature of notions regarding the human and the inhuman, self and other, reality and unreality, life and death.

The Naked and the Dead transforms military camaraderie, human will, autonomy and labour into estrangement, loss of control and dehumanisation. The strangeness of this fictional process is intensified by the process of fiction itself, which is necessarily bound up with attempts to transform language into entities perceived as human. This process remained "a mystery" for Mailer, who felt that the power of the writer "to alter reality in other people's minds by the way we use words" was "a mysterious matter" (qtd. in Gelmis 161). Because of this uncertainty regarding the power of words, Mailer veers disconcertingly between moments of verisimilitude and selfreflexivity. When the platoon is sent out on reconnaissance, they march in a leaden stupor "without any thought of where they went, dully, stupidly", but any empathy for military hardship is rendered problematic by the subsequent description of their heavy packs becoming "part of their bodies" (505). This oscillation between depictions of identifiable characters and uncanny machines complicates the reader's sense of security in a genre that appears to represent reality but which also gestures towards its status as fiction.

Although General Cummings wields significantly more power and authority than the platoon's soldiers, he too is merely a $\operatorname{cog}$ in the machine of war. His private journal is filled with thoughts not on his spiritual or emotional life, but on the life of weaponry. He decides it is "a not entirely unproductive conceit to consider weapons as being something more than machines, as having personalities, perhaps, likenesses to humans" (568). Fittingly, he also suggests that soldiers are "closer to machines than humans" (569). Instead of an heroic clash between opposing human forces, battle 
becomes "an organization of thousands of man-machines who dart with governing habits across a field, sweat like a radiator in the sun, shiver and become stiff like a piece of metal in the rain" (569). The General's conclusion is, "We are not so discrete from the machine any longer, I detect it in my thinking" (569). Intellectual uncertainty between human and inhuman is not merely played out on a physical level but has infiltrated into the very deepest recesses of personal space. The soldiers cease to "think of themselves as individual men" and become "merely envelopes" (658). Traumatised, exhausted and with no sense of agency, the man-machines recognise each other merely as "vague irritating obstacles into which they blundered" (658) and Private Red Valsen realises that war makes soldiers "just a little goddamm bolt holding on and squealing when the machine went too fast" (704).

Rendered mechanical parts of an uncontrollable machine, the soldiers' lack of agency sees them haunted by what Freud terms the "omnipotence of thoughts." The apparently surmounted yet still recognised belief in the ability of language or thoughts to affect reality is linked by Freud to animistic conceptions of the universe still existent in rational modes of thought. Interestingly, the superstitious belief in the ability of spoken words or unspoken thoughts to alter reality is very like the power of the written word and the writer who wields it which so disturbed Mailer. The weird ability to alter reality through language is even identified by Mailer as the mystery "that drove Hemingway insane" (qtd. in Gelmis 161).

The fears expressed by the soldiers in The Naked and the Dead regarding the omnipotence of thoughts animate Mailer's own fears regarding his power and status as a writer, as well as the threat posed to him by writing itself. Mailer explains how "a book takes on its own life" during writing, and suggests that an author has "a certain responsibility" to a book which becomes like "a creature to you after a while" (qtd. in 
Marcus 26). The writer feels "a bit like a master who's got a fine animal" and Mailer admits to often feeling "a certain shame with what I've done with a novel" (qtd. in Marcus 26). If Mailer feels guilty over his actions towards a novel which is raised "like a child" (qtd. in Marcus 26), then what kind of revenge might this ill-treated creature wreak on its author?

In his numerous interviews Mailer returns time and time again to Hemingway, who represents not just a great writer but one undone by the perils of writing. The mystery that drove Hemingway mad also threatens Mailer, who describes the writer's craft - as opposed to "the natural mystique of the novel" (qtd. in Marcus 29) - as a bulwark against "the terror of confronting a reality which might open into more and more anxiety and so present a deeper and deeper view of the abyss" (qtd. in Marcus 30). Reliance on craft is something Mailer attributes to mediocre writers yet he also admits that "there was a time when I wanted very much to belong to the literary world. I wanted to be respected the way someone like Katherine Ann Porter used to be ... As a master of the craft" (qtd. in Marcus 29). Mailer's fears about writing are thus twofold: on the one hand, he fears the mystery which rendered Hemingway insane; on the other, he fears not belonging to the literary world comprised of masters of craft to whom writing poses a threat.

This discomfort with the power of narrative plays out through the soldiers' superstitious fears about death. When Gallagher flippantly comments, "You're only gonna get your fuggin head blown off tomorrow", he is suddenly seized with "a cold shuddering anxiety as though he has blasphemed" (7). As he hurriedly recites the Hail Mary, he has a vision of himself "lying on the beach with a bloody nub where his head should have been" (7). Similarly, when Martinez cannot stop repeating the phrase "I don't care if I do die, do die", he is overwhelmed with certainty that 
"something terrible" (21) is about to happen. The awful "something" that constantly threatens the soldiers is annihilation wrought by combat as well as language. Croft is convinced with "passionate certainty" (29) that Hennessey will die that very day, and when this does indeed occur he becomes privy to "vistas of such omnipotence that he was afraid to consider it directly" (40). Red also correctly predicts (or conjures) Hennessey's death, interpreting it not as "large and devastating and meaningless" like the deaths of his other fallen comrades, but as a death which opens "a secret fear" because it seems "so ironic, so obvious, when he remembered the things Hennessey had said" (123). Red finds himself at the edge of a "bottomless dread" (123) thinking about a death seemingly caused by his thoughts and Hennessey's words. When he remembers the moment he knew his friend would die, he experiences "a moment of awe and panic as if someone, something had been watching over their shoulder that night and laughing. There was a pattern where there shouldn't be one" (39).

Red's suspicion that Hennessey's death reveals a pattern is of course correct since narrative relies on repetition. His sense of a voyeuristic presence is a disquieting moment when the strangeness of reading is revealed by recognition from within the text. Intensifying this weird moment is the way Red's suspicion points not only to the presence of the reader but to Mailer's own presence as an omnipotent force controlling his characters and his readers too. The soldiers' sense of being puppets controlled by a laughing "something" translates eerily into the reader's own experience of being controlled by narrative. Narrative's strange and potentially destructive power is literary and literal, for if the writer can order fictional events in their created worlds, then coincidences, repetitions and the omnipotence of thoughts in reality can be interpreted as a natural result of God's own narrative design. 
While Mailer suggests that if there is any order in the cosmos "it's not so exceptional that coincidences occur" (qtd. in Bragg 199), his perception of the individual as a battleground for the forces of good and evil reveals something more sinister in this universal order. Mailer describes his perception of reality by using battle motifs and suggests that a general preparing for combat is, in a very literal sense, surrounded by gods and devils whose fortunes are affected by the battle's outcome. These otherworldly beings will be "paying a great deal of attention to this general" and "insofar as he has any sensitivity to their presence," Mailer notes that the general is "not necessarily psychotic if he spends ten minutes in bed - he won't have the opportunity usually - debating whether to put the left foot down first or the right, because maybe he's calling on whole echelons of gods" (qtd. in Bragg 199). This concept of reality is complicated by Mailer's suggestion that "these gods are going to be up to their tricks. They're going to be doing their best to present coincidences, because a coincidence always inspires us with a terror that there's a superstructure about us and in this superstructure are all sorts of agents of a machine larger than our imagination" (qtd. in Bragg 199).

Coincidence and repetition are therefore loaded with meaning. In "The Uncanny" Freud observes that we "naturally attach no importance" to receiving a coat check ticket numbered 62, but if this number is subsequently repeated in addresses, hotel rooms or railway compartments we are "tempted to ascribe a secret meaning to this obstinate recurrence of a number" (360). Translator James Strachey points out in a footnote that Freud himself was sixty-two years old when he used this example, and Freud himself admits that "unless a man is utterly hardened and proof against the lure of superstition," this number's repetition might be taken "as an indication of the span of life allotted to him” (“Uncanny” 360). 
Death is the secret that lies at the heart of the uncanny. Uncertainties regarding what is animate or inanimate, real or unreal, are uncanny not merely because of a discomforting blurring of boundaries but because these liminal areas evoke the nothingness of nonbeing. Mortality remains a concept which neither the conscious nor the unconscious mind can fully comprehend and Freud observes that since "almost all of us still think as savages" regarding death, it is little wonder that "the primitive fear of the dead is still so strong" ("Uncanny" 356). The uncanniness of death and dead bodies is inextricably linked with what is gruesome, a commingling which is particularly apparent when one of Mailer's soldiers discovers a decapitated corpse and aches “dully as he realized the impossibility of ever seeing that man's face. There was only a bloody fragment at the terminus of the neck. The body seemed to lie in a casing of silence" (241). Another cadaver inspires the same kind of horror as "stepping on a coil of human feces in the middle of a lawn" (216). Eventually "the fetidness of this corpse would seep into the earth and be lost, but now it was horrible in its stench" and provokes "a deep pang of fear" (216). The smell of rotting flesh recalls the odour of the cave in which the soldier was similarly confronted with dead bodies, a "clear nauseous odour" which returns "to terrify him" (216). The "smell he would have expected if he had lifted a coffin lid" remains in him "for a long bad moment in which he looked at the body and didn't look, thought of nothing, and found his mind churning with the physical knowledge of life and death and his own vulnerability" (217).

In these disorienting moments of vulnerability, corpses exemplify Julia Kristeva's concept of the abject's ability to dissolve the crucial distinctions between subject and object necessary for the cohesion of identity. Kristeva suggests that a corpse "seen without God and outside of science, is the utmost of abjection. It is death infecting 
life" (Powers of Horror 3). Like the uncanny, Kristeva's concept of the abject involves repression and return; she points out that "refuse and corpses show me what I permanently thrust aside in order to live. These body fluids, this defilement, this shit are what life withstands, hardly and with difficulty, on the part of death. There, I am at the border of my condition as a living being" (Powers of Horror 9). This illuminates Mailer's juxtaposition of the horror inspired by a corpse with that of accidentally stepping on human faeces. Although rejected, the abject is never completely eluded and remains to act as a constant threat to identity. Abjection is "above all ambiguity. Because, while releasing a hold, it does not radically cut off the subject from what threatens it - on the contrary, abjection acknowledges it to be in perpetual danger" (Kristeva, Powers of Horror 9).

This danger inspires Stanley with "an intense horror which he repressed with difficulty", a "nameless anxiety" which comes in part "from fearing death, really fearing it for the first time" (297). Yet despite his "intense fear and loathing”, Stanley acknowledges the need "to get another stripe, and then another" (298). The imperatives of the military organisation combine with personal ambition to force his "weak and terrified" body forward, silencing his "vague oppressive horror" (298). Minetta attempts to escape combat by feigning battle fatigue, but rather than offering relief from the battlefield, his proximity to damaged bodies in the military hospital makes death "almost tangible" (363). He becomes "afraid to breathe, as if the air were polluted" (363), and is particularly fascinated by his neighbour's gruesome injuries. When he discovers that the soldier has died during the night, he is drawn to the corpse by "an acute curiosity about the man's face under the blanket" (365). Like the dull ache provoked by the decapitated corpse on the battlefield, it is the way that the corpse's face remains hidden that inspires dread and fascination. Death is equated 
with the loss of identity, and for those who remain living, an inability to know what lies beyond the borders of life.

Despite Minetta's profound curiosity, he does not remove the concealing cover but turns away wondering, "How do they expect a guy to stay here, after some poor Joe died right next to you?" (365). The difficulty of coping with death is compounded by military insensitivity, but Minetta's discomfort also reveals the menace posed to the living by the dead. When Gallagher receives news from America that his wife has died during childbirth, despite repeating to himself "She's dead, she's dead" (280), he is unable to really believe it. As if in confirmation of his sense of Mary's continuing existence, the delays of the postal system result in her letters continuing to arrive. Understandably unnerved by these spectral communications, what Gallagher comes to fear most is the arrival of the final letter. When this harbinger of death finally arrives (which he is able to judge by its postmark), Gallagher takes it to the beach where he experiences a "jolt of horror" (284) ostensibly inspired by the strange reptilian sheen of the giant kelp, but which seems more likely to stem from the intimate encounter with death that takes place beside it.

Gallagher attempts to control his communion with the returning dead by insisting it is the kelp that frightens him, and General Cummings adopts a similarly strategy when he reacts with horror to a cigarette butt discarded in his tent. Although he is fastidious, military order cannot fully explain his strangled cry of "God!" at the sight of this piece of litter, a reaction which comes out "as something between a grunt and a choked exclamation" (317). This discarded object represents not merely a deviation from military standards but causes a "deep pang of pain and fear" (317) to lance through the General's chest. While the kelp and the crushed cigarette butt obviously pose little physical threat, their ability to pose a psychic threat renders them aspects of 
the environment revealing repressed fears and desires. The strange object on the General's floor is perceived not only as a cigarette end but as a tangle of "ugly excrement" (317), suggesting that the relationship between this moment and Kristeva's theory of the abject is particularly relevant. What is rejected by the General - the humanness of the men he sends into combat - returns in a form perceived as grotesquely physical.

While indulging in nostalgic daydreams about his idyllic hometown back in America, Wilson remembers that amidst the old and pleasant houses, the bridge over the stream and the sounds of the leaves in the May breeze is "always the small rotting mansion with its broken shutters, its peeling columns, and the dull black-gray of its walls like a tooth after the nerves have been killed" (373). Like General Cummings, Wilson senses that the pleasantness of home involves something unhomely, and he admits that the rotting mansion "alters the loveliness of the streets, limns it with darker mortal lines" (373). This sense of the familiar made strange also occurs on the island of Anopopei, where the natural landscape of familiar beaches, trees and rivers is frequently perceived as alien. The sea becomes a "black dead ocean" resembling "a mirror of the night; it was cold, implicit with dread and death" (454). The men feel this ocean "absorb them in a silent pervasive terror" and retreat to their cots to "shudder ... for a long while in their blankets" (454). On reconnaissance in the jungle, the men become "engulfed" by its "rot and ordure", and "the wet pungent smell of growing things" provokes "a stifled horror, close to nausea" (457). Mailer emphasises the subtle strangeness of familiar vegetation by referring to kunai grass, a species native to South East Asia. This foreign grass overwhelms the men with its "terrifying heights" and rouses "a new kind of terror in them" (494). Not only do the men feel as though they are blundering through a forest, but the looming vegetation registers as 
"soft and yielding, and therefore nauseous" (494). They are "afraid to let the man in front move too far away, for they could not see more than two or three yards, and so they dogged at each other's heels, the grass whipping nastily into their faces" (494).

The emphasis on the specific kind of grass the men must negotiate is not just the careful rendering required of a realist writer, but also acts as a return of repressed anxieties regarding the Asian threat. While the men speak openly about the fear of enemy troops at the start of the patrol, this concern is soon replaced by "a new and subtler terror" inspired by the landscape's "unexplored weight, its somnolent brooding resistance" (495). When Wilson is seriously wounded by enemy fire, his comrades express fear not of Japanese troops potentially concealed in the bushes surrounding the clearing but of the clearing itself. They listen "uneasily to the silence" and Gallagher mutters, "Let's get out of here ... This place is spooky" (523). The uncanny's reliance on the coming to light of what should have remained hidden suggests that the spookiness of the clearing relies on what the soldiers have repressed, and the horror provoked by Wilson's limp body is experienced by the men as a sense of him being unfamiliar: the platoon "could not believe it was Wilson. It was just an unconscious wounded man" (523).

The connection between repression and the dread-inspiring landscape is particularly well illustrated in the sequence where Martinez stalks a Japanese sentry. As he conceals himself in the undergrowth, Martinez's face brushes against a leaf and a few insects dart across his cheek. He flicks them off, "his fingers moist with anxiety", but one holds onto his fingers and begins to slide up his forearm, causing Martinez to fling it off and stand "shivering in the darkness" (589). This unsettling encounter renders his will to advance "frustrated by the irrational terror the insects had caused," a terror made "more concrete" by the hidden presence of the Japanese 
soldier, but "most of all by the increasing deadening weight of all this strange earth he must explore at night" (589). When Martinez manages to sneak almost within touching distance of the sentry, he experiences a "sense of unreality" (594) as previously clear delineations between enemy and ally are threatened by his new perception of Japanese humanity. For a brief moment, "the entire structure of the war wavered in his brain" but this epiphany is soon dissipated by a "returning wash of fear" which renders the war "unreal to him again" (594). Martinez experiences "the qualified controlled terror that he knew in his nightmares. It was not real, and he shuddered once more" (594).

It is this sense of unreality that enables Martinez to overcome his qualms regarding murder and to carry out his military duty. After achieving his mission imperative and killing the sentry, Martinez describes the corpse as a "loathsome" thing "to be avoided" (595), and controls the implications of his actions by likening the experience of slitting the man's throat to how "a man feels after chasing a cockroach across a wall and finally squashing him" (595). The killing "affected him exactly that way and not much more intensely. He shuddered because of the drying blood on his hands, but he would have shuddered as much from the roach's pulp" (596).

Mailer's insistence on the soldiers' dehumanisation reflects acceptable postwar discourse surrounding conformity and corporatisation, but it also offers a critique of the processes through which violence to the human body is normalised during periods of war. It is Mailer's over-elaboration of this motif that registers as particularly odd. The repetition of mechanical descriptions renders description itself mechanical, sapping imagery of meaning and miring interpretation in a confusing space where familiar literary conventions become strange. The novel ends with yet another insistence on the unreality of the war, when following the final disastrous 
reconnaissance patrol, the surviving soldiers realise that "tomorrow the endless routine of harsh eventless days would begin once again. Already the patrol was unfamiliar, unbelievable, and yet the bivouac before them was also unreal." Finally, Mailer suggests, "everything in the Army was unreal" (709).

While constant reiteration of the unreality of war acts as a comment on psychological coping mechanisms during combat, it also reveals something of Mailer's inability to cope with his material. According to Mailer, civilisation depends on the sublimation of violence, but if this violence "gets too sublimated, you get a sick civilization" (qtd. in McGrady 114). Similarly, he argued that the exclusion of obscene language from polite conversation meant "it festered and took on anomalous forms" (qtd. in Fulford 131). For Mailer, the problem of civilisation "is how to maintain the expression of some modicum of primitive violence" (qtd. in McGrady 114), and by employing familiar concepts of Freudian theory regarding sublimation and sickness, Mailer attempts to position himself as a writer capable of healing society by reintegrating obscenity and violence.

As Rosemary Jackson observes, uncanny literature "threatens to transgress social norms" by permitting "an articulation of taboo subjects which are otherwise silenced" (72). Yet Mailer's adherence to literary and social norms through the utilisation of conventional military detail, familiar psychological portraits and the sanitisation of war and its violence by emphasising it unreality creates a profound tension within The Naked and the Dead between the subversive and the conservative. The gap between what is written by the conscious intelligence and the darker interests of the unconscious makes Mailer's war novel uncanny at what we might call a structural level; while it depicts the return of the repressed, it also acts as a return of the repressed, for while it is never mentioned, the detonation of the atomic bomb over 
Hiroshima and Nagasaki is never entirely banished either. In fact, Mailer's reluctance to describe the deaths of the Japanese soldiers as real, resorting to imagery of dolls and insects to describe their corpses, is particularly revealing.

Although the explosion of the bomb ushered in a new era of atomic anxiety, the initial news of the bombing of Japan was received with widespread relief, if not jubilation, by the majority of Americans. At once a profound threat, the atomic bomb was also the tool that hastened the war's end supposedly saving thousands of American lives. President Truman's memoirs published in the mid-fifties cite General George C. Marshall's prediction that the likely loss of American soldiers in an invasion of Japan would be 250 , 000, with an equal number of Japanese deaths. So while the St Louis Post-Dispatch warned on August 7, 1945 that science may have "signed the mammalian world's death warrant" (qtd. in Boyer 5), a letter to Time magazine praised the bomb for having "in one fell swoop, struck down three enemies of human progress. It destroyed the hopes of the Jap fascists and their followers; it shattered the illusions of the isolationists; and it all but demolished the silly argument that governmental planning is ineffective and incompatible with democracy" (Flamm 4). Little thought was publicly given to the fate of its Japanese victims, just as Mailer seems unable to grant his Japanese characters any humanity.

A Gallup Poll in the middle of August 1945 revealed that 85 percent of respondents approved of the use of the atomic bomb on Japanese cities (Gallup 521). During the war a poll of serviceman revealed that $38-48$ percent of soldiers agreed with the statement "I would really like to kill a Japanese soldier" whereas only 5-9 percent agreed in regard to German soldiers (Engelhardt 48). Wartime propaganda and the attack on Pearl Harbour rendered even Japanese civilians military and ideological enemies, and extensive firebombing carried out in Japan prior to the 
bombings had immured Americans to the idea of large-scale damage to Japanese cities. In the 1944 film Purple Heart, an imprisoned American pilot informs a Japanese judge, "We'll come by night and we'll come by day. We'll blacken your skies and burn your cities to the ground until you get down on your knees and beg for mercy...This was war. You asked for it. You started it...and now we won't stop until your crummy little empire is wiped off the face of the earth' (qtd. in Englehardt 49).

Anti-Japanese sentiment, which also played a large part in the internment of Japanese Americans in "War Relocation Camps", ${ }^{33}$ was undeniable a key factor in the reaction to the deployment of the atomic bomb, but repression was also at play. Margot Norris points out that although nearly 100, 000 feet of colour film was shot of Hiroshima and Nagasaki by Air Force film crews following the bombings, the entirety of this footage was classified top secret because of "the horror" it revealed (184). Marianna Torgovnick suggests that the censorship of photos documenting the horror of the bomb's effects stemmed partly from their evocation of images coming from the newly liberated Nazi camps (15), an obviously undesirable alignment. The human toll of the atomic bomb was so repressed that in 1955 when the "Hiroshima Maidens" visited the United States in order to have corrective surgery for their radiation burns (a trip organised by a group of Americans), some people were so threatened by the presence of these reminders of American atrocity that they wondered whether the

\footnotetext{
${ }^{33}$ For a study of the history of Japanese American internment see Caroline Chung Simpson, An Absent Presence: Japanese Americans in Postwar American Culture, 1945-1960 (2005). Simpson argues that the remembering and forgetting of this history is key to postwar articulations of America as a democratic superpower.
} 
organisers of the visit were Communist agents (Filreis, "Cultural Aspects of Atomic Anxiety"). ${ }^{34}$

Paul Boyer highlights the remarkable repression of the effects of the atomic bomb when he suggests that in "most of the major novels of the immediate post-Hiroshima years - Lionel Trilling's The Middle of the Journey; Saul Bellow's The Victim; Norman Mailer's The Naked and the Dead - the atomic bomb is notable by its absence" (246). The first and really only in-depth writing on the bomb by an American during the period was John Hersey’s 1946 article "Hiroshima" published in The New Yorker. Written in a dry journalistic style, the article tells the story of six Hiroshima residents from the moment they awake on the fateful day of August 6, 1945, through to the blast itself and the days following. The issue sold out almost immediately and the article was published in book form later that same year. Prior to the piece, discussions in the popular press regarding the bomb focused on statistics of devastation rather than the human toll, mainly in order to incite international control of atomic power or promote civil defence measures. There was also a great deal of self-congratulatory triumph over the technical mastery the development and use of the bomb represented. Hersey's story was the first to give a human face to the event, yet the dry tone of its writing struck some readers as oddly emotionless. Hersey explained that the style was a deliberate strategy and suggested that a "high literary manner, or a show of passion, would have brought me into the story as a mediator; I wanted to avoid such mediation, so the reader's experience would be as direct as possible" (qtd. in Boyer 208). The effect of this strategy, however journalistically appropriate, was to allow readers to bypass emotional engagement with the bomb's victims and most people appear to have remained unaffected by their "direct" experience with atomic

\footnotetext{
${ }^{34}$ For an in-depth study of the suppression of information regarding the human toll of the bomb, see Robert Jay Lifton and Greg Mitchell, Hiroshima in America: Fifty Years of Denial (New York: Putnam's Sons, 1995).
} 
devastation. One subscriber wrote to The New Yorker to commend Hersey's report for reasons other than what the author might have expected, stating: "I read Hersey's report. It was marvellous. Now let us drop a handful on Moscow" (qtd. in Luft 138). ${ }^{35}$ "Hiroshima" was not an in-depth exploration or protest of atrocity, which led Mary McCarthy to brand it an "insipid falsification of the truth of atomic warfare" (qtd. in Pells 46). Boyer suggests that in the "intense but strictly circumscribed engagement with the Hiroshima reality offered by John Hersey, it was as though Americans were saying: 'We have now faced what we did. We have been told. We have experienced its full human horror. But we must get on with our lives. We can now put all that behind us"" (210). This perhaps explains the surprising popularity of the article; it appeared at precisely the time when Americans were looking for something to help lay to rest a disturbing recent event. The impulse to put aside the war experience and move on is perhaps the defining trait of the immediate postwar period, and certainly the ruins and victims of those two Japanese cities were hardly mentioned in novels that purported to be about the war yet which excluded such a fundamental part of the conflict. $^{36}$

While there is frequently a time lapse between major events and their representation, particularly when they involve mass death, as early as the fall of 1945 Japanese writers were engaging with the implications of atomic warfare. In Writing

\footnotetext{
${ }^{35}$ As popular as the article proved to be, the effects for Hersey were not entirely positive. A favourite of Time publisher and strenuous anti-communist Henry R. Luce, Hersey had been considered a protégé who might one day succeed Luce to run the magazine. Yet by the time "Hiroshima" was published, Hersey had fallen out of favour and was no longer a contributor for Time. In his 1952 memoir Witness, Whittaker Chambers, a Time foreign desk editor, accused Hersey of slanting stories in a leftward direction. Hersey's dispassionate account of Hiroshima's devastation seems to have been viewed by the Time contingent as a subversion of American interests and a sign of suspiciously liberal beliefs. Hersey's credentials as a patriotic war reporter, however, protected him from too much career damage. ${ }^{36}$ The atomic bombing of Japan remains a sensitive area in American culture. In 1995 the Smithsonian was accused of being disrespectful to the military when it announced a commemorative exhibition of the end of the war that would include photographs and quotations from Japanese atomic victims. Bowing to intense pressure, the curators reduced the exhibit to the fuselage of the Enola Gay and a photograph of the smiling pilots. In 2003 this sanitised version of the Allied victory was permanently installed at the Smithsonian.
} 
Ground Zero, John Whittier Treat cites Toyoshima Yoshio's suggestion that the bomb ushered in a period in which literature must engage science "Not to win a victory, but rather to assimilate in the name of man what science has wrought" (11). For Yoshio, the problem was not whether the bomb could actually be assimilated, since he predicted "given the present turn of events in the world, that there will be some people capable of comprehending what has happened." Rather, he wondered "whether those people will continue to be "human"; or whether, unable to survive as human, they will stumble into a tragic abyss" (qtd. in Treat 11).

Japanese hibakusha writing attempts to delineate the experience of surviving the bomb, but also continually expresses the failure of language to encompass the atomic experience. The atomic bomb is technology at its most frighteningly modern and most humanly disengaged, and it is the lack of conventional malice and vengeance that identifies the start of the new atomic age, "an age not enjoined by emotions of epics, the stuff of storytelling from the beginning of our literacy, but rather one effectively voided of them" (Treat 17). This experience was true for those who bombed as well as those who suffered the bombing. Just hours following the bomb's detonation, a crew member of the Enola Gay explained, "I knew the Japs were in for it, but I felt no particular emotion about it" (qtd. in Treat 17).

If hibakusha writers were compelled to engage with the atomic bomb, repeatedly describing the blast and its repercussions, struggling with a language and a form that seemed incapable of describing the new age, American writers of the same period turned away. According to Treat, in a world where previously unimaginable atrocity was now a reality, the parameters of literature were "so expanded as to make it difficult for anyone who would write to find one place to begin, or end, without repressing that knowledge" (18). Unlike the Japanese, Americans were shielded by 
physical and psychic distance from the bombings, enabling them to avoid the actual toll of the bomb and shift their anxieties to its implication for the future. Nagaoka Hiroyoshi defines atomic bomb literature as expressing the evil of the bomb and the survival of human dignity (qtd. in Treat 20), a theme which was obviously problematic for American writers: if the surviving Japanese population represent the survival of human dignity, then what do the unscathed and prosperous Americans represent?

Consequently, the few American writers who took the bomb as their subject used it as a prediction of a future utopia. Morris Ernst's 1955 novel Utopia 1976 depicts a future atomic age where nuclear technology provides everlasting energy, controls the weather, manufactures germ-free foods, provides medical cures and revolutionises agricultural practise. Cute nicknames such as the "sunshine unit" (measure of Strontium-90 levels) and "kitten bombs" (small nuclear bombs) helped Americans calm their fears; businesses used the word "atomic" in their advertising; and there was even the Pernod and gin "Atomic Cocktail" (Boyer 10-11). According to Paul Boyer, utopian dreams of a new world of atomic energy "were a way of dealing with - or avoiding - unsettling immediate realities: America's use of two atomic bombs to obliterate two cities and the prospect that even more terrible atomic weapons might some day devastate the earth" (122). Speculations regarding the glorious promise of atomic energy enabled Americans to turn away from the horrific reality of its military application and to see that use as a necessary stage in a more beneficent process. Such utopian dreams of the future "facilitated the process by which Americans absorbed Hiroshima and Nagasaki into their moral history" (Boyer 124).

While the bomb unleashed a torrent of literary productivity in the newspapers of 1945, there was a silence in serious literature which suggested writers either struggled 
unsuccessfully to write about this aspect of the war or chose to ignore it. Paul Brians goes so far as to suggest that "nuclear war must be the most carefully avoided topic of general significance in the contemporary world" (3-4). Part of the strangeness of The Naked and the Dead relies on the reader's awareness of the detonation of the atomic bomb. Never mentioned, never alluded to, never implied, the bomb is nowhere in the text, but resides in what might be thought of as the text's unconscious, in the spaces created between a reader's knowledge and what the text depicts. The mechanisation of Mailer's soldiers becomes even more relevant in this context since the destruction and death meted out by the Second World War comes not from human hands but from technology. In this context, the grotesque softness of the kunai grass the soldiers recoil from represents Asian flesh more than Asian vegetation. Mailer's novel is a gritty and exciting war narrative filled with strategy, military detail, and the kind of social probing so popular in the postwar period, yet The Naked and the Dead also presents the gruesome results of violence and the disturbing effects of a superstructure on individuality. Although Mailer did his best to focus on the issues that concerned Cold War Americans by using the war as a fictional trope through which readers could view socio-political change, the atomic bomb makes its terrifying return through the murderous and strangely mechanical soldiers with which Mailer fills his novel. 


\section{Haunting and Race:}

\section{Ralph Ellison's Invisible Man}

The act of writing requires a constant plunging back into the shadow of the past where time hovers ghostlike.

Ralph Ellison, Shadow and Act

World War II saw more than one million African Americans in military service and by 1944 racial tensions within the rigidly segregated army were so problematic that the War Department was forced to prohibit racial discrimination in recreational and transportation facilities in an effort to ease the situation. Black leaders utilised the racial intolerance highlighted by the war in what was called the "double V" campaign: African Americans were urged to support the war effort and ensure victory over fascism abroad, while maintaining the fight against segregation and discrimination for a victory over Jim Crow in America. ${ }^{37}$ Although conditions for African Americans in the military did improve somewhat as the war progressed and they were increasingly able to hold combat rather than menial positions, there was continual racial harassment and little opportunity for career advancement. Perhaps even worse was the fact that many soldiers returned home after honourable service to find themselves expected to use separate bathrooms and train compartments.

One such returning soldier was Ralph Ellison, who was sent home in 1944 from service in the Merchant Marines suffering from wartime stress. Like Mailer, Ellison

\footnotetext{
${ }^{37}$ For a detailed discussion of the "double V" campaign see Lawrence P. Scott and William M. Womack, Double V: The Civil Rights Struggle of the Tuskegee Airmen (East Lansing: Michigan State University Press, 1994); and Bryan D. Booker, African Americans in the United States Army in World War II (Jefferson, N.C.: McFarland, 2008).
} 
decided to use his recent experiences to write a war novel, which only ran to a few pages of text and outline, but which was to be about a captured African American pilot who finds himself the designated spokesman for his fellow prisoners-of-war despite his racial identity. Once the war was over, Ellison set about expanding this fragment into a novel but his intentions were subverted by a mysterious voice which intoned, "I am an invisible man." Ellison's descriptions of the genesis of Invisible Man (1952) stress this disembodied voice as a source of artistic inspiration, but given the facts of his war stress it can also indicate repression. Although he sat down expressly to write about the war, and although thirty years later he described in his introduction to the thirtieth anniversary edition of Invisible Man how the spectral voice began by musing on the conundrum of black men fighting for a nation that kept them subjugated, Ellison's intentions were transformed by a voice which he insisted revealed the novel's real focus on ineffective black leadership. Turning away from the tradition of war literature and protest fiction to the patterns surrounding the hero in classical myth outlined in Lord Raglan's The Hero: A Study in Tradition, Myth, and Drama (1936), Ellison utilised a carefully structured conceptual framework to write the first section of what would eventually become Invisible Man. Yet despite his efforts to turn away from war literature to classical myth, and despite the rigid outlines which should have ensured strict control of his material, the first section Ellison wrote described the battle royal, a scene of bloody hand-to-hand combat between black boys performed for the perverse entertainment of white men. The spectral presence of race and war are never far from Ellison's novel.

Although Invisible Man's depression-era setting avoids World War II, its descriptions of the changing policies of the Brotherhood, an organisation with marked similarities to the Communist Party, reveal the connections between Ellison's 
conscious theme of black leadership and his submerged preoccupation with war. Christopher Z. Hobson points out that any reader familiar with changes in the Communist Party just before and during World War II "should recognise in the novel's pages a compressed, heightened, and allegorized version of those changes" (357). Invisible Man's protagonist is surprised to discover a change in party emphasis from local issues to those more national and international in scope, and that the interests of Harlem are no longer deemed to be of first importance. The Brotherhood claims to be making temporary alliances with other political groups, necessitating the sacrifice of one group's interests to that of the whole, and Hobson argues that with the Brotherhood's abandonment of their work in Harlem the focus of Invisible Man "broadens to include the issues posed by World War II" (358). Ellison offers "a recognizable though mythologized version" (Hobson 358) of the Communist Party's wartime turn from a pacifist stance to one which emphasised victory over fascism as its main goal. The Communist Party, of which Ellison was a member in the thirties, argued that too strong a show of support for black rights in America would interfere with the war effort, hence Ellison's reference to the "sacrifice" of the Harlem members during what can be interpreted as the Communist Party's wartime shift (Hobson 359). The Harlem riot that ends Ellison's novel recalls not only the real events of 1935 and 1943, but also the Warsaw uprising of 1944, which Soviet forces first encouraged and then allowed the Nazis to crush, probably as a way to ease the Polish Communists' way to power (Hobson 361).

Part of the reason for critical focus on anti-Communism rather than global conflict in Invisible Man is the novel's long gestation period. Although begun in 1945, the novel took seven years to complete and was published at the height of McCarthyism. Naturally this encouraged responses such as Ernest Kaiser's observation that "Written 
during the period of communist hysteria and McCarthyism, Ellison had his innocent Black hero tricked by so-called Communist duplicity" ("Critical Look at Ellison's Fiction"). Anti-Communism is indeed an important aspect of the novel, but Ellison's critique of Communist politics rests on his avowal of its incompatibility with African American civil rights rather than its threat to Cold War America. Ellison claimed that the Communist Party

fostered the myth that Communism was twentieth-century Americanism, but to be twentieth-century American meant, in their thinking, that you had to be more Russian than American and less Negro than either. That's how they lost the Negroes. The Communists recognised no plurality of interests and were really responding to the necessity of Soviet foreign policy, and when the war came, Negroes got caught and were made expedient in the shifting of policy. (qtd. in Graham and Singh 123)

Ellison's antipathy towards Communism is not the result of disagreement with Communist politics so much as with Communist Party policy. If the Party initially appeared to be an organisation to which Negroes could belong as twentieth-century Americans, this identity was denied with the advent of World War II.

Invisible Man's politics have long proved controversial. Critics such as Kaiser have condemned its deviation from the tradition of protest fiction and its seeming capitulation to white society through its depiction of the search for individual identity outside of a larger struggle for racial equality. The history of African American literature is based on politicized forms which sought to demonstrate that the Declaration of Independence's proclamation that "all men are created equal" necessitated equal rights. Phillis Wheatley's Poems on Various Subjects, Religious and Moral (1773) was the first book published by an African American and aimed to prove spiritual equality. In the early nineteenth century, African American literature and newspapers such as Freedom's Journal took up the abolitionist cause. David Walker's Appeal, in Four Articles; Together with a Preamble, to the Colored Citizens 
of the World (1829) warned of racial violence if slavery were not abolished and Productions of Mrs. Maria W. Stewart (1835) urged women in the North to take an active role in the Civil Rights movement. From 1830 to the end of the slavery era, the fugitive slave narrative dominated the African American literary landscape. The Narrative of the Life of Frederick Douglass, an American Slave, Written by Himself (1845) established Douglass as the leading African American writer of his time and Harriet Jacobs's Incidents in the Life of a Slave Girl (1861) was the first autobiography by a formerly enslaved woman. During segregation Booker $\mathrm{T}$. Washington's Up from Slavery (1901) suggested that African Americans could attain respect and prosperity by proving themselves productive members of society and William Du Bois' The Souls of Black Folk (1903) insisted that the dual heritage of African Americans could become a positive force for change. During the first two decades of the twentieth-century, racial injustice, frequently involving lynching, not surprisingly provoked a strong reaction amongst African American writers. In 1909 the National Association for the Advancement of Coloured People (NAACP) was founded and Du Bois was placed in charge of its magazine The Crisis, which became the most widely read African American magazine of the time. From the late 1930s to the late 1940s Richard Wright's fiction dominated African American literature, with Native Son (1940), a violent depiction of Chicago ghetto life, reinvigorating the nineteenth-century protest tradition. Wright's autobiography Black Boy (1945) revisited the slave narrative and chronicled his journey from the oppressive South to freedom in Chicago. ${ }^{38}$

The protest novel, like any genre, adheres to familiar conventions which potentially control the form's subversive effects. James Baldwin recognised

\footnotetext{
${ }^{38}$ For a comprehensive overview of African American literature see William L. Andrews, Francis Smith Foster and Trudier Harris, eds., The Oxford Companion to African American Literature (New York: Oxford University Press, 1997).
} 
something of this when he suggested in 1949 that the genre of literary protest categorises humanity rather than reflecting its full "beauty, dread, and power" (Notes of a Native Son 23). The protest tradition might have started with sympathy for African Americans, but Baldwin claims such novels soon enclosed their protagonists in the tones of hatred they themselves experienced. The protest novel's concern with social issues and racial groups necessitates its failure to treat the African American as a particular human being. Despite the attempt by protest novels to humanise figures of prejudice and provoke outrage at racial injustice, Baldwin's comments show how generic conventions can contain and control material that should be disturbing. Ellison's deviation from the conventions of protest fiction can thus be seen as actually intensifying depictions of racial injustice by provoking a more intense reaction in readers made complacent by familiar modes of representation.

Ellison's use of motifs of spectrality is an intentional employment of the uncanny that nevertheless suggests something else haunting Invisible Man. At the time Ellison received his weird message from a disembodied voice he regarded himself, in his "most secret heart at least," as a musician (Shadow xi). After encouragement from Richard Wright, he began to write and soon realised that his insistence on being a musician was the result of "a complicated, semiconscious strategy of self-deception, a refusal by my right hand to recognize where my left hand was headed" (Shadow xi). For Ellison, writing "was an acting-out, symbolically, of a choice which I dared not acknowledge. Indeed, I repressed it beneath my old concern with music and my current involvement in the intense social and political activity which claimed so many of us who came of age during the thirties" (Shadow xi).

Like Mailer, Ellison displays acute awareness of the divide between his conscious and unconscious preoccupations, and his engagement with the uncanny also occurs at 
what can be called representational and structural levels. While instances of the uncanny in The Naked and the Dead are balanced by the novel's detailed depiction of a recognisable reality, the preponderance of spectral figures and dream states in Invisible Man renders the realism that marks the first section of the novel increasingly surreal as the narrative progresses. Ellison was aware of this shift and pointed out that "a more naturalistic treatment was adequate" (qtd. in Graham and Singh 15) for the first section set in the South, since the protagonist is attempting to fit into a traditional pattern and has not yet had his assumptions challenged. As the protagonist passes from the relatively stable world of the familiar South to the new, swiftly changing North, "his sense of certainty is lost and the style becomes more expressionistic" (qtd. in Graham and Singh 16). Towards the end of the novel, during the protagonist's fall from grace in the Brotherhood, Ellison suggests that the novel's style becomes "somewhat surrealistic." The changing styles "try to express both his state of consciousness and the state of society" (qtd. in Graham and Singh 16), and are also inextricably linked to the uncanny episodes that propel the protagonist from a familiar world of stable assumptions into one of strangeness and flux.

As well as depicting a spectral hero, haunting ancestors, incest, insanity and castration, the novel itself is oddly estranged from the era in which it first appeared. Robert O'Meally notes that the hero's mix of idealism and alienation, his escapes into music and marijuana, the book's study of racial angst and urban riot, its false-faced establishmentarians and false hero-figures all point to the ferment of the sixties rather than the staid and repressive fifties (2). The novel's prophetic ability is profoundly uncanny: the voice which spoke to Ellison acts not just as a message from a traumatised psyche, but as a message from the near future, a future which would have its own traumatic war in Vietnam to negotiate. 
Not only does Invisible Man seem to predict the future of civil rights activism and urban angst, it also recalls a history of war and enslavement, all the while avoiding precise temporal markers for its narrative action. The novel opens at an unspecified point during the years of the Depression and there is little indication as to what period of time the narrative covers. This temporal uncertainty is only emphasised by the changes in the Brotherhood policy and the Harlem riots, which suggest that the action occurs during World War II, yet the war is never mentioned. The scene with the African American war veterans in the Golden Day tavern is particularly confusing, since the reader is not told which war they served in. This creates an odd sense of déjà vu as the reader negotiates a narrative that circles back and forth, in a sense doubling back on itself. Ellison suggests something of his novel's uncanniness when he describes writing as involving a "plunging back into the shadow of the past where time hovers ghostlike" (Shadow xix). The writer is capable of predicting the future, revisiting the past and plunging into the shadows of the unconscious, an ability which is both magical and demonic, with writing becoming a weird act capable of revealing the hidden mysteries of self and history.

For Ellison, being a writer involves a split between conscious craft and unconscious inspiration: characters "say things or see things" which, for all Ellison's attempts "to be conscious" and to work out of a conceptual outline, are "suddenly just there" (qtd. in Hersey, "Completion of Personality" 10). The lack of control over his material renders writing a conjuring act in which "things seem to emerge out of the empty air", and like Mailer's "spooky art," Ellison describes a weird revelation in which "the dreams, emotions, ironies, and hidden implications" of the writer's material "find ways of making themselves manifest." Yet he also stresses that the artist must "work to make them reveal themselves" (qtd. in Hersey, "Completion of 
Personality 10). Invisible Man thus exists on two levels: one unconsciously inspired, the other consciously crafted.

Ellison's conceptual outlines were clearly devised to facilitate a well-written novel, but they also facilitated the novel's success in a period defined by antipathy towards criticism of American society. Albert Canwell of the Washington State Legislative Fact-Finding Committee on Un-American Activities proclaimed that "If someone insists that there is discrimination against Negros in this country, or that there is inequality of wealth, there is every reason to believe that person is a Communist" (qtd. in Whitfield 21). Reprisals against social protest during the McCarthy era were swift and serious. Paul Robeson, one of the most famous and successful African Americans of the era, was bought before HUAC, blacklisted and had his passport revoked in 1950, a decision upheld by the State Department in 1951 because of "the appellant's frank admissions that he has been for years extremely active politically in behalf of independence of the colonial peoples of Africa" (qtd. in Whitfield 195). Although a talented athlete and performer beloved by the American public, Robeson was not immune to the punishments meted out to those who campaigned for, or even expressed sympathy with, African American civil rights. The fact that Ellison wrote a novel about an African American protagonist who must negotiate a segregated nation in search for a cohesive identity without suffering any sort of reprisal shows how firm a grasp he has on his material.

The widespread avoidance of the topic of racial injustice saw Ellison's novel hailed not as an expression of the invisibility caused by racial repression, but as a defence of the individual that transcended its racial subject matter. In "The Unity of Experience" Robert Penn Warren praised Ellison for being "more concerned with the way a man confronts his individual doom than with the derivation of that doom" (22), 
and Saul Bellow, himself a minority writer, commended Ellison for rejecting "a minority tone" ("Man Underground" 28). During the sixties, however, the novel drew censure from a new generation of politically active black Americans who deemed Ellison's novel a capitulation to the dominance of white culture. In "Black Boys and Native Sons" (1963) Irving Howe criticises Ellison for failing to follow in the militant footsteps of Richard Wright and suggests that to write about African American experience with the aesthetic distance urged by the critics of the fifties is impossible, since protest is inseparable from that experience. Like Ernest Kaiser, Howe associates the novel with the McCarthy era and suggests it is marred by the demands of New Criticism and anti-Communism.

While it is true that Ellison's novel differs radically in focus and style from protest fiction and from the Black Nationalist writing that would appear in the sixties and seventies, Invisible Man's ambiguity enabled its success in an era defined by consensus. Other African American writers did not fare so well. Langston Hughes, one of the leading lights of the Harlem Renaissance, struggled to even make a living following his 1953 appearance before HUAC. Hughes' politicised fiction and his past involvement with the Communist Party complicated his status in the literary mainstream of Cold War America. Consequently, he maintained a low political profile and chose to concentrate on writing fiction for children. Wright's strategy following his own blacklisting was to leave America for Paris, where he continued to write in the social realist mode. Similarly, expatriation seemed to help Baldwin ignore his publisher's dire warnings regarding his 1956 novel Giovanni's Room, which sparked controversy over its explicit homosexual content and exclusively white characters. Physical and psychological distance from America appears to have 
enabled Wright and Baldwin to tackle taboo topics most American writers awaited the more liberal sixties to explore.

Hughes, Wright and Robeson all suffered the devastating consequences of McCarthyism, but Ellison, despite his association with the Communist Party and numerous pieces published in leftist forums, escaped unscathed. This is partly because of his eagerness to denounce Communism in interviews and his novel's unflattering depiction of a fictionalised radical political group with clear similarities to the Communist Party, but it also stems from a very carefully edited public persona. Barbara Foley points out that Random House's dust jacket biography of Ellison mentioned the author's studies in music and sculpture; his work experience in a factory, for a psychologist, and as a photographer; his World War II service; and his lectures on American literature at New York University and Bennington College. What was omitted were the more than thirty pieces of left-wing writing he had produced prior to 1946. Similarly, a New York Times profile ignored Ellison's many publications in leftist magazines and the Saturday Review identified T.S. Eliot as Ellison's formative influence and ignored Wright. Foley concludes that "Ellison's partisans were clearly willing to expunge a résumé indicating high productivity in order to guarantee him acceptable writerly credentials. The 'Ralph Ellison' packaged for Cold War public consumption was, to borrow a phrase from William Carlos Williams, a pure product of America" (539).

Ellison's success as a writer and Invisible Man's success as canonical fiction thus depends on omitted, disguised or repressed material. As Robert Bone observes, Ellison's work is imbued with a sense of "unseen reality behind the surfaces of things" (103), a tension revealed by Ellison's frequently noted fascination with masks, disguises and figures such as the conman and trickster. Houston A. Baker identifies 
Ellison himself as a sort of trickster figure, whose apparent devotion to Modernist high culture is in fact a mask behind which he conceals his real devotion to a politicised African American vernacular. Ellison's desire to make the repressed black vernacular conscious saw him describe his method of listening to a folk story as "looking for what it conceals as well as what it states" (qtd. in Ostendorf 109), yet interestingly enough, Ellison appears to have been unaware of the value of what was concealed within his own novel. He initially doubted the importance of Invisible Man, citing what he perceived to be his own "failure of eloquence" and the fact that by the sixties many of its immediate issues were "rapidly fading away" (Shadow 175). He did tentatively suggest, however, that "If it does last, it will be simply because there are things going on in its depth that are of more permanent interest than on its surface" (Shadow 175). The novel has lasted and if we are to accept Ellison's reasoning, its enduring value lies in what resides within the text's hidden spaces. Just as Ellison's identity as a politicised musician hid his secret life as an apparently depoliticised writer, Invisible Man's overt articulation of the achievement of personal identity and individual artistic production conceals another story, one connecting race and war.

Ellison points out that the figure of the African American in canonical American literature is less a fictionalised individual than a symbol of "both the man lowest down and the mysterious, underground aspect of human personality" (Shadow 104). Politicised and psychologised, the African American is metaphorically visible but remains invisible as a particularly human being. Ellison describes the Negro stereotype as "an image of the unorganized, irrational forces of American life, forces through which, by projecting them in forms of images of an easily dominated minority, the white individual seeks to be at home in the vast unknown world of 
America" (Shadow 41). The role of this stereotype is to symbolically manifest repressed material in order to facilitate the white American's sense of power and belonging in a nation fundamentally estranged from its founding doctrines of freedom and democracy. Racial supremacy obviously results in the repression of minorities, but the reluctance of white America to resolve the conflict between racial supremacy and democratic ideals figuratively forces the African American "down into the deeper level" of white consciousness, where "reason and madness mingle with hope and memory and endlessly give birth to nightmare and to dream" (Shadow 99). This subterranean space is "the province of the psychiatrist and the artist, from whence spring the lunatic's fancy and the work of art." This inner world is "a dangerous region even for the artist, and his tragedy lies in the fact that in order to tap the fluid fire of inspiration, he must perpetually descend and re-encounter not only the ghosts of his former selves, but of all the unconquered anguish of his living" (Shadow 99).

Reading and writing American literature involves a traumatic re-encounter with the submerged agony of centuries of prejudice and enslavement, and because Ellison argues that it is practically impossible for the white American to think of sex, economics, family or socio-political changes "without summoning into consciousness fear-flecked images of black men," a writer's attempt to tap the "charged springs issuing from his inner world" results in "his misshapen and bloated images of the Negro" floating up "like the fetid bodies of the drowned" (Shadow 100). According to Ellison, American writers have become accustomed to a culture that is "opposed to the deep thought and feeling necessary to profound art", and consequently the artist turns away from "an ambiguous substance which the artists of other cultures would confront boldly and humanize into the stuff of tragic art" (Shadow 100). Yet writers wanting to rectify this literary burial are forced into a profoundly disturbing 
engagement with "misshapen and bloated images" from which they are understandably tempted to turn away. For writers both white and black, there is always horror lying beneath the surface of American life and letters: the horror of what has been inflicted and the horror of what has been endured.

Marcus Klein suggests Invisible Man reveals something "hidden, mysterious, and wilfully obscured, a something kinetic and not fixed" in African American life, which necessitates the adoption of shifting roles concealing the reality beneath (After Alienation 132). Invisibility is the perfect metaphor for this sort of existence and Ellison's fictional hero encapsulates the repression of African Americans in an unequal society, as well as the discrepancies between democratic ideals and the reality of a national history involving slavery and segregation. Invisible Man's protagonist is repeatedly described as a spectre, an invisible presence and "a phantom in other people's minds" (7). Surrounded by "mirrors of hard, distorting glass," ghostliness renders the protagonist paradoxically powerless and powerful; while he cannot break free of imprisoning forces of perception, spectrality also renders him "a figure in a nightmare which the sleeper tries with all his strength to destroy" (7). Although he physically collides with a white man in the street, he realises that the "man had not seen me" (8). Since this "phantom" is invisible, his attack is impossible for the white man to fend off. The protagonist's lack of identity and visibility are the very factors that enable his powerful retaliation.

The vocabulary of ghostliness used to describe the attack on the white man renders the experience strangely unreal. The protagonist notes that his victim is attacked by something springing from his own "thick head" which has "beaten him within an inch of his life" (8). The divide between reality and unreality in the novel is complicated by the protagonist's difficulty in proving he really exists. He articulates his deep need 
to convince himself that he really does "exist in the real world," but despite striking out with his fists, cursing and swearing in order to force a recognition, "alas, it's seldom successful" (7). This assertion by a fictional character is potentially disconcerting, for although readers know that characters encountered in novels are not "real," we are accustomed to narrative conventions which enable us to believe they are for the duration of the story. Ellison's continual reminders of the spectral nature of his hero destabilises the reader's accustomed framework. We need the illusion of a character's "reality" to fully enter the text, so while the protagonist strikes out with his fists in an effort to penetrate the real world, the reader must similarly struggle to penetrate the fictional one. This blurring of boundaries between the real and the unreal, between world and story, makes not only the protagonist disturbingly ghostly but pulls the reader into a similarly spectral space. This may be the danger Ellison referred to in an interview when he suggested that "when reality is deranged in fiction, one must worry about the seams" (qtd. in Graham and Singh 17).

Renée L. Bergland points out that the dynamics of spectrality and haunting rely on unsuccessful repression: ghosts are "the things that we try to bury, but that refuse to stay buried. They are our fears and our horrors, disembodied, but made inescapable by their very bodilessness" (5). Since the eighteenth century, ghosts have increasingly been interpreted as mental or perceptual beings rather than external phenomena, yet rather than diluting the threat of an apparently only imaginary figure, internalisation increased its power. If ghosts do exist as external phenomena, they challenge assumptions regarding the nature of accepted reality; if they are projections of the interior mind, ghosts throw into doubt the most intimate processes of individual perception. Terry Castle notes that by relocating the world of ghosts into the space of the imagination, the mind itself becomes strangely supernatural (17). 
For Ellison's protagonist, ghostliness affects people's perceptions of him as an individual as well as his own perception of himself. His need to prove that he exists as a real person in the real world suggests his uncertainty regarding his status as a symbol or as a particular human being. These doubts are compounded by the fact that the "Invisible Man" exists both as a character in a story and as the narrator of that story. This split seems to privilege the narrating self who is able to distance himself from a more naïve past version, but if the narrated self is subject to the narrator's representation, the narrator is himself subject to the narrative conventions on which he depends. This fragmentation renders both selves vulnerable to the conventions of narrative, which is obviously the case for all first-person narratives, but Ellison's novel is unusually insistent on its hero's recognition of the "feeling that I had been talking beyond myself, had used words and expressed attitudes not my own, that I was in the grip of some alien personality lodged deep within me" (203). Who is this alien personality? His future self putting words into his mouth by writing the story? Ellison himself? Or perhaps the reader?

The oddness of this moment relies on the revelation of an unknown aspect of personal identity which is a familiar trope in doppelganger fiction, but the episodes in which the protagonist engages in impassioned rhetoric subverts the popular convention of the threat posed by the hidden self as depicted in novels such as The Strange Case of Dr Jekyll and Mr Hyde (1886) and The Picture of Dorian Gray (1891) by suggesting that it is the public self that should be feared. Moments before he is to deliver a speech, Ellison's protagonist describes feeling "that the moment I walked out upon the platform and opened my mouth I'd be someone else" (271). Ellison's suggestion that it is the public self that poses a threat is highly unusual, not 
to mention subversive, since it appeared in an era which placed enormous value on belonging to the social group.

The Invisible Man's anxieties about identity, which Ellison identified as "the American theme" (qtd. in Graham and Singh 15), are connected with an American history combining the desire to escape colonist regimes with continuing colonisation, a paradox in which the figure of the African American represents the failure of democratic ideals as well as the success of American power. The formation of American identity has long been centred on race; in 1857 the Dred Scott decision made by the United States Supreme Court rendered it the determining factor of citizenship by ruling that African Americans, whether enslaved or free, were not and could never be citizens of the United States. Racial repression reinforced the sense of superiority of white Americans but also guaranteed continual reminders of American injustice. Those excluded from an American identity might thus be experienced "as the uncanny confirmation of the terrifying possibilities of powerlessness" (Bergland $15)$.

This process is enacted within Ellison's novel through the haunting presence of the protagonist's grandfather, who after being freed from slavery adjusted to consensus, stayed in his place, worked hard and brought up his children to do the same. Yet on his deathbed this ostensibly powerless and obedient old man orders his descendents to "keep up the good fight" (17). Utilising combat metaphors, he claims "our life is a war" and confesses to having been "a traitor" and "a spy in the enemy's country ever since I give my gun back in the Reconstruction." By urging his descendents "to overcome 'em with yeses, undermine 'em with grins, agree 'em to death and destruction, let "em swoller you till they vomit or bust wide open", the old man "who never made any trouble" (17) confronts the protagonist with the repressed reality of 
his ancestor's experience, as well as again pointing to the importance of war in the context of racial inequality.

The grandfather's outburst implicates his grandson, who wins a scholarship to college precisely by adhering to acceptable Southern white modes of behaviour. When he arrives at a gathering of his white sponsors in order to deliver a speech identifying humility as the essence of black progress, he is unexpectedly coerced into a battle royal. Yet this degrading experience of violence, in which the boys are blindfolded, forced to fight each other, taunted with a naked white woman and forced to scramble for coins on an electrified rug, fails to deter the protagonist from delivering the speech he hopes will successfully further his career. Halfway through his summary of ideals, which recall those of Booker T. Washington, he chokes on his own blood and via a Freudian slip proclaims "social equality" instead of "social responsibility" as his aspiration. This small moment of revelation startles both the protagonist and his white benefactors; he quickly corrects his mistake and the white men remind him "to know your place at all times" (30). By acknowledging his rightful place and accepting white authority, the protagonist succeeds in obtaining the scholarship which will permit his higher education.

For once, this "triumph" is not ruined by the spectre of the grandfather, whose “deathbed curse" (31) usually spoils his grandson's successes. But as the young man stands beneath his grandfather's portrait to smile 'triumphantly into his stolid black peasant's face" (31), he notices that the portrait's eyes seem to follow him. This haunting portrait illustrates the inescapability of inherited fate and acts both as a warning and a threat. The grandfather's deathbed confession implies he fought for the Confederates in the Civil War in exchange for his freedom, a capitulation he comes to see as traitorous to the abolitionist enterprise, and his inescapable gaze following the 
protagonist's participation in the battle royal points to a similar moment when fighting under white authority betrays the African American cause. Ellison links the grandfather's lingering presence to the ability of language to reveal hidden meaning by emphasising the "yeses" this figure demands his descendents employ. Like ghosts, words are disembodied presences "intended to conjure forth an unreal reality, to embody and to animate a strange imaginary entity that is both there and not there, actual and not actual" (Bergland 5). The ability of literature to animate a dead realm is matched by language's capacity to reveal buried content. When the protagonist unintentionally declares equality as his aim or when the grandfather's condemnation of complicity resides in "yes," a clear connection is made to language's ability not only to represent a return of the repressed but to actually be that return.

The relationship between the ghosts of Invisible Man and the hegemonies that bind them are both symbolic and causal: racial supremacy is something that creates ghosts as well as being itself a ghostly entity. Jacques Derrida highlights the relationship between ghostliness and hegemony in Spectres of Marx (1994) by observing that power, which is all too real, is also insubstantial. Unlike electricity for example, hegemonic power is visible only through its effects. American socio-political structures as well as language can be seen as haunted by racial injustice and by the people denied agency and power through their description in literature or in derogatory slang such as "spook" as nameless, bodiless and inhuman. When the protagonist wakes up in hospital following an explosion in the factory where he works, he discovers himself hooked up to a machine via his naval in a bizarre parody of the birth process. He frets over the question that constantly plagues him - "Who am I?" - and is forced to confront the fact that "I could no more escape than I could think of my identity. Perhaps, I thought, the two things are involved with each other. When 
I discover who I am, I'll be free" (198). These anxieties are clearly provoked by racial issues, but uncertainties regarding the effects on the individual of increasing mechanization were particularly acute during the postwar period. Wartime concerns regarding the potential of Allied military forces to mirror the structures of totalitarianism carried over into postwar discourse about the other-directed individual, conformity and the effects of corporatization and mass-culture. Ellison's use of these popular concerns universalizes his hero's dilemma and is just one example of what has been interpreted as the novel's capitulation to mainstream white culture.

In "Race Man, Organization Man, Invisible Man", Andrew Hoberek argues convincingly that the novel is closely related to "organization man" discourse exploring postwar estrangement, alienation and apathy. This adherence to a white middle-class concern, however, is complicated by Ellison's use of the uncanny, which points to the significant gaps between the applicability of such discourse to postwar African American life. Hoberek notes the similarities between Ellison's novel and Sloan Wilson's The Man in the Gray Flannel Suit, which is the fictional exemplar of organization man discourse. Protagonist Tom Rath struggles to negotiate both his World War II experience, which returns to haunt him through the discovery that he fathered an illegitimate child in Italy, and his Cold War experience, which sees him living in suburbia and worrying about his position in a Manhattan public relations firm. Tom's corporate anxieties are matched by his wife's more domestic concerns, and as befits a novel written in an era of rampant material consumption, money is constantly on their minds. Despite this representative couple's pervasive, if somewhat superficial anxieties, it never occurs to them to question postwar values or social structures, nor does it take too much effort to eventually achieve peace of mind. Wilson has his characters adopt the popular strategy of accommodation rather than a 
revolutionary bid for freedom. By the end of the novel Tom has successfully negotiated his position in the company so that he can spend more time with his family, and the couple's marital bond is strengthened rather than weakened by the revelation of the Italian affair. Betsey confirms that it is their attitudes that need changing rather than the structures or ideologies that surround them when she reminds her husband that, "We shouldn't be so discontented all the time" (5). As if in reward for their adjustment to the system, the couple conveniently inherit an estate from Tom's grandmother which allows them to live happily ever after.

Hoberek points out that Ellison's focus on threatened identity mirrors concerns over the transformation of the American class system during the postwar years, which saw the rise of mass-culture forms such as television, the prevalence of suburban living and the dominance of white-collar jobs. Invisible Man's primary motif of roleplaying is linked by Houston A. Baker to the role-playing necessary for agency in a racially segregated America, which rendered evasion and illusion the only expressive modes enabling African Americans to "barter for a semblance of decency and control in their lives" (196). But Ellison's depiction of African American identity based on role-playing closely resembles the contemporary descriptions of white American identity found in organisation man discourse. Reisman's other-directed individual depends on role-playing as a way to adjust to the signals of both the peer group and mass media, thus becoming a succession of roles which are adapted to suit the demands of any situation. In organisation man discourse, as in Ellison's novel, roleplaying is the basis of an identity which disguises one that remains hidden, and Ellison concurs with other postwar intellectuals when he sets his role-playing characters within an organisation environment, notably the Brotherhood and the college. The alienation and conforming pressures that Ellison's protagonist 
experiences are different from popular treatments of organisation man discourse in one important way: Ellison's hero remains on the outside of the white-collar business world. Although he imagines his association with the Brotherhood as a way forward “that didn't lead through the back door, a way not limited by black and white," his hope of achieving "the highest possible rewards" and of "seeing through the mystery of how the country, the world, really operated" (355) is not achieved through belonging to the organisation. The Brotherhood hires the protagonist solely because of his race and denies him both autonomy and agency. He is subordinated not only to the group, which makes its decisions for every member, but to the group's white members who remind him, "You were not hired to think" (469). Thus as Hoberek's essay highlights, the postwar era's tendency to see a white middleclass discourse as a universal one affecting every American is challenged in Ellison's novel by the depiction of racial demarcations preventing conformity. Invisible Man's account of African American identity can thus be seen as connected with the aspects of the novel that have been read as avoiding race (104).

Ellison uses organisation man discourse not so much to universalise his protagonist's plight, but to illustrate that this discourse is a white middle-class one not open to America's subjugated minorities. Although Invisible Man's hero longs to belong, just as Wilson's flannel-suited protagonist does, the perceived threats of corporatisation and conformity ultimately pose little danger for him, since the narrative reveals he will never be permitted entry to executive suites or leafy suburbia. Furthermore, rather than accommodation to consensus and conformity, Ellison champions dissent and individuality by sending his protagonist away from society into an underground life. The journey into the bowels of the city is a quest for cohesive identity, a search that involves, symbolically and literally, processes of 
burial. Carrying a briefcase laden with objects symbolic of racial conquest - a "Jolly Nigger" money bank, freedom papers, a link of chain that bound the unfairly imprisoned Brother Tarp - the protagonist is horrified when he is challenged by two black men to reveal the case's contents. Overwhelmed with a "wave of shame and outrage" (455), he tumbles down a hole in the sidewalk while trying to escape, and when his pursuers call down after him to ask once more what is in his briefcase, he replies, "You ... What do you think of that?" (455). This downward plunge is the start of a process through which he will realise his true identity and, like Dostoevsky's Underground Man, it is in the depths of the city's unconscious that the protagonist is truly "at home."

At the start of the novel, the protagonist identifies the College he attends as necessary for the formation of an identity based on group belonging, but Ellison destablises this space by peopling it with blind or masked automatons implying the ineffectiveness of Booker T. Washington's integrationist doctrines on which the college is based. In a pivotal scene, the protagonist listens to a sermon delivered by a visiting preacher who identifies humility and deference as the best methods by which African Americans can make social progress. It is some time before Ellison's hero realises that this adviser is completely blind. While the novel does not overtly challenge integrationist doctrine, the uncanny events and characters in the College episodes provoke a feeling of discomfort difficult to ignore. When the protagonist is entrusted with driving the white trustee Mr Norton on a sightseeing tour, he accidentally takes him to the rural slums, resulting in a strange interaction between the trustee and the black farmer Jim Trueblood who reveals that he has committed incest with his daughter and impregnated her, although he insists this occurred while he was asleep and dreaming. Mr Norton grows increasingly disturbed as he listens to 
Trueblood's tale, an agitation which appears linked to his own, perhaps unseemly, feelings for his dead daughter. The two men are doppelgangers, or at least Mr Norton perceives Trueblood as a return of his own repressed desires. Trueblood explains that while he has been ostracised by the African American community following his crime, he is now embraced and financially rewarded by the town's whites. Trueblood's heightened status amongst the whites of the town reveals the way stereotypes act as conduits for repressed fears and desires.

The protagonist takes Mr Norton to a nearby tavern in order to recuperate from his disturbing encounter with the taboo and they discover it filled with black veterans on an excursion from the local psychiatric institution. The Golden Day tavern is a sort of house of the unconscious whose unruly aspects are kept in check by an attendant significantly named Supercargo. Because of the novel's temporal dislocation - we are told in the prologue that the narrative spans twenty years, seemingly spanning a period from around 1930 to 1950 - it is unclear whether the black veterans served in World War I or World War II. The reader is only informed that the doctor veteran who befriends the protagonist served in France. Whether the men served in the 191418 or the 1939-45 conflict, their presence recalls the many African Americans who fought for their country only to discover that service in the military did not necessarily translate into respect either during the war or after. The simmering resentments of World War trauma are held in check by the veterans' Supercargo/Super-ego attendant who controls his charges through sheer repressive force, with one man explaining, "Sometimes I get so afraid of him I feel that he's inside my head" (73).

In addition to its Freudian associations, "Supercargo" is a maritime term which refers to an officer on board a merchant ship who superintends the cargo and the commercial transactions of the voyage. The attendant's name implies his authority 
over men who are not only his charges but who are also aligned with goods for sale, thus recalling the slave trade which transformed the oceanic journeys of people into a maritime distribution of objects. Supercargo also recalls the cargo cults which flourished in the Pacific Islands in the wake of World War II. The arrival of troops to previously isolated communities drastically altered traditional ways of life, and following the end of the war cults sprang up designed to lure back desired goods such as tinned food and weapons. The veterans' attendant in Invisible Man thus suggests the legacy of slavery and war, as well as suggesting the difficulties of appropriating and absorbing material from different cultures. Cargo cults tended to appear among people unable to obtain coveted goods through established trade or traditions, and acts as an interesting parallel to Ellison's desire to use European literary traditions rather than a specifically African American vernacular tradition.

Despite Supercargo's formidable authority, he is overpowered by the veterans who are incited by Mr Norton's appearance. During the melee which follows, the protagonist is assisted by the doctor veteran who reveals that following his military service he attempted to practise as a surgeon, only to be beaten by masked men and driven out of the city. It is this terrible injustice that seems to be responsible for the veteran's mental fragility. He explains that what happened to him

is an issue that I can confront only by evading it. An utterly stupid proposition, and these hands so lovingly trained to master a scalpel yearn to caress a trigger. I returned to save life and I was refused...Ten men in masks drove me out from the city at midnight and beat me with whips for saving a human life. And I was forced to the utmost degradation because I possessed skilled hands and the belief that my knowledge could bring me dignity - not wealth, only dignity and other men health! (80)

The protagonist fails to understand the point of this revelation, which reveals the novel's hidden preoccupation with the relationship between the trauma of war and racial discrimination, and the veteran accuses him of being "a walking zombie" who 
has "learned to repress not only his emotions but his humanity" (81). He is a "walking personification of the Negative," a "mechanical man", and according to the veteran, who bears the psychic wounds of battles both foreign and domestic, the hero "fails to understand the simple facts of life" (81). Like the blinded students at the College, the protagonist "believes in the great false wisdom taught slaves and pragmatist alike, that white is right" (82).

This false wisdom contributes to Dr Bledsoe's bizarre transformation from a normally passive man to one whose face displays uncharacteristic rage at the protagonist's botched expedition with Mr Norton. After expressing his fury to the protagonist when they are alone, Bledsoe then transforms his angry expression into "a bland mask" (87) in order to meet the trustee, a masking which reveals the racially defined roles necessitated by social hierarchies. The protagonist is so disconcerted by this performance that he clutches his eyes in order to keep from blundering into "some familiar object" swerved into his path by "distorted vision" (123). What he has thought of as a home is suddenly unhomely and his grandfather seems to hover over his confused descendent "grinning triumphantly out of the dark" (123).

The grandfather's appearance at a point in the novel which engages with the racial discrimination associated with war recalls what was commonly referred to as the "grandfather clause." One of the many methods used to prevent African Americans from voting, the grandfather clause held that a man could only participate in democratic process if his grandfather had voted. One year into World War I, the Supreme Court ruled in the case of Guinn v. United States that the grandfather clauses in the Maryland and Oklahoma constitutions were null and void because they violated 
the Fifteenth Amendment to the Constitution. ${ }^{39}$ Invisible Man's grandfather is thus not just a personal symbol reminding the protagonist of the inescapability of inherited fate, but a communal symbol of widespread political repression.

Following his expulsion from college after the Norton debacle, Ellison's hero relocates to New York City where his increasing "black anger" (210) finds outlet in a compulsion for rhetoric. When roused to deliver an impromptu speech on the streets of Harlem, he is brought to the attention of the radical political group the Brotherhood, who see potential in his fervent delivery. Although initially inclined to refuse their job offer, the protagonist is swayed by his precarious finances and accompanies Brother Jack to a building called the Chthonian. Here the underground associations of both the building and the organisation strike him "with an uncanny sense of familiarity" as though he "had been through it all before" (243). Additionally disturbing is his inability to decide whether this sense of déjà vu stems from experiencing similar scenes in fiction or whether it springs "from some recurrent but deeply buried dream" (243). He feels as if he "were here, and yet not here" (244), and upon discovering that the Brotherhood plan for him to be the new Booker $\mathrm{T}$. Washington, he is overwhelmed with "a sense of unreality" (249). Like all postwar organisation men, he overcomes his uneasiness and accepts the lucrative position.

Once part of the organisation, the protagonist is given a new name written on a slip of paper, but despite his new sense of identity and belonging, the fact that this name is imposed on him and remains unknown to the reader suggests his identity remains spectral. Upon embarking on his new career as speechmaker, the protagonist fears not just that he is "a nobody with a manufactured name, which might have belonged to

\footnotetext{
${ }^{39}$ For a discussion of the grandfather clause see Michael J. Klarman, From Jim Crow to Civil Rights: The Supreme Court and the Struggle for Racial Equality (New York and Oxford: Oxford University Press, 2004), 69-71.
} 
anyone, or no one" (207), but that under the concentrated gaze of his audience he might become another personality entirely. This sense of self-dissolution renders his limbs foreign parts that can "of their own volition" (270) lead him to either safety or danger. He feels as if he is "returning after a long suspension of consciousness" and suffers "a disturbing vagueness" about his identity, which has an "unformed quality, as when you see yourself in a photo exposed during adolescence" (270). These anxieties are triggered by the power of the audience's gaze and he worries that membership in the Brotherhood requires him keeping separate the part of himself that looks on with "remote eyes" (271). The part that observes listlessly but objectively is his "grandfather part" whose dissent always threatens "internal discord" (271). In order to belong to the organisation the protagonist realises that he must keep this critical aspect "at the distance of the campus, the hospital machine, the battle royal" (270), and objectivity “pressed down” (271).

Just moments after this decision, the protagonist experiences a hallucination illustrating just how difficult successful suppression can be. The alley in which he waits outside the meeting hall reminds him of a large hole in his hometown, which then provokes a waking dream of a stooped man emerging from a shanty who shuffles towards him and stretches out a hand "from which the fingers had been eaten away" (272) by syphilis. This figure emerges from a homely space rendered unheimlich and points to the protagonist's suppressed awareness that the words he employs on behalf of the Brotherhood are not his own; he has become the organisation's puppet.

The horror of subjugation of the (black) self to the (white) organisation is intensified by Tod Clifton's perverse decision after leaving the Brotherhood to sell dancing Sambo dolls on a corner of Fifth Avenue. The protagonist's shock at discovering the African American Harlem Youth leader peddling racist toys is 
matched by his outrage at the grotesque nature of the dolls. Inanimate yet able to flex their paper joints in a gruesome parody of human dance, the dolls provoke "hatred as for something alive" (358). When he picks one up it is "strangely weightless" yet he half expects "to feel it pulse with life" (350), a particularly visceral experience of intellectual uncertainty which inspires a violent desire to "leap upon it with both feet" (350).

Although part of this reaction stems from disgust at racial stereotypes, the dancing dolls also recall the humiliating episode of the battle royal, which involved black boys being jerked into a semblance of dancing by an electrified rug. When the protagonist receives shock treatment at the paint factory hospital, his electrically-inspired movements are similarly likened to dancing, with one doctor snidely commenting, “They really do have rhythm, don't they?" (237). The protagonist himself has endured an ontological ambiguity similar to that of the dolls, and his horror at the sight of their controlled bodies is linked to his own suppressed feelings of subservience in the Brotherhood and to his more deeply repressed anger at racial injustice. These instances of forced entertainment are linked by the fact that in each case it is black Americans being controlled and contained by processes of white agency and perception: although the Sambo dolls are controlled by Clifton, their performance and purchase is primarily intended for the white gaze; the boys of the battle royal "dance" for the white businessmen; and the protagonist's "performance" impresses his white doctors with its rhythm. While the protagonist initially views Clifton's minstrel show as the worst kind of betrayal, it reveals the former youth leader's awareness of the role played by African Americans in the predominantly white Brotherhood. Clifton's ironic display forces the hero to face the fact that he has been "the Brotherhood's ventriloquist dummy" (75). 
The urge to destroy the Sambo dolls is matched by the equally violent destruction of the grotesque "Jolly Nigger" money bank discovered in the protagonist's landlady's house. Like Clifton's appropriation of the minstrel figure, Mary Rambo utilises an object intended mainly for whites. The protagonist smashes it to pieces but is then compelled to carefully wrap up the shards and add it to the cultural legacy he carries in his briefcase. The need to destroy the money bank and preserve it reveals its ability to elicit repulsion and desire. The grossness of the money bank's appearance, as Bill Brown points out in his discussion of "negro memorabilia," springs partly from its ability to deanimate a racial stereotype and concretely fix it in three dimensional form. The money bank's volition (it has a swallowing mechanism enabling it to eat coins) and its demands to be fed (it bears the imperative "Feed Me") through its garish red lips also evoke cartoon images of cannibalism. Brown suggests that the uncanniness of such objects relies not merely on intellectual uncertainty, but on the fact "that the history of this ontological ambiguity - human or thing - is precisely what remains repressed within U.S. culture" (199). The institution of slavery was riddled with contradictions regarding the conceptual distinction between person and thing. In the legal system the American slave was deemed both a human being responsible for criminal acts and an object for purchase, ownership or sale. The effect of the mechanical bank relies on its ability to encapsulate this ontological instability, making it one of "the most despised and most prized objects of black memorabilia, simultaneously the object of repulsion and fascination" (Brown 199).

Bledsoe's performance of the role of educated yet humble Negro (which conceals bitter frustration) and the protagonist's role as the new Booker T. Washington (despite his increasing "black anger") is presented less as a necessary survival skill in a repressive society than a capitulation to that society. Ellison's hero finally realises 
something of this when he purchases a disguise to evade pursuit by the followers of Harlem's Nationalist movement. By donning dark sunglasses and a white hat he is repeatedly mistaken for a man named Rinehart, whose myriad roles include pimp, numbers runner, hipster and preacher. Although this protean figure seems to offer a solution to the protagonist's dilemma regarding identity, the fact that he must wear dark glasses relates this strategy to the blindness of figures such as the College preacher.

The disguise also recalls another invisible man, H.G. Wells' unfortunate scientist in the 1897 novel The Invisible Man, who similarly dons a hat and glasses in order to appear in society. In a 1982 interview published in the New York Times, Ellison explained that although it was suggested his book's title would be confused with The Invisible Man, he fought to keep the title "because that's what the book was about" (qtd. in Mitgang 13). The relationship between the two novels is far more complicated than Ellison's comment might suggest. Michael Hardin points out that Wells' hero is repeatedly described as "black" and "dark" thus reflecting fears about blacks "passing" as whites in British society. By the end of Wells' novel, his invisible scientist has become insane and set on a path of revolutionary action he calls the "Reign of Terror", but his plans to terrorise the nation are thwarted and he is killed by an angry mob. When Ellison's hero takes on the guise of Rinehart, he not only assumes the role of protean shape-shifter but also revolutionary terrorist. By discarding the glasses and hat, he rejects disguise and violence in favour of discovering a true sense of his own identity and a strategy for effective leadership.

The protagonist decides to listen to his grandfather's advice and subvert the Brotherhood's interests by "yessing" it to death. The fallibility of this strategy, which eventually implicates him in the Harlem riot, is revealed when during a Brotherhood 
meeting something suddenly erupts out of Brother Jack's face. The protagonist is confronted by "an eye staring fixedly at me as from the dark waters of a well" (381), a startling disruption which forces him to acknowledge Brother Jack's deceptive appearance. Like the Sambo dolls which blur the boundaries between the animate and the inanimate, the glass eye is "an almost perfect imitation that seemed alive" (382). This loss of an eye, coupled with the repetition of sight and blindness motifs, recalls Hoffmann's "The Sandman" which paradoxically locates the main culprit for distortion of vision in the objectivity of optical instruments. It is through the lens of a telescope that Nathanael mistakes the automaton Olimpia for a real woman and his eventual suicide is similarly linked to a distorted vision of his fiancée through the same instrument. The journey towards cohesive identity taken by Ellison's hero depends on his rejection of the imperfect doctrines represented by the blind figures of the College, the Brotherhood and the Harlem streets. Freud interprets fear of eye loss as connected with castration anxiety, a conflation Ellison uses in order to highlight his protagonist's vulnerability to a disempowering white gaze. This is made explicit towards the end of the novel when the protagonist dreams of being castrated by Brother Jack, a nightmarish episode which has the unexpected result of freeing the hero from his illusions. Although he admits his loss is painful, it means that he can now see what he was once blind to, since his mutilated testicles are plainly visible.

As in Freud's uncanny experience when he kept involuntarily returning to the street of painted women, repressed sexuality is capable of staging an especially potent return. When Ellison's protagonist decides to gain political power through learning secrets from one of the Brother's girlfriends or secretaries, he is unable to follow through with sex when Sybil reveals that she wants him to enact a rape fantasy. This scenario clearly relies on racial stereotype and is understandably distasteful for the 
protagonist, so instead of literally raping Sybil he uses her purplish lipstick to rape her literarily by writing on her stomach:

\section{SYBIL. YOU WERE RAPED}

\section{BY}

\section{SANTA CLAUS}

\section{SURPRISE}

This is one of the novel's most surreal moments and the image of a sexually violent Father Christmas is also one of its most bizarre. The jolly gift-giver of childhood with his cosy connotations of home and hearth is transformed by Ellison into a figure of sexual predation. Santa Claus is closely related to the clown, a figure which has inspired such levels of dread that it demanded its own term, coulrophobia. From its jester origins to the present, the clown is a trickster figure who exists on the borders of society functioning both as magical shaman and taboo-testing fool. The trickster's association with the spirit world in tribal practise imparts a residue of supernatural dread to the leering clown and the jolly Santa. The garish red costume, exaggeratedly fleshy body, the ability to fly and omniscience make Father Christmas an enigmatic figure beyond rational control, whose boundary blurring power inspires fascination and fear. ${ }^{40}$ Santa's role as a fulfiller of desire becomes ambiguous, if not downright frightening, when seen in this context. His moralistic function (who has been good and who has been bad?) makes Santa a father figure who both encourages desire and enforces symbolic law. As Douglas Steward observes, both Ellison's protagonist and Sybil "project a fantasy image onto the other person, misrecognizing the other as that which can fulfil a deep desire, just as Santa Claus is himself an impossible fantasy figure that makes untenable promises of obscene gratification" (530).

\footnotetext{
${ }^{40}$ A visit to the shopping mall at Christmas will often reveal Santa's fearsome aspect for children, many of whom cry when confronted with the prospect of sitting on his lap.
} 
The sinister Father Christmas evoked by the protagonist's graffiti is a manifestation of repressed desires undeniably sexual in nature, and the threat of the sexualised (white) female body returns during the Harlem race riot. ${ }^{41}$ Although he has dispatched Sybil in a taxi to escape the violence, when the protagonist sees a "white, naked, and horribly feminine" (447) body hanging from a lamppost he is convinced it is her. Spinning around in horror, it is as though he has "turned some nightmarish somersault" (447) when he sees seven corpses hanging before a gutted store-front. He stumbles and hears the cracking of bones underfoot, but is then relieved to notice a physician's skeleton shattered on the street. He steadies long enough to observe the unnatural stiffness of the hanging bodies, which turn out to be mannequins not corpses. This knowledge fails to fully reassure him, however, and he wonders, "But are they unreal... are they? What if one, even one is real - is...Sybil?” (447).

Bill Brown argues that the scene's mannequins invoke an iconic source of the modern uncanny. Mannequins were integral to the surrealist imagination, as illustrated by Breton and Éluard's famous "Surrealist Street," a line of female mannequins propped up outside the Galerie des Beaux-Arts in 1938. Brown suggests that if the displaced mannequins in Paris registered the uncanny effects of consumer culture, then the mannequins in Ellison's Harlem register a threat to life and provincialise Modernism within the context of American racial conflict. The horror provoked by the mannequins recalls once more the repressed apprehension "that within things we will discover the human precisely because our history is one in which humans were reduced to things" (Brown 207).

If the Harlem riot involves a return of repressed fears regarding subjugation and sexuality, it also illuminates the relationship between World War II and racial

\footnotetext{
${ }^{41}$ There is also a noticeable connection between the "grandfather clause" and Santa Claus, both of which return throughout the text to remind the protagonist of racial discrimination.
} 
oppression. On August 1, 1943, Harlem erupted into violence following the arrest of Private Robert Bandy, a 26-year-old African American soldier who was charged with attacking a white police officer arresting a black woman. The riot was provoked by rumours that police officers had killed a black soldier who was trying to protect his mother. Approximately five hundred people were injured in the resulting violence, up to five hundred more were arrested, there was extensive property damage, and six people lost their lives. ${ }^{42}$ While there were numerous long-simmering resentments involved in the riot, particularly economic, the spark was lit by rumours of violence inflicted by white authority not only upon a black man but upon a black soldier. Ellison's depiction of a riot inspired by the death of Tod Clifton at the hands of white police implicates racial violence as well as revealing another story, one in which the cause of Harlem unrest is the racial discrimination highlighted by World War II.

Racial oppression and military conflict obviously recall slavery and the Civil War, the repressed legacy of which is detailed in the novel's prologue. High on marijuana, the protagonist enters the music of Louis Armstrong and descends into the depths of buried history. In this space beneath a specifically African American musical tradition, the protagonist discovers an old woman singing a spiritual, and on a lower level, a beautiful girl standing naked before a group of slave owners. The spiritual singer both conceals and reveals the more deeply repressed figure on the auction block, who is not only a slave doomed to oppression and sexual predation but a woman whose pale skin reveals her mixed parentage. The old woman expresses profound ambivalence describing her feelings for the white master who is also the father of her daughter. While writers such as Faulkner locate the fear of miscegenation as a specifically white anxiety, Ellison points out that the repressed

\footnotetext{
${ }^{42}$ See Herbert Shapiro, White Violence and Black Response: From Reconstruction to Montgomery (Amherst: University of Massachusetts Press, 1988): 330-6.
} 
history of sexual relations between white and black, whether consensual or not, is capable of being registered as uncanny for African Americans as well. The protagonist's vision makes repressed racial trauma the legacy of every American regardless of race.

The protagonist of Invisible Man flees from the legacy his grandfather represents, which only results in him being haunted by that unintegrated history. Repression renders him invisible and, despite his numerous speeches, ultimately voiceless. By writing his own history incorporating the ghostly figures buried by repression, the protagonist is able to achieve identity and agency, a process facilitated by journeys underground. At the end of the novel he is living in the basement of a whites-only tenement using the illegally siphoned electricity of the Monopolated Light Company to power the hundreds of light bulbs he has installed, thus drawing on power previously monopolised by white culture in order to articulate his own narrative.

Alain Locke points out that the African American has been alternately something to be condemned or defended, something to be "kept down," held "in his place," or "helped up." African Americans were similarly forced to think of themselves in terms of a social problem or controversial issue, so that the African American's shadow "has been more real to him than his personality" (Locke qtd. in Klein 76-77). Spectral existence denies Ellison's hero a cohesive identity and imbues him with strange power. Haunting the boundaries between the visible and invisible worlds, spectres can be defined as frontier beings who navigate what Arnold Krupat defines as the "shifting space in which two cultures encounter one another" (5). Spectrality is thus a potent symbol for articulating the encounters which occur within the shifting grounds of American cultural frontiers. 
Although Ellison differed from the views of many African American writers of the mid-twentieth century by seeing America as potentially offering a context for personal identity and African American culture, his novel is far from a capitulation to the dominance of white culture. Ellison did align his novel with popular postwar discourse, and his unflattering portrayal of radical left-wing politics certainly guaranteed Invisible Man's success upon its publication, but the return of the repressed points to the novel's more subversive elements. Alongside the depiction of a reality acceptable to a mainstream postwar audience, a reality of white-sponsored education, of plentiful, albeit menial, employment, and of the accessibility of whitecollar mass culture, the novel provokes an odd feeling of disorientation. As Irving Howe points out in his 1952 review, the novel's first-person singular prevents Ellison from fully establishing ironic distance between the matured "I" telling the story and the "I" who experiences recalled events. Howe suggests that because the experiences are "so apocalyptic and magnified," the protagonist is absorbed and dissolved; "every minor character comes through brilliantly, but the seeing "I" is seldom seen" (454).

This is the final strangeness in a very strange novel, for in what appears to be a highly aesthetic rumination on personal identity there is no real sense of the character we are supposed to engage with. The protagonist's complaints about being invisible are certainly well-founded, since the lack of information regarding his childhood, particular tastes and aversions, his pastimes and relationships means that the protagonist remains oddly unformed in the reader's mind. Ellison's use of two versions of his protagonist - the older and wiser one writing the tale of his naïve younger self - is essentially a paradigm of haunting. Behind the invisible man is another invisible man, behind whom there is yet another invisible man: Ellison himself. The reader never really gets access to who tells the story since events are 
mediated through several versions of an ultimately intangible protagonist. In Ellison's novel, author haunts narrator who haunts protagonist, just as the war hovers through its pages constantly evoking the trauma not only of combat but of being black in America. 


\section{The Sacred Other:}

\section{Flannery O'Connor's Wise Blood}

I wish we would hear more about the harm we do from the things we do not face and from all the questions we give Instant Answers to.

Flannery O’Connor, Habit of Being

Flannery O'Connor's Wise Blood (1952) begins by depicting a burial of the war experience which acts not only as a catalyst for the fictional action but as a metaphor revealing the defining impulse of postwar American life. ${ }^{43}$ The opening pages describe Hazel Motes travelling home just two days after his release from military service and his first action upon disembarking the train is to buy a new suit and unceremoniously stuff his uniform into a trashcan. Hazel disguises this desecration by wrapping his uniform in paper and O'Connor's potentially subversive views on the war are similarly disguised. From this outrageous moment the narrative turns resolutely away from the Second World War to focus on the postwar commodification of religion and Hazel's struggle towards enlightenment. The protagonist's reactions to the recent conflict are barely alluded to and the society into which he attempts to reintegrate has similarly discarded the ambiguous aspects of mass violence and largescale destruction in order to promulgate a censored version of the "good war" and pursue successfully socialised domestic lives. For Wise Blood's protagonist as well as its author, the homogenised value systems which parade as postwar religion, outlined

\footnotetext{
${ }^{43}$ Sarah Gordon argues that O'Connor's story "The Displaced Person" displays a similar evasion, bypassing the Holocaust through focus on her Christian vision. See Sarah Gordon, Flannery O'Connor: The Obedient Imagination (Athens: University of Georgia Press, 2000).
} 
by authors such as Norman Vincent Peale and described by O'Connor in Habit of Being as a "poor man's insurance system" (231), pose a real threat to spiritual life. The thought of "everyone lolling about in an emotionally satisfying faith" was deemed "repugnant" (Habit 100) by the devout Catholic O'Connor, guaranteeing her a place on the edges of a mainstream postwar culture more than willing to take refuge in easily accessible spiritualised solace.

While the novels previously discussed in this study are reactions to the repression of the World War II experience, Wise Blood is a double refraction in that it reacts to the culture created by that repression. Part of the way Americans coped with the new world ushered in by the war was a mass return to organised religion, yet the belief systems outlined in popular non-fiction and radio formats during the era reveal a religiosity that remained secular rather than sacred. In The Elementary Forms of Religious Life (1912) Emile Durkheim suggests the ambiguity of the sacred by pointing out that it encompasses forces that are negative and positive, pure and impure. The sacred is split, with monotheism frequently attributing the impure and destructive aspect of the sacred to the Devil, thus forming a binary that elides the sacred's dual nature. As in all monotheisms, the popular religion of the postwar era in America also split the sacred, but because the doctrines of preachers such as Peale omitted a devil, the split reduced the positive sacred to the banal and bland secular. O'Connor's protagonist returns from a secular war which paradoxically denies mass violence and large-scale destruction only to find himself inundated with religious doctrine revealing a similar sanitisation. Hazel reacts to a secular war and a secular "religion" by asserting the impure aspect of the sacred through founding the Church Without Christ, a strategy which brings him to a violent transcendence bearing little 
similarity to the solace offered by the proponents of self-help tomes such as Peale's Faith is the Answer (1950).

Critics of O'Connor's fiction as well as her biographers have focused almost entirely on the relevance of religion to her work and life, obscuring the relevance of the war and rendering her views on the conflict difficult to ascertain. ${ }^{44}$ Wise Blood's oblique way of dealing with Hazel's military service renders interpretation similarly difficult, but his fears upon receiving the draft seem to cast World War II as a secular event with no relevance to sacred concerns. ${ }^{45}$ Hazel's first thought is to shoot himself in the foot, a radical avoidance strategy unconnected to a pacifist stance but which seems to stem from fears regarding the war's threat to his soul. Hazel could hardly be accused of harbouring humanitarian views, he certainly does not adhere to the commandment "thou shalt not kill," and his self-flagellation refutes physical cowardice as the reason for his fears of war. Rather, he seems to fear immersion in an all-encompassing secular event. As if in confirmation of these fears, military service persuades Hazel that he has no soul and he returns from war to discover a secular

\footnotetext{
${ }^{44}$ In the introduction to Flannery O'Connor in the Age of Terrorism, Avis Hewitt points out that theological approaches to O'Connor are so dominant as to overshadow feminist and new historicist studies such as Katherine Hemple Prown, Revising Flannery O'Connor: Southern Literary Culture and the Problem of Female Authorship (Charlottesville: Virginia University Press, 2001), and Jon Lance Bacon, Flannery O'Connor and Cold War Culture (Cambridge: Cambridge University Press, 1993). Recent theological readings of O'Connor include Christina Bieber Lake, The Incarnational Art of Flannery O'Connor (Macon, GA.: Mercer University Press, 2005); Ralph Wood, Flannery O'Connor and the Christ-Haunted South (Grand Rapids, Michigan: William B. Eerdmans Publishing, 2004); Susan Srigley, Flannery O'Connor's Sacramental Art (Notre Dame, Ind.: University of Notre Dame Press, 2004); Richard Giannone, Flannery O'Connor: Hermit Novelist (Urbana: University of Illinois Press, 2000) and Flannery O'Connor and the Mystery of Love (New York: Fordham University Press, 1999). See Avis Hewitt and Robert Donahoo, ed., Flannery O'Connor in the Age of Terrorism: Essays on Violence and Grace (Knoxville: University of Tennessee Press, 2010), xi. Going against the grain of these dominant approaches are Prown's feminist study, Bacon's examination of the relationship between O'Connor's fiction and the conservatism and materialism of the Eisenhower years, and Thomas Hill Schaub's exploration of the critiques of both liberal and conservative Cold War politics that he identifies in her work. See Thomas Hill Schaub, American Fiction in the Cold War (Madison: Wisconsin University Press, 1991).

${ }^{45}$ In O'Connor's short story "Greenleaf' the war is cast in terms of its ability to promote individuals up the social ladder. Mrs May's ironic discussion of the way the Greenleaf boys' military service in France enabled them to marry French women "who naturally couldn't tell that they murdered the King's English or that the Greenleafs were who they were" (292) highlights the social and material advantages wrought by the war and does not address its devastation.
} 
society peddling religion as a commodity. The novel is a clear condemnation of the postwar domestication of the sacred and positions the war as the catalyst for spiritual corruption. This view runs counter to popular perceptions of the morality of the war, as well as refuting the perception of the religious boom as indicating an increasing connection with the sacred.

In 1940 less than half of America's population belonged to institutionalised churches, but by the late fifties this figure had risen to over 63 percent. Part of this mass return to religion is attributable to anti-Communist rhetoric which positioned religion as a powerful defence against the atheist Communist threat, but the majority of popular religious texts, particularly self-help books and "twelve-step" spiritual guides, presented belief in God as a method for alleviating personal fears. As Robert Laurence Moore notes, "religion has always been most popular in its intellectually debased forms" (11) and the phenomenal return to religion during the fifties reveals less a desire for the divine than desire for successful socialisation. The focus of popular religion was similar to that of popular psychology: it aimed to improve selfesteem; ease psychic tension; facilitate success in business; even assist weight loss. The success of preachers such as Peale and Billy Graham depended on the accessibility of their message and the ease with which their solutions could be applied. Peale's popularity also relied on the way he legitimised avoidance strategies. In Faith is the Answer (1950) he advised his congregation to "develop the habit of not talking about anxieties and worries" and suggested removing anxiety from conversation since then "it will tend to drop out of your mind" (71).

Peale's books enjoyed only a modest circulation until the great religion boom of the fifties when the new demand for succour saw books with religious themes swell 
the bestseller lists. ${ }^{46}$ Titles such as Fulton Oursler's The Greatest Story Ever Told (1949), Henry Morton Robinson's The Cardinal (1950) and Thomas B. Costain's The Silver Chalice (1951) achieved widespread popularity, with Publisher's Weekly observing that "the theme of religion dominates the non-fiction best-sellers in 1953" (qtd. in Mart 289). In fact, 1959 was the first year in the decade in which no religious books reached the top ten in either the fiction or non-fiction category. Bizarre titles such as Franklin Loehr's The Power of Prayer on Plants (1959) and Charlie W. Shedd's Pray Your Weight Away (1957) point to the perception of prayer as cure-all, while Dale Carnegie's How to Stop Worrying and Start Living (1948) clearly identifies prayer as the best way to conquer anxiety and achieve success.

The marketing of religion as an all-purpose antidote did meet with some criticism. In a 1955 article entitled “Think Right: Reverend Peale’s Panacea,” psychiatrist R. C. Murphy challenged Peale's dilution of traditional Christian doctrines and questioned his emphasis on material rather than spiritual reward. Murphy points out that Peale refuses to allow his followers to hear, speak or see any evil. For him real human suffering does not exist; there is no such thing as murderous rage, suicidal despair, cruelty, lust, greed, mass poverty, or illiteracy. All these things he would dismiss as trivial mental processes which will evaporate if thoughts are simply turned into more cheerful channels. (409)

Murphy identifies the way the marketing of popular religion and its focus on socialisation subordinates the spiritual to the psychological and the sacred to the secular. Peale's doctrines create an oddly unreligious religion catering to psychological process, in which negative thoughts and neurosis have taken over from sin and retribution. Peale's assertion that negative forces are ultimately conquerable by the power of positive thinking reassures the reader that perceived threats are rational, minimal and ultimately surmountable.

\footnotetext{
${ }^{46}$ Peale's The Art of Living (published in 1937) met with reasonable success, but 1952's The Power of Positive Thinking eclipsed his previous publications. It was one of the best-selling books of the decade and has gone on to sell an estimated 20 million copies.
} 
In Peace with God (1953) Billy Graham divides his treatise on sin and redemption into three easy sections: "Assessing the Situation"; "Advancing the Solution"; and "Applying the Antidote." The antidote is, of course, the power of Christian belief to achieve "Peace at Last." Graham emphasises the accessibility of this peace by suggesting that spiritual belief is "all yours," "it's free", and even better, "You don't have to work for it" (220). This ability to tap into the cultural zeitgeist saw Graham label Communism as the work, quite literally, of Satan. There was, he argued, no explanation for the "tremendous gains of Communism in which they seem to outwit us at every turn, unless they have supernatural power and wisdom and intelligence given to them" (qtd. in Whitfield 81).

This statement, which is an unusual instance of the era's popular religion admitting to evil or supernatural powers, delineates a clearly divided moral world in which the sacred is harnessed to political ideologies. While Graham's message was far more apocalyptic than Peale's, both men acknowledge negative forces only to reinforce the refuge organised religion offers. Furthermore, the negative aspects they admitted were secular rather than sacred, psychological in Peale's case and political in Graham's. The movements expounded by these popular preachers did not deal with the sacred at all, but positioned religion as a system of secular values designed to be adopted with ease. In "Biblical Authority in Evangelism" Graham disclosed the secret to the success of his ministry: "I stopped trying to prove that the Bible was true. I had settled in my own mind that it was, and this faith was conveyed to my audience" (6). His conclusion - "Authority creates faith" (6) - resulted in a commoditised religion where the individual quest for enlightenment was subverted into the individual's acceptance and purchase of the word of an "expert." 
Catholic archbishop Patrick A. O'Doyle observed that the era's believers turned to religion as "a benign sedative to soothe their minds and settle their nerves" (qtd. in Miller and Nowak 101), which distinguishes the postwar revival from America's earlier religious booms such as the Second Great Awakening (1790-1840), which were frequently characterised by frenzied exhilaration. Popular titles such as Rabbi Joshua Liebman's Peace of Mind (1946), Fulton Sheen's Peace of Soul (1949) and Graham's Peace with God (1953) all reveal the religious consumer's desire for ease and tranquillity. Peale's Power of Positive Thinking (1952), Sheen's Way to Happiness (1954) and Graham's Secret of Happiness (1955) point to a quest for control over anxiety, with such tomes presenting easily obtainable happiness, success and harmony.

Stephen Whitfield observes that what was revived during the postwar decade was not so much religious belief as belief in the value of religion. The benefits of religious devotion "were not seen as mystical and metaphysical, nor existential, and less psychological or ethical than political and social" (Whitfield 87). Church membership was seen as a powerful advantage in America's quest for political and social power, and in 1954 the phrase "under God" was added to the American pledge of allegiance. The particularity of faith was less important than its perceived ability to combat external threat and maintain internal order. President Eisenhower went so far as to declare in 1954 that "Our government makes no sense unless it is founded in a deeply felt religious faith - and I don't care what it is" (qtd. in Wood 19). Eisenhower's statement illustrates both the importance of faith during the postwar period and how homogenised concepts of religious belief had become.

Compared to this officially sanctioned haze of homogenised value, to which the name of Wise Blood's protagonist surely alludes, O'Connor's literary exploration of 
religion is troubling and complicated. A 1952 review in the Atlanta Journal and Constitution noted that Wise Blood is a novel "whose overtones are chilling and whose horror is undiluted," and concluded that "It's not a book to read late at night, alone" (Smith F7). Rather than promising an easily obtainable peace of mind, Wise Blood reintegrates the destructive aspects of the sacred that popular religion omitted. Although O'Connor's fiction is frequently categorised as Southern Gothic, Wise Blood differs in several key aspects from the tradition best exemplified by the novels of Faulkner and Truman Capote's Other Voices, Other Rooms (1948). O'Connor insisted that, "The word gothic means nothing to me" (Habit 501) and wearily resigned herself to The Violent Bear It Away being called "another Southern Gothic" since "I have an idiot in it" (Habit 301). This reluctance to categorise herself as a writer of the gothic (she preferred the term "grotesque") is validated by Wise Blood's lack of recognisable Southern Gothic motifs: there are no crumbling antebellum mansions, no decaying aristocratic families and no gloomily oppressive rural environments. O'Connor's main protagonists Hazel and Enoch are young workingclass men navigating an urban environment replete with the artefacts of postwar modernity and materialism.

Like other writers of the period, O’Connor explores an increasingly industrialised mass culture, but rather than concentrating on the effects of commodification and conformity on individuality, her preoccupation is with spirituality. Hoover Shoates and Asa Hawkes are portrayed as peddlers of diluted doctrine whereas Hazel struggles with a divine that is disturbing, threatening and ultimately annihilating. His profanity, blasphemy, nihilism and violence lead him to an encounter with the sacred, and his stubborn rejection of easy panaceas leads him to a religious belief that is profoundly unsettling. O'Connor explained that what bothered her about writing "about the return 
of modern people to a sense of the Holy Spirit is that the religious sense seems to be bred out of them in the kind of society we've lived in since the $18^{\text {th }}$ century. And it's bred out of them double quick now by the religious substitutes for religion" (Habit 299-300). Although the proponents of Pray Your Weight Away attest to a reassuringly cosy vision of the divine, the dual nature of the sacred enables it to inspire dread as well as joy. O'Connor's resolve was to depict a grace which "cuts with the sword Christ said he came to bring" (qtd. in Cash 260).

The sacred is uncanny both through its revelatory power and through its destabilising effect on rational assumptions, but Wise Blood's strangeness relies on more than O'Connor's register of the return of the repressed. ${ }^{47}$ When she suggests that violence is "strangely capable" of returning characters to reality and "preparing them to accept their moment of grace," there is an unsettling sense that this description of the literary use of violence applies just as much to O'Connor's readers as to her characters. The violence depicted in O'Connor's novels and stories is often noted, but it is the violence inflicted by her texts that defines the experience of reading her work. ${ }^{48}$ Her use of the grotesque involves a two-fold process in which the reader is drawn into the text through empathy only to be thrust out again. It is O'Connor's ability to combine the horrific with something uncomfortably close to the comic that proves so disorienting and the reader is left to negotiate profoundly conflicting responses to her fiction. Entering the fictional world of Wise Blood entails a strangely real risk: that we too will be assaulted and forced to receive the gift of an epiphany

\footnotetext{
${ }^{47}$ Jeffrey Gray posits the uncanny as an excellent tool for analysing Wise Blood's strange violence, its disoriented subjectivities, and its uneasy fit in generic categories, but fails to go beyond this identification to an analysis of the uncanny's meaning. See Jeffrey Gray, “'It's Not Natural': Freud's 'Uncanny' and O'Connor's Wise Blood," The Southern Literary Journal 29, no. 1 (Fall 1996): 56-68. ${ }^{48}$ One reviewer observed upon Wise Blood's publication that "One cannot take this book lightly or lightly turn away from it, because it is inflicted upon one in the same way its people take their lives: like an indefensible blow delivered in the dark. Perhaps this sense of being physically struck and wounded is only the beginning of an arousal of one's questioning of the credibility of such a world of horror" (Goyen 4).
} 
from which we might never recover. In Mystery and Manners, O’Connor suggests that "reality is something to which we must be returned at considerable cost," an idea which although "seldom understood by the casual reader ... is one which is implicit in the Christian view of the world" (112). The reality O'Connor attempts to reveal through violence is a reality much postwar fiction and non-fiction sought to avoid.

Although O'Connor's fiction is a stark repudiation of the complacent vision so many Americans were eager to embrace in the period, it also adheres to many concerns guaranteeing critical and popular success. So although she responded to a Life magazine editorial which demanded American literature illustrate the joy and prosperity of postwar culture by wondering whether "these screams for joy would be quite so piercing if joy were really more abundant in our prosperous society," her perception of the insidious threat posed by desire for "the good things in life, like supermarkets" (qtd. in Magee 30) adhered to popular intellectual concerns about mass culture. Similarly, although O'Connor identified her use of the literary grotesque and her identity as a Catholic as anti-bourgeois, her defiant sense of being outside the status quo did not entirely protect her from the pressures of conformity. In Mystery and Manners, she admits that "writers who speak for and with their age are able to do so with a great deal more ease and grace than those who speak counter to prevailing attitudes" (47). When she received a letter from a disgruntled reader who insisted that readers wanted "uplifting" fiction, O'Connor was both derisive and quick to realise the detrimental effect this could have on her sales: "One old lady who wants her heart lifted up wouldn't be so bad," she observed, but "multiply her two hundred and fifty thousand times and what you get is a book club" (Mystery 48).

While O'Connor was ultimately able to shrug off one old lady's demands for inspirational fiction, as well as one reviewer's hope that "Miss O'Connor may write 
about some happy people" (Smith F7), she adhered strictly to the period's dominant New Critical values. Drafts of almost everything she ever wrote were sent to Caroline Gordon, one of the leaders in developing practical criticism from the tenets of New Criticism, a strategy which ensured O'Connor's work was consistently moulded by the dominant critical mode. O'Connor was also anti-Communist, but not for the same reasons as the majority of Americans. Her rejection of the secular meant that she disagreed not only with the American, largely Protestant, consensus, but even more strongly with Soviet atheism, and in 1956 she refused to sell her work to Czech and Polish publishers for fear it might be used for propaganda purposes. She was close friends with Granville Hicks, the anti-Communist editor of Saturday Review, and even joined with several other writers in attempting to oust the allegedly Communist Agnes Smedly from the directorship at the Yaddo writer's retreat. Religious beliefs bought their own pressures too, particularly in the form of the Vatican's Index of Forbidden Books which O'Connor chose to honour. She did, however, ask her confessor for a dispensation to read Sartre, since she feared that the Protestant members of her book club would imagine her Catholicism unable to withstand atheist opposition.

O'Connor's work thus displays a tension between an adherence to consensus culture and a rebellion against it, which is part of the reason her work was received in decidedly different ways. On the one hand, her audience consisted of Southern ladies who invited her to speak at their literary soirées and who seemed altogether undisturbed by the violence of her fiction; on the other hand, there was an audience best exemplified by T.S. Eliot, who while professing a great admiration of O'Connor's work, nevertheless confessed to being "quite horrified" by the stories he read. Eliot concluded that, "She has certainly an uncanny talent of a high order but my 
nerves are just not strong enough to take much of a disturbance" (qtd. in Jordan 56). It is this doubleness that makes O'Connor's fiction so disorienting. She identified "seeing" as the most important process for a writer, by which she meant not just the close observation necessary for descriptive art but also the mystical process of prophetic vision. Mystery and Manners outlines O'Connor's double vision of the prophetic writer who sees the extension of near things (things that are visible) and the magnification of far things (things that are invisible). This means that the description of a concrete object contains both physical and spiritual reality, and encompasses the quotidian and the sacred, the familiar and the strange.

Like Ellison's protagonist, O'Connor's young veteran is propelled along a path from blindness to vision, but Hazel's revelation ironically relies on the loss of sight. His complicated evasions and returns to the sacred involve a series of ontological crises between self and other, reality and dream, life and death. Hazel experiences dreams and waking visions of his dead relatives in their coffins, hallucinations which render his train berth and the automobile he later purchases similarly tomb-like spaces. Hazel has experienced more than his share of loss, with his childhood involving the death of his grandfather, two brothers, and later his father and mother. Young Hazel is certain that his dead grandfather will never allow his coffin to be shut, and believes that "when the time comes, his elbow is going to shoot into the crack" (20). This confusion about death becomes profound anxiety following the gruesome death of one brother who falls beneath a mowing machine, and during the funeral Hazel attempts to wrench open the coffin because of a sudden fear that he himself is in the casket. Anxiety about death continues into Hazel's adulthood, and while in the train berth which he thinks is "like a coffin" (19), he dreams of his father being carried to the graveyard as a remarkably animate corpse declaring, "If I can keep my 
can in the air, nobody can shut nothing on me" (20). When the pallbearers arrive at the hole, however, the coffin is dropped down "with a thud and his father flattened out like anybody else" (20).

Hazel's dread of death is understandable given the litany of loss he suffers, but it is also inextricably linked to his dread of the sacred Christ. Just as Hoffmann's "The Sandman" conflates a bogeyman figure with anxieties associated with female figures and sexuality, Hazel's dread of Jesus is linked to a sexualised experience as a preadolescent, which is also strangely tinged with overtones of death. When he is twelve years old, Hazel is taken by his father to a carnival where he is left to wait outside a tent announcing an "EXclusive" and "SINsational" attraction (60). He manages to persuade the doorman to let him enter this forbidden realm where he discovers a group of men "looking down into a lowered place where something white was lying, squirming a little, in a box lined with black cloth" (62). At first he thinks it is a skinned animal in the coffin-like container, but then he realises it is a woman. The conflation of sex, sin and death is certainly disturbing for the young protagonist, but the effect of this scene for the reader is especially discomforting since exactly what we are witness to remains unexplained. Is it merely a lurid peepshow with a funereal theme or is there something more sinister going on?

When Hazel returns home he is confronted by his intimidating mother whose insight verges on the supernatural. Dressed entirely in black, she stares fixedly at her son and demands that he tell her what he has seen. Although Hazel attempts to avoid this penetrating gaze, he is able to "feel her watching him through the tree" (62) he attempts to hide behind. In an effort to extract a confession, this frightening matriarch whips her son's legs while reminding him that "Jesus died to redeem you" (63), a fact already impressed upon him by his grandfather. During the sermons delivered by the 
old preacher from the top of his Ford, he shouts at his listeners that "Jesus had died to redeem them! Jesus was so soul-hungry that He had died, one death for all, but $\mathrm{He}$ would have died every soul's death for one!" (21). Hazel's grandfather uses him as an example during these tirades and asserts that "for that boy there, for that mean sinful unthinking boy standing there with his dirty hands clenching and unclenching at his sides, Jesus would die ten million deaths before He would let him lose his soul" (22). The redemption offered by Christ is inextricably linked to the fact of his death, and Hazel's stubborn refusal to explain what he saw at the carnival despite his mother's reminders that Jesus died for him is alleviated only by a single response, "I never ast [sic] him" (63).

The experience in the carnival tent is transformed by the mother's relentless gaze into a "nameless unplaced guilt" (63), and as in Hoffmann's story, the son's agency is threatened by a female figure. Hazel is so frightened of the Christ portrayed by his grandfather's sermons and evoked by his mother that he develops "a deep black wordless conviction ... that the way to avoid Jesus was to avoid sin" (22). Following the "SINsational" experience in the carnival tent, Hazel becomes vulnerable to the redeeming Christ whom he imagines moving "from tree to tree in the back of his mind, a wild ragged figure motioning him to turn around and come off into the dark where he was not sure of his footing, where he might be walking on the water and not know it then suddenly know it and drown" (22). In an effort to ward off the sacred, Hazel fills his shoes with pebbles and walks a mile in order to "satisfy Him" (64). His commitment to avoid sin does not stem from the desire to be a good Christian deserving redemption, but from a determination to escape the uncanny divine.

The only thing that complicates Hazel's early vocation as a preacher is World War II, which he deems "a trick to lead him into temptation" (23). His "strong confidence 
in his power to resist evil" dissuades him from shooting his own foot, since he trusts himself "to get back in a few months, uncorrupted" (23). He plans to tell "anyone in the army who invites him to sin that he was from Eastrod, Tennessee, and that he meant to get back there and stay back there, that he was going to be a preacher of the gospel and that he wasn't going to have his soul damned by the government or by any foreign place it sent him to" (23). Although he takes with him his bible and his pious mother's glasses (which blur his sight but which he nevertheless always wears while reading scripture), these bulwarks fail to ward off the corrupting effects of war. He successfully resists an invitation to visit a brothel with his platoon, but is seduced by their mocking suggestion that he has no soul. No soul means no damnation, which in turn means no redeeming Christ. Nihilism thus offers an opportunity for Hazel to be rid of his soul without corruption, "to be converted to nothing instead of to evil" (24), thus denying the sacred.

Noticeably absent from the brief description of Hazel's military experience is destruction or death. Once converted to the nihilism provoked by war, however, he returns to America to discover his childhood home merely "the skeleton of a house" (26). When he finds his dead mother's chifforobe still in the abandoned house, he tapes a sign to it warning off thieves and observes that his mother "would rest easier in her grave, knowing it was guarded. If she came looking any time at night, she would see" (26). He visualises this maternal ghost entering the house "with that look on her face, unrested and looking; the same look he had seen through the crack in her coffin" (26). Like his other dead family members, Hazel's mother appeared strangely alive in her coffin, as though "she were going to spring up and shove the lid back and fly out and satisfy herself" (27). Hazel is haunted by this unsatisfied matriarch and while in the train which takes him from Eastrod to Taulkinham he dreams of her 
emerging from her coffin "like a huge bat." Despite her efforts to escape, however, the coffin lid falls "on top of her, closing down all the time." Hazel's vision of the coffin closing down upon his mother becomes a vision from inside the coffin, and he sees the lid "coming closer closer down and cutting off the light." When he wakes up, he once again mistakes the berth for a coffin and springs up "between the crack and wedged his head and shoulders through it and hung there, dizzy, with the dim light of the train slowly showing the rug below" (27).

In "Criticism and the Terror of Nothingness" Jason C. Lee highlights the attempts by O'Connor's characters to avoid a fearful destiny through self-recreation, which only leads them inevitably into the graves of their dead ancestors. Hazel's conversion to nihilism during the war involves a refutation of his vocation as a preacher and guarantees his haunting by death. Despite adopting a scornful attitude towards those he deems to hold conventional religious views, rudely informing a fellow passenger on the train that "If you've been redeemed ... I wouldn't want to be" (16), Hazel's need to deny Jesus sees him illogically stating that he would not believe in Him "even if He existed. Even if he was on this train" (16). O’Connor points out that although her protagonist is "such an admirable nihilist," Wise Blood is 'entirely Redemptioncentered in thought" (Habit 70). In fact, it is Hazel's nihilism that "leads him back to the fact of his redemption ... which is what he would have liked so much to get away from" (Habit 70). As much as Hazel longs to escape his sacred vocation, his calling remains insistent. In Taulkinham, a taxi driver immediately identifies him as a preacher despite Hazel's stubborn denials, insisting that, "You look like a preacher ... That hat looks like a preacher's hat" (31). It is not just Hazel's outfit, however, since the driver adds, "It's a look in your face somewheres [sic]" (31). When Hazel responds with the blunt rebuttal, "I don't believe in anything," the driver replies, 
"That's the trouble with you preachers ... You've all got too good to believe in anything" (32).

Hazel's attempt to rebel against his destiny is doomed to failure since his repeated assertions that he believes in nothing ultimately lead him back to what he attempts to deny. His blasphemy and violence are not profane but link him to the destructive aspect of the sacred. Hazel's previous commitment to avoiding sin in order to avoid Jesus suggests that his pursuit of $\sin$ in Taulkinham is a method of establishing contact with the threatening figure that lurks in the shadows of his mind. Upon arrival his very first action is to visit a prostitute in order to commit the very sin he has spent so many years studiously avoiding, and despite his overt denials of redemption Hazel is immediately compelled towards the preacher Asa Hawks, whose blindness is a selfinflicted proof of faith. Yet although Hawks' daughter Sabbath fervently distributes religious pamphlets, Hawks is more inclined to beg than preach. His refrain "Come on and give a nickel if you won't repent" (40) reveals the commodification of religion and his faith is eventually exposed as fraudulent. Although a charlatan, Hawks did once possess true faith and he recognises something similar in Hazel, observing that he "can hear the urge for Jesus in his voice" (50). Although apparently blind, Hawks can see enough to accurately diagnose Hazel and suggests that "Some preacher has left his mark on you ... Did you follow for me to take it off or give you another one?" (51).

Sabbath Hawks is similarly interested in Hazel's salvation and insists that "there's nothing for your pain but Jesus" (51). The seemingly random and grotesque story she regales him with is in fact a remarkably apt analogy for Hazel's position:

This here man and woman killed this little baby. It was her own child but it was ugly and she never give it any love. This child had Jesus and this woman didn't have nothing but good looks and a man she was living in sin with. She sent the child away and it came back and she sent it away again and it came back again 
and ever' [sic] time she sent it away, it came back to where she and this man was living in sin. They strangled it with a silk stocking and hung it up in the chimney. It didn't give her any peace after that, though. Everything she looked at was that child. Jesus made it beautiful to haunt her. She couldn't lie with that man without she saw it, staring through the chimney at her, shining through the brick in the middle of the night. (52)

Hazel's response to this Poe-like tale of the macabre is a quiet "My Jesus" (52). Like Christ, the child this woman attempts to banish gains power through death and becomes an inescapable and omniscient presence.

Hazel is haunted not only by the ragged figure of a redeeming Christ but by recurring signs that appear in the landscape to remind him of what he avoids. One such sign confronts him with: "WOE TO THE BLASPHEMER AND WHOREMONGER! WILL HELL SWALLOW YOU UP?" This doomsday message is then amended with smaller letters suggesting "Jesus saves" (75). When Hazel least expects it, he is confronted with 666 signs and yet another message, "which he saw and deliberately did not read", that re-iterates his mother's comment: "Jesus Died for YOU" (207). In order to combat these reminders Hazel embarks on a vigorous preaching mission promoting a church which defiantly excludes Jesus. Although Hawks warns, "You got eyes and see not, ears and hear not, but you'll have to see some time" (54), Hazel insists on the truth of what he preaches. He responds by asking, "Don't I have eyes in my head? Am I a blind man?" (55) and declares, "I don’t need Jesus ... What do I need with Jesus? I got Leora Watts" (56). Hazel's blasphemous replacement of Christ with a whore is not just part of a defiant rejection, but is also a comment on commodification. As a prostitute, Leora is reduced to an object available for purchase, and Hazel's conflation suggests a similar reduction and marketing of the sacred. The popular religion advertised by billboards and accessible via donation peddles a commodified Christ rendered secular and therefore profane. 
If buying a sexual experience is the same as purchasing a religious one it is not surprising that Hazel replaces both with yet another purchase. After his second night with Leora he wakes up with "only one thought in his head: he was going to buy a car" (67). So urgent is this need that "he didn't think of anything else" (67). Seemingly controlled by external forces, Hazel makes his way to a used car lot and knows as soon as he sees the "high rat-coloured" Essex that "This was the car he was going to buy" (69). This potent, particularly American, symbol of self-willed mobility symbolises the affluence and consumption of the postwar era, which saw cars become progressively bigger and superhighways stretch across the country. It is thus extremely ironic that the car Hazel is compelled to purchase is consistently described as "high rat-coloured" since the word "hieratic," which O'Connor is surely alluding to, can be translated as "priestly writing." Although Hazel intends to assert his freedom through the purchase of the car, his choice of automobile only reinforces his destined vocation. Hazel intends his new car to be a home, but soon discovers it to be an unheimlich space in which he suffers a nightmare of being "not dead only buried" (160).

Hazel's inability to escape his destiny is mirrored by Enoch Emery's inherited "wise blood." Enoch is convinced that this inherent or unconscious wisdom gifted to him by his father will lead him towards a fate he senses but does not know. Enoch is increasingly convinced his fate involves the shrunken man in the Taulkinham Museum, a mummy he interprets as a "mystery" sensed like "a terrible knowledge without any words to it" (81). Every day after his work guarding the gate of the zoo (perhaps an ironic reference to St Peter's possession of the keys to heaven), the apostle Enoch enacts a ritualised approach to the museum and his grotesque idol. He hides in the bushes at the swimming pool in order to spy on women; visits the milk 
bar where he insults the waitress; and then walks though the zoo to verbally abuse the animals. Like Hazel's reluctance to read the signs proclaiming "Jesus saves," Enoch shivers at the sight of the sign "MVSEVM" and is superstitiously afraid to repeat the word twice. The ritualised approach and strange solemnity of the dark hall filled with "coffin-like" (97) display cases contributes a sense of worship to Enoch's museum visits, but his lascivious spying and insults coupled with his compulsive repetition to Hazel of "I've got to show you this thing ... I got to show it to you, here, this afternoon. I got to" (86), suggests the profanity of his "mystery." When Hazel stands in front of the mummy's case to view what his new acquaintance is so obsessed with, he sees superimposed on his own reflection that of a grinning woman who stands behind him. Hazel "jerked back and he made a noise. It might have come from the man inside the case. In a second Enoch knew it had" (99).

The uncanny experience of seeing an alien face staring back from a reflective surface is further compounded by the mummy's face imposed on the faces of the woman and Hazel to create a weird triumvirate. Mummies troublingly combine the inanimate with something that is at the same time human; like Christ, the mummy is death disinterred, but unlike Christ the mummy lacks agency and redemptive power. In preaching the gospel of his new Church Without Christ, Hazel declares himself “member and preacher to that church where the blind don't see and the lame don't walk and what's dead stays that way. Ask me about that church and I'll tell you it's the church that the blood of Jesus don't foul with redemption" (105). This is a rational church devoid of mystery and miracle where the boundaries between the living and the dead remain inviolate. Yet Hazel's insistence on the exclusion of Christ from his church only reinforces the haunting presence of the sacred outside the limits he establishes to keep it at bay. 
Despite appearing profane, the Church Without Christ acts as a rational bulwark against the threats of the sacred, which only ensures Hazel's continuing connection with it. This explains why his preoccupation with excluding the sacred co-exists with an obsession with Hawks, who supposedly blinded himself for Christ. Hazel is disappointed not to receive "a secret welcome" from Hawks and wonders, "What kind of a preacher are you ... not to see if you can save my soul?’ (108). It is eventually revealed that Hawks lacked the faith to blind himself, which suggests that Hazel's ability to put lime into what Sabbath describes as eyes that "don't look like they see what he's looking at but they keep on looking" (109) reveals true religious faith.

The doubled relationship between the two preachers Hazel and Hawks is mirrored in the connection between Hazel and Enoch. Enoch experiences his new acquaintance as strangely familiar, an uncanniness which sees him become caught in involuntary repetition as he insists "I think I seen you sommers before" (57), "I seen you sommers before. I know I seen you sommers before” (58). Enoch's obsession with Hazel sees him become a sort of disciple to the Church Without Christ and when he hears Hazel preaching that the church needs a "new jesus" that is "all man, without blood to waste ... one that don't look like any other man" (140-1), he is convinced of his ability to provide this profane messiah.

Hazel's call for a "new jesus" makes sense of Enoch's prior actions which saw him ready his room for an event of which he had only a vague intuition. Led on by his wise blood, Enoch cleans his room and removes a painting of a moose wearing what he interprets as an irritating look of self-satisfaction. He senses "the time had come when something had to be done; he didn't know what was going to happen in his room, but when it happened, he didn't want to have the feeling that the moose was running it" (133). By removing the frame from this strangely animate painting, he 
effectively undresses the moose so that he can "only snicker and look at him out the corner of his eyes" (133). André Beikasten observes that O'Connor has "a weird gift for deadening people into things while quickening things into objects with a life of their own" (142), and Enoch even feels as though the "weary" chair in his room is somehow alive since it sits "as if this were the end of long years of inner struggle" (131). Enoch does not know whether the chair is "for him or against him" and experiences "a nasty impulse to kick it to pieces" (131).

O'Connor's ability to complicate descriptions of the inanimate by imbuing them with life is matched by her depictions of Enoch as increasingly animalistic. Controlled by instinct and a sense of impending destiny, Enoch helplessly complains, "I don't want to do it ... Whatever it is, I don't want to do it" (137). His ritualised approach to the museum each day and his mode of repetitive speech are symptoms of a compulsion to repeat, and as the novel progresses Enoch is rendered increasingly incapable of resisting his unconscious desires. When he passes a cinema displaying a poster of a monster stuffing a woman into an incinerator, despite his conscious assertion "I ain't going in" (138), he is unable to resist his buried impulses. The film he watches is a science fiction about a scientist named The Eye who performs gruesome operations by remote-control. Victims of these omniscient procedures wake up to discover slits in their chests or heads and "something you couldn't do without would be gone" (138). When Enoch emerges from this involuntary immersion in a world of remote controlled people and disembodied eyes he has completely submitted to his instinct and no longer thinks of "escaping his duty" (139). This duty is to steal the "new jesus" from the museum and in an act of profane worship install it in his washstand shrine. 
While Hawk's charlatanism co-exists with at least the remnants of faith, Wise Blood's other preacher, Hoover Shoates alias Onnie Jay Holy, displays little spiritual insight. Shoates strongly advocates the postwar marketing of religion and insists that "If you want to get anywheres in religion, you got to keep it sweet" (157). He listens to four of Hazel's sermons, prompting the founder of the Church Without Christ to think he finally has a disciple, but it soon becomes clear that Shoates' motivations are entirely financial. When Hazel's declaration that the "only way to truth is through blasphemy" (148) drives away his tiny audience, Shoates interrupts in order to lure back what he sees as escaping customers. Shoates pretends that Hazel's preaching has made him a "new man" and a crowd of people gather to hear him attribute a message of humanity's "natural sweetness" (152) to Hazel's church. Shoates explains that the church they supposedly advocate together is trustworthy because there is "nothing foreign" connected with it, a clear appeal to postwar suspicion of ideologies deemed alien. Displaying canny insight, Shoates assures his audience, "You don't have to believe nothing you don't understand and approve of. If you don't understand it, it ain't true, and that's all there is to it" (152). Hazel counters Shoates' message by insisting once more that "Blasphemy is the way to the truth" and when Shoates attempts to sell church membership for a dollar he fiercely shouts, "It don't cost you any money to know the truth! You can't know it for money!" (154). He rejects the businessman-preacher's suggestion that the "new jesus" is a good business idea that simply needs "a little promotion" (157), and when Hazel accuses him of being phony, Shoates reveals his dubious credentials by explaining, "I was on the radio for three years with a program that give real religious experiences to the whole family. Didn't you ever listen to it - called, Soulsease, a quarter hour of Mood, Melody, and Mentality?" (155). 
Hazel refuses to have anything to do with the diluted dogma peddled by Shoates, who is forced to hire a look-alike to perform the role of prophet in the renamed version of the Holy Church of Christ Without Christ. Hazel's attempts to avoid the sacred thus results in a return of the repressed through a series of doppelgangers mirroring his church and his own self. Taulkinham is filled with paired doubles - the two boys at the swimming pool, the two attendants at the car lot, the two policemen who locate Hazel after he has gone missing - which give the town "the air of a sinister funhouse where distorting images send mocking images of man back at himself" (Beikasten 42). Shoates' new institution confronts Hazel with a more accurately named version of his own church and his look-alike confronts him with the falsity of his own position. When a bystander asks Hazel whether he and Solace Layfield are twins, his response reveals his awareness of the threat posed by his doppelganger: "If you don't hunt it down and kill it, it'll hunt you down and kill you" (168). Solace Layfield and the Church of Christ Without Christ confront Hazel with his own false performance and propel him via violence into union with the sacred.

In "The Sandman" Hoffmann depicts optical instruments which paradoxically obscure vision, whereas Wise Blood suggests that spiritual insight relies on a certain sort of blindness. When Hazel stands before a mirror wearing his dead mother's spectacles, which are reserved for reading the bible and which he has not used since the war, the blurry image he makes out seems to reveal "his mother's face in his" (187). Before he can remove the glasses to banish this disquieting image, two more faces appear to merge with his own, recalling the triumvirate in the museum display case. Although he is four feet away from Sabbath and the mummy she is cradling, they seem to be "just under his eyes" (187). The glasses transform Hazel's perception of reality and facilitate his realisation that the "new jesus" is false. He snatches the 
shriveled body and throws it against the wall causing the mummy's head to pop open sending "the trash inside spraying out in a little cloud of dust" (188). By wearing the glasses of his devout mother, Hazel accesses the prophetic vision which reveals the far in the near and the near in the far. He claims that "what you see is the truth and I've seen it ... I've seen the only truth there is!" (189).

For Hazel and the reader too, the shrunken man is disquieting. Like a ghost, the mummified being's continuing existence after death obscurely suggests the ability of the dead to haunt the living. When Sabbath first examines the mummy she is struck by something familiar about it, and although "she had never known anyone who looked like him before ... there was something in him of everyone she had ever known" (185). This weird familiarity encourages Sabbath to view it as a sort of child, even going so far as to call it "cute" (185). When Hazel catches sight of Sabbath and her baby in the mirror he is not struck by the endearing potential of the mummy's "squinched" (185) face, but by a vision of merged identity where past meets present, where male meets female, and where the living meets the dead. This vision brings him face to face with a false idol he cannot tolerate. Although both the mummy and Christ are uncanny figures, one offers sanctifying blood and eternal life while the other offers only dust. The sacred transcends the limits of human perception by being human and divine, crucified and risen, singular and merged in the Holy Trinity. As much as Hazel has attempted to deny and avoid the uncanny sacred, he ultimately rejects the profane idol offered in its place.

Hazel's twisted double, however, is fully committed to the profane. After leaving the "new jesus" in Sabbath's care and unaware of Hazel's rejection, Enoch is convinced he will be rewarded for his services. Like any good American, Enoch wants "to better his condition until it was the best. He wanted to be THE young man 
of the future, like the ones in the insurance ads. He wanted, some day, to see a line of people waiting to shake his hand" (191). When he discovers that the film star Gonga, the Giant Jungle Monarch, is to visit cinemas around town in order to shake hands with his fans, he seems to represent the very success Enoch dreams of. Yet when he approaches this matinee idol he is met with a disturbing vision: an "ugly pair of human eyes" lie behind the celluloid ones and a surly voice inside the ape suit responds to Enoch's overtures by ordering, "You go to hell" (182). Although this insult is symptomatic of an overworked actor's frustration, it also acts as a literal condemnation of Enoch's profanity. His confidence in reward for his delivery of a new religious idol is subverted by this suggestion that his religious activities guarantee damnation.

Enoch's secular desire to be "THE young man of the future" (191) is subverted into an enactment of a past evolutionary stage revealing the errors of his chosen path. After assaulting Gonga and stealing his costume, Enoch's humanity is subsumed by the bestial as he steps into the gorilla suit and a "black heavier shaggier figure replaced his" (197). For a moment this strange figure has "two heads, one light and one dark, but after a second, it pulled the dark black head over the other" (197). This reverse evolution brings to mind Stevenson's famous recidivist nightmare in The Strange Case of Dr. Jekyll and Mr. Hyde. Enoch's desire to become the image he sees in advertising campaigns results in him losing his identity in the very clothing he believes will provide a culturally sanctioned role. Jon Lance Bacon observes that a 1952 symposium on mass culture published by the Partisan Review outlined a commonly held differentiation between regimentation of thought and regimentation of taste: the first being considered a foreign development linked to totalitarianism; while the second was a domestic development linked to affluence. In discussions about 
mass culture most intellectuals of the period made this distinction, and preferring the topic that was safer politically, 'the bogeyman of homogenized 'taste,' they neglected to criticise the modes of collective 'thought' enforced by American consumer culture" (Bacon 36). Enoch's weird reversion is unusual in that it not only suggests the threat to the soul of secular obsessions, but the threat to self posed by mass marketing and material consumption.

Taulkinham is overflowing with the material goods of rampant postwar consumption, including the religious doctrine peddled on the streets. The urge of its inhabitants to consume is so great that on certain nights shops have extended hours so "people could have an extra opportunity to see what was for sale" (29). The streets are lined with signs advertising "PEANUTS, WESTERN UNION, AJAX, TAXI, HOTEL, CANDY" (29), and O'Connor emphasises the threat posed by marketing and materialism when Enoch's tiny figure is dwarfed by an enormous Walgreen's display of “alarm clocks, toilet waters, candies, sanitary pads, fountain pens, and pocket flashlights, displayed in all colors to twice his height" (135). Material consumption is so pervasive that Taulkinham's shoppers are blind to signs suggesting the divine. Although the sky is "underpinned with long silver streaks that looked like scaffolding," behind which are "thousands of stars that all seemed to be moving very slowly as if they were about some vast construction work that involved the whole order of the universe and would take all time to complete" (37), the town's inhabitants are so distracted by signs of capitalism that signs of a divine architect are completely overlooked. The mindless consumption of material goods sees them become actual objects of worship: the potato peeler salesman delivers his spiel from a card table "altar" (38), and Enoch spends an hour of worship each day in the supermarket browsing the canned goods and reading the stories on cereal boxes. 
Mass marketing has become such a threat to personal identity that the waitress in the diner actually becomes part of an advertising display. The diner counter is pink and green marble linoleum and the waitress wears "a lime-colored uniform and a pink apron. She had green eyes set in pink and they resembled a picture behind her of a Lime-Cherry Surprise, a special that day for ten cents" (136). When Enoch cannot decide which flavour of soda to purchase, the waitress presents him with an already made Lime-Cherry Surprise which he is reluctant to drink. She then prepares a fresh Lime-Cherry Surprise and again attempts to force the daily special on her customer. This incorporation of self into the goods one sells was described in C. Wright Mills' White Collar (1951) when he pointed out that the one area of a salesgirl's occupational life in which she might have some freedom, the area of her own personality, "must now also be managed, must become the alert yet obsequious instrument by which goods are distributed." According to Mills, in the "normal course of her work, because her personality becomes the instrument of an alien purpose, the salesgirl becomes self-alienated" (qtd. in Bacon 124).

Similarly, Solace Layfield's role as salesman for the Holy Church of Christ Without Christ sees him lose his own identity to become a mere imitation of Hazel, who coldly informs his double prior to murdering him, "You ain't true" (203). When Hazel gets out of the Essex to look at Solace's crumpled body, "the man didn't look so much like Hazel, lying on the ground without his hat or suit on." "Two things I can't stand," Hazel tells his dying victim, "a man that ain't true and one that mocks what is" (204). Hazel's contempt of phoniness sees him eventually uncover the falseness of Asa Hawk's role of preacher blinded for faith. His desire to see "behind the black glasses" (145) that Hawks wears results in a strange episode recalling Poe's "The Tell Tale Heart," in which Hazel picks the lock to the preacher's room and 
silently creeps over to the bed where he sleeps. When Hazel carefully lights the match he hopes will spark a spiritual revelation, he discovers two open and sighted eyes staring back at him.

Following this discovery, Hazel begins to preach against conscience by claiming that it "doesn't exist though you may think it does" (166). By denying conscience, Hazel is able to commit the sins of fornication, blasphemy and murder which represent rebellion against Christ but which also guarantee Christ's benediction. After committing these sins and ridding himself of the profane idols of materialism (his automobile) and false religion (Solace Layfield and the shrunken man) Hazel experiences a metaphysical vision of a "blank, gray sky that went on, depth after depth, into space" (209). Following this prophetic vision, he returns to his boarding house and puts lime in his eyes, thus destroying his "I" or sense of self which prevents union with the sacred.

In Habit of Being, O'Connor notes that Hazel's rejection of the mummy "suggests everything" (404). What he has been looking for "with body and soul throughout the book is suddenly presented to him and he sees it has to be rejected, he sees it ain't really what he's looking for" (Habit 404). Hazel "is saved by virtue of having wise blood; it's too wise for him ultimately to deny Christ" (Habit 350). Hazel's conflict between self and other, between the physical eye of earthly reality and the spiritual vision of the sacred, is resolved through the depiction of a profound insight that is also profoundly disturbing. Through murder and self-mutilation Hazel destroys all the obstacles of the profane world to gain access to the sacred, and his empty eye sockets are a symbol of the new vision he has gained through kenosis, or self-emptying.

Hazel's landlady Mrs Flood is initially horrified by her tenant's disfigured face and refuses to allow him in the house, since "he wouldn't wear dark glasses and she didn't 
like to look at the mess he had made in his eye sockets" (213). Yet Hazel's mutilation soon inspires a fascination that co-exists with repulsion. If Mrs Flood does not "keep her mind going on something else when he was near her, she would find herself leaning forward, staring into his face, as if she expected to see something she hadn't seen before" (213). Like Hazel with Asa Hawks, she longs to see what is behind the darkness. Hazel's blindness is actually illuminating since as he points out, "If there's no bottom in your eyes, they hold more" (222).

While Hazel previously insisted on his spiritual cleanliness, explaining that "If Jesus existed, I wouldn't be clean" (91), by the end of the novel he admits his uncleanliness and submits to brutal mortification. Mrs Flood holds a series of oneway conversations with the strange figure that sits silently on her porch, because "If she didn't talk and keep her mind going, she would find herself sitting forward in her chair, looking at him with her mouth not closed. Anyone who saw her from the sidewalk would think she was being courted by a corpse” (217). Mrs Flood believes her weird tenant "could have been dead and get all he got out of life but the exercise. He might as well be one of them monks ... he might as well be in a monkery. She didn't understand it" (218). It is this mystery, as well as the lure of unspent government cheques, that provokes her growing obsession with Hazel and she eventually proposes marriage. Hazel's response is to abruptly leave the house and disappear, only to be discovered in a drainage ditch several days later. $\mathrm{He}$ insists to the police who discover him, "I want to go on where I'm going" (230), and go on he does. By the time he is returned to the boarding house, Hazel Motes is dead.

O'Connor defended her violent literary strategies by claiming her artistic vision involved a reasonable use of the unreasonable (Magee 39), which suggests that her grotesques are not as isolated from social concerns as they may at first appear. 
Although primarily engaged with spiritual issues, Wise Blood also deals with the fears that haunted postwar America, particularly in the South. Following the significant numbers of women who entered the workforce during World War II, ideals of femininity were increasingly called into question. This gender crisis occurred all over America, but the impact of these changes was felt especially in the South because of strongly entrenched notions of the Southern belle, whose virginity and chasteness seemed to safeguard the purity of white blood and against whose fragility a strong masculinity was constructed. The value of the Southern belle paradoxically relied on her physical body and her disembodiment; O'Connor's depictions of grotesque female physicality suggest a critique of this repressive discourse. Sarah Gleeson-White observes that O'Connor's female characters are defiantly physical, aggressively sexual, and often challenge notions of ideal feminine beauty and behaviour. Ill-fitting dental plates, mottled flesh, puffy figures and sickly hues of green and yellow are characteristic of the women in the novel.

Even women one might expect to be conventionally desirable, such as the prostitute Leora Watts, are described in terms close to repulsive. Leora's face is greasy and her teeth are speckled with green, while the woman Enoch ogles at the swimming pool has matted hair ranging in colour from deep rust to a greenish yellow. In Revising Flannery O'Connor: Southern Literary Culture and the Problem of Female Authorship, Katherine Hemple Prown argues that O'Connor started her literary career as a more feminist writer, or at least one more sympathetic to transgressive female sexuality, but soon suppressed this aspect of her writing to fit in with a literary culture dominated by New Criticism. The Wise Blood manuscripts were heavily revised to change or even eliminate the once central themes of abortion, rape, sexual exploitation of women, the limited job opportunities open to them and the 
potentially redemptive power of female sexuality. The repression of these overt themes leads to a potent return, which in terms of the revision of femininity finds expression in the freakishness of Wise Blood's female characters as well as their numerous unbidden appearances in reflective surfaces.

Although O'Connor's work displays little overt engagement with the racial issues so profoundly affecting the South during the early years of the Civil Rights Movement, there are several moments in Wise Blood that suggest she was more attuned to these issues than is immediately apparent. One remarkably strange aspect of Taulkinham is the complete absence of African Americans, an absence only accentuated by the completely unnecessary "whites only" bathroom at the train station. The only African American character in Wise Blood is the porter in the first few pages, who despite Hazel's claims of recognition insists he is from Chicago not the South. The car salesman Hazel purchases his Essex from tells him that all the African Americans of the town are living in Detroit "putting cars together" (71), prompting Susan Edmonds to argue in "Through a Glass Darkly: Visions of Integrated Community in Flannery O'Connor's Wise Blood" that the absence of an African American population in the novel is less an authorial oversight than an exaggerated tribute to the effects of the great migration.

It is also important to note the emphasis O'Connor puts on skin tones that seem to reveal a mixing of races: the porter is described as having a "yellow bald head" (11); while the "new jesus" whom Enoch describes as "a dead shriveled-up part-nigger dwarf" (176) is also "a dried yellow color" (98); and when Enoch sneaks into the museum to steal the mummy, he blacks his face with shoe polish "so that if he were seen in the act, he would be taken for a colored person" (174). The car salesman is profoundly disturbed by signs of racial integration and describes one African 
American in Detroit as "almost as light as you or me" (72). The classically Southern horror of miscegenation returns in the novel's episodes involving reflections, which present a racial mixing and gender confusion in which cohesive identity collapses. ${ }^{49}$

The uncanniness of Wise Blood relies on its reintegration of the destructive and impure aspects of the sacred omitted in popular postwar religion, but it also develops from the theological concept of mystery. In Christian theology, mystery is not something unknown or unknowable but is, according to O'Connor's favourite Old Testament scholar Claude Tresmontant, "the particular object of intelligence, its fullest nourishment. The mysterion is something so rich in intelligible content, so inexhaustibly full of delectation for the mind that no contemplation can ever reach its end. It is an eternal delectation of the mind" (qtd. in Wood 24). O'Connor suggests that "mystery isn't something that is gradually evaporating" but something that "grows along with knowledge" (Habit 489). This view of mystery mirrors the uncanny since according to the Greek orthodox bishop Kallistos Ware it "signifies not only hiddenness but disclosure." A mystery is something revealed for understanding but which can never be fully understood: "The eyes are closed - but they are also open" (Ware qtd. in Wood 24).

Hazel's blinded eyes, although sightless, are open upon the eternal delectation of the mysterious, which threatens the revelation of what is hidden. This unveiling inevitably threatens the destruction of the ego since the disclosure of mystery obliterates known certitudes. Hazel's hieratic Essex initially appears to function as the altar of a new religion also offering Hazel "a place to be that I can always get away in" (115), but the policeman who stops him perceptively suggests that "maybe you

\footnotetext{
${ }^{49}$ For a further discussion on this point, see Susan Edmonds, "Through a Glass Darkly: Visions of Integrated Community in Flannery O'Connor's Wise Blood," Contemporary Literature 37, no. 4 (Winter 1996): 559-85.
} 
better had get out ... I think you could see better if you was out" (208). The view Hazel is privy to following the destruction of his car reveals an emptiness so revelatory it causes his knees to buckle. O'Connor's God of annihilating yet redeeming transcendence is the very antithesis of the comforting figure of postwar consolation offering solace to anxious housewives and flannel-suited executives, and she had nothing but scorn for what she referred to as the "cult of reassurance" forming a congregation of people who "think faith is a big electric blanket" (Habit 354).

The commingling of nightmare and satire in Wise Blood creates what Frederick Asals identifies as a "deep doubleness" (49) within the novel. Its satirical elements depend upon the depiction of a rational fictional reality, but at the same time O'Connor's concept of the mysterion creates an equally strong sense of the irrational. This encouraged one reviewer to observe that "What the characters do does not seem real, but the town does", adding up to a sense of "deliberate unreality" which seems "to float over the surface of an ordinary Southern town" ("Frustrated Preacher," 114$5)$.

The uncanny is a powerful strategy for voicing what is ignored and O'Connor points out that in writing fiction "you both reveal and obscure the things you know best or feel most concerned about" (Mystery 41). She suggests that a writer who believes in mystery will create fiction always "pushing its own limits outward" because for this kind of writer the meaning of a story does not begin "except at a depth where adequate motivation and adequate psychology and the various determinations have been exhausted." Such a writer "will be interested in what we don't understand rather than in what we do" (Mystery 41). In fiction as in life, meaning lies not just in objective reality but in the hidden mysteries that await revelation. According to O'Connor, “it is what is left over after everything 
$-155-$

explainable has been explained that makes a story worth writing and reading" (qtd. in Friedman and Lewis 252), and it is "the business of the artist to reveal what haunts us" (qtd. in Fitzgerald 861). 


\section{$\mathrm{V}$}

\section{Dubious Reality and the Double:}

\section{Saul Bellow's The Victim}

... now we have the universe itself to face, without the comforts of community, without metaphysical certainty, without the power to distinguish the virtuous from the wicked man, surrounded by dubious realities and discovering dubious selves.

Saul Bellow, "Where Do We Go From Here?"

According to Arnold Jacob Wolf, Saul Bellow's Jewish heritage is often perceived as an "equivocal and somewhat mysterious" aspect of his identity (241), a perception encouraged both by Bellow's personal statements and interpretations of his fiction. Bellow consistently denied he was a "Jewish writer," preferring to identify himself as “an American, a Jew, a writer by trade" (qtd. in Wolf 242). This stance emphasises his American identity, important during the forties and fifties when integration was deemed highly desirable, while also protecting the author from anti-Semitism and his work from myopically "ethnic" interpretation. It also reveals something of Bellow's feelings about the Holocaust. His 1947 novel The Victim includes an opening epigraph depicting mass trauma, a title referring to individual suffering and a narrative revolving around anti-Semitism, yet despite the novel's depiction of pervasive dread and ethnic intolerance, and despite the fact that it appeared just two years after the end of World War II, the Holocaust is noticeable primarily through its absence. While Bellow's 1970 novel Sammler's Planet focuses on a Jewish protagonist whose war experience includes escaping from a pit of corpses and spending the war years hidden in a tomb, his 1947 novel resolutely avoids the trauma of the Final Solution. 
In a letter to Cynthia Ozick written in the late 1980s, Bellow expresses unease that while European Jews were suffering systematic extermination under the Nazi regime, he was "too busy becoming a novelist to take note of what was happening in the forties." He suggests,

It's perfectly true that "Jewish writers in America" (a repulsive category!) missed what should have been for them the central event of their time, the destruction of European Jewry. I can't say how our responsibility can be assessed. We (I speak of Jews now and not merely writers) should have reckoned more fully, more deeply with it. (qtd. in Wolf 243)

Like many intellectuals of the era who consistently blamed conformity for the ills of the age, Bellow argues that because "the mental life of the century" was "disfigured by the same forces of conformity that produced the Final Solution, there were no minds fit to comprehend" it (qtd. in Wolf 243). Whether or not conformity is to blame for the inability to comprehend the horror of the Holocaust, Bellow's suggestions provoke several questions. Why does he label Jewish writers in America "a repulsive category"? Is it the categorisation of individuals based on their ethnicity that he finds offensive or the qualities of the group so categorised? And what sort of responsibility could American writers of Jewish heritage claim for the fate of European Jews at the hands of the Nazi regime? Furthermore, since the Holocaust is precisely what American Jews have spent the past six decades reckoning with through literature, films, historical study, commemoration and education, which Bellow could hardly have been unaware of, his statement seems to point to a particular period in which the full implications of the Holocaust were avoided.

Bellow suggests his involvement with literature was so overwhelming during the 1940s that he was completely

given over to preoccupations with art, with language, with my struggle on the American scene, with claims for the recognition of my talent or, like my pals of the Partisan Review, with modernism, Marxism, New Criticism, with Eliot, Yeats, Proust, etc. - with anything except the terrible events in Poland. Growing 
slowly aware of this unspeakable evasion I didn't even know how to begin to admit it into my inner life. Not a particle of this can be denied. And can I really say - can anyone say - what was to be done, how this "thing" ought to have been met? (qtd. in Wolf 244)

Bellow's dilemma is not uncommon, for while the Holocaust is an atrocity that demands articulation, it remains something many believe unspeakable. The process of representing the Holocaust is fraught with both aesthetic and ethical difficulties. Elie Wiesel suggests that a Holocaust survivor will never entirely reveal their experience, that "Between our memory and its reflection there stands a wall that cannot be pierced" (7). Theodor Adorno's famous comment in "An Essay on Cultural Criticism and Society" about the barbarity of writing poetry after Auschwitz illustrates the perception of a seemingly unbridgeable gap between modes of representation before and after the Holocaust (Adorno 34).

In "Writing and the Holocaust" Irving Howe points out the dangers of aesthetics when he suggests that the representation of a horrific event, "especially if in drawing upon literary skills it achieves a certain graphic power, could serve to domesticate it, rendering it familiar and in some sense even tolerable" (180). Yet by attempting to directly represent the full extent of the horror, a writer risks transgressing taboo. There are "some things in our experience, or some aspects of the universe, that are too terrible to be looked at or into directly. In ancient mythologies there are things and beings that are not to be named" (Howe, "Holocaust" 181). It is worth pointing out, however, that taboo concerns things "not" to be named rather than those things that "cannot" be named, suggesting that the avoidance of direct representations of horror has just as much to do with ethics and social taste as it does with the perceived failure of language, all of which leaves the writer, as Galia Glasner-Heled points out, facing a double bind: "the use of familiar literary forms may 'shear away part of the horror' 
but extreme forms and explicit delineation of the horror transgress the aesthetic taboo against the direct representation of the unspeakable" (111).

These myriad difficulties have not prevented the creation of what might be termed a Holocaust industry in art, literature and film. What is surprising though, given the central place of the Holocaust in American culture since the mid-sixties, is the absence of Holocaust representations in the immediate postwar period. While it is understandable that significant time was required to cope with such unprecedented trauma, the silence regarding the Holocaust lasted significantly longer in America than it did in Europe where that trauma was experienced firsthand. Primo Levi, an Italian survivor of Auschwitz, published his first version of If This is a Man in 1948, later revising it for wider publication in 1956. Yehiel De-Nur, a Polish survivor who published his work under the pseudonym Ka-Tzetnik ("Concentration Camper"), published The House of Dolls in 1955. The first American representation of the Holocaust is generally agreed to be Edward Lewis Wallant's The Pawnbroker, which did not appear until 1961, closely followed by Daniel Stern's Who Shall Live, Who Shall Die in $1963 .{ }^{50}$

While it might be deduced that the Holocaust was a topic of major interest mainly to those who experienced it, i.e. European Jews, from the 1960s onwards the Holocaust has become a particularly American topic. Critics have identified the mass interest provoked by the televised trial of Adolf Eichmann in 1961 as breaking the American silence regarding the Holocaust, which led in turn to a flourishing in

\footnotetext{
${ }^{50}$ Although some critics point to John Hersey's The Wall (1950) as the first American Holocaust novel, it differs in form and focus from those that would follow and relates the building of the Warsaw ghetto and the wall that separated it from the rest of the city. Whether or not Hersey's novel is the first American Holocaust novel, there was little to follow until the sixties ushered in a new phase of Holocaust studies.
} 
American publishing on Holocaust topics. ${ }^{51}$ Critics such as Elizabeth Stephens also point to the Six Day War in 1967 as an event that accelerated the pace of cultural identification between Israel and America, consolidating a place in American culture for Jewish concerns. But even if we accept that Americans initially deemed the Holocaust a solely Jewish issue, this still does not explain the absence of the Holocaust in postwar literature, since America's Jewish population was far from insignificant. The importance of writers such as Bellow, Bernard Malamud, Mailer and Roth raises the question why the Holocaust was broached so rarely in literary and intellectual circles until two decades after its occurrence.

While the imperatives of the Cold War privileged discussion of present threats rather than those of the recent past, a large portion of blame must be attributed to rampant anti-Semitism. Sociologist David Reisman observed in 1942 that American anti-Semitism had been on the increase since the 1930s and had reached a level "slightly below the boiling point" by the time America entered World War II (qtd. in Wyman 9). The rising wave of American anti-Semitism in the 1920s and 1930s was led by respected figures such as the auto magnate Henry Ford, whose newspaper the Dearborn Michigan Independent published Ford's serialisation of the false antiSemitic Russian secret police creation, the Protocols of the Elders of Zion. Ford believed that World War I had been caused by German Jewish banking interests and American anti-Semitism was bolstered by fears generated by the Great Depression. Jews were scapegoated and directly affected when the Bank of the United States, of which almost all of its 400, 000 depositors were Jews, failed in 1930. From the start of the Depression and on into the years of World War II, more than one hundred antiSemitic organisations existed in America and during the war there was an epidemic of

\footnotetext{
${ }^{51}$ For a compelling account of Eichmann's trail see Haim Gouri, Facing the Glass Booth: The Jerusalem Trail of Adolf Eichmann (Detroit: Wayne State University Press, 2004).
} 
serious attacks against Jews, particularly in urban centres in the North East of America. Jewish cemeteries and synagogues were damaged and defaced with swastikas; anti-Semitic propaganda was distributed; even physical attacks occurred, mainly by juveniles against Jewish children. Yet as David S. Wyman points out, such overt attacks represented only the surface of the problem. Beneath the façade of a civilised population who would never deface a synagogue or attack a Jewish child there was a pervasive anti-Semitism that encouraged American Jews to downplay concerns specific to them and which also contributed to a lack of action regarding the plight of European Jews.

Paradoxically, liberal awareness of American anti-Semitism resulted in a strange lack of engagement with the horrific display of racial hatred that occurred in Europe. Laura Z. Hobson's Gentleman's Agreement (1947) illustrates something of the complex strategy by which literature avoided the Holocaust by focusing on the more manageable issue of domestic anti-Semitism. Hobson's protagonist is a widowed veteran newly hired as a journalist for a New York magazine, whose first assignment is to write a piece about anti-Semitism. Phil is less than enthusiastic about this topic, which turns out to have originated from his boss's niece Kathy who "carried on about how the big magazines were helping to spread it by staying off it except for bits here and there." Why "didn't somebody go after it the way they do taxes or strikes? Yell and scream and takes sides and fight?" (16). Phil is more concerned with issues associated with the Cold War. As he looks up at the Chrysler Tower, he wonders "whether an atomic bomb could really vaporize it out of existence" (10). He is surprised at the significance of World War II to his young son, whose chatter consists largely "of technical talk about firing power, flying range, rockets, radar" (31). He wonders whether he had "so lethal a vocabulary" at his son's age in 1917, whether he 
had been "so conscious of the other war?" (31). Phil blames the mass media - radio, magazines such as Life and Look, newsreels and comic books about "martial daredevils" - for this "incessant instruction in the very sounds and colors and sights of killing and dying" (31). But Phil is wrong to think that it is the sounds and sights of death that his son is bombarded with; in fact, his son's talk is concerned with the technical specifics of warfare rather than the human implications of mass violence.

Phil's disinterest in anti-Semitism stems from his awareness that it is not a topic capable of eliciting the mass interest he needs to advance his career. So rather than writing a regular exposé, he decides to use a more sensational approach and go undercover as a Jew, an idea which is met with enthusiasm by his boss and increasing dismay by his new love-interest, Kathy. Despite the series being her idea and despite her claims of tolerance, Kathy is reluctant for her family to think she is romantically involved with a Jew. While ostensibly about anti-Semitism, the novel uses the issue primarily as an obstacle in the creation of a new nuclear family, for as Phil becomes more obsessed with his work, the tensions between him and Kathy become more untenable.

Phil is increasingly disturbed at the anti-Semitism he discovers in America, but the novel's exploration of prejudice is strangely superficial, even at some points disconcerting. The anti-Semitism Phil's role-playing uncovers reveals discrimination in apartment rentals, country club memberships and upscale hotels, but does not involve exile, violence or genocide. When Phil peruses several books authored by Jewish writers he notices that in each of these novels "the central character, the Jew, was a heel - dishonest, scheming, or repulsive. A Goebbels, a Rankin might have written these books. But in each case a talented Jew had been the author. It was before the war that each had done it but he had done it" (55). The suggestion that the guilt for 
racial stereotypes lies at the hands of Jews themselves is particularly disturbing, not to mention rather devious. It allows readers (whose ostensible lack of prejudice might be a little too like Kathy's) to absolve themselves of blame. Hobson's musings on the "dark unconscious hatreds" that must have been operating in the Jewish authors to make them choose "these subjects" becomes uncomfortably racist when she has her mouthpiece exclaim, "How neurotic they themselves must have been made by the world of hatred!" (55).

Hobson's suggestion that Jewish writers bear some responsibility for the fate of European Jews overlooks centuries of persecution and exile. The anti-Semitism that Hobson (herself a Jew) explores is a reassuringly superficial one affecting which hotel Phil can secure a room in or in which tenement building he is welcome, and does not require the reader to engage seriously with a Jewish history of oppression. The novel's preoccupation with writing suggests that prejudice towards Jews is simply based on negative stereotypes which liberal reportage will eventually correct. Phil's public relations exercise does not delve into the horrors of anti-Semitism, it never involves physical violence or mass trauma, and it never refers to centuries of suffering at the hands of Gentiles. Instead it focuses on the social implications of anti-Semitism in the present and suggests it is a negotiable social issue. If good people such as Kathy and her parents appear to be marred by racial prejudice, ultimately this is a state of affairs that can be easily rectified. Kathy eventually redeems herself by allowing Phil's Jewish friend to rent her family's summer house in Connecticut, even though she fears the condemnation of her upstate social group, thus conquering antiSemitism, at least in Phil and Kathy's reassuringly liberal world. While Hobson's novel can be seen as an attempt to expose the evils of anti-Semitism, it does so in a way that completely sidesteps the implications of the Holocaust. Gentleman's 
Agreement allows readers to bemoan racial prejudice without confronting the horrors such beliefs engender and without confronting the implications of America's involvement, or lack of involvement, with the Holocaust.

When Hobson and Bellow speculate about the responsibility of American Jewish writers for the Holocaust, they ignore the very real responsibility both America and Britain bear for the fate of European Jews during World War II. Although authenticated information regarding the systematic murder of the Jewish population in Europe was made public in America in November 1942, political action was stalled by President Roosevelt for fourteen months. Assisting European Jews to flee persecution would have put pressure on Britain to open Palestine and America to receive more refugees, both unwanted repercussions. Anti-Semitism and antiimmigration attitudes were firmly entrenched in America, and coupled with the mass media's failure to fully publicise Holocaust information, there was little public pressure exerted to assist Europe's Jewish population.

In Buried by the Times, Laurel Leff notes that during the war the New York Times reported on Nazi atrocities in 1186 stories, but only twenty-six of these reached the front page, with a mere six identifying Jews as the primary victims of Nazi persecution. While all American newspapers minimised reporting on Jewish genocide, the silence of the New York Times is especially surprising given its focus on international issues and the fact that it was owned by Jews of German ancestry. According to Leff, the Times' publisher Arthur Hayes Sulzberger was eager to avoid Nazi charges that his paper was a "Jewish newspaper" and his own belief in cultural assimilation meant he was reluctant to focus on issues perceived as Jewish rather than American. Much reportage of the events in Europe during the war stressed Nazi terror against civilian populations in occupied countries and did not identify Jews as the 
main targets of persecution. Accounts of mass killings of hostages, executions of suspected anti-Nazis and other atrocities were regularly featured in newspapers and magazines, so that even when accounts appeared of specific Jewish massacres they tended to blend into a background of Nazi terror against all civilians.

When confirmed news of the Final Solution reached America in August 1942, it was several months before it was made public, since the State Department insisted on verifying the news. David S. Wyman points out that the focus of war reportage meant that many Americans were unaware of the extermination of Europe's Jews until well into 1944. Magazines such as Time, Newsweek and Life remained virtually silent on the topic, and it was not until the autumn of 1944 that Collier's magazine published an account written by Jan Karski detailing the ordeals suffered by Jews in Poland. Hollywood released numerous feature films on European refugees and on Nazi atrocities during the war, yet despite extensive Jewish influence in the film business, none of these dealt with the Final Solution.

Conflicting details, inconsistent numbers of victims and the fabricated atrocity stories of the First World War have all been suggested as contributing to editorial caution about reporting the Holocaust. Adding to these hesitations may have been credibility since the reports that found their way into America were unprecedented. Wyman suggests that for many publishers and broadcasters the extermination of the Jews made little sense since it served no conceivable practical purpose. The German explanation that Jews were being deported to labour camps seemed far more plausible. It was not until the liberation of the German concentration camps in 1945 that Americans were faced with the unavoidable proof that the stories were in fact true. The result was a complicated mesh of horror and guilt, which coupled with widespread anti-Semitism, resulted in silence regarding the Holocaust during the 
forties and fifties in America. Kurt Dittmar suggests that for many American writers of Jewish heritage, a complex "survivor's guilt" contributed to "the avoidance of immediate literary responses to the Jewish fate in Europe" (65), and he argues that Bellow's early fiction does not so much as omit the Holocaust as approach it obliquely.

Bellow's consternation over how to deal with the Holocaust explains something of the strangeness of the novel he published in its wake. Although the Holocaust is obscured in The Victim to such an extent that it is little wonder reviewers and critics generally miss its significance, the novel's plot revolves around the protagonist's haunting by an anti-Semitic double symptomatic of repressed fears about victimisation and persecution. ${ }^{52}$ Even more disconcerting than the depiction of the uncanny, however, is the protagonist's weird awareness of his role in an uncanny narrative. While the reader recognises The Victim as a doppelganger story in the tradition of Poe's “William Wilson” or Dostoevsky's The Double, we do not expect Bellow's protagonist to be similarly aware. From the moment Leventhal encounters Kirby Allbee, he is aware of an impending doom which only an awareness of Allbee as a double could engender. Leventhal registers Allbee as a reminder of unpleasant memories as well as a threat to identity; Allbee is both a rounded character in the realist tradition and a doppelganger in the tradition of psychological fantasy. Although The Victim seems to be a realist novel, Leventhal's sense of being in a doppelganger story renders the familiar conventions of realism uncomfortably strange.

The double is particularly prevalent in nineteenth-century fiction, where it acts as a figure illustrating the relationship between self and other. It also presents a threat to

\footnotetext{
${ }^{52}$ For an excellent and detailed discussion of the Holocaust's influence in Bellow's fiction see Lillian Kremer's “The Holocaust in The Victim," Saul Bellow Journal 2, no. 2 (1983): 15-23. Kremer discusses both The Victim and Mr Sammler's Planet and is one of few critics to argue for the symbolic and allusive presence of the Holocaust in the earlier novel.
} 
cohesive identity, often represents evil and usually acts as a harbinger of death. The chief characteristic of the double is its disruptive effect; as Andrew J. Webber notes, it represents the subject as "pathologically divided between reality and fantasy" (1). Almost all victims of the double exist in a paranoid state where the fear of an unbidden and uncontrollable return of the repressed is overwhelming. In Dostoevsky's The Double (1846) for example, Golyadkin's social awkwardness leads him to envision a persecuting double bearing his own name and likeness. Like Bellow's protagonist, Golyadkin exhibits classic symptoms of paranoia: he is highly suspicious of others; feels that he is being constantly observed and discussed; is hyper-sensitive, defensive and antagonistic. Golyadkin is a classic example of persecution mania, where sufferers believe that they are being poisoned, spied upon, or are the victims of plots or conspiracies, a mania which takes on a whole new meaning when aligned with Bellow's protagonist and an unprecedented historical example of racial persecution. ${ }^{53}$

Irving Howe's suggestion that the novel "be read as a fable concerning the difficulties of attempting a secure moral judgement in our day" (qtd. in Trachtenberg 34) has been continually reiterated during decades of critical analysis which attempt to universalise the nature of Bellow's theme of victimisation. In 1948, Leslie Fiedler attempted to cast Leventhal as a Jew both particularized and universal, suggesting his affinities with Leopold Bloom. The same year, Martin Greenberg argued that The Victim was the first American novel to see Jewishness not in terms of its singularity but as the quality of modernity itself. ${ }^{54}$ In 1990, Ellen Pifer suggests that both the

\footnotetext{
${ }^{53}$ For a discussion of persecution mania in The Victim see Helge N. Nilsen, "Anti-Semitism and Persecution Complex: A Comment of Saul Bellow's The Victim,” English Studies 60, no. 2 (1979): 183-91.

54 In 1963, Malcolm Bradbury cast Leventhal as a typical Bellow hero - an intellectual unsure of his own nature and worried about his obligations towards his fellowman - and traced the protagonist's moral development through anarchy to social complicity. Jonathon Baumbach focuses on the
} 
Jewish and Gentile protagonists fear being victimised "either by the random forces of a chaotic universe or by a conspiracy that has singled him out for punishment" (49), but what exactly this conspiracy might be Pifer does not say. Jeanne Braham interprets the novel as a move away from specific social relations to more metaphysical questions and suggests that the Jewish protagonist "is forced to confront the nature of evil within himself, the nature of obligations to his fellowman, the individual's inability to remain an "isolatoe"" (42). For Braham, the meaning of the novel relies not on "a victim-victimizer mirror reflecting Jewish-Gentile relations in New York, but on the levels of evil present in us all" (42).

In 1953, Norman Podhoretz suggested that The Victim is "marred by its failure to relate Leventhal's anxiety to the world outside" (379), a failure which is symptomatic of repression and which has resulted in the Holocaust's relevance to the novel being overlooked. The protagonist does express fear of racial persecution, but his only reference to the Holocaust is the anguished query: "Millions of us have been killed. What about that?" (131). While the universality of the novel is incontestable, its title, the dynamic between Jewish and Gentile identities, and the epigraphs all point to an interpretation linking the claustrophobic atmosphere, pervasive guilt, simmering violence and images of suffocating heat to the specific historical example of victimisation that occurred during World War II.

relationship between Leventhal and Allbee and argues for its redemptive implications as Leventhal learns compassion; Allan Chavkin compares The Victim with Dostoyevsky's The Brothers Karamazov and suggests that both novels share the theme of responsibility to accidental suffering; and Ada Aharoni explores the universal metaphysical issue as to whether an individual's fate is chosen or determined. See Leslie Fiedler, "The Fate of the Novel," Kenyon Review 10, no. 3 (1948): 519-27; Martin Greenberg, "Modern Man as Jew," Commentary (January 1948): 86-7; Malcolm Bradbury, "Saul Bellow's The Victim," Critical Quarterly 5, no. 2 (1963): 119-28; Jonathon Baumbach, "The Double Vision: The Victim by Saul Bellow," The Landscape of Nightmare: Studies in the Contemporary American Novel, ed. Jonathon Baumbach (New York: New York University Press, 1965): 35-54; Allan Chavkin, "Ivan Karamazov's Rebellion and Bellow's The Victim," Papers on Language and Literature: A Journal for Scholars and Critics of Language and Literature 16, no. 3 (1980): 316-20; and Ada Aharoni, “The Victim: Freedom of Choice," Saul Bellow Journal 4, no. 1 (1985): 33-44. 
The Victim begins with two epigraphs which have frequently been used by critics to identify its universal concerns regarding responsibility, but nevertheless, the second epigraph from De Quincy suggests a mass trauma that demands attention yet defies containment:

Be that as it may, now it was that upon the rocking waters of the ocean the human face began to reveal itself; the sea appeared paved with innumerable faces, upturned to the heavens; faces, imploring, wrathful, despairing; faces that surged upward by thousands, by myriads, by generations...

As Kimberly Rostan points out, "one of the most strenuous undertakings in twentiethcentury literature and criticism has been the attempt to engage ethically with collective trauma" (172). The difficulty inherent in representing collective trauma is that it stages a confrontation between the ordinary and the extraordinary while taming the extraordinary into a collective generalised experience. William Styron, the author of Sophie's Choice (1979), was troubled by reading Holocaust literature because while it was "so terribly sincere, most of these novels and non-fictional accounts were so close to the event - in the way they described things - that they suffocated the reader with a sense of horror" (qtd. in Kakutani 1). To avoid this horror, Annette Insdorf suggests that artists can either deal with the Holocaust through utter simplicity or use extreme stylisation providing distance through aesthetic innovation. The Victim reveals a third strategy, an oblique approach in which the return of the repressed unites the ordinary with the extraordinary, provoking discomfort in the reader while controlling anxiety within manageable levels. Although this approach tends to obscure issues of collective trauma to the point of invisibility, Bellow's novel can be seen as the first American attempt to negotiate the fraught realm of Holocaust literature.

The Victim is defined by a sense of claustrophobic entrapment which extends from Leventhal's imprisonment in the sweltering city and his airless apartment to the 
reader's resulting confinement in an unusually limited series of fictional spaces. Leventhal walks the same streets, dines in the same stuffy restaurant, crams himself into hot subway carriages, traverses the same route from Manhattan to Staten Island and works all day in the same oppressive office. The episode when he shows his nephew the sights of the city is a rare moment of spatial expansiveness which soon narrows down again when the duo retreat to a darkened cinema. The trip to the zoo, which should provide relief from the unnatural closeness of the fictional surroundings, is made uncomfortable by Leventhal's constant sense of being observed by his double. His fear of the gaze is an extension of the sense of being immolated in a stifling and airless environment, creating an anxiety linked not just to physical discomfort but to psychic dread.

Despite the fact that New York is Leventhal's hometown, its familiarity is distorted by the summer heat wave. The "whole continent seems to have moved from its place and slid nearer the equator, the bitter gray Atlantic to have become green and tropical, and the people, thronging the streets, barbaric fellahin among stupendous monuments of their mystery" (1). This once-familiar space has become so strange that the first time we meet Leventhal he is almost missing his usual subway stop. When he finally recognises it and shouts to the conductor, he must physically struggle through the door of the carriage which is already sliding shut. The train departs and Leventhal, "breathing hard, stared after it, cursing, and then turned and descended to the street" (1). His workplace is also antagonistic; when he is forced to leave the office unexpectedly to attend to his frantic sister-in-law, he overhears an anti-Semitic remark made by his boss. In response to Leventhal's abrupt absence, which he neglects to explain is because of his nephew's sudden illness, Mr Beard suggests that his 
employee "Takes unfair advantage ... Like the rest of his brethren. I've never known one who wouldn't. Always please themselves first” (3).

With both his wife and brother temporarily out of town, Leventhal is isolated without his usual support systems and loaded with increased responsibility. One responsibility he particularly resents is his sister-in-law Elena, his dislike of whom is couched in distinctly ethnic terms. Yet coupled with the distrust provoked by Elena's Italian Catholic heritage is a more obscure sense of her uncanniness. When Leventhal arrives at her apartment following her plea for assistance, he discovers her in a state of extreme anxiety: her eyes are "altogether too bright and too liquid; there was a superfluous energy in her movements, a suggestion of distraction or even madness not very securely held in check" (5). Leventhal's suspicion of Elena's barely checked madness is countered by his awareness that he is "too susceptible to such suggestions" (5), but when she tells him that her youngest son stopped breathing and then later revived Leventhal's composure wavers and becomes "tinged with fear." "What superstition!" he thinks, "Just like in the old country. The dead can come back to life, too, I suppose, and all the rest of it" (6). Yet as much as Leventhal attempts to scoff at Elena's suggestion, hints of madness, superstition and the reanimation of the dead affect him so much that he loses his temper. After snapping, "Don't be such a peasant," he is "annoyed with himself for being so vehement, but everything here oppressed him - the house, his sister-in-law, the sick child" (8).

Sickness, madness and death are particularly worrying for Leventhal, and the supernatural suggestion that his nephew returned from the dead combined with the perceived markers of insanity behind his sister-in-law's eyes remind him of his own mother, who died in an insane asylum when he was eight years old. Leventhal's mother's illness is a dark secret in his family history and he is almost an adult before 
he learns the truth about her abrupt disappearance. It is the fear of madness, particularly the fear that madness may lurk somewhere within himself, that informs Leventhal's relationship with Elena as well as the subsequent events of the novel's story. Haunted by madness and death, it is only when Leventhal's wife Mary leaves town, deserting him as his mother did, that he is vulnerable to the threats he has so far kept at bay. Mary's departure transforms a safe domestic realm into a suddenly unfamiliar and dangerous environment, making possible the entrance of a doppelganger who confronts Leventhal with all he attempts to avoid.

Leventhal is a neurotic man plagued by feelings of guilt and fear, and convinced his good luck is undeserved. In his youth he made several mistakes in judgement that led to his unemployment during the Depression and his initial engagement with Mary, a match he deems significantly above what he deserves, was broken off for several years after she confessed her unresolved feelings for a married man. After a period of destitution, loneliness and menial employment, Leventhal eventually secures a good job and is reconciled with Mary thus avoiding the doom he seems destined for. $\mathrm{He}$ remains aware of the fact that "I was lucky. I got away with it" and acknowledges that "the things that might have wrecked him, had somehow combined to establish him. He had almost fallen in with that part of humanity of which he was frequently mindful ... the part that did not get away with it - the lost, the outcast, the overcome, the effaced, the ruined" (16). Although grateful for his escape, Leventhal struggles to understand the forces that dictate one person's luck and not another's. His consternation as to what forces determine an individual's fate are clearly aligned with social success and personal happiness in the postwar era, but Leventhal's anxiety about anti-Semitism suggests this confusion is related to another far more troubling issue: why is one Jew spared the fate of six million others? 
While critics are correct in pointing out the universality of the novel's themes of victimisation and responsibility, it is also true that the years prior to the novel's publication had seen these themes acted out on an unprecedented scale. Leventhal's feelings of confusion, guilt and anxiety arise during the immediate postwar years when the full extent of the Holocaust was becoming known, and his experience of the suffocating city is repeatedly described in terms of heat, fire and gas. When Leventhal looks at a sunset it resembles "the flame at the back of a vast baker's oven" (18), and following a particularly nasty encounter with Allbee involving anti-Semitic opinions, Leventhal crosses the street only to be caught in "the blink of a yellow light" as an "eddy of exhaust gas caught him in the face" (132).

The threat posed by weirdly oven-like environments continues in the protagonist's own apartment, which Mary's absence and the summer heat have turned into an airless prison. When he returns home after attending Elena, Leventhal is thrilled by the ring of the doorbell since he thinks someone has "come to keep him company" (19). This is partly true, but in a far more sinister way than Leventhal wishes, since the ring announces the arrival of a presence which will radically transform his life. He opens the door but no one is there, so he lies down to take a nap. Suddenly he finds himself standing at the window clutching the curtain and although he is under the impression that he has slept, the clock insists that only five minutes have passed. Disoriented both spatially and temporally in an increasingly unfamiliar domestic space, the very divisions between waking life and dreaming suddenly become confused. Leventhal's first thought is "No, I shouldn't have gone" and he is "suddenly full of misgivings", realising that "it was a mistake to run out of the office like that" (19). 
Leventhal's anxieties are clearly professional, but the fact that his misgivings arise at the moment his double appears (the reader soon learns it was Allbee ringing the doorbell) suggests a return of the repressed. The comments made by his boss indicate no professional repercussions for Leventhal's absence but illuminate the buried hatreds he longs to avoid. The pressure of keeping this knowledge out of his conscious mind sees Leventhal increasingly concerned for his mental health. While the fact that no one is at the door is strange, what really concerns him is "that perhaps his nerves were to blame and that he had imagined the ring just as he had imagined that he had slept" (20). Since Mary's departure Leventhal acknowledges that his nerves have been "unsteady" (21). He has developed a new habit of keeping the bathroom light burning all night, and "somewhat ashamed of himself, he had yesterday closed the bathroom door before getting into bed, but he had left the light on." He realises that "this feeling that he was threatened by something while he slept" is absurd, but he is helpless to counter it. Furthermore, he is especially worried by his hallucinations of mice darting along the walls. Although he professes no dread of these creatures, he has begun "to jerk his head around at the suspicion of a movement." Adding his unusual insomnia to this list of neurotic symptoms, Leventhal concludes he might be "unwell" (21).

Leventhal has been stripped of all the familiar elements that construct his sense of reality: he is denied the reassuring presence of his wife; his environment is increasing strange; and even his own thought processes are becoming unhinged. When he decides to leave the apartment for a walk in his local park, Leventhal's desire for the solace of familiarity is thwarted by a sense of strangeness. People seem to be looking at each other "as though in the dark heat some interspace of reserve had been crossed and strangers might approach one another with a kind of recognition" (22). This 
interspace renders Leventhal vulnerable to an intimate approach by what is other and he is suddenly aware of being "not merely looked at but watched." As he queues for the water fountain he becomes convinced that a man is "scrutinizing him, pacing slowly with him as the line moved." Leventhal automatically assumes this recognition poses a threat and squares himself resolutely. Nevertheless, there is a tremor in his arms and "during all of it he felt that he himself was the cause of his agitation and suspicion, with his unreliable nerves. Then in astonishment he heard the stranger utter his name" (22).

The manifestation of this figure in an environment once familiar confronts Leventhal with his own repressed fears as well as the return of a buried past. The stranger is in fact Kirby Allbee, an old acquaintance whom Leventhal admits to disliking, but about whom he also insists "he had never really thought much about" (23). Yet despite this assertion, he immediately recollects the man and wonders why, with his "poor memory for names," the man's name "came to him so readily?" Leventhal attempts to assert the man's insignificance, but at the same time points out how readily the man's name comes to his lips and how he "recognized him in a moment." "What a box, the mind," Leventhal thinks, "You'd just as soon expect hair to grow in your hand as some of the things that come out of it" (23). This grotesque image recalls Kristeva's notions of the abject and is symptomatic of Leventhal's deep distrust of his own psyche. The fact that hairy palms are popularly said to be the result of masturbation also suggests some sort of sexual repression. Allbee's lingering presence manifests various fears that Leventhal attempts to repress but which stage a haunting return.

Allbee and Leventhal met at a party several years previous where an inebriated Allbee made some mildly offensive anti-Semitic remarks. Leventhal is 
understandably repelled but nevertheless petitions Allbee to arrange a job interview for him with his employer, which takes place during a particularly trying period of Leventhal's life when he is unemployed, completely reliant on friends and increasingly frustrated. Leventhal reacts angrily when he is treated rudely at the arranged interview and Allbee's employer becomes convinced that the abuse has been orchestrated between the two men. Consequently, Allbee loses his job and begins to drink heavily, his wife leaves him and is killed in an automobile accident soon after. Like his paranoid employer, Allbee comes to believe that Leventhal's outburst reveals a sinister intent and returns to accuse him of purposefully planning the disastrous interview as revenge against the anti-Semitic remarks. The seeming coincidence of their meeting turns out to actually be planned; Allbee reveals it was he who rang Leventhal's doorbell as he delivered a letter requesting a meeting in the park at that very hour. Although Leventhal never received the letter, he weirdly manages to turn up at the assigned place at the assigned time.

John Jacob Clayton contends that "Allbee is the anti-Semite Leventhal needs to justify his sense of persecution and feed his guilt, while Leventhal is the persecutor Allbee needs to be able to believe that not he but the world is responsible for his fall" (143). But Allbee is more than that: he serves as a disturbing reminder of the disastrous interview and confronts Leventhal with the denied possibility that Allbee's accusation is true, that he did, perhaps unconsciously, behave badly to exact revenge. Sitting next to Allbee on a park bench, Leventhal suddenly feels he has been "singled out to be the object of some freakish, insane process, and for an instant he was filled with dread" (26). Caught between a guilt he acknowledges and one he does not, Leventhal admits misgivings about his undeserved luck but is unable to explore his responsibility for Allbee's fate. 
Consequently, Leventhal attempts to invalidate Allbee's claims by deeming him irrational, if not insane. Leventhal wonders whether "this queer, beaten, probably suffering Allbee was in control of his actions" and he imagines the other man's life with remarkable ease:

down and out, living in a moldy hotel somewhere, hanging out in bars, sleeping whole days, picked up off the streets by the paddywagon or the ambulance, haunted in his mind by wrongs or faults of his own which he turned into wrongs against himself; and that stirring around of the thoughts and feelings, that churning - everybody experienced it, but for a man like that it must be ugly, terrible, those thoughts wheeling around. (32)

It is "something like this" (32) that Leventhal thinks of when he occasionally admits "he had gotten away with it" (33), and the ease with which he imagines Allbee's destitute life and resentful emotions relies on the fact that they are his own. The one job Leventhal could obtain during his period of hard luck was as a clerk in a Bowery flophouse and his anger towards his friends at their attempts to help is similar to the hostility he attributes to Allbee.

Another way that Leventhal avoids acknowledging his past is by suggesting that it was not really him in the interview with Allbee's boss. His initial expansive confidence in speaking with Rudiger was "so radically unusual" that "it was like a seizure or possession, and he said things which his memory, limited by what was habitual, could not retain ... He shrank from the recollection as from a moment of insanity" (39). This moment of madness sees Leventhal act out against a powerful figure of authority and after coming to his senses he becomes terrified that Rudiger will have him blacklisted. Leventhal's friend and benefactor Harkavy attempts to reassure him that these particularly postwar fears are groundless, saying, "don't get ideas like that into your head. He can’t persecute you" (40). Harkavy also warns Leventhal to "be careful" (40) of his tendency to imagine persecution, which is linked 
to the legacy of anti-Semitism as well as to the developing Cold War environment of subterfuge, betrayal and blacklisting.

In addition to this socio-political context is the sense that Leventhal's persecution mania relies on his own tendency to persecute. His musings on the mechanisms of hate recall the instant dislike he feels for Allbee, which although understandable, occurs before he has any real opportunity to know him. Leventhal is profoundly aware that "People met you once or twice and they hated you ... You had only to be yourself to provoke them" (71). He even believes that "If they still believed it would work, they would make little dolls of wax and stick pins into them" (71).

Leventhal's defensive attacks in the face of imagined persecution render people and the environment menacing forces. The towers on the Jersey shoreline seem "scorched, smoky, gray" and the "notion brushed Leventhal's mind that the light over them and over the water was akin to the yellow revealed in the slit of the eye of a wild animal" (44). The oven-like aspect of the barbaric and menacing urban environment is combined with the repetitive use of the colour yellow, recalling the yellow Stars of David imposed upon Jewish populations in Nazi Europe. Although Leventhal associates this colour with what is animalistic, he also admits that the predatory threat it stands for is "implanted in every human being too" (45).

Leventhal's dread about what lies beneath seems to stem from his mother's insanity. He remembers her "abstracted" expression, describing it as "a familiar face ... yet without anything in it directed toward him. He dreaded it; he dreaded the manifestation of anything resembling it in himself" (46). Unlike the protagonists in popular novels and films such as The Three Faces of Eve and Spellbound, Leventhal does not take refuge in the therapist's office to have the mysteries of his psyche reassuringly laid bare. For Bellow's protagonist, the mind remains a profoundly 
disturbing mystery. Yet despite his conviction that Allbee is deranged, Leventhal increasingly allows himself to be drawn into a relationship with him. The intimacy that develops between the two men becomes increasingly weird as the novel progresses until the two men cease to maintain the cohesion of their previous identities. When Allbee dismisses Leventhal's assertion that he too knows something of destitution, Leventhal is confronted with

the most horrible images of men wearily sitting on mission benches waiting for their coffee in a smeared and bleary winter sun; of flophouse sheets and filthy pillows; hideous cardboard cubicles painted to resemble wood, even the tungsten in the bulb like little burning worms that seemed to eat up rather than give light. Better to be in the dark. He had seen such places. He could still smell the carbolic disinfectant. And if that was his flesh on those sheets, his lips drinking that coffee, his back and thighs in that winter sun, his eyes looking at the boards of the floor...? (61)

Somehow it is Leventhal living this destitute life, just as the death of Allbee's wife provokes fears for Mary's safety. When Leventhal learns about Allbee's loss, his sympathy is matched by the thought, "She was much too good for him, much too good" (66). Although Leventhal wonders why he has such an ungenerous thought, it is clear that his connection with Allbee involves the mirroring of doubles. Leventhal is constantly putting himself in the other man's shoes, feeling himself in Allbee's environment and projecting his own feelings regarding his marriage onto Allbee's. Leventhal feels himself “come nearer" to Allbee after hearing about his wife's fate, nearer "to something clear, familiar, and truthful in him." Yet this feeling soon passes and Leventhal is "repelled again. He wondered whether Allbee was not actually a little drunk" (66).

Leventhal is constantly oscillating between feelings of sympathy and antipathy for Allbee, between physical repulsion and physical intimacy. As he studies Allbee by the light of a lamp, the skin of his forehead appears wet "and that of his jaw and throat was creased in a way that made Leventhal think of gills ... for an instant he was no 
more human to him than a fish or crab or any fleshy thing in the water" (68). Precisely at a moment when Leventhal begins to recognise Allbee's humanity, images arise in his mind of animals deemed unclean by Judaic law. Allbee's resemblance to a fish dehumanises him and his association with crabs and mice renders him repulsively impure. This moment causes Leventhal's sense of reality to be torn asunder in a particularly domestic way: "Suddenly he twisted about and his heart sprang. He thought he had seen a mouse dart into the corner and he hurried after it, lit a match, and examined the molding. There was no hole" (68).

Leventhal's fears regarding the mice that threaten to appear at moments when his double approaches or is present invite connection with Nazi propaganda casting Jews as vermin. The 1940 anti-Semitic German film Der ewige Jude (The Eternal Jew) opens with an image of a pack of rats emerging from a sewer, which is then juxtaposed with a crowd of Jews as the narration explains that rats are the vermin of the animal kingdom and Jews are the vermin of the human race. An anonymous review of Der ewige Jude published in Unser Wille und Weg, the Nazi Party's monthly for propagandists, was subtitled "The Film of a 2000-Year Rat Migration" and suggested that "Just like rats, the Jews 2000 years ago moved from the Middle East to Egypt, at that time a flourishing land" ("Eternal Jew" 54). Leventhal's assumption that the vermin he imagines infesting his home are mice rather than rats is symptomatic of his tendency to avoid or minimise what is disturbing.

In another disconcerting moment, Leventhal becomes convinced he is being observed and is "so conscious of Allbee, so certain he was being scrutinized, that he was able to see himself as if through a strange pair of eyes: the side of his face, the palpitation in his throat, the seams of his skin, the shape of his body and of his feet in their white shoes" (95). Transformed into his own observer, Leventhal is also able to 
see Albee "and imagined himself standing so near behind him that he could see the weave of his coat, his raggedly overgrown neck, the bulge of his cheek, the color of the blood in his ear; he could even evoke the odor of his hair and skin." The "acuteness and intimateness" of this vision astounds, oppresses and intoxicates Leventhal and for a moment the sun deprives him of "his sense of the usual look of things" (95).

Leventhal's struggle with his double is not helped by his friend Williston's belief that he is in fact partially responsible for Allbee's predicament. Despite Williston never even implying it, Leventhal immediately associates his stance with anti-Semitic persecution and angrily claims, "You think that he burned me up and I wanted to get him in bad. Why? Because I'm a Jew; Jews are touchy, and if you hurt them they won't forgive you. That's the pound of flesh" (103). Leventhal is willing to "accept the blame for losing his head at Dill's" (107), but he remains unable to face the reasons why he might have done so. Rather than admitting even the possibility that it was unconscious revenge, Leventhal suggests that he had begun to fear "that the lowest price he put on himself was too high" (107) and that Rudiger's treatment made him believe what he was afraid of. He reacts bitterly to what he perceives to be Williston's lack of empathy and suggests that "another man's words and looks" could never convert Williston into "his own worst enemy. He did not have to worry about that" (107). Leventhal's fear of the gaze is clearly linked to a threat posed to him because of his Jewish identity, a threat his Gentile friend does not have to cope with. Leventhal suspects that Williston's opinion stems from "an influence against which he could not help himself" (81). If his friend is ready to believe that Leventhal is "such and such a person - why avoid saying it? - that he would carry out a scheme like that because he was a Jew, then the turn he always feared had come and all good 
luck was cancelled and all favors melted away.” Leventhal sees himself and Williston as "carried on currents, this way and that. The currents had taken a new twist, and he was being hurried, hurried. His heart shrank and he felt faint for a moment and shut his eyes" (81).

Leventhal's growing awareness of the precarious nature of reality and the currents of evil that run beneath the surface world of friendship and favour sees his domestic realm become disquieting, with banal objects like kitchen appliances suddenly seeming menacing. He is kept awake at night by the noise of the refrigerator shuddering and rocking, and even his respectable neighbourhood seems to be transforming before his very eyes. He wakes up one morning to witness two women and two soldiers being harassed by a man Leventhal imagines to be one of the women's husbands. This revelation of polite society's illicit underbelly has a profound effect on Leventhal, who keeps thinking about it "with the feeling that he did not really know what went on about him, what strange things, savage things" (84). Hidden threat hangs near him all the time "in trembling drops, invisible, usually, or seen from a distance" and Leventhal realises that although this distant savagery is disturbing, far worse is his knowledge that there was not always to be a distance, that there is no reason why "sooner or later one or two of the drops might not fall on him." This frightening thought leads inevitably to Allbee, and Leventhal is "not sure that he had stopped spying on him - and with the thought came a faint sick qualm" (84).

Leventhal's attempts to avoid disturbing realities are confounded by Allbee who reminds him that "there's no denying that evil is as real as sunshine" (130). When Leventhal calls the hospital to enquire about his nephew's condition, he wonders how the girls at the switchboard could be expected to know anything but "the bare facts about each patient - whether he was dead or alive, that is?" (122). The word "dead" is 
immediately ominous "and he made haste to get rid of it, simultaneously realizing, in another part of his mind, how superstitious he was becoming. All he meant was that the hospital was too vast, and suddenly he had to erase an incidental word" (122). It is not an incidental word, however, but one representing the dark mystery beneath life. As much as Leventhal longs to "get rid of" and "erase" what is disturbing, Allbee's haunting pursuit and the anti-Semitism he embodies allow him no peace.

Allbee claims to be a descendent of Governor Winthrop and tries to make Leventhal imagine how New York affects him, since "It's really as if the children of Caliban were running everything" (129). He suggests that

you people take care of yourselves before everything. You keep your spirit under lock and key. That's the way you're brought up. You make it your business assistant, and it's safe and tame and never leads you towards anything risky. Nothing dangerous and nothing glorious. Nothing ever tempts you to dissolve yourself. What for? What's in it? No percentage. (130-31)

This litany of offensive stereotypes renders Leventhal's expression "uncomprehending and horrified" (131). His heart beats "agonizingly' and he falters out, 'I don't see how you can talk that way. That's just talk. Millions of us have been killed. What about that?" (131). This sole reference to the Holocaust results in a headache and a spot between Leventhal's eyes that is particularly painful, suggesting a third eye facilitating new perception. His nerves, however, are "worse than ever" and he worries that "his rage had done him harm, affected his very blood" (132). This anxiety is linked both to the racial persecution represented by Allbee's comment about Caliban as well as to Leventhal's horror of inherited madness. He imagines bad blood as "something black, thick, briny, caused by sickness or lust or excessive anger", an image which causes his heart to quicken and provokes the impulse to "cast a glance behind" (132). Even the briefest rumination on fearful material causes Leventhal to imagines himself pursued or observed. 
Leventhal realises that the saga with Allbee cannot continue indefinitely and the impending showdown will involve

a crisis which would bring an end of his resistance to something he had no right to resist. Illness, madness, and death were forcing him to confront his fault. $\mathrm{He}$ had used every means, and principally indifference and neglect, to avoid acknowledging it and he still did not know what it was. But that was owing to the way he had arranged not to know. (141)

Leventhal admits to making things easier for himself by "toning down, softening, looking aside", but "the more he tried to subdue whatever it was that he resisted, the more it raged, and the moment was coming when his strength to resist would be at an end. He was nearly exhausted now" (141).

Bellow's protagonist slowly surrenders to what he attempts to avoid, a surrender hastened by his young nephew's death. Working at his office, Leventhal is alarmed by the ring of the telephone, which causes him to strike his shoulder on a doorframe and momentarily lose his sight. The interior of the office suddenly seems black and the ringing of the phone fills the air, coming from all four corners of the room. Despite not knowing the information the call will impart, Leventhal experiences "a clutch of horror at his heart" (157). The dread inspired by death is conflated with the fear of persecution and madness when Leventhal becomes convinced that Elena blames him for Mickey's death. He misinterprets her grief-stricken gaze at the funeral as indicating blame and uses this misapprehension as further proof of her insanity. Yet when Leventhal broaches the topic with his brother, who returns to New York for his son's funeral, Max insists that his wife is simply in mourning. Leventhal's thoughts immediately turn to the implications of his false assumption, realising that if he were wrong about Elena and had misinterpreted her look, "the mistake was a terrible and damaging one; the confusion in himself out of which it had risen was even more 
terrible" (216). If Elena is not mad, Leventhal reasons, it must be he himself who is hopelessly confused.

The spectre of insanity haunts the pages of Bellow's novel. Like Leventhal, Harkavy is convinced that Allbee is "disturbed in his mind" (80), and his family history similarly includes madness. He describes how his aunt "got strange during the change of life - said all the clocks were warning her to look out, look out, look out" (80). Despite Leventhal's initial desire to believe Allbee irrational, he reacts violently to Harkavy's suggestion, presumably because he recognises the strange links between himself and his double. Yet Allbee himself confesses his psychological vulnerability by suggesting that Leventhal "ought to realize that I'm not entirely...that I'm not entirely under control." Allbee confesses that "Things get away from me. I'm not trying to excuse myself. But you wouldn't believe how much..." Leventhal concludes this sentence by suggesting rather wryly that "nowadays you can believe almost anything" (143).

As the novel progresses and as the relationship between Leventhal and Allbee becomes more fraught, the recent events in Europe are increasingly suggested. Leventhal's grim joke about being able to believe anything nowadays seems to point to the new postwar era grappling with mass death wielded by technological bureaucracies gone mad. When Leventhal meets some acquaintances in his local diner, he is annoyed by one man's suggestion that Bismarck's recipe for a great race combining "a German stallion and a Jewish mare" - is a compliment. Daniel Boyarin points out that the feminisation of Jewish men goes back at least to the thirteenth century in Europe, when it was widely maintained that Jewish men menstruate. The curse of menstruation visited upon women as punishment for Eve's sin was transposed onto Jewish men following the death of Christ. The anti-Semitic stereotype 
of the Jewish man as a sort of woman, additionally encouraged by perceptions of circumcision as emasculating, clearly informs Leventhal's reaction to a comment his acquaintance sees as praise. Observing this reaction, Goldstone shrewdly suggests that Leventhal is blaming Bismarck "for the Germans of today" (116).

Leventhal refuses to acknowledge this charge, but he cannot quite shake the horror of discrimination. His dreams become reminiscent of the Holocaust, with one "unclear" dream involving him being held off "like an unwilling spectator; yet it was he that did everything" (150). He finds himself in a railroad station forcing his way through a crowd, "the sound of whose shuffling rose towards the flags hanging by the hundreds in the arches" (150). In Freudian terms, the dream's train imagery and pervasive dread might point to phallic anxiety, but the numerous national emblems dominating a mass of people heading towards train carriages also recalls the transport of Jewish populations from European centres to concentration camps during the Nazi regime. Leventhal's dream suggests guilt over his status as a spectator who is nevertheless clearly implicated in the "unclear" events.

Initially unwilling to accept Allbee's assertion of the randomness of fate, Leventhal longs for the solace of a rational solution. Allbee insists that people have a destiny forced on them and moreover, 'that's all the destiny they get, so they'd better not assume they're running their own show" (62). Although Leventhal longs to deny the lack of agency this enforced randomness entails, he acknowledges "explicit recognition in Allbee's eyes which he could not doubt was the double of something in his own" (151). Leventhal's anxiety about the connections between Allbee's fate and his own leads to superstitious dread and Allbee's comments about Mary's wellbeing "bothered him more than he knew. He had brushed them side. What reason did he 
have to be anxious about her? Nevertheless there were coincidences; things were mentioned and then they occurred" (183).

Leventhal's obscure suspicion about the programmed nature of existence reverberates at a double level for Bellow's readers, who are fully aware of the protagonist's utter powerlessness against the forces of a narrative seemingly moving towards the fate suffered by the majority of protagonists in doppelganger fiction: death. Reading The Victim involves a peculiar feeling of being both "in" and "out" of the text. While its realist strategies of rounded characterisation and psychological detail encourage identification with Leventhal as a "real" person understandably upset by a disturbing figure from his past, the protagonist's odd awareness of his role in a doppelganger story complicates this identification by reminding the reader of Leventhal's role as a literary convention.

From initial meetings in public places, Allbee increasingly invades Leventhal's most private spaces, eventually turning up at his office and finally managing to ingratiate himself into Leventhal's apartment. The threat that Allbee represents - the return of repressed guilt, insanity, illness and death - thus subverts the homely. While he only reluctantly capitulates to Allbee's invasion, Leventhal soon finds himself "singularly drawn with a kind of affection" (200) to his new housemate, a feeling which is both oppressive and repellent. Leventhal confesses that he does not know "what to make of it" but that "he welcomed it, too" (201), since Allbee's presence involves a sort of cathartic intimacy. Allbee frequently mentions his dead wife, his ill health exacerbated by heavy drinking renders him a figure of increasing decrepitude, and he regales Leventhal with an awful story about a man struck by a subway train who died because bystanders were reluctant to assist him. Allbee's story suggests the guilt of those who do nothing to alleviate the suffering of others, even if inaction 
springs from cowardice or fear rather than maliciousness. Leventhal asks, "Was he yelling for help?" to which Allbee replies, "Well, of course, when a man is spreadeagled like that. He was filling the tunnel with his noise" (202). Leventhal wonders, "What does he tell me this for ... Does he want to work on my feelings?" (202) and dimly realises that this story has a connection with him. The crowd's willingness to obey the policeman whose instructions regarding accidents are to await assistance suggests not only a reluctance to become involved in tragedy but also suggests the complicity this stance entails.

Leventhal's friend Schlossberg is a manager in show business and reveals the postwar tendency to avoid what is disturbing when he insists that "Anybody could be a hit today ... With the public so crazy to be pleased. It's a regular carnival. Everybody is on the same side with illusion" (118). Harvaky's wife even believes that "Someday science will conquer death ... Last Sunday there was a symposium in the Times about it" (220). When Leventhal questions this remarkable development, Mrs Harkavy complacently replies, "Oh, it looks definite. Then the size of the population will have to be controlled. But science will figure that out, too" (221). Yet despite this reassuring assertion, Leventhal becomes increasingly distressed at the Harvaky's party and drinks much more than usual. Like his heavy-drinking houseguest, Leventhal becomes so drunk he must spend the night on his friend's sofa. In the morning an abashed Leventhal explains, "I've been having a lot of trouble. My family - you heard about that. And Mary's away, that's been hard on me, too. My nerves aren't in very good shape. I feel I've been trying to throw something off' (236).

When Leventhal returns home, it is not until he recognises a fire bucket with cigarettes buried in the sand that he knows quite where he is. As he wonders "why the place did not look more familiar" (241), he arrives at the door of his apartment only to 
discover it firmly locked. Although Allbee begs for a few moments, Leventhal breaks through the door to discover his double has been entertaining a woman in his flat, and more disturbingly, in Leventhal's own bed. Enraged by this desecration and repulsed by the woman's scent which lingers in the air, Leventhal experiences Allbee and his guest as if they are moving "toward him out of a depth of life in which he himself would be lost, choked, ended. There lay horror, evil, all that he had kept himself from" (249). Clerking in the flophouse had involved him being

as near to it as he could ever bear to be. He had seen it face on then. And since, he had learned more about it out of the corner of his eye. Why not say heart, rather than eye. His heart was what caught it, with awful pain and dread, in heavy blows. Then, since the fear and pain were so great, what drew him on? (249)

Leventhal's reaction is surprisingly violent; surprising too is his admittance of an obscure desire to know more of what he cannot bear to face.

Although anger is an understandable response to Allbee's inconsiderate behaviour, Leventhal's perception of the tryst as representing horror and evil reveals a deep dread of illicit sexuality. His dismay over Allbee's essentially harmless fling, coupled with his previous reaction to the soldiers and women he witnesses on the street, appears to stem from Mary's infidelity during their first engagement. His wife's absence involves suppressed anxiety about her faithfulness as well as his own. When Leventhal visits the superintendent's wife Mrs Nunez to request cleaning services, he discovers her sitting cross-legged on the divan putting up her freshly washed hair. Even when she becomes aware of Leventhal's presence at the door, she neither changes her position nor attempts to cover her gartered legs, forcing Leventhal to explain his errand while gazing at her exposed thighs. It is revealing that Leventhal initially mistakes Allbee's date for Mrs Nunez, the "horror" of which "bristled on him, and the outcry he had been about to make was choked down" (242). When he 
realises his mistake he feels "enormously lightened, but at the same time it gave him a pang to think of his suspicion" (242). John Jacob Clayton suggests that Leventhal's horror at the thought of Allbee sleeping with Mrs Nunez stems from him "seeing a projection of his own unconscious desires - seeing the scene he wanted to act out" (151). As if in penance for this imaginary transgression, Leventhal embarks on a vigorous spring cleaning and when his brother Max visits he observes, "Your radio's on pretty loud. Got a drive on against spooks?" (251).

A drive against spooks is exactly what Leventhal is engaged in, but the very insubstantiality of his haunting phantoms makes this task impossible. After securing the door with a chair so that the banished Allbee cannot re-enter during the night, Leventhal goes to bed and dreams of buying rouge for his wife. The salesgirl demonstrates each shade by drawing on her own face, afterwards wiping each colour off with a towel, the odour of which "had from the beginning seemed familiar" (253). Leventhal's attempt to identify this odour rouses him from sleep and he becomes aware that the smell comes from his own bed. Upon identifying it as Allbee's date's scent lingering in the bedding, Leventhal's environment suddenly becomes hostile: "He raised his head, feeling stifled, and saw the dazzling wall of the bathroom, the yawning clothes hamper, the black fin of the scale. He thought he could hear the steam in the pipes, and yet the room was not warm. He shivered and lit the lamp" (253). This sudden illumination reveals the front door is open and Leventhal hears movements in the kitchen. Although his terror is "like a cold fluid ... released by the breaking open of something within him" (253), it is not an intruder he fears but the manifestation of his own irrationality. He wonders, "what if the chair had slid down and the door opened by itself? And what if the kitchen were empty?" (254). This 
would mean the conquest of what Leventhal most fears: his nerves and "his sick imagination" (254).

Leventhal is not dreaming or hallucinating, however, and when he ventures out of bed, he discovers Allbee in the kitchen where the air is foul and hard to breathe because of the gas pouring from the oven. As Leventhal grapples with Allbee to save himself from a death specifically associated with the Holocaust, he realises, "I have to kill him" (254). For Leventhal, the experience is one of being gassed by an antiSemite but when he confronts his attacker with the accusation of murder, Allbee responds despairingly with "Me, myself ... Me...!' (254). It is suicide Allbee is attempting not murder, and after this harrowing admission he wrenches himself free and escapes down the stairs and into the street. Leventhal throws open the window to release the built-up gas and leans out with "tears running down his face in the cold air" (255). Yet in spite of the struggle and "the revolting sweetness of the gas like the acrid sweetness of sewage," Leventhal remains "impassive." He doubts that Allbee will return yet barricades the door with the dresser so that he would "sleep undisturbed; he cared about nothing else" (255).

This is a peculiar anti-climax for a novel built on paranoid fears of impending doom, and for readers of doppelganger fiction the fact that both men survive their fragmentation is almost disappointing. ${ }^{55}$ Although Leventhal remains impassive following his near-gassing, the fact that he is prepared to murder Allbee implies an emotional response slightly more heated. Leventhal leans out the window with tears pouring down his face, but the text seems to imply these are caused by gas rather than emotion. Leventhal's desire to go to sleep following what should be a thrilling

\footnotetext{
55 In a 1947 New York Times review, Alan S. Downer criticizes the novel's ending for what he perceives as its timidity. See "Skullduggery in Chungkin and Manhattan," New York Times (November 30, 1947), 29.
} 
dénouement is strangely unsatisfying. Has he really grappled with and triumphed over his repressed fears or has he simply avoided the implications of this encounter?

The concluding chapter of the novel reveals that life has gone well for Leventhal since the Allbee affair. His "consciousness of an unremitting daily fight, though still present, was fainter and less troubling. His health was better, and there were changes in his appearance. Something recalcitrant seemed to have left him; he was not exactly affable, but his obstinately unrevealing expression had softened" (256). Leventhal has "lost the feeling that he had, as he used to say, 'got away with it,' his guilty relief, and the accompanying sense of infringement" (256). He now questions whether it is "a conviction or illusion that at the start of life, and perhaps even before, a promise had been made", and decides that he "was almost ready to affirm that there was. But it was misunderstood" (257). Leventhal initially thinks of this promised destiny as a theatre ticket guaranteeing entrance to certain sections, but he then realises that "this was incorrect. The reality was different ... There were more important things to be promised" (257).

Yet the final episode of the novel occurs at a theatre where Leventhal stands outside during intermission with his now pregnant wife. "Something about the queerness of existence, always haunting Leventhal at a short distance" approaches "very close to him" (259), and when a car pulls up at the curb and he hears a familiar voice, he is certain that the man is Allbee. With "a rigid face and a look approaching horror in his eyes" (264), Leventhal awaits his old friend's appearance, and when Allbee emerges from the car, Leventhal notices that his initial appearance of success in fact reveals dissipation. Allbee takes the opportunity of the unexpected meeting to explain that he meant only to kill himself that night and confesses, "I don't remember 
how it was ... I must have been demented. When you turn against yourself, nobody else means anything to you either" (264).

As Ralph Freedman asserts, the problem of the doppelganger "which underlies The Victim, could have been enacted through any theme. The pervasive use of the Jewish theme, therefore, compels a social interpretation" (56). Yet the social interpretations that the majority of critics have posited have steadfastly avoided the events of World War II, mostly because the novel gives little overt evidence to the centrality of the Holocaust. Reviewing the novel upon its release, Diana Trilling wrote that "not the least impressive aspect of Mr. Bellow's novel is that he dares to place this study of the difficult problem of responsibility in that most difficult of spheres, the sphere of interracial relationships" (25). But Trilling goes on to suggest that it would be "a mistake to read The Victim as only a novel about anti-Semitism: its implications are much wider, and its insights are as relevant to members of majority groups - that is, to any human being - as to members of oppressed minorities" (25). The fact that Trilling can suggest, a mere two years after the liberation of the concentration camps, that a story about anti-Semitism might lack relevance is staggering. Opinions such as this forced the Holocaust into the depths of postwar American culture where it took on uncanny guises.

While Bellow's depiction of a doppelganger contributes to The Victim's strangeness, even odder is the novel's ability to provoke a sense of a double narrative in a narrative about a double. In Writers at Work, Bellow explains that while composing The Victim "I accepted a Flaubertian standard" which "in the end, I found repressive - repressive because of the circumstances of my life and because of my upbringing in Chicago as the son of immigrants" (183). The literary standard Bellow chose could not express the things he knew most intimately. "A writer", he points out, 
"should be able to express himself easily, naturally, copiously in a form which frees his mind, his energies. Why should he hobble himself with formalities? With a borrowed sensibility? With the desire to be 'correct'? Why should I force myself to write like an Englishman or a contributor to The New Yorker?" (Writers at Work 183). Just as Allbee confronts Leventhal with a dark mirror image of buried fears and desires, thirty years later The Victim's doppelganger appeared in the form of $\mathrm{Mr}$ Sammler's Planet (1970), which reveals Bellow's attempt to include "the thing" so dimly glimpsed in his earlier novel. Sammler is a Holocaust survivor who loses his wife and his eye in a horrific mass grave in Poland. Bludgeoned with a rifle butt, Sammler must crawl over the bodies of dead Jews to affect his escape, and as a partisan soldier in the forests of Poland he ignores a German soldier's pleas for mercy and kills him without qualm. While this later novel is not solely about the Holocaust, it does depict something of its horror and explores the human implications engendered by twentieth-century historical events.

When Jeanne Braham points out that Leventhal sees his own face in Allbee's, "his own cries of victimization in Allbee and Elena, his own evasions of responsibility in Max, and his yearning for sonship in Philip," she locates these reflections as the space in which Leventhal "sees, however murkily, his own image" (63). This statement can be meaningfully extended to suggest that part of what Bellow's protagonist witnesses in this mirror are the "imploring, wrathful, despairing" faces described by the novel's epigraph; the six million faces claimed by the Holocaust. 


\section{VI}

\section{The Familiar Made Strange:}

\section{Paul Bowles' The Sheltering Sky}

I was running toward something, although I didn't know what at the time ... I found it over the years. What I was ultimately running toward was my grave.

Paul Bowles, "The Art of Fiction LXVII"

Paul Bowles' uncompromising explorations into the darker aspects of human existence saw him occupy a curious position in postwar American culture. Given the era's predominant urge to celebrate the familiar and cosy, Bowles' depictions of extreme and often random violence in prose characterised by "a terrifying and macabre stillness that scarcely masks a cruel and compassionless universe" (Folz 81), his status as an expatriate in North Africa, his brief membership in the Communist Party during the late 1930s and his open disavowals of modernity (of which America was perhaps the leading example) seem more likely to promise commercial failure than success. Nevertheless, The Sheltering Sky (1949) remained on the New York Times bestseller list for ten weeks in early 1950 and sold more than two hundred thousand paperback copies in 1951.

Although it "smashed pieties about the broadening aspects of travel, the power of Western ideals, the sacramental nature of existence, and the fundamental decency of man" (Friend 90), and although it was written by an author who labelled America "a huge monstrous "non-culture"” (qtd. in Loshitsky 130), The Sheltering Sky was a commercial success because it was perceived as adhering to a popular literary mode that combined the exotic and the spiritual. The same year that Bowles' book was published, three of the top-selling novels were Mika Waltari's The Egyptian, Lloyd C. 
Douglas' The Big Fisherman, and Sholem Asch's Mary, all of which combined historical drama, exotic Middle Eastern settings and, in the case of the last two, religious subject matter. The Sheltering Sky's success relied on reviews such as Time magazine's anonymous "Sex and Sand," which describes Bowles' novel as "a lurid, supersexy Sahara adventure story completely outfitted with camel trains, handsome Arabs, French officers, and a harem.” Similarly, in 1951, John Aldridge suggested that the final episodes of the novel "would be perfectly suitable as material for an oldtime movie thriller, especially if the leading roles could be played by Theda Bara and a dozen Rudolph Valentinos" (After the Lost Generation 192). Aldridge seems particularly titillated by the "innumerable picturesque rapes performed upon the desperately willing Kit by savage tribesmen during the long Arabian nights," and his descriptions of the "endless comings and goings on camelback among the moonlit sand dunes" and the "exotic revelations of secret harem ceremonies" (After the Lost Generation 192) makes Bowles' nightmarish novel sound more like a Saharan bodice-ripper.

Comments such as Aldridge's align The Sheltering Sky with a popular literary mode of risqué exoticism, while Tennessee Williams' review in the New York Times highlighted its spiritual content. A close friend of Bowles, Williams declared that The Sheltering Sky "alone of all the books that I have recently read by American authors appears to bear the spiritual imprint of recent history in the western world" ("An Allegory of Man"). Like other critics, Williams described the novel as a "chronicle of startling adventure against a background of the Sahara”, but also stressed the way it acts as "an allegory of the spiritual adventure of the fully conscious person into modern experience." This "might suggest the very opposite kind of novel from the one that Paul Bowles has written" and Williams was right to suspect that "a good 
many people will read this book and be enthralled by it without once suspecting that it contains a mirror of what is most terrifying and cryptic within the Sahara of moral nihilism." Sure enough, two months after The Sheltering Sky's appearance in bookstores, Life magazine - the epitome of the middle-brow - featured Bowles in a two page spread on "Four New Writers" (Brier 194), proving that the lure of sex, sand and spirit was impossible to resist.

Evan Brier notes that at the time of Williams' laudatory review, his play $A$ Streetcar Named Desire had just finished a hugely successful two year run on Broadway and Williams' approbation served to legitimise Bowles' novel in the public eye. Bowles' subsequent publications were less propitiously timed and did not match the commercial success of The Sheltering Sky. Charles Jackson's 1950 review of The Delicate Prey and Other Stories suggested that although the tales are highly literate, they range from the "completely incomprehensible" to the "indescribably unpleasant", the final story being "one of such unspeakable horror and brutality that there is no sense in trying to describe it" (6). For Jackson, the emotional effect of reading "A Distant Episode" is "far less that of repulsion than active anger at having to put up with it at all" (6). Bowles' next novel Let It Come Down (1952) saw the author praised for his imaginative way of dealing with the macabre and the dreamlike, but Robert Gorham Davis argued that "as a comment on the human situation in Western civilisation" it has exactly the same relevance as gothic fantasies such as "The Pit and the Pendulum" and The Castle of Otranto. Davis acknowledged the novel's place in a literary tradition with deep historical roots, but argued that "if we try to make it mean more than that, if we take it as a serious social or philosophical novel, then it seems malign and corrupting" (1). 
Critics and readers alike soon came to realise that Bowles was not a writer of sexy or exotic bestsellers and his status underwent a radical transformation from Life magazine's "new writer" to a cult figure for the countercultural movements of the late fifties and sixties. Beat writers such as William Burroughs and Allen Ginsberg claimed him as a literary father-figure, making pilgrimages to his home in Tangier. Mailer categorised Bowles more accurately than Life magazine by pointing out that it was Bowles who first "let in the murder, the drugs, the incest," and who opened American literature to "the call of the orgy, the end of civilization" (Advertisements 468).

Bowles' achievement in writing a novel that was both a sexy bestseller and a cult fiction relies not just on the imperatives of marketing but on a complicated oscillation within the novel itself. As Tennessee Williams points out, there is "a curiously double level” to The Sheltering Sky (“An Allegory”). Beneath the startling Saharan adventure is a narrative registering what Williams identifies as the "spiritual imprint of recent history in the western world." While we might expect the novel's more profound meanings to be available only to those readers willing to go beneath surface depictions of sex and sand, Williams unexpectedly suggests that its meaning resides “above that surface." While arguing for The Sheltering Sky's sophisticated and meaningful content, Williams cannot help making the novel sound strangely superficial by describing its "philosophical aura," which although "intangible and powerful" (“An Allegory”) suggests an impression of content rather than content itself.

Williams' review reveals something of the strange way that Bowles' novel manages to provoke a level of discomfort not entirely justified by its story. The "philosophical aura" it apparently emanates relies on language and imagery loaded 
with associations which the reader brings to the text. In fact, the effect of reading The Sheltering Sky relies upon an impression of meaning which close examination reveals to be either absent or obscure. Bowles' use of the uncanny at a thematic level, particularly through Kit Moresby's constant interpretation of omens spelling impending doom, creates a sense of anxiety in the reader as well as the suspicion that in some mysterious way the Moresbys have willed their own destruction. But when asked during an interview about the Moresbys' motivations for leaving their predictable world for an unknown realm where they will be destroyed, Bowles' reply was "they wanted to travel, a simple, innocent motivation" (Halpern, “An Interview"). Although it is possible to argue that the novel's initial categorisation as a sexy bestseller mistook its real status as a profound philosophical treatise, it is equally possible to argue the reverse: that its philosophical aura is a sort of smoke and mirrors device merely reinforcing its appeal in an era defined by interest in surfaces rather than depths.

Bowles' cult classic-bestseller depicts psychological breakdown in familiar psychoanalytic terms. The depiction of Kit Moresby's breakdown is clearly influenced by Freudian theories of trauma, repression, hysteria and neurosis, since she attempts to control constant anxiety through a system of omen interpretation. After the trauma of her husband's death in the middle of the Sahara desert, Kit fears returning to the West because she will be forced to "pry open the wall she had built" and be forced to "look at what she had buried there" (305). By the end of the novel, Kit's fear of impending doom has become fear of the moment when her pursuers will stand her up before a great mirror into which "she would be obliged to look, and then it would all be over. The dark dream would be shattered; the light of terror would be 
constant; a merciless beam would be turned upon her; the pain would be unendurable and endless" (308).

At a moment of particular stress, Kit recognises that she is on the brink of hysteria, thus recalling a long tradition of aligning particular psychic disturbances with the feminine. The word "hysteria" comes from the Greek hystera, meaning "womb," and originally designated a link between nervous disorder and diseases of the female sexual and reproductive organs. Although Freud's work with Joseph Breuer in Studies in Hysteria (1895) and "The Aetiology of Hysteria" (1896) focuses on the psychological rather than physical origins of a psychiatric condition characterised by excitability, anxiety, sensory disturbances and psychosomatic illness, thereby suggesting that it is not a pathology suffered exclusively by women, Freud's thesis that hysteria is the result of childhood sexual trauma emphasises the different manifestations trauma takes for men and women. Freud argues that while all psychoneuroses have the same sexual cause, the attitude of the patient toward the experience (whether abuse or more benign experiences such as stimulation during washing) determines what form the pathology will take. If the sexual encounter is experienced actively with pleasure, then the pathology will manifest itself as the obsessional disorders occurring most commonly in men. If experienced passively with displeasure, the pathology will manifest itself as hysteria occurring most commonly in women. After denying hysteria's basis in gender and physiology, Freud's work returns the theory of hysteria to its gendered origins by reintroducing gender distinctions based in masculine and feminine attitudes.

Leslie Fishbein argues that during the 1940s in America, intellectual women became the "bête noires of popular Freudianism" (135). World War II saw many women experience unprecedented freedom as they took over abandoned jobs and 
assisted with the war effort, only to be pushed back into the domestic realm by the return of veterans to their previous employment and the subsequent postwar baby boom. While many women welcomed a domestic life based on home and family during the postwar years, many struggled with the expectation that they retreat back into the home. Significant numbers of women remained in the workforce but there was increasing pressure to adhere to more traditional female roles, with particular stress being laid on the naturalness of the woman's role in the home. The 1954 publication of Lawrence and Mary Frank's How to be a Woman, however, suggests that many women had to learn how to behave in ways considered appropriate to their gender. In The Feminine Mystique (1963) Betty Friedan argues that Freudianism frequently served to buttress the mystique of female fulfilment in the roles of wife and mother. Alfred Kinsey's initial report on female sexuality implied that between 50 and 85 percent of college-educated women had never experienced sexual orgasm, whereas this problem affected less than 20 percent of high school-educated women. When the report was published in full a decade later, it actually revealed that the more educated a woman was the more likely she was to be sexually fulfilled, but the damage, Friedan suggests, had already been done. Intellectualism in women seemed not only unnatural but unhealthy.

While adhering to Freudian understandings of the psyche, Bowles' depiction of female psychological breakdown is very different from those in popular postwar fiction and film. In the film version of Mary Jane Ward's hugely popular 1946 novel The Snake Pit for example, the obscurity of the psyche is made reassuringly clear by Dr Kik's diagnosis of the well-educated, psychologically frail female protagonist. Although Ward's novel does not fully explain the reasons for Virginia's breakdown, the 1948 film version carefully links her mental disturbance to her inability to achieve 
an appropriate femininity. The film clearly diagnoses Virginia, who has aspirations to be a writer, with a sexual frigidity resulting from her masculine pretensions. The film's emphasis on Freudian psychoanalysis was a conscious strategy on the part of the filmmakers, who sought advice from three top psychiatrists regarding the accuracy of their fictional case study (Fishbein 143). Not surprisingly, the film stresses the "talking cure" as the key to unlocking repressed trauma and facilitating recovery, allowing Virginia's successful integration into a more "womanly" domestic role. Veda Semarne's “The Snake Pit: A Woman's Serpentine Journey Toward (W)holeness" points out how the film identifies Virginia's intellectual aspirations as an unnatural by-product of her avoidance of a healthy feminine interest in love, sex and family.

The novel is notably less Freudian in its approach and suggests that Virginia's breakdown is the result of anxiety provoked by her inability to negotiate her desire to write with her domestic duties, which is further compounded by her husband's failure to provide for the family financially. While the novel is a more nuanced exploration of female psychic disorder, it is scarcely less reassuring than the later film version. In a New York Times review, one critic suggested that despite the potentially "horrible" or "pitiful" nature of psychiatric illness, Ward's novel succeeds in making it "natural and understandable" (qtd. in Fishbein 138). Although psychiatry cannot always discover the cause of illness, the reviewer observed that recoveries "are sometimes made anyway" (qtd. in Fishbein 138). The eventual recovery of The Snake Pit's protagonist reassures readers that even if the cause of madness is never fully discovered, recovery can still be made. So although the novel provides a harsh exposé of the deplorable conditions in American psychiatric institutions, it also implies that 
Virginia is restored simply by being institutionalised. The film version goes one step further by removing the obscurity surrounding the causes of Virginia's breakdown.

Although The Sheltering Sky's female protagonist displays the classic hysterical manifestations of repression, Bowles' reader is denied the reassurance of diagnosis and cure. Port's death certainly has a profound impact on his wife, but from the start of the novel Kit's obsession with omens, her paralysis when she is unable to interpret her signs, her sexual dysfunction and hysterical outbursts reveal a highly disturbed woman. But there is no psychiatrist in the Sahara to save Kit and no "talking cure" to explain the roots of her trouble. The canny Freudianism of popular postwar films and novels about psychological breakdown is subverted by Bowles into a confrontation with the mystery of the human psyche. The therapeutic return of the female to the domestic realm does not occur in The Sheltering Sky and Kit remains the antithesis to popular postwar notions of femininity by being childless, promiscuous and living outside the conventional domestic realm. Kit's psychic decay is never aligned with her transgression of accepted gender roles, however, and the novel suggests not only that it is entirely possible for women to escape the domestic realm but that this is not the cause of illness. Kit does go mad, but not because she chooses to remain childless and uninterested in kitchen appliances. She goes mad for a reason which remains discomfortingly obscure.

While Bowles' fiction is clearly engaged with a long literary tradition of psychological horror - he identified Edgar Allen Poe as a formative influence ${ }^{56}$ - it remains deeply connected with the socio-political context of postwar America. Bowles' decision to live in Tangier and write almost solely about his adopted culture

\footnotetext{
56 For an in-depth discussion of Poe's influence on Bowles' writing see Catherine Rainwater, "'Sinister Overtones,' 'Terrible Phrases': Poe's Influence on the Writing of Paul Bowles," Essays in Literature 2 (Fall 1984): 253-66.
} 
inspired both fascination and suspicion for a Cold War readership preoccupied with ideological differences between East and West. In a 1952 New York Times interview, Bowles described Muslim culture as "essentially barbarous" and its people "purely predatory" (qtd. in Breit 10). Yet Bowles' continuing preoccupation with this other world was considered highly problematic, for if North Africa was a barbarous land populated with predatory people, why would a reasonably affluent and well-educated American choose to live there? In a 1950 review in the New York Times entitled "On the Seamier Side," Charles Jackson urged Bowles to return to his native scene in order to write "personal, intimate, and, shall we say, down-to earth stories or glimpses of the small town in which he was brought up" (6). Jackson's suggestion reveals the discomfort provoked by Bowles' deviation from the American lifestyle, as well as his fiction's deviation from the appropriate "stuff of our literature" (6).

Yet concepts of the alien and foreign were of paramount importance to a postwar American culture marked by a commingling of fear and fascination with what lay beyond its geographical and ideological borders. Following the State Department's call for "containment policy" in 1947, America embarked on a series of international interventions, including the Marshall Plan for European aid, the formation of NATO in 1949 and the decision to assist South Korea in 1950, which broke with its former isolationism and forced Americans to consider their country's new role in world affairs and to negotiate ideas about what constitutes the foreign. For Brian T. Edwards, The Sheltering Sky "is intricately a part of that moment when the US was coming to terms with itself as a global power" (314), and he points out that just a few months prior to the novel's publication the Saturday Evening Post featured an article by Demaree Bess entitled "We're Invading North Africa Again," which described the move (encouraged by President Truman's Point Four programme) by American 
business interests to areas occupied by the military during World War II. In his 1948 Harper's essay "Young Man, Go to Casablanca," Edward Toledano associates this new colonisation with the frontier injunction to "go west" and describes American GIs with their relish for Camel cigarettes, Hershey bars and Coca Cola as "very effective salesmen for American products." According to Toledano, although Morocco did not realise it, "the Fuller brush man had been taken to the bosom of its family. Eventually it was bound to cherish and buy his line" (qtd. in Edwards 317).

While articles of this sort emphasise the cultural invasion of foreign territories and suggest that this journey into a new frontier might provide an opportunity for the formation of a new American identity, Bowles' novel takes a much more disquieting approach. Rather than North Africa embracing or yielding to American culture, Bowles portrays America as fundamentally unable to successfully penetrate the foreign. His American protagonists arrive in North Africa apparently healthy and affluent, but the further they venture into the heart of the Sahara, the more devastating their mental and physical disintegration becomes. If writers such as Toledano stress the frontier-like aspects of North Africa and laud America's colonising efforts, then Bowles suggests the inevitable failure of this imperialist project. Even more disturbingly for capitalist America, Bowles illustrates the feebleness of American culture in the face of older civilisations. Toledano's belief that Coca Cola and Hershey can rule the world is countered by Bowles' depictions of their relative inefficacy.

Alan Hibbard notes that all of Bowles' characters "set out from a known place of safety and comfort to find themselves in an unfamiliar region fraught with possibilities of deception and terror" (15). This journey also applies to readers of The Sheltering Sky, who embark from the familiar site of the travelogue genre only to 
discover themselves in an unfamiliar literary realm. Although the text describes harems, dancing girls and extra-marital affairs, Bowles renders them in terms decidedly disturbing, and while the setting is indeed foreign, the author does a rather poor job of rendering a Casablanca-like vision of glamorous exoticism. Readers are denied most of the details customarily provided for character portrait and background story, and Bowles' perverse strategy of killing off his main protagonist halfway through the narrative is both unexpected and disquieting.

Although The Sheltering Sky displays a particular reticence regarding World War II, Williams suggests that the only other place in which to find the "spiritual imprint" of recent history that characterises Bowles' novel is in "one or two war books by returned soldiers" (“An Allegory"). Bowles' book could hardly be called a war novel and nor was he a war veteran, but Williams is correct in pointing out the connections between The Sheltering Sky and the Second World War. The novel describes the journey of three Americans - a married couple, Kit and Port Moresby, and their male companion, Tunner - in North Africa immediately after the war's end, and despite the fact that both Port and Tunner are young and apparently healthy, neither appears to have served in any military capacity. The reader is never informed how or why they were spared military service, only that Port spent the war years travelling with his wife in the West Indies and South America. This reticence may be linked to the fact that Bowles also spent the war years making short trips to Mexico and Central America after being rejected by the draft board as a "psychoneurotic personality" (Dillon 173), that is one characterised by repression, anxiety and obsessive compulsions.

Prior to 1939, Europe is the one place where Port admits to feeling at home. After 1945, however, his intention is to keep "as far as possible from the places which had 
been touched by war" (14). Given Port's insistence that they avoid areas affected by the war, it is surprising that he should insist upon North Africa as the ideal location for their first postwar journey. Upon their arrival in an unnamed port city, Kit disappointedly observes that "The war has certainly left its mark here", and although Port attempts to pass off signs of the conflict as natural, since troops were passing through the region for more than a year, Kit sulkily suggests, "It seems as though there might be some place in the world they could have left alone" (15). This comment, however, is made "to please her husband" (15), suggesting that the couple's stance on war reflects Port's opinions more than his wife's. The Moresbys attempt to justify their antipathy towards the war and their desire to avoid its reminders by insisting that its main effect is cultural impoverishment. Kit despises "the whole horrible thing that happens after every war, everywhere" (15), and suggests that the "people of each country get more like the people of every other country. They have no character, no beauty, no ideals, no culture - nothing, nothing" (16). Yet as Tunner perceptively points out, neither Port nor Kit are old enough to know anything about the effects of any other war. Port's need to avoid facing the war's aftermath is thus never properly explained, and it is revealing that neither he nor Kit mention the loss of human life, large-scale destruction, concentration camps or the atomic bomb as aspects of the war worthy of condemnation. Kept at a physical distance and reduced to an event affecting tourism, World War II is transformed by the Moresbys into a manageable event.

Although Bowles' travellers express open disillusionment with Western civilisation, their attempt to infiltrate a more "authentic" world in North Africa is decidedly Western. They travel with a ridiculously large amount of luggage, stay at fine hotels for as long as possible, dine in restaurants, and drink Perrier and scotch 
during cocktail hour. Port attempts to align his Saharan journey with that of his pioneering great-grandparents into the American West, but if American identity was forged during that iconic journey, it is destroyed as he travels east outside American geographical boundaries. Although Port is eager to define himself as a traveller rather than a tourist, his identification with the figure of the pioneer renders him unintentionally a colonist. It is thus interesting to note that Port bears the same name as the capital city of Papua New Guinea, which was colonised by Britain in the late nineteenth century. In an interview, Bowles admitted that naming his lead protagonist after the city "was a kind of perverse thing to do. But I liked the name and wanted to visit it, and the nearest I'll ever come to seeing Port Moresby is to name a character after it' (Patterson, “Tangier Days”). Bowles' statement is somewhat disingenuous, since it obscures the relevance of the name's association with colonisation as well as World War II. Port Moresby was an important strategic point between Japan and Australia and the Battle of Coral Sea in May 1942 prevented its seaborne invasion and was significant for being the first time that a Japanese invasion force had been turned back without achieving its objective. As if in confirmation of Port and Kit's theory regarding war and cultural impoverishment, Port Moresby was acknowledged in 2004 as the worst capital city in which to live by the Economist Intelligence Unit's ranking due to high levels of violent crime.

Port's name also implies travelling, so it comes as no surprise that his life has been one of almost constant movement. Even during the short intermittent periods when the Moresbys have been sedentary, Port, like the young Marlow of Heart of Darkness, "had only to see a map to begin studying it passionately, and then, often as not, he would begin to plan some new, impossible trip which sometimes eventually became a reality" (13). For Port, the difference between the tourist and the traveller is partly one 
of time (and presumably money): whereas the tourist "generally hurries back home at the end of a few weeks or months, the traveller, belonging no more to one place than to the next, moves slowly, over periods of years, from one part of the earth to another" (14). The tourist has a home to return to whereas Port is unable to tell among the many places he had lived "precisely where it was he had felt most at home" (14). When he awakes in a hotel room upon arrival in North Africa, this constant sense of estrangement disorients him to such a degree that he realises only that he has "come back through vast regions from nowhere" to arrive "somewhere" (11). The only thing Port can cling to is the infinite sadness at his core, which he finds reassuring "because it alone was familiar" (11).

Because the Moresbys are largely insulated from the harsher realities of the countries they visit, it is not so much the strangeness of North Africa that troubles them but a commingling of the unfamiliar and familiar. The Arabs of the port city are dressed in European clothing, and as the Americans linger on an unfamiliar street they are subjected to a radio "sending forth the hysterical screams of a coloratura soprano" (16). This mixture of familiar Western musical tradition with the streets and cafes of the East causes Kit to shiver and she insists upon hurrying to the hotel where they can escape. This proves difficult since at the hotel they discover the cinema next-door showing a film with the very Hollywood-sounding title Fiancée for Rent. Even the food is oddly familiar. French colonial influences enable them to breakfast on pastries and when they purchase food for their train journey it turns out to be English goods from the black-market.

When Port heads out into the city at night unthinkingly seeking the darker streets, the familiar becomes increasingly threatening. In the streets off the main thoroughfare, Arab faces become masks rendering their wearers "a thousand years 
old" (22). Port's sense of identity begins to fragment when he realises that it is "as if either he or they did not exist. Both suppositions were possible" (23). As he walks he suddenly notices that he is crushing innumerable large insects beneath his feet which break with little explosions. Although "ordinarily he would have experienced a thrill of disgust on contact with such a phenomenon," Port instead feels childishly triumphant and defiantly states, "I'm in a bad way and so what?" (24). Port's rebellious reaction reveals his sense of liberation and discomfort, a mix of excitement and anxiety which stems from his new proximity to the taboo. He interprets the odours of the street as representing "filth of one sort or another" and abandons himself "to the perverse pleasure he found in continuing mechanically to put one foot in front of the other, even though he was quite clearly aware of his fatigue" (24).

Mechanically trudging further into the forbidden, a faint vision begins to haunt Port's mind:

It was Kit, seated by the open window, filing her nails and looking out over the town. And as he found his fancy returning more often, as the minutes went by, to that scene, unconsciously he felt himself the protagonist, Kit the spectator. The validity of his existence at that moment was predicated on the assumption that she had not moved, but was still sitting there. It was as if she could still see him from the window, tiny and far away as he was, walking rhythmically uphill and down, through light and shadow; it was as if only she knew when he would turn around and walk the other way. (24)

Port's doubts regarding the possibility of his existence alongside Arabs reflects a suspicion that there is no reality capable of containing both self and other. His sense of homelessness intensifies until it becomes a sense of his own unreality and Port recognises his identity as someone whose existence is predicated on the perception of someone "tiny and far away" (24). While this moment reveals Port's interior life in familiar psychological terms, his identification as a protagonist destabilises a reader accustomed to the conventions of literary realism. Port imagines himself controlled by his wife's gaze, an analogy easily extended to implicate the reader's role in Port's 
existence. This reminder is potentially empowering until we remember that the control we exert over Port is ultimately wielded by the author over us. Port's reality might rely on the perception of an observing other, but the reading experience is ultimately controlled by the author's narrative power.

Unlike Port's willingness to venture into the darker areas off the main thoroughfare, Kit fears and avoids the unknown. Controlled by a series of superstitions that see her imbue objects and landscapes with supernatural power, she is terrified of Port's dreams since she cannot help interpreting them as omens. Her life consists of days "when from the moment she came out of sleep, she could feel doom hanging over her head like a low rain cloud" (43). This feeling of doom is so strong that it becomes "a hostile consciousness just behind or beside her, foreseeing her attempts to avoid flying in the face of the evil omens, and thus all too able to set traps for her" (43). A large part of Kit's life is thus dedicated to the categorising of omens, and when she finds it impossible to exercise that function because of doubt, her ability to go through the motions of everyday existence is reduced to a minimum. On such days it is "as if she had been stricken by a strange paralysis. She had no reactions at all; her entire personality withdrew from sight; she had a haunted look" (44). Kit becomes subdued and reasonable "only because she was imitating mechanically what she considered rational behaviour" and she dislikes hearing dreams recounted because they remind her of the internal struggle between reason and atavism. In intellectual discussions she always supports scientific method, but she admits that "at the same time it was inevitable that she should regard the dream as an omen" (44).

This struggle between reason and instinct, between the rational and the irrational, is the defining aspect of the protagonists' inner lives. Unlike the majority of postwar books and films influenced by Freudian theory, however, The Sheltering Sky never 
identifies the causes of its protagonists' neurotic symptoms. Bowles does adhere to popular Freudianism by hinting at some sort of sexual rupture within the Moresbys' marriage, since although Port and Kit are unable to sleep with each other, they are fully capable of sexual intimacy outside their marriage. Tunner's presence thus implies a sort of ménage à trois. His bland good looks are repeatedly referred to and both Kit and Port seem oddly unnerved in his company; in fact, Kit's violent reaction to Port relating a dream stems entirely from the fact that Tunner is present. Kit seems to subscribe not only to the superstitious fear of dreams as omens, but also to the psychoanalytic belief that dreams reveal the unconscious. Port's dream involves being on a train which threatens to plunge into "a big bed with the sheets all in the mountains" (17). In the dream, Port realises that he has the ability to relive his life all over again, which initially provokes dismay since this would involve reliving "all those God-awful fears and pains again, in detail" (17). He changes his mind, however, and decides "I'd be willing to go through the whole thing again just to smell the spring the way it used to smell when I was a kid" (18). But it is too late. Port discovers that he has reached up and snapped off his incisors as if they were made of plaster. The dream ends with the train stopped and Port sobbing with his teeth in his hands.

By the 1940s, Freud's The Interpretation of Dreams (1900) was part of popular parlance, with films such as Hitchcock's Spellbound relying on viewers familiar with psychoanalysis and dream symbols. The extraction of teeth in a dream was commonly interpreted as representing castration, while trains were associated with phallic symbols, suggesting that Port's dream reveals his awareness that living life over again necessitates continued sexual repression. When Kit attempts to prevent Port describing his dream, he insists that although "You don't want to hear it ... I'm going 
to tell it to you anyway" (17). This comment is made with a certain ferocity that Port attempts to pass off as feigned, but which Kit feels actually disguises the violence he feels. Once they are alone in their room, Kit expresses displeasure that Port should have revealed this dream to Tunner and rather vaguely suggests her mistrust of their companion. Although Port repeatedly asks why she feels this way, Kit merely snaps, "For God's sake stop talking about it," to which her husband "submissively" agrees (21). He then asks, with an inflection of mock innocence, "Can't I even think about it?" Kit's annoyed response is: “it's much more your business than mine” (21).

While this opaque exchange seems to imply Kit's pique at her husband's blasé reaction to Tunner's romantic interest in her, Kit's reluctance to hear about Port's inner life and his violent assertion that she must be told points to an unacknowledged awareness that Tunner's appeal might prove more seductive for Port than for his wife. Kit wants her husband to stop talking about "it" and although her husband agrees, he is less able to control thinking about it. Just what "it" is remains unclear, but repressed sexuality haunts The Sheltering Sky. In her biographical portrait of Bowles, Millicent Dillon confesses her discomfort with the novel's depiction of Kit's first sexual encounter with the nomad Belqassim, explaining that "I found it difficult to accept that Kit would take such delight in being raped. Even if - especially if - she'd just gone through the agonizing death of her husband and was half out of her mind with grief and guilt" (30-1). Dillon concludes that the rape sequence "was one of those instances in which an author's personal reverie has broken through into his fictional world", and she sums it up as "a jarring note, with the voice of the author, as man, intruding" (31).

Dillon's sense of Kit's rape as a symptom of repressed sexual desire is correct, but not in the way she imagines. The scene is less a regrettable instance of chauvinistic 
sadism than one in which the spectre of repressed homosexuality makes a return. Port's dream of the train in the mountains and Kit's sexual experience with the nomads are connected via delight associated with childhood spring. Port identifies the smell of spring in childhood as the one experience worthy of reliving the pain of life all over again, and Belqassim's assault on Kit is described as follows:

He reached out and took hold of her skirt, pulling her quickly down beside him. Before she could attempt to rise again she was caught in his embrace. "No, no, no!" she cried as her head was tilted backward and the stars rushed across the black space above. But he was there all around her, more powerful by far; she could make no movement not prompted by his will. At first she was stiff, gasping angrily, grimly trying to fight him, although the battle went on wholly inside her. Then she realized her helplessness and accepted it. Straight-way she was conscious only of his lips and the breath coming from between them, sweet and fresh as a spring morning in childhood. (272)

The connection between Kit and Port is one of profound empathy, with Kit admitting that "a section of her consciousness annexed him as a buttress, so that in part she identified herself with him" (83). This identification leads to Kit's submission to a sexual slavery described in terms of her husband's unfulfilled desire. Port's longing for the smell of spring in childhood becomes Kit's longing for that same smell, which she discovers on the breath of her attacker and which renders the initially unwelcome assault a "delight" (273). Kit's complete submission to her attacker/lover thus implies not only fantasies of violation but fantasies of homosexuality. When the nomads approach a town, Belqassim is delighted to be compelled to disguise Kit as a boy. Kit too is pleased by her transformation and the lovers experience especial pleasure when Belqassim lavishes Kit with physical affection while calling her "Ali."

Bowles' own life was marked by sexual ambiguity. While he refused to publicly define his sexual orientation, it was common knowledge that his wife Jane was a lesbian and Bowles himself had a long-term homosexual relationship with Ahmed Yacoubi, a Moroccan artist. Bowles' childhood was marked by repression and Dillon 
points out that "almost everything that had to do with sex was dealt with in secrecy" (209). Sexuality was so repressed that Bowles insisted that he was unaware of any anatomical differences between male and female until he studied biology in high school. William Burroughs reveals something of his friend's reticence when he suggested that Bowles' autobiography Without Stopping (1972) would have been more aptly titled "Without Telling" (qtd. in Ramey, "Talk with Paul Bowles"). In an interview, Bowles identified "Pages from Cold Point" as the only story in his oeuvre to treat male homosexuality and expressed discomfort with being categorised as a gay author on the basis of this one tale. When questioned whether this antipathy was because the label had no relevance to most of his work, Bowles replied that 'It's not even relevant to most of my life' (Ramey, “Talk With Paul Bowles"). This comment seems to deny homosexuality, but the qualification "most" points to areas of Bowles" life and work where homosexuality does have some relevance. The refusal to acknowledge what category his sexual tastes might fall into contributes to the strange doubleness of The Sheltering Sky, which Tennessee Williams (himself homosexual) identified.

When Port first encounters Mrs Lyle, he is unnerved by her "glassy black eyes" (52), which remind him of those of a doll. Although Port's morbid fascination with this woman is attributed to his delight in "the sight of a human being brought down to the importance of an automaton or a caricature" (54), there is more to Port's reaction to Mrs Lyle than meets the eye. Just prior to his first glimpse of the strangely doll-like woman, Port has noticed her son Eric sitting alone in the hotel bar. When Eric orders a Tio Pepe, Port orders the same, causing Eric to look at him "with a certain curiosity in his eyes" (53). During dinner that night, Port compulsively observes the Lyles and remains downstairs after the meal while Kit returns to their rooms. Agitated for no 
apparent reason, Port wanders around the hotel until finally he finds himself back at the bar, where he experiences "a tiny physical unhappiness in some unlocatable center" (57). It is not long before Eric appears and Port approaches him, ostensibly hoping to secure an invitation to travel to the next town in the Lyles' comfortable car. When Eric does offer an invitation, Kit refuses because there is no room for Tunner, but rather than remaining with his companions Port chooses to join the Lyles, despite the fact that Kit quite accurately describes them as "monsters" (64).

Although Port is the first to admit the extreme unpleasantness of the Lyles, he continues to seek out their company. An explanation seems to be offered when Mrs Lyle implies that her son is a homosexual. Somewhat inappropriately, she tells Port that Eric has contracted an infection, apparently through fraternising with "some filthy swine of an Arab woman", but she adds uncertainly, "I've been told that such infections can even be transmitted among men directly. Do you believe that, $\mathrm{Mr}$ Moresby?" (90). This hesitant query, coupled with her comments regarding Eric's mysteriously busy social agenda with Arab men, hints at the young man's sexual orientation and explains why during tea Eric sits "devouring Port with his eyes" (118). Port acknowledges that Eric seems to want something from him, but he prefers to think that the motivation is financial greed. When he notices Eric's gaze, he concludes that the young man wants another loan, but when Kit notices Eric's “extraordinary expression" she puts "a different interpretation on it" (118).

When Kit decides to ride on the train with Tunner rather than in the car with Port and the Lyles, she experiences acute anxiety. Port resents her decision and spitefully wishes that the train will crash, which Kit characteristically interprets as a curse. When she discovers that Tunner has bought several bottles of champagne on the train, she decides they represent a magic object capable of saving her from disaster. Yet 
despite generous doses of this magical elixir, Kit's anxiety forces her out of her own compartment where an intimacy with Tunner is growing and into a fourth class carriage filled with native Berbers and Arabs. In this carriage, Kit feels for the first time that she is "in a strange land" (84), her initial satisfaction soon turning to discomfort when she discovers that her neighbour's crunchy snacks are locusts with the heads removed. Attempting to escape the carriage, she finds her way barred by a wild-faced man holding a severed sheep's head. Kit lets out an involuntary moan, fights her way around this obstacle, "rubbing her skirt against the bloody neck as she squeezed past" and finds herself looking "directly into the most hideous human face she had ever seen" (85). Instead of a nose there is only "a dark triangular abyss" and for "no reason at all she thought of a lion's muzzle; she could not take her eyes away from it" (85). When the train finally stops and she is able to make her way back to the confines of her own carriage, Kit has the impression of "living a dream of terror which refused to come to a finish. She was not conscious of time passing; on the contrary, she felt that it had stopped, that she had become a static thing suspended in a vacuum" (86).

Port soon realises that the silence and emptiness of the desert landscape which touches his soul serves only to terrify his wife. He attempts to domesticate the "very strange" African sky by describing it as "a solid thing up there, protecting us from what's behind", but Kit can only shudder and wonder "what is behind?" (101). Port's response - "Nothing, I suppose. Just darkness. Absolute night" (101) - does not succeed in comforting Kit, and as they journey deeper into the North African interior the Moresbys react in increasingly different ways. For Port, the boredom of a long bus drive past monotonous landscapes is tolerable only because he is "journeying into regions he did not know" and he finds pleasure in venturing deeper into the Sahara 
"leaving behind all familiar things" (109). Kit, however, is convinced that her omens reveal that she is being saved up for a vast and ineluctable horror still to come. Plagued by a sense that "what she saw and heard around her was not really happening, or if it were, she was not really there herself" (128), Kit retreats to her hotel room and unpacks her numerous suitcases to seek solace among familiar material objects. When Port discovers her amidst piles of sequin gowns and evening shoes, Kit explains her overwhelming need to "see something civilized" (161). Kit believes her cosmetics and accessories will protect her from the nothingness that yawns outside her window and insists that "It'd be abnormal if I were able to adapt myself too quickly to all this. After all, I'm still an American, you know. And I'm not even trying to be anything else" (161).

Despite Port's initial eagerness, he too becomes frightened by their increasing proximity to the centre of the Sahara. In Aïn Krorfa he is seized with a chill which provokes "a sudden fear, akin to the terror of the child when it brushes against an unidentifiable object in the dark" (160). He runs along the crest of a hill in order to warm up, but he remains impervious to exercise, woollen layers and cognac. Even worse, he loses his passport and discovers that "it's a very depressing thing in a place like this to have no proof of who you are" (160). The lingering chill turns out to be an early symptom of typhoid fever, and as Port deals with a rapidly disintegrating sense of self, Kit attempts to protect herself by clinging to familiar objects, finding solace in the "dark little world" (195) of her handbag which she places on her chest as a barrier between herself and the hostile air. The handbag answers her need for a controlled environment and she is reassured by "the same objects" which fall against each other in "the same limited chaos". Kit feels that the names of her cosmetics "still represented the same things" yet the brands Mark Cross, Caron and Helena 
Rubenstein become ludicrously sapped of meaning when she pronounces them aloud in the desert landscape. She is confronted with the ultimate meaninglessness of the phrase "Helena Rubenstein" and the object it represents. Panicky laughter wells up inside her and she realises, "I'm going to be hysterical in one minute" (195).

In the midst of his delirium, Port realises that his journey has been "one strict, undeviating course inland to the desert, and now he was very nearly at the center" (198). The centre turns out to be a small town called Sbâ, a place of absolute silence and isolation that makes Kit believe there is not another living being within a thousand miles. The silence of the Sahara is so overwhelming that it renders Sbâ "alien to the surrounding landscape" (203). Inside this void, Kit again discovers that speech is meaningless, for although she repeats aloud the name of the town, it means nothing to her, "it did not even represent the haphazard collection of formless huts" (203). All the former signposts of identity and meaning are swept away in the centre of the Sahara, and Kit can only rouse herself to make a half-hearted attempt at nursing her dying husband, all the while telling herself, "Here I am in the middle of horror" (207).

From then onwards, the novel becomes especially strange. Although the point of view has alternated between the Moresbys throughout the narrative, Port's increasing delirium means that he can no longer fulfil the role of primary protagonist. An unsettling change occurs when the reader is shut out of the primary perspective and left with Kit's increasingly incomprehensible viewpoint. She becomes "conscious of a defect in her functioning - it was as if an entire section of her mind were numb" (208). Aware of an enormous blind spot inside her but unable to locate it, Kit watches herself as if from a distance. Her reluctance to nurse her dying husband is unnerving, even alienating. Disease "reduces man to his basic state: a cloaca in which the 
chemical processes continue" and Port has become the "ultimate taboo", "helpless and terrifying beyond all reason" (214). Kit must choke back a wave of nausea at her husband's touch and struggle with the powerful desire to run out of the room. No longer affected by her "familiar fear", Kit becomes subject to "a steadily mounting sentiment of revulsion" (215). At the touch of her husband's flesh, she feels the hair at the back of her head rise and stiffen.

The dread that Port inspires relies on his ability to pass between life and death. His consciousness oscillates between reality and an isolated "fever world" in which he cannot remember the idea of not being alone. In a moment of lucidity Port explains that "When I'm there I can't remember being here; I'm just afraid. But here I can remember being there" (216). Port longs to stop remembering it because "It's awful to be two things at once" (216). Split between two different dimensions which confusingly merge, Port's illness is an exile in which there are "no familiar objects along the way" (222). The space in which he becomes lost is full of things which defy rational apprehension: at times Port is able to almost see these things, while "knowing at the same time that really they could only be heard" (222); sometimes these things are "absolutely still, like the printed page, and he was conscious of their terrible invisible motion underneath, and of its portent to him because he was alone" (22223); sometimes he is able to touch these things with his fingers and at the same time they pour in through his mouth. It is "all utterly familiar and wholly horrible" (223).

When Kit escapes the sickroom for a moment, the desert air is "like something paralyzed" and the landscape suggests only one thing: "negation of movement, suspension of continuity" (226). Little by little, however, a doubt slips into Kit's mind. She experiences a sensation, faintly at first but then increasingly strongly, that some part of the landscape is moving. When she looks up, Kit is confronted by the 
sky turning sideways before her eyes: "It looked still as death, yet it moved" (226). Similarly, Port realises that "Slowly the split would occur, the sky draw back, and he would see what he never had doubted lay behind advance upon him with the speed of a million winds" (233). The terrible cry that this realisation provokes is "a separate thing beside him in the desert" which goes "on and on" (233). Port's final vision is of blood and excrement merging in the sky above the desert and "a point of darkness in the night sky's clarity" (235). He reaches out and pierces "the fine fabric of the sheltering sky" (235) and passes beyond to where Kit cannot follow.

Because Port will never again be conscious of her, Kit feels that it is really she who has "entered partially the realm of death" (237). Like "an insect spinning its cocoon thicker and more resistant," she attempts to strengthen the partition that locks off the memories of her recent trauma and avoid "the danger spot of her being" (267). Repression renders her automatic and she wanders aimlessly into the desert to join a group of nomads. As they travel past the endlessly repetitive sand dunes it occurs to Kit that "they were not really moving at all, that the dune along whose sharp rim they were now travelling was the same dune they had left behind much earlier, that there was no question of going anywhere since they were nowhere" (269). With this thought comes the haunting question: “Am I dead?” (269).

Kit no longer agonises over omens and does "only the things she found herself already doing" (276). After being smuggled into Belqassim's house to be kept prisoner in male disguise (so as not to raise the ire of his three wives), Kit is "profoundly troubled without knowing why, vaguely terrified, but for no reason she could identify" (281). Alone in her silent room, Kit feels as though she is waiting for something to happen in a place she has forgotten yet still dimly remembers. She is "frozen inside her skin" and her inability to know where or what she is requires an 
"impossible step that must be taken toward one side or the other before she could be back in focus" (286). The cosmetics that she once looked to for a reassuring reminder of familiar reality are now "the fascinating and mysterious objects left by a vanished civilization. She felt that each one was a symbol of something forgotten. It did not even sadden her when she knew she could not remember what the things meant" (291).

Kit has "no feeling of being anywhere, of being anyone" (300), and when she finally rouses herself to escape Belqassim's house, the distant walls of the city rise "from the realm of the invisible, but still only as emanations of the shadowy depths beneath" (300). When she finally discovers a post office the only message she can think to write is "CANNOT GET BACK" (304). Once Kit is located by the French authorities, the roar of the plane that will transport her out of the desert to the American consul smashes through her mental haze, and like her husband she finds herself staring into "the violent blue sky - nothing else. For an endless moment she looked into it. Like a great overpowering sound it destroyed everything in her mind, paralyzed her" (312). She remembers that "someone once had said to her that the sky hides the night behind it, shelters the person beneath from the horror that lies above", and she realises that at any moment "the rip can occur, the edges fly back, and the giant maw will be revealed" (312). This prospect is too much for Kit and she flees protective custody, presumably making her way back into the desert where she will not be forced to face what lies behind the sheltering sky.

Ian Almond points out that the cruelty in Bowles' fiction “constitutes a flight from the just and democratic world of Christian humanism. The arbitrary cruelty is there to remind readers we are not 'at home"" (311). This is compounded for the Western reader by the use of foreign settings, which Morris Dickstein suggests sees Bowles' 
supposedly "civilised" characters, like Joseph Conrad's Mr Kurtz, drawn into the heart of a void "exposing their secret wishes and vulnerabilities" (76). The similarity between Conrad's Heart of Darkness and The Sheltering Sky is often noted by critics, ${ }^{57}$ but little close analysis has been done on the ways Bowles' novel adheres to and deviates from the earlier text. Conrad's protagonist Marlow (who shares Port's fascination with maps) takes a physical journey into the heart of the Belgian Congo which also acts as a psychic journey into darkness. His mission is to find Kurtz, a representative of the International Society for the Suppression of Savage Customs, who has thrown off the shackles of Western civility to preside over "certain midnight dances ending with unspeakable rites" (123). Like Port and Kit Moresby, Marlow suffers from feelings of unreality and describes how "For a time I would feel I belonged still to a world of straightforward facts; but the feeling would not last long" (78). The heads on stakes that comprise the fence around Kurtz's hut are just one instance of the very real horrors which abound in Heart of Darkness, but the text emphasises internal horror as the most profound threat. Marlow is "completely unnerved by a sheer, blank fright, pure abstract terror, unconnected with any distinct shape of actual physical danger" (141). What makes this terror so overwhelming is what Marlow identifies as the moral shock he has received, "as if something altogether monstrous, intolerable to thought and odious to the soul" has been thrust upon him. Compared to this internal terror, the possibility of sudden onslaught and massacre is "positively welcoming and composing" (141).

\footnotetext{
${ }^{57}$ Yosefa Loshitzky cites The Sheltering Sky and Heart of Darkness as postcolonial texts which suggest that "the alluring fascination of the other and the desire it invokes culminate in madness." Morris Dickstein posits that "Conrad's Heart of Darkness is the tutor text of all Bowles's best work." See Yosefa Loshitzky, "Orientalist Representations: Palestinians and Arabs in Some Postcolonial Film and Literature," Cultural Encounters: Representing Otherness, ed. Elizabeth Hallam and Brian V. Street (London and New York" Routledge, 2000), 61; and Morris Dickstein, "On and Off the Road: The Outsider as Young Rebel," The Cambridge History of American Literature: Prose Writing 1940-1990. ed., Sacvan Bercovitch and Cyrus R. K. Patell (Cambridge: Cambridge University Press, 1999), 157.
} 
David Rudrum suggests that Heart of Darkness is a novel "beset by the limits of subjectivity" (409) and one which foregrounds the limits of language, a description equally applicable to The Sheltering Sky. Kit's realisation that reaching the centre of the Sahara means finding herself in the "middle of horror" (207) recalls Kurtz's famous final words, "the horror, the horror," and Conrad's insistence on the inconceivable and unspeakable is similarly stressed by Bowles. Yet the difference between the two texts, which both insist on an indescribable reality behind that which is commonly recognised, is that Conrad's novel supplies clear signposts which the reader can associate with horror. Although Marlow struggles to describe the insight provided by his journey into the jungle, he can describe the emaciated black workers, the cannibals, the decapitated heads decorating Kurtz's compound and the fact that the former great rhetorician has completely surrendered to his darker impulses. The subjective experience of Kurtz and Marlow remains indescribable, but there are external horrors that suggest and illustrate what remains ineffable. In Bowles' novel, neither Port nor Kit shed their social masks to engage in unspeakable desert rites, nor are they confronted with the horrors of the colonial project, yet they both suffer a similar fate to that of Kurtz. In Heart of Darkness disintegration is the end for those who abandon themselves to "primitive" desires, but what are we to make of a novel in which psychic and physical disintegration are the result of simply travelling?

While Bowles' emphasis on darkness, emptiness, silence and solitude renders his novel uncanny at mostly a thematic level, there is no denying the uncomfortable anxiety the book arouses. Like Hamlet, according to T.S. Eliot's essay "Hamlet and His Problems" (1919), The Sheltering Sky depicts an experience in excess of the facts. Although the Moresbys' dreadful experience in the desert is described in Freudian terms which render psychological breakdown familiar, it seems entirely unjustified. 
Kit's insanity is highly disturbing since it afflicts her to a degree beyond what the reader might expect from the events that seem to provoke it. ${ }^{58}$ Port's death appears to be explained by the fact that he contracts a disease, but that does not mitigate the weird suspicion that there is something else contributing to his death, something destined and preordained, something willed.

There is something obscure about The Sheltering Sky, which Williams sought to describe by suggesting its "philosophical aura" and "intangible" power. Freud's discomfort with obscurity saw him seek concrete dictionary definitions for the unheimlich and roundly reject Jentsch's theory of intellectual uncertainty, yet doubt remains an integral part of the uncanny. Unable to explain the uncanniness of silence, solitude and darkness, Freud suggests that "we can only say that they are actually elements in the production of the infantile anxiety from which the majority of human beings have never become quite free" ("Uncanny" 642), thus transforming what is inexplicably uncanny into factors contributing to psychic dread. Heidegger is more comfortable with obscurity and argues that the particular anxiety referred to as unheimlich "reveals the nothing" (103). Darkness and solitude are also identified as uncanny by Heidegger, who suggests that the "indeterminateness of that in the face of which and for which we become anxious is no mere lack of determination but rather the essential impossibility of determining it" (103). Reading The Sheltering Sky involves a thematic engagement with this nothing or no-thing, while at the same time the novel itself is defined by indeterminateness. The doubleness which Williams notes and which facilitated the novel's dual success as a bestseller and a cult classic relies not so much on a hidden story but on one that is weirdly absent. The detailed

\footnotetext{
${ }^{58}$ Even more disturbing is the fact that Bowles' wife Jane, upon whom he modelled the character of Kit, insisted that his narrative had prophesised her terrible end from a series of strokes (Dillon 184).
} 
psychologies of Port and Kit, which should create a sense of fully rounded characters with rich inner lives, cannot combat the text's insistent gestures towards the nothing.

The Sheltering Sky illustrates its author's thesis that society is a "fiction that serves as an anaesthetic" against the knowledge of isolation (qtd. in Caponi 123). While adhering to the popular demand for books with a spiritual focus, The Sheltering Sky provides the very antithesis of the "peace of mind" school. Bowles' protagonists are stripped of their cultural and social certitudes and thrust into the immense and silent Saharan landscape where they experience excremental visions, psychic breakdown and death. Although it adheres to popular Freudian notions of psychology, Bowles' novel confronts the reader with the unknowable mysteries of the psyche rather than representing a detective-like investigation and subsequent cure of neurosis. Kit's disintegration follows recognisable patterns of trauma, repression and neurosis, but Bowles stresses that these are ways of categorising psychological mechanisms rather than explaining them. In an era of canny avoidance, Bowles was one of the few figures suggesting that "this is certainly no time for anyone to pretend to be happy, or to put his unhappiness away in the dark." Rather than retreat into suburbia, he advocated watching "your universe as it cracks above your head" (qtd. in Breit 10). 


\section{VII}

\section{Repression and Confession:}

\section{Jack Kerouac's On the Road}

If I can't admire things for their strangeness what sense writing?

Jack Kerouac, unpublished letter to Neal Cassady, 3 Jan. 1951

In Vanity of Duluoz (1968) Jack Kerouac confesses through his fictional alter ego that the events of the 1940s rendered him "eviscerated of 1930s innocent ambition" (150). The sense of disillusionment engendered by the mass trauma of World War II and the personal losses Kerouac suffered during those years - his best friend Sebastian Sampas killed serving as a medic, over five hundred of his Merchant Marine colleagues killed in a torpedo strike, his father's death in 1946 - is palpable in Vanity of Duluoz but strangely obscured in On the Road, which was composed and set in the late forties and early fifties. Because On the Road was not published until 1957, and because it uses a confessional mode that was to become dominant during the 1960s, it has become common to associate it with the ferment of an emerging counterculture of protest and revolt rather than with the repressive years following the end of World War II. Although Gilbert Millstein's 1957 review in the New York Times suggests the relevance of the events of the 1940s to On the Road by likening it to that "testament" (27) of the Lost Generation, Ernest Hemingway's The Sun Also Rises, the dominant response to the book followed David Dempsey's lead, whose review in the Times three days after Millstein's emphasised its “aimless travel, women, car stealing, reefers, bop jazz, liquor and pseudo-intellectual talk" (4). 
On the Road's publication saw Kerouac hailed as a cultural revolutionary, the "King of the Beats." The writing of Kerouac, Ginsberg, Gary Snyder and Gregory Corso were received with enthusiasm by a new generation eager to move away from postwar conformity, conservatism and materialism, ${ }^{59}$ but by the end of the sixties, Kerouac's free-wheeling bohemian persona had undergone a radical change. Overweight, alcoholic, isolated and belligerent, the hero of the road had become a staunch Republican friendly with William F. Buckley and a supporter of the war in Vietnam. This transformation becomes less surprising when the doubleness of $O n$ the Road is acknowledged, since insistence on Kerouac's text as a bohemian bible ushering in a new generation of alternative lifestyle and political protest overlooks the more conservative impulses the novel displays, which tie it to the era in which it was first conceived and written rather than when it was published.

Although certainly connected to the emergence of a new counterculture, On the Road is also part of the early postwar period's concern with the reintegration of disenfranchised veterans to American civilian life. ${ }^{60}$ Marked by motifs of haunting and spectrality offset by buoyant descriptions of an idealised America, the effect produced by Kerouac's novel is oddly schizophrenic. Its use of the confessional mode renders repressed material revised and controlled, and its use of the picaresque provides a comfortingly familiar literary framework, yet the very presence of ghostly figures and the novel's insistence on homelessness create a sense of something not

\footnotetext{
${ }^{59}$ For an excellent overview of Beat literature see Matt Theado, The Beats: A Literary Reference (New York: Carroll and Graf, 2003).

${ }^{60}$ Mark David Van Ells notes that Willard Waller's 1944 book The Veterans Come Back identified the veteran as "our gravest social problem" since their experiences with the military and combat positioned them as "a threat to existing institutions" (23). A 1946 Life editorial highlighted the economic problems of reintegrating veterans and suggested that this posed an "unprecedented situation" for the nation. According to Life, the only way to avoid disaster was to limit financial assistance, suggesting that veterans need "genuine rehabilitation, to be trained and helped into good jobs and into stations in society where they do not need pensions. Except in cases of extreme disability, pensions are really confessions of failure" ("The Veterans," 36).
} 
quite right beneath its exuberant surface. Kerouac's novel is perhaps the clearest illustration of the shift between an era marked by repression and the uncanny, and the following decade defined by confessionalism and ironic black comedy.

Written between 1948 and 1952, On the Road belongs to the period marked by the Soviet bomb test, the "fall" of China, the war in Korea and McCarthy's rise to notoriety. Although Kerouac's advocacy of "spontaneous prose" championed a trance-like writing mode allowing the subconscious to admit what conscious art would censor, On the Road is probably the most heavily edited of all his books. Concentration on the famous 1951 Benzedrine-fuelled writing marathon, during which Kerouac typed the novel onto a 120-foot roll of paper in an effort to avoid what he described as "literary, grammatical and syntactical inhibition" (qtd. in Charters 59), overlooks the fact that this text was based on several versions written during the previous three years. Howard Cunnell reveals that there were three previous major versions of the novel: the fifty-four page "Ray Smith Novel of 1948"; the fifty-four page Red Moultrie/Vern Pomerey version of 1949; and the thirty page heavily edited version "Gone on the Road" of 1950 (4). When the manuscript was finally accepted for publication it underwent yet another rewrite by Kerouac as well as further revision by editors at Viking Press. Kerouac himself suggested that the published version of On the Road, far from being a spontaneous manifestation of unconscious art, was actually an "emasculation" of the original (qtd. in Clark 152).

In a letter to his friend Neal Cassady written in December 1951, Kerouac complains about the publishers of his first novel, The Town and the City:

I don't see how these cocksuckers could have done a better job trying to fuck me up as a first \& second novelist if they had laid out a blueprint in an attic: Giroux immediately begins by deleting my prophetic-feeling tone, carefully wrought over the years; removes the flow, some of the best chapters; turns a dark book of sorrows into an ordinary novel. 
By acknowledging the editorial processes involved in readying Kerouac's work for publication, On the Road's relevance to the postwar period becomes far more complicated than commonly perceived. After all, for a countercultural novel On the Road is strangely conservative, and for a novel haunted by insanity and ghostly phantoms, it is also strangely reassuring. The protagonist's search for an authentic America and a cohesive American identity never involves overt criticism of sociopolitical structures; in fact, what Sal Paradise most longs for is a sense of belonging. Despite the apparent bohemianism of its author and its characters, On the Road's first person narrator is a true postwar everyman. Like Sloan Wilson's protagonist in The Man in the Gray Flannel Suit, Kerouac's Sal is a returned veteran, disillusioned and disenfranchised, struggling to make sense of his place in a modern America of affluence, corporatisation and conformity. Unlike Wilson's protagonist, however, who accommodates to suburban and corporate pressures, Sal avoids the responsibilities of marriage, family, and a regular job in order to strike out on a series of journeys across the nation. This bid for freedom is depicted in pioneering terms, so although Sal rejects one version of the American dream - the suburban haven of the nuclear family - he wholeheartedly pursues another.

In Studies in Classic American Literature (1923), D.H. Lawrence insists that the American dream was never about freedom but was actually about escape: the Pilgrim Fathers did not set out for America for freedom of worship but for "that most simple of motives. To get away" (9). Leslie Fielder identifies the typical male protagonist of American fiction as "a man on the run" whose rebellion against the restrictions of civilization see him become a "pariah in flight" haunted at every step by "phantoms" (26). Using similarly spectral imagery, Lawrence suggests that America exerts "a powerful disintegrative influence upon the white psyche" since it is "full of grinning, 
unappeased aboriginal demons" and "ghosts" (54). The quest for freedom undertaken by the American hero is also an impossible escape from a haunting past, which helps explain why Kerouac's affirmations of Wyoming cowboys, Mississippi farmers and the road West are accompanied by unsettling descriptions of decay and spectrality. Sal's journey is a quest for authentic identity and freedom in the West that also involves self-disintegration and flight from the sins of the past. The novel's duality necessitates affirmation and celebration of America at the same time as it provokes dissent and unease, revealing a fragmented nation oddly combining beauty and ugliness, comfort and threat.

Although Millstein's review acknowledges that there is no technical or philosophical similarity between The Sun Also Rises and On the Road, it does imply that both books are capable of summing up a generation defined by the trauma and disillusionment of global war. However, Kerouac's military service was rather different to Hemingway's heroic ambulance missions; in fact, it was somewhat ignominious. After enlisting with the U.S. Marine Corp in 1942, Kerouac was lured by the better pay of the Merchant Marines and shipped out on a vessel carrying dynamite to Allied bombers in Europe. When he did eventually report for Navy service he ended up, either through pretence, nervous collapse or a combination of both, in the Navy psychiatric facility. He announced himself incapable of adhering to military discipline and the official verdict was "indifferent character." He was discharged from the Navy, denied a veteran's pension, and signed on to another Merchant Marine vessel which only narrowly survived its mission. Kerouac's first ship sank on its next voyage losing over five hundred men, many of whom Kerouac had known, and although he signed on for another mission following his own near death, he deserted before sailing and was barred from further service. 
Kerouac later admitted he had "goofed" through the entire war (Duluoz 272). Guilt at not having played a suitably heroic role was compounded by grief over his lost friends, especially his childhood friend Sebastian Sampas, who died a lingering four month death from gangrene in a military hospital. Having "goofed" a football scholarship and study at Columbia University as well as military service, Kerouac wound up hospitalised in 1945 from a combination of thrombophlebitis and Benzedrine abuse. Here, Kerouac came to the realisation that life was "brute creation" and he described the dew on a flower as serving only to hasten its death by encouraging "the bud to flower out just so's it can fall off sere dead dry" (qtd. in Maher and Amram 141).

Kerouac's disorienting experience of loss and failure during the war years, openly admitted to in 1968's Vanity of Duluoz, is obscured by the emphasis on freedom and fun within On the Road. The constant movement and camaraderie override Sal's admission in the opening sentences that he has "just gotten over a serious illness" and his "feeling that everything was dead (3). The published version of the novel links this feeling of decay to the break up of Sal's marriage, whereas the original manuscript cites the death of his father as the cause of distress. Kerouac's own recent losses suggest a double level to a narrative ostensibly about movement and life, but which is just as concerned with stagnation and death.

Sal's disenchantment at the start of the novel is alleviated by the appearance of Dean Moriarty (based on Kerouac's friend Neal Cassady), whose mobility and unconstrained physicality align him with freedom and life. He is a "young Gene Autry - trim, thin-hipped, blue-eyed, with a real Oklahoma accent - a sideburned hero of the snowy West" (4). Dean claims to be able to "go anywhere in America and get what I want because it's the same in every corner, I know the people, I know what they do" 
(109). Yet his confident insistence that "we know America, we're at home" (109), is countered by the mad cross-country dashes he and Sal make through a land neither knowable nor welcoming. When they are surrounded in their car at night "by a great forest of viny trees," they long to escape the "mireful drooping dark, and zoom on back to familiar American ground" (143). Their immersion in darkness and the smell of "dead water" in the air provokes anxiety, Sal explaining that "This was a manuscript of the night we couldn't read" (143).

The novel's preoccupation with the familiar and the unfamiliar, its anxieties regarding interpretation, the protagonists' experiences of dislocation and the lingering presence of a haunting past suggest a profound ambivalence about being "at home" in postwar America. When Sal climbs onto an old wrecked ship he perceives as "the ghost of the San Francisco of Jack London," he discovers that while once upon a time the "beautifully appointed ship" housed "a blue-eyed sea captain" (65), the only things living in the wreck now are rats. But Sal's flight from the modern metropolis, "with its millions and millions hustling forever for a buck among themselves ... grabbing, taking, giving, sighing, dying, just so they could be buried in those awful cemetery cities beyond Long Island City" (96), does not lead to a more authentic America but one in which he is never truly at home. Before he departs on his first trip from New York to California, he eagerly researches the pioneer journeys of the past, "savouring names like Platte and Cimarron" (11). His excitement at re-enacting the journey west is soon dissipated when he discovers that the iconic American sites of the past now contain "only cute suburban cottages of one damn kind and another, all laid out in the dismal gray dawn" (17). When he arrives in Cheyenne he discovers it is Wild West Week and the town is filled with "fat businessmen in boots and ten-gallon hats, with their hefty wives in cowgirl attire" (30). This commercialisation of 
American identity strikes Sal as ridiculous and he laments the "absurd devices" the West has fallen back on "to keep its proud traditions" (30).

Dean's first arrival in New York offers a "wild yea-saying overburst of American joy" which acts as an antidote to Sal's "stultified" (9) life of jaded intelligentsia. His New York friends are in the "negative, nightmare position of putting down society and giving their tired bookish or psychoanalytical reasons, but Dean just raced in society, eager for bread and love" (9-10). Sal can "hear a new call and see a new horizon" (10), and eagerly turns away from the disenchantment of postwar society to a man who seems to offer a nostalgic version of life prior to the advent of global war. But although Dean seems to provide access to an iconic America of freedom and authenticity untouched by the suburban and the commercial, his manic automobile trips, serial marrying and uncontrollable womanising link him to a postwar world of superhighways, suburbia and rampant consumption. Sal's attempts to access an authentic America are repeated attempts to get to a centre which remains inaccessible; the America Dean really offers is one defined by sham, masquerade and banality.

Despite Sal's constant journeying, he cannot completely escape the reminders of twentieth-century conflict. In Washington D.C. he meets with "Great displays of might lined along Pennsylvania Avenue" for Truman's second term inauguration, and at the sight of "B-29s, PT boats, artillery, all kinds of war material that looked murderous in the snowy grass," the car they journey in becomes a "battered boat" (122) recalling Sal's oblique references to his war time journeys at sea. Similarly, the first ride that Sal hitches on his first journey west is on a dynamite truck, which recalls the first mission Kerouac took with the Merchant Marines.

Waking up one morning in a rented room, Sal's spatial dislocation is matched by a dislocation from self: 
I didn't know who I was - I was far away from home, haunted and tired with travel, in a cheap hotel room I'd never seen, hearing the hiss of steam outside, and the creak of the old wood of the hotel, and footsteps upstairs, and all the sad sounds, and I looked at the cracked high ceiling and really didn't know who I was for about fifteen strange seconds. I wasn't scared; I was just somebody else, some stranger, and my whole life was a haunted life, the life of a ghost. (15)

Dislocation from home results in a spectral existence and in San Francisco Sal wanders around "like a haggard ghost" in a city whose long bleak streets are "shrouded" (53) in fog. Sal describes how "you start your life a sweet child believing in everything under your father's roof", but then comes the day "when you know you are wretched and miserable and poor and blind and naked, and with the visage of a gruesome grieving ghost you go shuddering through nightmare life" (95). Estrangement renders Sal an automaton and he realises, "I had no more control. All I could see of the morning was a whiteness like the whiteness of the tomb. I was starving to death" (96).

These articulations of the unhomely and the spectral are countered by Sal's insistence that such experiences are not really frightening; similarly reassuring is the fact that his homelessness and ghostliness are temporary since he remains aware of his aunt back home in New York from whom he receives periodic support. The confessional mode of the novel relies on disclosure which renders dark secrets controlled and contained, but Sal remains haunted by the feeling that he has forgotten something, some decision "driven clear out" (112) of his mind by Dean's arrival. This lingering sense of something not there that should be is connected by Sal to the Shrouded Traveller who stalks his dreams, a "strange Arabian figure" (112) that pursues him across a desert and finally overtakes him just before the Protective City. Sal realises that

Something, someone, some spirit was pursuing all of us across the desert of life and was bound to catch us before we reached heaven. Naturally, now that I look back on it, this is only death: death will overtake us before heaven. The one 
thing that we yearn for in our living days, that makes us sigh and groan and undergo sweet nauseas of all kinds, is the remembrance of some lost bliss that was probably experienced in the womb and can only be reproduced (though we hate to admit it) in death. But who wants to die? (112)

Sal's explication of the message from his unconscious controls a potentially frightening figure by interpreting it as "only death" (112). The rush of events which Dean's arrival precipitates distracts Sal from an uncanny experience and allows him to translate it into the familiar trope of heavenly bliss. Dean's response to his friend's dream is to recognise the Shrouded Traveller as the "mere simple longing for pure death", which although rendered in language which minimises threat, he will "have nothing to do with" (112). By denying the obscure threat posed by the Shrouded Traveller, the two men become the very thing they attempt to avoid. Sal and Dean are described as a "band of Arabs" (106), and Dean becomes an "Angel of Terror" (212), a "burning shuddering frightful" figure pursuing Sal "like the shrouded traveller" (236). Ed Dunkel is similarly inclined to make ghosts reassuring, only to become a ghost himself. He describes seeing a vision of his dead mother standing in a corner with light all around her, and when he walks down to Times Square he suddenly realises, "I was a ghost - it was my ghost walking on the sidewalk" (118). Ten hours later, in the midst of someone else's conversation, Ed repeats again, "Yep, it was my ghost walking on the sidewalk" (118).

The novel's use of spectral motifs reveals anxieties about death as well as what lies beyond the limits of rational knowledge. Sal's aunt takes one look at Dean and immediately decides that he is a "madman" (5), but Sal interprets his friend's potential insanity as a "holy lightning ... flashing from his excitement and his visions" (6). Yet these holy visions are never described and manifest as physical tics rather than spiritual enlightenment, vocal noise rather than speech. Towards the end of 
the novel, Dean's madness has "bloomed into a weird flower" (102) and he has become "absolutely mad" in his movements:

he seemed to be doing everything at the same time. It was a shaking of the head, up and down, sideways; jerky, vigorous hands; quick-walking, sitting, crossing the legs, uncrossing, getting up, rubbing the hands, rubbing his fly, hitching his pants, looking up and saying 'Am,' and sudden slitting of the eyes to see everywhere; and all the time he was grabbing me by the ribs and talking, talking. (103-04)

Dean's utterance “Am" recalls the interaction between Moses and God recorded in the Old Testament, when God gives his name as "I Am Who I Am" (Exodus 3:14). It also recalls the subsequent claims made by Jesus recorded in the New Testament, such as "I Am He" (John 4:1), "I Am the Bread of Life" (John 6:35) and "I Am the Way" (John 14:6). The Catholic Church, of which Kerouac was a devout believer, interprets "I Am Who I Am" as God's way of revealing himself to the people of Israel, but in revealing the mysterious name, $Y H W H$, God is revealed and concealed. While a name of sorts, it is also the refusal of a name, thus expressing God as beyond the comprehensible.

If statements such as "I Am" point to what lies beyond rational comprehension in a religious context, they veer towards nonsense in a secular one. Although Kerouac seems to insist on the holy madness of his enlightened protagonists, the emptiness of their message is also suggested. Like Dean, Rollo Greb is afflicted with a sort of spastic spiritualism: he "crawls like a big spider through the streets"; excitement blows out of his eyes "in stabs of fiendish light"; he rolls his neck in "spastic ecstasy"; "He lisped, he writhed, he flopped, he moaned, he howled, he fell back in despair. He could hardly get a word out" (115). Greb's ecstasy is inarticulate whereas Carlo has "developed a tone of voice which he hoped sounded like what he called The Voice of Rock; the whole idea was to stun people into the realization of the rock." Carlo's attempts to enlighten rely on the sound of his voice rather than the meaning of his 
words, and he warns Sal and Dean, "You pin a dragon to your hats ... you're up in the attic with the bats" (117). Although Carlo's mind is "a riot of radiant ideas that had come to enlighten his brain" (117), none of these ideas seem to mean anything and Sal admits that this "madness would lead nowhere" (116). This realisation is alleviated by Sal's drug-induced conviction that "everything was about to arrive - the moment when you know all and everything is decided for ever" (116). He imagines himself to be "like the Prophet who has walked across the land to bring the dark Word", but the only word this prophet has is "Wow!" (33).

On the Road reveals a particular anxiety regarding words and voice, which appears to be symptomatic of its author's concerns regarding his style and status as a writer. Dean and Carlo are involved in a project of "trying to communicate with absolute honesty and absolute completeness" everything on their minds (38), but this project stalls and Carlo accuses Dean of talking "absolute bullshit and Wolfean romance" (44). Dean insists that “old Sal won't tell, old Sal won't tell”, to which Sal responds, 'It isn't that I won't tell ... I just don't know what you're both driving at or trying to get at." When Sal is accused of being negative he asks, "Then what is it you're trying to do?" One man responds, "Tell him," the other counters with, "No, you tell him," to which Sal succinctly replies “There's nothing to tell” (44).

Carlo's condemnation of "Wolfean romance" provoked by Sal's musings about "that last thing" that "Nobody can get to" (44) is particularly revealing, since writing On the Road involved Kerouac abandoning his early devotion to Thomas Wolfe in an attempt to forge his own unique writing voice. Gerald Nicosia relates how Kerouac's first novel The Town and the City (1950) was criticised in manuscript form by his creative writing teacher Brom Weber for being too imitative of Wolfe, and a few months prior to this criticism Allan Ginsberg had suggested that Kerouac might be 
using Wolfe more as a vehicle than a master (Nicosia 229). Kerouac initially denied the charges, but during the process of revising The Town and the City for publication he judged it flawed by "grave imitations of Wolfe" (qtd. in Nicosia 294). Kerouac was dismayed to discover that the blurb for The Town and the City proclaimed him "wiser than Thomas Wolfe' (Nicosia 296), and when the novel was published in March 1950, both positive and negative reviews stressed his debt to the earlier writer. By the end of 1949 Kerouac resolved to move beyond "adolescent naturalism" (qtd. in Nicosia 295) but it was not easy to escape reminders of Wolfe's influence. In a letter written to Neal Cassady in December 1951, Kerouac describes writing with "a picture of Tom Wolfe in front of me: people are still saying he's for the immature; I could read him all day long and couldn't stand a page of careful Katherine Mansfield prose, and why, because he's talking and she's styling." By 1953, however, an undated letter from Kerouac to Cassady reveals, "I don't even believe in Melville or Wolfe anymore."

Writing On the Road involved a difficult attempt to break free of Wolfean derivations, and the anxiety the novel displays about authentic voice and meaning are moments when Kerouac's insecurity about his technical innovations override his confidence. Although he insisted to his agent Sterling Lord that he would "rather die" than betray his faith in his work (Selected Letters 11), and although he dismissed his publisher's dislike for spontaneous prose in a 1954 letter to Alfred Kazin by noting that "the list at Harcourts isn't exactly going to make history", Kerouac's letters to friends and editors during the 1950s are also filled with defensive comments about his writing style, with his reaction to editorial comments often deeply personal, as evidenced by his use of words like "castrating" and "emasculating." 
Over and over again, Kerouac stressed his desire for authenticity, an ideal which informs his characterisation of Dean, who is both real and a "con-man" (141), whose exuberant insistence on an idealised America in which he can access "IT" necessitates denial and omission. The "holy con-man with the shining mind" tells Sal that "we know what IT is and we know TIME and we know that everything is really FINE" (189), but Sal points out that Dean's early ability to "dig" life later becomes "so much sadder and perceptive and blank" (7). Mark Richardson notes that Kerouac's novel conflates perception with sadness and blankness; to be "digging" everything is somehow to be willingly subjected to a con (222).

Sal's pursuit of the frontier version of America sees him "dig" lifestyles he feels are "authentic" and offer access to "IT," but which are actually highly censored versions of reality. When he falls in love with Terry, a young Mexican woman, he plays at being a farm labourer in a pastoral idyll that completely omits the realities of that life. Picking cotton makes Sal's fingertips bleed and his back ache, but "it was beautiful kneeling and hiding in that earth" (87). When he feels like resting he does so "on the pillow of brown moist earth" (87), birds sing an accompaniment to his labours and Sal is convinced he has found his life's work. Working alongside him is "an old Negro couple" who "picked cotton with the same God-blessed patience their grandfathers had practised in antebellum Alabama" (87), and Sal feels himself "a man of the earth, precisely as I had dreamed I would be, in Paterson" (88). In fact, Sal has become so much a part of this rural life that he is thought to be Mexican or at least he implies that "the Okies" think so.

Sal's attempts to live an authentic life see him idealise what he calls the "Fellahin." As Richardson points out, however, putting on the mask of "the primitive" is "really to take off the mask of the White bourgeois" (224) and Sal's role-playing is a con. 
Not only does he fail to recognise the legacy of slavery which bound African Americans to the plantations, as well as the economic slavery that keeps his Mexican family living in tents, as soon as winter approaches Sal decides he is finished with his labour in the cotton fields and feels his old life calling him back. Because his Fellahin life is merely a game, he is able to wire his aunt for another fifty dollars and leave his experiment in authenticity behind. Sal's Romanticism is painfully naïve and depicts poverty as idyllic and oppressive socio-economic positions as free and authentic. Sal's search for an authentic America simultaneously involves a critique of white middleclass life and an affirmation of it. While Kerouac's protagonist flees New York's materialism, consumption and corporatisation in favour of a life lived close to the land, his experience of the Fellahin life propels him back to the middleclass world.

Going on the road might mean an interaction with new people and new ways of life, but it also means perceiving people and cultures through a lens that is white, male and middleclass. When Sal first meets Terry and takes her to a hotel room, he becomes convinced that she is a prostitute and calls her "a dumb little Mexican wench" (76); when Sal, Dean and Marylou cross the Mississippi River, they "dig" the 'Negroes ... working in the hot afternoon, stoking the ferry furnaces" (127), and later imitate Southern aristocracy (134); when they become lost in the swamps they eagerly imagine finding "a jazzjoint in these swamps, with great big black fellas moanin guitar blues and drinkin snakejuice and makin signs" (142). Even more disquieting is Sal's walk through "the Denver colored section, wishing I were a Negro, feeling that the best the white world had offered was not enough ecstasy for me, not enough life, joy, kicks, darkness, music, not enough night” (163). After buying some hot red chilli, Sal wishes he were "a Denver Mexican, or even a poor overworked Jap" (164). Passing the dark porches of Mexican and African American homes, Sal envisages 
"the dusky knee of some mysterious sensual gal" and wishes he could "exchange worlds with the happy, true-hearted, ecstatic Negroes of America" (164). Sal seems to return to the bourgeois world unchallenged by his experiences outside its boundaries. His wilful blindness is revealed upon his visit to Jane Lee, who asks him whether he sees signs of a distant fire. Sal replies, "I don't see anything," to which she responds, "Same old Paradise" (128).

Yet the novel's pastoral scenes of cotton-picking Negros and carefree peasantry are destabilised by haunting figures from a troubling past. Dean's search for his father in the slums of Denver are a reflection of Sal's own search for belonging, a theme which appears related to Kerouac's father's death which was forced beneath the narrative by editing prior to publication. In an early draft of the novel written in 1950, when Sal Paradise was called Peter Martin, Kerouac writes that after the death of his father,

Peter Martin found himself alone in the world, and after all what is a man going to do when his father is buried deep in the ground other than die himself in his heart and know that it won't be the last time before he dies finally in his poor mortal body, and, himself the father of children and sire of a family he will return to the original form of a piece of adventurous dust in this fatal ball of earth. (qtd. in Cunnell 15)

The ancestral figure thus encompasses origins and endings, life and death. The published version of On the Road omits the death of the father but remains haunted by paternal apparitions. When Dean sees a group of bums around a fire he admits, "I never know whether my father's there or not ... I never know whether to ask. He might be anywhere" (211). Sal also wonders where Dean's father might be; "riding freights, working as a scullion in railroad cookshacks, stumbling, down-crashing in wino alley nights, expiring on coal piles, dropping his yellowed teeth one by one in the gutters of the West" (119-20). 
The search for the guiding paternal figure as represented by Dean's father is matched by a flight from the obligations towards the past as represented by paternal figures either clinging or misleading. When the minor character Sam Shephard attempts to join Sal and Dean on a leg of their journey, he has to extricate himself from the physical and emotional grip of his grandfather. The old man begs him not to go with skin "white as a sheet" (242), and as they move away the grandfather still calls to his grandson with "something paralyzed about his movements, and he did nothing about leaving the doorway, but just stood in it, muttering, 'Stan,' and 'don't go,' and looking after us anxiously as we rounded the corner" (242). Although Sal imagines that "somewhere an old man with white hair was probably walking toward us with the Word, and would arrive any minute and make us silent" (49), when he does meet an old man, the advice this ancestral figure offers is dubious at best. During "the night of the ghost of the Susquehanna", when all Sal wants to do is "get home" (94), he joins up with an old hobo who insists he knows the right road. In fact, the old man is leading Sal in the wrong direction along a terrifying river lined with cliffs on both sides "that lean like hairy ghosts over the unknown waters" (94).

Gladys Foxe suggests that On the Road's "careening journeys, the repetitive crashes and crises all recreate a virtual trauma experience", which is why it did not see publication until 1957 since by then it was "no longer associated with the pain of war and war-haunted flight" and "different, more palatable associations to it could be made" (56). This is undoubtedly true, but Kerouac's own insistence on the palatable implicates authorial strategy just as much as reader reception. The disquieting experience of being misled by the Ghost of the Susquehanna is countered by Kerouac's recasting of a story of disorientation into a myth of American colonisation. Sal describes how he thought that 
all the wilderness of America was in the West till the Ghost of the Susquehanna showed me different. No, there is a wilderness in the East; it's the same wilderness Ben Franklin plodded in the oxcart days when he was postmaster, the same as it was when George Washington was a wild-buck Indian-fighter, when Daniel Boone told stories by Pennsylvania lamps and promised to find the Gap, when Bradford built his road and men whooped her up in log cabins. (95)

This concept of Eastern wilderness is couched in terms distinctly familiar and domestic; the colonial project might involve experience with the wild and the strange, but its purpose is to render America "home."

Author and close personal friend of Kerouac, John Clellon Holmes, suggested that the break-up of Kerouac's home in Lowell, the chaos of the war years and the death of his father had "left him disrupted, anchorless, a deeply traditional nature thrown out of kilter" (qtd. in Cunnell 7). Yet Holmes' claim that a Western ideology comprising the freedom of the road with a place in which to make a stand had been outlawed to the margins of American life during the postwar period is not entirely correct. Kerouac's desire to chronicle what was happening on those margins was a familiar and popular desire, as evidenced by the era's love of the Western genre. Kerouac cannily managed to write a novel adhering to popular postwar concerns regarding threats to individuality, while couching those concerns in a manner belonging to the American canon of quest narratives such as Huckleberry Finn and Moby Dick. At the same time, On the Road garnered adoration from a generation of disaffected youth seeking alternatives to Cold War values and lifestyles. The success of On the Road thus relies on its ability to be many things to many people: a celebration of postwar America that focuses on promise rather than reality; an archetypal quest through an iconic landscape; a risqué series of sexual affairs and drug-use; and a countercultural vision of a new stance advocating free love, bohemian values and alternative religion. 
As Howard Cunnell points out, the famous 1951 scroll version of the novel is a "markedly darker, edgier, and uninhibited" (31) text than the published version. The On the Road that was finally published almost ten years after Kerouac began to write it skirts away from the war or from condemning accepted American values, yet the numerous revisions which forced out overt references to dissolution and death left traces that sit oddly in such an exuberant text. When Sal arrives at the end of the continent he realises, "Here I was at the end of America - no more land - and now there was nowhere to go but back" (70). The repetitiousness of Sal's journeys is symptomatic of a compulsion to repeat; each trip promises new adventures and new horizons, but by the end of the novel the protagonists appear not to be travelling so much as fleeing. When Sal finally makes his way back to the East Coast of America, he finds himself crossing Long Island only to discover "there was no more land, just the Atlantic Ocean and we could only go so far" (224).

In a letter written to Kerouac in February 1950, John Clellon Holmes echoes D.H. Lawrence's suggestion about the American dream by pointing out that

Europeans always talk about running here, they hold out as long as they can and then they "throw up everything" and come. As a result, we in American have nowhere to run to, and so much to escape from. This is an endless, spacious prison in which we are caught.

The final pages of On the Road acknowledge the "awful land" over which Dean must travel back west but the disastrous trip to the "exceedingly hot and strange" (254) Mexico, which despite its initial promise turns out to involve the disintegration of friendship and health, suggests that the search for authenticity must remain within the geographical and ideological boundaries of America. The search for "IT" that propels Sal and Dean into constant peregrinations across the country leads them both back to the domestic hearth. Sal's wistful wish that "someday we'll be able to live on the same street with our families and get to be a couple of oldtimers together" (231) 
comes partly true: Dean heads back to his home in California where his wife and children await him, and Sal heads back to his home in New York where he finds "the girl with the pure and innocent dear eyes I had always searched for and so long" (278).

On the Road's oscillation between angst and joy, desolation and hope, authenticity and sham, and confession and repression reveals the fragmented nature not only of postwar American culture but of the postwar American self. Kerouac's "evisceration" was a shattering disillusionment shared by many of his generation and his inability to articulate this deep pessimism was mirrored in a culture that turned away from the legacy of the war to a cosy vision of life represented by television sitcoms such as Father Knows Best, fads such as hula hoops and the insulated homes of Levittown. Surging just beneath, however, were darker currents. The end of On the Road depicts Sal sitting on an old pier looking at the sky over New Jersey and thinking of Dean Moriarty, but just which Dean Moriarty he thinks of remains unclear: the Dean who wears the clothing outfitted to him by the "Natural Tailor of Natural Joy" (9), or the "burning shuddering frightful Angel" who leaves nothing in his wake but "charred ruins" (236) and whose "mad, bony purpose" and "gleaming eyes" pursue Sal like the Shrouded Traveller. 


\section{VIII}

\section{The Concealment that Fails to Conceal}

The civilized human spirit, whether one calls it bourgeois or merely leaves it at civilized, cannot get rid of a feeling of the uncanny...

\section{Thomas Mann, Doctor Faustus}

In a 1945 Saturday Review editorial written just four days following the Japanese surrender, Norman Cousins suggested that whatever elation America's victory entailed was "severely tempered by a primitive fear of the unknown, the fear of forces man can neither channel nor comprehend." The classical form of this terror, "the fear of irrational death," was transformed during one night in August 1945 to "burst out of the subconscious and into the conscious, filling the mind with primordial apprehensions" (qtd. in Boyer 7). If Cousins is correct in observing this terrifying return of the repressed, it did not take long for the primitive fears provoked by World War II to be contained and controlled. In the first few months of the postwar era anthropologist Robert Redfield observed that America was in the grips of a "fear psychosis" (qtd. in Boyer 21), but by 1950 Lewis Mumford suggested that so profound was the state of "self-enclosed delusions" through which Americans were blotting out the new and terrible reality that surrounded them, that if it appeared in an individual it would demand psychiatric treatment (qtd. in Boyer 282).

The 1998 film Pleasantville depicts a postwar suburban population rendered neurotic by repression, but according to Maxwell Geismar the "true victim of the prevailing cultural climate in the fifties was American literature itself" (54). Edmund Wilson was particularly stinging in his appraisals of the era's fiction and his critique of William Saroyan's The Adventures of Wesley Jackson (1946) is worth quoting at length: 
the last part of Wesley Jackson, in which the hero finally gets to England and eventually takes part in the invasion of France, is the record of an appalling victory over Saroyan's realistic instincts of the impulse toward self-befuddling and self protective fantasy. Wesley Jackson, who talks constantly of his trust in God, is specially exempted from misfortune by a darling old Providence who adores him. When he picks up what appears to be a tart in Piccadilly Circus, she turns out to be a sweet little golden-haired seventeen-year-old girl who has run away from home and who, never having slept with a man, is trying pathetically to qualify as a prostitute. Wesley takes her home to his rooms (God quickly got him out of barracks), gives her a bath and makes her his wife, and they are soon going to have a baby, to which Wesley looks forward with tears in his eyes. At last he is sent to France. But don't be alarmed for a minute. Two of his best friends are killed, to be sure, but this becomes a very beautiful thing; and when he is captured by the Germans, they prove charming and presently run away, leaving their prisoners in the camp, from which Wesley escapes back to England. He is pretty well scared for a moment when he discovers that his house has been bombed, but of course his little blue-eyed bride had luckily gone away to the country the night just before this happened, and he finds her safe and sound with her people. Even when Wesley buys tips on the races, both the horses he bets on wins, and the good old tipster is so delighted! ... This is surely some of the silliest nonsense ever published by a talented writer. (328-29)

As Wilson's summary reveals, much of the American literature written immediately after 1945 ostensibly about World War II is actually a canny avoidance of its traumatic implications. One of the protagonists in James Gould Cozzen's war novel Guard of Honor sums up the predominant postwar strategy: when faced with the uncontrollable or unmanageable, the best recourse was "you thought of something else" (198).

The complexities of being an American during the first postwar decade were, according to novelist Herbert Gold, "enough to tempt all of us to turn to partial, limited, maybe soothing half-views" (104). Another commentator noted how the mass audience "nervously rejects" many of the best novels of the period because such fiction could potentially raise questions "upon which it is unprepared and unwilling to reflect in the fat years of the fifties" (Swados 178). In a letter to Jack Kerouac written in April 1950, John Clellon Holmes explains that

It is so easy to be horrified, to feel thoroughly violated, sitting helpless among the broken stones of beliefs, ideals, hopes. Most people can sweep the nuisance 
under the rug: the alarming delinquencies, the revelation of wicked wishes, the foul expression that hurls muck on our consciences, the intensity of the quest for the "real", "gone", "mad" that is mirrored in bop and our night time world. Those who can sweep it away ... save themselves the shock of recognition.

John P. Marquand's Point of No Return, which reached number five on the bestseller list in 1949 and resolutely focuses on acceptable postwar issues such as family relationships and economic stress, reveals how the omission or denial of unpleasant reality frequently renders the familiar and homely uncomfortably strange. The novel's protagonist Charles shares with his wife and children a suburban retreat in Sycamore Park, which acts not just as a symbol of postwar success but as a constant reminder "of what might have happened and of what he would have done if things had turned out differently" (Marquand 102). Charles obsesses about the copper gutters and the way the conductors drain over part of the lawn:

It would be necessary to have a dry well dug for the conductors; and then there was the broken latch on the garage door, and the oil burner needed a new lining of firebrick; and then there was the weather stripping around the living room windows, and there was something still wrong with the gas water heater. Then there was the mortgage. Then there was the part of the cellar that he was going to turn into a workshop for himself and Bill, now that you could buy lathes and drills again. Those were the species of thoughts that came over him as he stood there by the door, and they were a relief after everything else. (102)

Charles' thoughts, while domestic and ostensibly comforting are rattled off in a manner close to hysterical. What exactly is meant by "what might have happened" and if "things had turned out differently" (Marquand 102)? Is he really referring to the vagaries of corporate advancement and financial success, or are there other threats he is aware of narrowly escaping? The war is not mentioned overtly, making itself known only through the reference to the new availability of tools after wartime restrictions: could it be the horrors of the war that Charles refers to when he states that domestic thoughts are a relief "after everything else"? Rather than discussing this "everything else", Marquand's protagonist suggests it is "better to turn on the 
phonograph ... better to get out the ice cubes and have some friends in and talk broadmindedly about the misfortunes of others. It was better to go to the club on Tuesday evenings and to talk about something else" (Marquand 110).

The avoidance strategies which mark the 1950s were subverted during the $1960 \mathrm{~s}$, which Philip Roth describes as "the demythologizing decade" in which much that had been considered taboo in the recent decade "forced itself upon the national consciousness, loathsome or not" (Reading Myself 87). What was once assumed to be "beyond reproach became the target of blasphemous assault; what was imagined to be indestructible, impermeable, in the very nature of American things, yielded and collapsed" (Reading Myself 88). Truman Capote's In Cold Blood (1966) was a marked departure from his atmospheric 1948 gothic Other Voices, Other Rooms and must have confused readers who knew him primarily from Holly Golightly's adventures in Breakfast at Tiffany's (1958). Capote demolished perceptions of the wholesome nature and safety of the American heartland and the American home, with Tony Tanner's review in the Spectator suggesting that In Cold Blood "is the American dream turning into the American nightmare.” By juxtaposing the lives and values of the Clutters with those of their murderers, Tanner points out that "Capote produces a stark image of the deep doubleness of American life" (qtd. in "Truman Capote, In Cold Blood.").

Change was on the horizon as early as 1955 , when Lionel Trilling bucked critical consensus on the role of the writer by reminding readers of The Opposing Self that the modern post-Enlightenment individual had at its disposal an "indigent perception" able to make visible the hidden aspects of cultural life (x). Countering the widespread silence regarding racial inequality in popular literature and film since 1945 was Lorraine Hansberry's play A Raisin in the Sun (1959), the plot of which revolves 
around the attempts of white middleclass Americans to prevent a black family purchasing a house in their neighborhood. This overt representation of American racism unexpectedly found success on Broadway, where it was the first play to appear written by a black woman and directed by a black director. Mailer's 1957 essay "The White Negro" articulated many aspects of postwar life which just a few years earlier would have been far more difficult to enunciate. Countering the widespread silence of the previous years, Mailer claims that "Probably, we will never be able to determine the psychic havoc of the concentration camps and the atom bomb upon the unconscious mind of almost everyone alive in these years" (Advertisements 338). Rather than avoiding the Holocaust or depicting the myth of atomic survivability, Mailer identifies the suppressed knowledge of being

doomed to die as a cipher in some vast statistical operation in which our teeth would be counted, and our hair would be saved, but our death itself would be unknown, unhonored, and unremarked, a death which could not follow with dignity as a possible consequence to serious actions we had chosen, but rather a death by deus ex machina in a gas chamber or a radioactive city. (Advertisements 338)

In 1957 Philip Rahv countered critical consensus on the causes of the era's literary banality by pointing out that the sort of imaginative transaction represented by Flaubert's Madame Bovary was unthinkable in America not because of the absence of materials "but the absence of writers prepared to cope with the materials actually at hand" (561). Like Trilling, Rahv subtly advocates dissent by suggesting that American literature of the 1920s, which showed "far more creative force" than that of the 1950s, relied on its "bitter assault on the national pieties" (564). As the late 1950s moved into the 1960s, cultural mores shifted away from accommodation and/or alienation to active rebellion. In 1960 poet Kenneth Rexroth announced that in the 1920s students "were cutting loose. In the thirties, they were joining up ... During the McCarthy Epoch and the Korean War, they were turning their backs and walking 
away. Today they are striking back" (113). The literature of the Beat writers offered an alternative to compliance or retreat and heralded the coming age of "dropping out," communal living, sexual experimentation and alternative religion. Ginsberg's 1956 poem "America" instructs the nation to "go fuck yourself with your atom bomb" and defiantly lists its author's subversive activities: "I used to be a communist when I was a kid and I'm not sorry./I smoke marijuana every chance I get.” The message this new poet of protest bore was a mocking parody of the Cold War mentality: "America it's them bad Russians./Them Russians them Russians and them Chinamen. And them Russians" (39).

Literature about World War II still navigated treacherous waters, but the Vietnam War countered the widespread consensus regarding the military that defined the decade following 1945. Fiction and film of the sixties displays little reverence for the military and introduces the more unsavoury and morally ambiguous aspects of America's role in the 1939-45 conflict. Kurt Vonnegut's Slaughterhouse-Five (1969) deals with the Dresden firebombing, which obliterated a city with no military significance killing tens of thousands of civilians, an event noticeably absent from earlier American war narratives. When Vonnegut's protagonist meets the official historian of the American Air Force, the omission of the Dresden bombing in his military history is justified by the military's fear that "a lot of bleeding hearts" (Vonnegut 191) might take exception to it. Interestingly, Vonnegut's war novel is also a science-fiction involving time travel and otherworldly beings called Tralfamadorians, who engage in the "“don't worry, be happy' school of psychobabble therapy" (Cacicedo 361). The Tralfamadorians advise the protagonist to use time travel as a method of avoidance, but Vonnegut's hero is unable to adhere to this Norman Peale-like advice. Joseph Heller's Catch-22 (1961) is a blackly comic satire 
on the insanity of war that shifts tone at one point to include an episode of "almost insupportable horror" (Burhans 241). An undefended Italian village is mercilessly attacked for no justifiable reason and, unlike some of the other violent events in the novel which "reflect real horrors but to some degree, at least, cushion the reader against experiencing them," the mission against the village is "stark murder" and "uncushioned horror" (Burhams 242).

The tendency towards demythologizing in fiction produced in the 1960s was mirrored in non-fiction. If the fifties were marked by reassuring non-fiction texts promising Peace of Mind, Eric Berne's 1964 bestseller Games People Play revealed, according to the reviews listed in its opening pages, the "real-life horrors, played in dead earnest in public places" (Chicago Tribune, qtd. in Berne 2). Newsweek similarly observed that the social games the book describes are not necessarily fun but are "hair-raisingly neurotic rituals in which tensions are discharged and satisfactions are gained, usually at the expense of others" (qtd. in Berne 2). Yet Berne's non-fiction revelation of social horror was hailed by the Chicago Tribune for its ability to be both "disturbing and delightful" (qtd. in Berne 2), revealing the way 1960s demythologisation resulted in a marked prevalence of black comedy. While Stanley Kubrick's popular film Dr. Strangelove or: How I Learned to Stop Worrying and Love the Bomb (1964) insists on the unsurvivability of atomic attack, it illustrates particularly well the way in which the representation of what is essentially unknowable - mass death - pushes a text into the realm of the canny. Although a review in the New York Times by Bosley Crowther admitted discomfort regarding the film's "discredit and even contempt" for America's defense establishment and described the overall effect "malefic and sick", Crowther also found some of the War 
Room conversations "hilarious" and suggested that "there are parts of this satire that are almost beyond compare."

Freud's acceptance of Schelling's definition of unheimlich as the name for everything that ought to have remained hidden but has come to light describes a concealment which fails to conceal, a concealment which "gives way to unconcealment; concealment shows itself as such" (Krell 49). It is the inaccessibility of the uncanny that enables Mailer's The Naked and the Dead, the ostensible grittiness of which is matched by its avoidance of "demonic reality," to provoke more unease than Joseph Heller's Catch-22 (1961), despite the latter's depiction of an insane American military, an attack on an undefended Italian village, the rape and murder of a female civilian and a gruesome scene of disembowelment. Heller's litany of the horrors of war might provoke discomfort but its overt representations of what was previously absent from American World War II novels means there is no repressed material to provoke an uncanny response in the reader. Similarly, the confessional mode used by the poets of the sixties, such as Sylvia Plath, John Berryman and Anne Sexton, although reliant on the revelation of dark secrets, reveals through conscious disclosure material that can hardly be described as repressed.

Although an aesthetic exploration that appears to have little obvious connection with war, Freud's essay on the uncanny remains haunted by global conflict. Published just one year after the end of the First World War, Freud apologises for not having made a more thorough exploration of foreign literature dealing with the uncanny, citing "reasons which, as may easily be guessed, lie in the times in which we live" (619). Despite his claim to a "special obtuseness" (620) in regard to experiencing the uncanny, Freud's sole personal example of an uncanny response to literature occurred in "the middle of the isolation of wartime", when a copy of Strand magazine 
randomly fell into his hands and in which he read a tale that although "naïve" nevertheless provoked a "quite remarkable" (636) feeling of uncanniness. As Ken Gelder and Jane M. Jacobs point out, Freud's essay on the uncanny, while obviously concerned with the workings of the psyche, is also about "one's sense of place in a modern, changing environment, and it attends to anxieties which are symptomatic of an ongoing process of realignment in the post-war modern world" (23). This realignment stems from the profound disorientation war provokes. In "Thoughts for the Times on War and Death" (1915), Freud identifies confusion and one-sided information as aspects complicating an individual's response to global conflict. Living through a time of war means "standing too close" to great changes "without a glimmering of the future that is being shaped" and Freud admits that in the face of World War I, "we ourselves are at a loss as to the significance of the impressions which bear down upon us and as to the value of the judgements which we form" (Complete Works Vol. 14, 275).

The anxiety provoked by the return of the repressed is essentially anxiety provoked by death, which Heidegger defines as the "Nothing of the possible impossibility" of existence (qtd. in McNeil 324), and which Hélène Cixous points out "does not have any form in life. Our consciousness makes no place for the representation of our mortality" (543). World War II is characterised by death on a mass scale, forcing a subject into confrontation with that which is most strongly repressed and which gives rise to the most intense feelings of anxiety. The period in America between 1945 and 1955 saw the difficulties inherent in negotiating the mass trauma of World War II further compounded by the threats of the Cold War and the Korean War, while repressive socio-political mechanisms silenced articulation of disturbing realities. In "McCarthyism: Political Repression and the Fear of Communism," Ellen Schreker 
points out that wars breed political repression, and it is certainly true that America's sense of itself as a postwar superpower - politically, ideologically, morally and economically - required a good deal of studious avoidance and omission, but repression is also bred by trauma. In a letter sent home from Okinawa in 1945 and included in the $P B S$ online collection of wartime correspondence, American soldier John Taussing describes the "stink and smell of dead, bloated bodies in the air everywhere. Dried up blood and bones are strewn around, and wounded people straggling around. When I get home I want to forget about all this that I've seen. I don't want to remember it." But the need to repress the trauma of war is inextricably mingled with the urge to reveal it. The same soldier apologises for "such a gruesome letter but it's the truth, something you rarely hear in the papers. I wish you'd read this letter to your friends, so that they will know what it's really like over this way, and so they will not be misled by the papers" (Taussing, "The Mental Toll").

In the context of war, a certain amount of repression and censorship is necessary, but by continuing to deny the horror of World War II and its aftermath, American culture created an ambiguous space in which peace and plenty were constantly haunted by a sense of anxiety. To be "at home" in postwar America always involved the threat of estrangement, a paradox perfectly encapsulated in the fiction of John Cheever, whose domestic tales of material comfort remain riddled with angst. As one critic notes, despite depictions of affluent homes in leafy suburbs it is "quite easy to finish a Cheever story and find oneself profoundly depressed" (Aubrey 77). Cheever's stories are marked by "a thematic subtext that is never fully expressed" (O'Hara 55), but only rarely do they represent the uncanny. One of the few stories to consciously deal with the uncanny is "The Enormous Radio" (1947), which depicts a sinister wireless enabling a married couple to eavesdrop into their neighbours' lives. This 
apparently supernatural radio, which emanates "a malevolent green light" and contains "violent forces" (Cheever 34), confronts the protagonist Irene Westcott with the ugly truths she attempts to ignore. The apparently civilised apartment building in which she lives turns out to be home to sordid affairs and violence, and the story ends with the revelation that the values represented by the Westcotts are also a façade. "The Enormous Radio" is an anomaly among Cheever's oeuvre not only in its depiction of the uncanny and its urban rather than suburban setting, but in its failure to adhere to the "fairly neat conclusions" that characterize his fiction (Andersson 432). The apparently occult nature of the radio is never addressed and the reader is left not only with the disquieting reaction provoked by the depiction of the uncanny radio, but also with the uneasiness provoked by a story that is profoundly ambivalent.

Cheever's later stories focus on representations of the quotidian rather than the uncanny, but his narratives remain suffused with a powerful sense of repressed material apparently linked to his struggles with alcoholism and bisexuality, which remained secret until the posthumous publication of his diaries. In 1974 he shared his sexual inclinations with a graduate student studying his writing, who then suggested, "It's been in your work all along, hasn't it?" Cheever replied, “Of course it has. It's always been there, for all the world to see" (qtd. in Aubrey 69). It is in precisely this way that all literature can be considered uncanny. For everything consciously selected to compose a specific text, there exists, like a shadowy double, those things which remain excluded, either consciously rejected or unconsciously repressed. Reading involves an interaction not only with what is on the page but with what is left out. Realism is capable not only of verisimilitude or of reflecting the reality we imagine to be true, but is also capable of countering that vision with the darker horrors we attempt to omit. For Cheever, verisimilitude is "a technique one exploits in order to 
assure the reader of the truthfulness of what he's being told. If he truly believes he is standing on a rug, you can pull it out from under him" (qtd. in Grant 3). While a fictional domestic interior might appear real, Cheever points out that verisimilitude is also a lie; at any moment "a mad woman could come in the door" (qtd. in Grant 3).

Rosemary Jackson identifies the recurrent motifs in fantasy literature as ghosts, shadows, vampires, werewolves, doubles, partial selves, reflections, enclosures, monsters, beasts and cannibals. She also suggests that impulses towards incest, necrophilia, androgyny, cannibalism, recidivism, narcissism and abnormal psychological states are all involved with fantasy's erasing of the demarcations of gender and genre. Jackson's discussion of fantasy literature reveals some startling parallels between the themes she identifies as particular to that genre and the realist novels discussed in this study. While there are no supernatural beings or paranormal events in any of the texts included here, Invisible Man features a strangely spectral protagonist, a drug-induced hallucination, and a tale of incest; the plot of The Victim revolves around paranoia, a double, and fears regarding abnormal psychology; Wise Blood's protagonist is haunted by ghastly reflections erasing demarcations of gender, race, animal, vegetable and mineral; The Naked and the Dead is strangely caught up with dreams and portents; The Sheltering Sky is obsessed with abnormal psychological states; and the protagonist in On the Road is haunted by spectral figures.

Although this study argues for realism as the most appropriate "home" for the postwar uncanny, the return of the repressed complicates verisimilitude and pushes ostensibly realistic texts into liminal, genre-defying spaces. Defined by its relationality, the uncanny can only exist alongside homely and familiar reality, yet at the same time the uncanny is a profound threat to this reassuring vision. Uncanny 
realism might be thought of as the dark double of canny fantasy. While fantasy's enactment of taboos frequently re-confirms institutional order 'by supplying a vicarious fulfilment of desire and neutralizing an urge towards transgression' (R. Jackson 72), uncanny realism leaves the reader oddly off-balance. Fantasy reveals an awful threat, allows the safe engagement with that threat, and reassuringly vanquishes threat in order to re-establish the status quo. Uncanny realism only ever implies a threat; we never quite know what we are supposed to be afraid of. Jackson suggests that a "dialogue between fantastic and realistic narrative modes often operates within individual texts," but rather than realism attempting "to repress and defuse the subversive thrust" (124) of the fantastic, it is the reassuringly familiar fantasy that attempts to neutralise the diffuse dread provoked by uncanny realism.

America during the 1940s and 1950s relied on fantasy, both positive and negative. The "happy days" fantasy of white picket fences and the Red Threat fantasy of antiCommunism avoided the more troubling aspects of mid-twentieth-century "demonic reality", creating and reinforcing a highly circumscribed version of postwar American life. The six key texts of "uncanny realism" covered in this study reveal a range of strategies different writers took to negotiate the conformism and the denial or evasion of the unpleasant that stifled their world. Freud's theories concentrate on the unspoken and the taboo, which suggests that gaps in literary representation are potentially spaces filled with meaning. This text behind the text is a potent strategy for bypassing censorship, meaning that while the uncanny can be seen as a result of repression, it simultaneously acts as a strategy for articulating that repression. 


\section{Works Cited}

Adams, Michael C.C. The Best War Ever: America and World War II. Baltimore and London: John Hopkins UP, 1994.

Adorno, Theodor. Prisms. Cambridge, Mass: MIT Press, 1967.

Agee, James. "The Bomb.” Time, August, 20, 1945. http://www.time.com/time/ magazine/article/0,9171,797639,00.html?internalid=ACA.

Aharoni, Ada. "The Victim: Freedom of Choice." Saul Bellow Journal 4, no. 1 (1985): $33-44$.

Aldridge, John. After the Lost Generation: A Critical Study of the Writers of Two Wars. New York: McGraw Hill, 1951.

- - $\quad$ The Devil in the Fire: Retrospective Essays on American Literature and Culture 1951-1971. New York: Harper's Magazine Press, 1972.

- - - " "The Search for Values." The American Novel since World War II. Ed. Marcus Klein. New York: Fawcett World Library, 1969: 39-57.

All That Heaven Allows. Film. Directed by Douglas Sirk. Universal International Pictures, 1955.

Almond, Ian. "Experimenting with Islam: Nietzschean Reflections on Bowles's Araplaina." Philosophy and Literature 28, no. 2 (October 2004): 309-24. Altick, Richard D. The Shows of London. Cambridge, Mass: Harvard UP, 1978. America and the Intellectuals: A Symposium. New York: Partisan Review, 1953. Andersson, Lars. "Burglary in Shady Hill and Sarsaparilla: The Politics of Conformity in White and Cheever." Australian Literary Studies 22, no. 4 (October 2006): 432-43.

Andrews, William L. Francis Smith Foster and Trudier Harris, eds. The Oxford Companion to African American Literature. New York: Oxford UP, 1997. 
Appy, Christian G. “'We'll Follow the Old Man': The Strains of Sentimental Militarism in Popular Films of the Fifties." Rethinking Cold War Culture. Ed. Peter J. Kuznick and James Gilbert. Washington and London: Smithsonian Institution Press, 2001: 74-105.

Asals, Frederick. Flannery O'Connor: The Imagination of Extremity. Athens, GA: Georgia UP, 1982.

Asch, Sholem. Mary. New York: G.P. Putnam \& Sons, 1949.

Aubrey, Timothy. "John Cheever and the Management of Middlebrow Misery." Iowa Journal of Cultural Studies 3 (Fall 2003): 64-84.

Auchincloss, Eve and Nancy Lynch. "An Interview with Norman Mailer." Conversations with Norman Mailer. Ed. Michael J. Lennon. Jackson and London: UP of Mississippi, 1988: 39-51.

Bacon, Jon Lance. Flannery O'Connor and Cold War Culture. Cambridge: Cambridge UP, 1993.

- - - "A Fondness for Supermarkets: Wise Blood and Consumer Culture.” New Essays on Wise Blood. Ed. Michael Kreyling. Cambridge: Cambridge UP, 1995: 25-49.

Baker J., Houston A. “To Move Without Moving: Creativity and Commerce in Ralph Ellison's Trueblood Episode.” Blues, Ideology, and Afro-American Literature: A Vernacular Theory. Chicago: University of Chicago Press, 1984.

Baldwin, James. Giovanni’s Room. New York: Dial Press, 1956.

- - $\quad$ Go Tell it on the Mountain. New York: Dell, 1953.

- - - Notes of a Native Son. Boston: Beacon Press, 1955.

Baumbach, Jonathon. "The Double Vision: The Victim by Saul Bellow.” The Landscape of Nightmare: Studies in the Contemporary American Novel. Ed. 
Jonathon Baumbach. New York: New York UP, 1965: 35-54.

Beaune Jean-Claude. "The Classical Age of Automata: An Impressionistic Survey from the Sixteenth to the Nineteenth Century." Zone: Fragments for a History of the Human Body 3, no. 1. Ed. Michel Feher. (1989): 430-80.

Becker, Susan. Gothic Forms of Feminine Fictions. Manchester: Manchester UP, 1999.

Beikasten, André. “The Heresy of Flannery O'Connor.” Critical Essays on Flannery O’Connor. Ed. Melvin J. Friedman and Beverly Lyon Clark. Boston: G.K. Hall \& Co, 1985: 138-58.

Bell, Daniel. The End of Ideology: On the Exhaustion of Political Ideas in the Fifties. Glencoe Ill: Free Press, 1960.

Bellow, Saul. The Adventures of Augie March. New York: Viking Press, 1953.

- - - "Man Underground.” Review of Invisible Man, by Ralph Ellison. Ralph Ellison: A Collection of Critical Essays. Ed. John Hersey. Englewood Cliffs, NJ: Prentice Hall, 1974: 27-30.

- - - Mr Sammler's Planet. New York: Viking, 1970.

- - - "Some Notes on Recent American Fiction." The American Novel Since World War II. Ed. Marcus Klein. New York: Fawcett World Library, 1969: 159-74.

- - - The Victim. London: Weidenfeld and Nicholson, 1947.

- - - "Where Do We Go From Here: The Future of Fiction." Saul Bellow and the Critics. Ed. Irving Malin. London and New York: University of London Press and New York UP, 1967: 211-20.

Bergland, Renée L. The National Uncanny: Indian Ghosts and American Subjects. Hanover and London: UP of New England, 2000.

Berne, Eric. Games People Play: The Psychology of Human Relationships. New 
York: Grove Press, 1964.

Bernstein, Susan. "It Walks: The Ambulatory Uncanny.” MLN 118, no. 5 (December 2003): 1111-40.

Bessel, Richard and Dirk Schumann, eds. Life After Death: Approaches to a Cultural and Social History of Europe during the 1940s and 1950s. Cambridge: Cambridge UP, 2003.

The Best Years of Our Lives. Film. Directed by William Wyler. RKO Radio Pictures, 1946.

Beveridge, Allan. "The Detective, the Psychiatrist and Post-modernism." Psychiatric Bulletin 22 (1998): 573-4.

Bhabha, Homi. The Location of Culture. London and New York: Routledge, 1994.

Bone, Robert. "Ralph Ellison and the Uses of the Imagination." New Essays on Invisible Man. Ed. Robert O’Meally. Cambridge: Cambridge UP, 1988: 95114.

Booker, Bryan D. African Americans in the United States Army in World War II. Jefferson, N.C.: McFarland, 2008.

Bowles, Paul. The Delicate Prey and Other Stories. New York: Random House, 1950.

- - - $\quad$ Let It Come Down. New York: Random House, 1952.

- - $\quad$ The Sheltering Sky. New York: Ecco Press, 1998.

Boyarin, Daniel. Unheroic Conduct: The Rise of Heterosexuality and the Invention of the Jewish Man. Berkeley: University of California Press, 1997.

Boyer, Paul. By the Bomb's Early Light: American Thought and Culture at the Dawn of the Atomic Age. New York: Pantheon, 1985.

Bradbury, Malcolm. “Saul Bellow's The Victim.” Critical Quarterly 5, no. 2 (1963): 119-28. 
Bragg, Melvyn. "Norman Mailer Talks to Melvyn Bragg about the Bizarre Business of Writing a Hypothetical Autobiography of Marilyn Monroe.” Conversations with Norman Mailer. Ed. Michael J. Lennon. Jackson and London: University of Mississippi Press, 1988: 193-206.

Braham, Jeanne. A Sort of Columbus: The American Voyages of Saul Bellow's Fiction. Athens, GA: University of Georgia Press, 1984.

Breit, Harvey. "Talk With Paul Bowles.” New York Times, March 9, 1952, 10.

Breuer, Joseph and Sigmund Freud. Studies in Hysteria. Trans. A.A. Brill. Boston: Beacon Press, 1950.

Brians, Paul. Nuclear Holocausts: Atomic War in Fiction 1895-1984. Kent, OH: Kent State UP, 1987.

Brier, Evan. "Constructing the Post-war Art Novel: Paul Bowles, James Laughlin, and the Making of The Sheltering Sky.” PMLA 121, no.1 (January 2006): 186-99. Brinkley, Alan. "The Illusion of Unity in Cold War Culture." Rethinking Cold War Culture. Peter J. Kuznick and James Gilbert, eds. Washington and London: Smithsonian Institution Press, 2001: 61-73.

Bristow, Gwen. Jubilee Trail. New York: Crowell, 1950.

Brown, Bill. "Reification, Reanimation, and the American Uncanny." Critical Inquiry 32, no. 2 (Winter 2006): 175-208.

Brown, Norman O. Life Against Death: The Psychoanalytical Meaning of History. London: Routledge and Kegan Paul, 1959.

Burger, Nash K. Review of Catcher in the Rye, by J.D. Salinger. New York Times, July 16, 1951, 19.

Burhans, Clinton S. Jr. "Spindrift and the Sea": Structural Patterns and Unifying Elements in Catch 22." Twentieth Century Literature 19, no. 4 (October 
1973): 239-50.

Cacicedo, Alberto. "You Must Remember This": Trauma and Memory in Catch-22 and Slaughterhouse-Five." Critique 46, no. 4 (Summer 2005): 357-68.

Canby, Vincent. "When Irish Eyes Are Smiling, It's Norman Mailer." Conversations with Norman Mailer. Ed. Michael J. Lennon. Jackson and London: University of Mississippi Press, 1988: 139-44..

Caponi, Gena Dagel, ed. Conversations with Paul Bowles. Jackson: University of Mississippi Press, 1993.

Capote, Truman. Breakfast at Tiffany's. New York: Random House, 1958.

- - - $\quad$ In Cold Blood. New York: Random House, 1965.

- - - Other Voices, Other Rooms. New York: Random House, 1948.

Caputo, Philip. A Rumor of War. New York: Holt, Rinehart and Winston, 1977.

Carnegie, Dale. How to Stop Worrying and Start Living. New York: Simon and Schuster, 1948.

Cash, Jean W. Flannery O'Connor: A Life. Knoxville: University of Tennessee Press, 2002.

Castle, Terry. The Female Thermometer: Eighteenth-century Culture and the Invention of the Uncanny. New York: Oxford UP, 1995.

Chalupa, Cynthia. “Re-Imaging the Fantastic: E. T. A. Hoffmann's 'The Story of the Lost Reflection."” Marvels and Tales 20, no. 1 (2006): 11-32.

Charters, Ann, ed. The Portable Beat Reader. New York: Viking, 1992.

Chavkin, Allan. “Ivan Karamazov's Rebellion and Bellow's The Victim." Papers on Language and Literature: A Journal for Scholars and Critics of Language and Literature 16, no. 3 (1980): 316-20.

Cheever, John. The Stories of John Cheever. London: J. Cape, 1979. 
Cixous, Hélène. "Fiction and Its Phantoms: A Reading of Freud's Das Unheimlich." New Literary History 7, no. 3 (Spring 1976): 525-48.

Clark, Tom. Jack Kerouac: A Biography. New York: Harcourt, 1984.

Clayton, John Jacob. Saul Bellow: In Defense of Man. Bloomington and London: Indiana University Press, 1968.

Coates, Paul. The Double and the Other. New York: St Martin's Press, 1998.

Conrad, Joseph. Heart of Darkness and The Secret Sharer. Ed. Albert J. Guerard. New York: New American Library of World Literature, 1964.

Costain, Thomas B. The Silver Chalice. New York: Dial Press, 1951.

Cozzens, James Gould. Guard of Honor. New York: Harcourt, Brace and Company, 1948.

Crowther, Bosley. Review of Dr. Strangelove Or: How I Learned To Stop Worrying and Love The Bomb, directed by Stanley Kubrick. New York Times, January 31, 1964, http://movies.nytimes.com/movie/review?res= EE05E7DF173DE367BC4950DFB766838F679EDE.

Cunnell, Howard. On the Road: The Original Scroll. New York: Viking, 2007.

Cuordileone, Kyle A. Manhood and American Political Culture in the Cold War: Masculinity, the Vital Center and American Political Culture in the Cold War, 1949-1963. New York and London: Routledge, 2005.

Davis, Robert Gorham. “A Relentless Drive Toward Doom.” Review of Let it Come Down, by Paul Bowles. New York Times, March 2, 1952, 1.

Dempsey, David. "The Dusty Answer of Modern War." Review of The Naked and the Dead, by Norman Mailer. New York Times, May 9, 1948, 6.

- - - " "In Pursuit of Kicks." Review of On the Road, by Jack Kerouac. New York Times, September 8, 1957, 4. 
Derrida, Jacques. Specters of Marx: The State of the Debt, the Work of Mourning, \& the New International. Trans. Peggy Kamuf. New York: Routledge, 1994.

Dickstein, Morris. Leopards in the Temple: The Transformation of American Fiction 1945-1970. Cambridge, Mass: Harvard UP, 2002.

- - - " "On and Off the Road: The Outsider as Young Rebel." The Cambridge History of American Literature: Prose Writing 1940-1990. Ed. Sacvan Bercovitch and Cyrus R. K. Patell. Cambridge: Cambridge UP, 1999: 165223.

Dillon, Millicent. You Are Not I. Berkeley: University of California Press, 1998. Dittmar, Kurt. “The End of Enlightenment: Bellow's Universal View of the Holocaust." Saul Bellow at Seventy-Five: A Collection of Critical Essay. Tübingen: G. Narr, 1991: 63-80.

Doherty, Thomas. Cold War, Cool Medium. New York: Columbia UP, 2003.

Dorsey, John T. "Atomic Bomb Literature in Japan and the West.” Neohelicon 14, no. 2 (September 1987): 325-34.

Dos Passos, John. Three Soldiers. New York: Penguin, 1997.

Dostoevsky, Fyodor. The Double. Trans. Hugh Aplin. London: Hesperus, 2004.

Douglas, Lloyd C. The Big Fisherman. Boston: Houghton Mifflin, 1948.

Douglass, Frederick. The Narrative of the Life of Frederick Douglass, an American Slave, Written by Himself. New York: Library of America, 1994.

Downer, Alan S. "Skullduggery in Chungkin and Manhattan." New York Times, November 30, 1947, 29.

Dr. Strangelove or: How I Learned to Stop Worrying and Love the Bomb. Film. Directed by Stanley Kubrick. Columbia Pictures, 1964.

Du Bois, William. The Souls of Black Folks. New York: Dodd, Mead, 1961. 
Duck and Cover. Film. Directed by Anthony Rizzo. Archer Productions, 1952.

Durkheim, Emile. The Elementary Forms of Religious Life. Trans. Joseph Ward Swain. London: Allen \& Unwin, 1976.

Edmonds, Susan. "Through a Glass Darkly: Visions of Integrated Community in Flannery O'Connor's Wise Blood." Contemporary Literature 37, no. 4 (Winter 1996): 559-85.

Edwards, Brian T. "Sheltering Screens: Paul Bowles and Foreign Relations." American Literary History 17, no. 2 (2005): 307-34.

Eisenhower, Dwight. Commencement address. Columbia University, New York, NY. June 8, 1949.

- - - Republican Groups of Southern California breakfast. Address. Statler Hotel, Los Angeles, CA. September 24, 1954.

Eliot, T.S. "Hamlet and His Problems." The Sacred Wood: Essays on Poetry and Criticism. London: Methuen, 1966.

Ellis, Katherine. “Charlotte Smith's Subversive Gothic.” Feminist Studies 3, no. 3/4 (Spring-Summer 1976): 51-5.

Ellis, Kate Ferguson. The Contested Castle: Gothic Novels and the Subversion of Domestic Ideology. Urbana and Chicago: University of Illinois Press, I989. Ellison, Ralph. Invisible Man. New York: Penguin, 1952.

- - S Shadow and Act. New York: Vintage, 1972.

Englehardt, Tom. The End of Victory Culture: Cold War America and the Disillusioning of a Generation. Amherst: University of Massachusetts Press, 1998.

Ernst, Hugo. "Labor Views the Campaigns." The Nation, May 10, 1952, 447.

Ernst, Morris. Utopia 1976. New York: Rinehart, 1955. 
“The Eternal Jew: The Film of a 2000-Year Rat Migration.” Review of Der ewige Jude, directed by Fritz Hippler. Unser Wille und Weg, 10, 1940, 54-5.

Fairhall, James. James Joyce and the Question of History. Cambridge: Cambridge UP, 1995.

Father Knows Best. Television. CBS. Los Angeles. October 3, 1954 - May 23, 1960.

Fiedler, Leslie. “The Fate of the Novel." Kenyon Review 10, no. 3 (1948): 519-27.

- - $\quad$ Love and Death in the American Novel. $2^{\text {nd }}$ Ed. New York: Stein and Day, 1966.

- - - “The State of American Writing, 1948: Seven Questions.” Partisan Review, August 15, 1948.

Filreis, Alan. "Cultural Aspects of Atomic Anxiety." The Literature and Culture of the American 1950s. University of Pennsylvania Center for Programs in Contemporary Writing (May 31, 2007): http://www.writing.upenn.edu/ afilreis/50s/atomic-anxieties.html.

Finney, Jack. The Body Snatchers. New York: Dell, 1955.

Fishbein, Leslie. "The Snake Pit (1948): The Sexist Nature of Sanity." Hollywood as Historian: American Film in a Cultural Context. Ed. Peter C. Rollins. Lexington, KY: UP of Kentucky, 1998: 134-58.

Flamm, Irving. "The Atomic Bomb.” Time, September 10, 1945, http://www.time.com/time/magazine/article/ 0,9171,776043,00.html.

Foley, Barbara. "Ralph Ellison as Proletarian Journalist." Science and Society 62, no. 4 (Winter 1998-9): 537-56.

Folz, Anne. "Paul Bowles." Review of Contemporary Fiction 20, no. 2 (Summer 2000): 81-121.

Foster, Hal. “Exquisite Corpses.” Visual Anthropology Review 7, no. 1 (Spring 1991): 
$51-61$.

- - $\quad$ Compulsive Beauty. Cambridge, MA: MIT Press, 1993.

Foxe, Gladys. “And Nobody Knows What's Going to Happen to Anybody: Fear and Futility in Jack Kerouac's On the Road and Why it is Important." Psychoanalytic Review 95, no. 1 (February 2008): 45-62.

Frank, Lawrence K. and Mary Hughes Frank. How to be a Woman. Indianapolis: Bobbs-Merrill, 1954.

Freedman, Ralph. "Saul Bellow: The Illusion of Environment." Saul Bellow and the Critics. Ed. Irving Malin. London and New York: University of London Press and New York UP, 1967: 51-68.

Freud, Sigmund. "The Aetiology of Hysteria." The Standard Edition of the Complete Psychological Works of Sigmund Freud. Trans. James Strachey. Vol. 3. London: Hogarth, 1953: 191-221.

- - - The Interpretation of Dreams. Trans. Joyce Crick. Oxford: Oxford UP, 1999.

- - J Jokes and their Relation to the Unconscious. Trans. James Strachey. New York: Norton, 2001.

- - - "Thoughts for the Times on War and Death." The Standard Edition of the Complete Psychological Works of Sigmund Freud. Trans. James Strachey. Vol. 14. London: Hogarth, 1953: 275-300.

- - - "The Uncanny.” Trans. James Strachey. New Literary History 7, no. 3 (Spring 1976): 619-45.

Fried, Albert. McCarthyism: The Great American Red Scare. New York and Oxford: Oxford UP, 1997.

Fried, Richard M. Nightmare in Red: The McCarthy Era in Perspective. Oxford: Oxford UP, 1990. 
Friedman, Melvin J. and Lewis A. Lawson, eds. The Added Dimension: The Art and Mind of Flannery O'Connor. New York: Fordham UP, 1966.

Friend, Tad. "Years in the Desert: The Sheltering Sky at Fifty." The New Yorker, January 15, 2001, 90.

“Frustrated Preacher.” Newsweek, May 19, 1952, 114-5.

Fulford, Bob. "Mailer, McLuhan and Muggeridge: On Obscenity." Conversations with Norman Mailer. Ed. Michael J. Lennon. Jackson and London: University of Mississippi Press, 1988: 116-38.

Gallup, George. The Gallup Poll: Public Opinion 1935-1971. Vol 1. Random House: New York, 1972.

Geismar, Maxwell. "The Shifting Illusion.” American Dreams, American Nightmares. Ed. David Madden. Carbondale and Edwardsville: Southern Illinois UP, 1970: $45-57$.

Gelder, Ken and Jane M. Jacobs. Uncanny Australia: Sacredness and Identity in a Postcolonial Nation. Melbourne: Melbourne UP, 1998.

Gentry, Marshall Bruce. Flannery O'Connor's Religion of the Grotesque. Jackson and London: University of Mississippi Press, 1986.

Giannone, Richard. Flannery O'Connor: Hermit Novelist. Urbana: University of Illinois Press, 2000.

- - Flannery O'Connor and the Mystery of Love. New York: Fordham UP, 1999.

Giedion, Siegfried. Mechanization Takes Command. Oxford: Oxford UP, 1948.

Gilbert, Sandra M. and Susan Gubar. The Madwoman in the Attic: The Woman Writer and the Nineteenth-Century Literary Imagination. $2^{\text {nd }}$ Ed. New Haven: Yale UP, 2000.

Gilmore, Thomas B. “Allbee’s Drinking.” Twentieth Century Literature 28, no. 4 
(1982): 318-96.

Ginsberg, Allen. Howl and Other Poems. San Francisco: City Lights, 1956.

Glasner-Heled, Galia. "Reader, Writer, and Holocaust Literature: The Case of KaTzetnik.” Israel Studies 12, no. 3 (2007): 109-33.

Gleeson-White, Sarah. “A Peculiarly Southern Form of Ugliness: Eudora Welty, Carson McCullers, and Flannery O’Connor.” Southern Literary Journal 36, no. 1 (Fall 2003): 46-57.

Gold, Herbert. The Age of Happy Problems. New York: Dial Press, 1962.

Goldman, Eric. The Crucial Decade: America 1945-1960. New York: Vintage, 1961. Gordon, Sarah . Flannery O'Connor: The Obedient Imagination. Athens: University of Georgia Press, 2000.

Gouri, Haim. Facing the Glass Booth: The Jerusalem Trail of Adolf Eichmann. Detroit: Wayne State UP, 2004.

Goyen, William. “Unending Vengeance.” Review of Wise Blood, by Flannery O’Connor. New York Times, May 18, 1952, 4.

Graham, Billy. "Biblical Authority in Evangelism." Christianity Today, October15, 1956, 5-6.

- - - Secret of Happiness. Kingswood, Surrey: World's Work Ltd, 1955.

- - $\quad$ Peace With God. Nashville: Word Books, 1984.

Graham, Maryemma and Amritjit Singh, eds. Conversations with Ralph Ellison. Jackson: University of Mississippi Press, 1995.

Grant, Annette. Interview with John Cheever. "The Art of Fiction No. 62.” Paris Review 67 (Fall 1976): 1-28.

Gray, Jeffrey. “'It's Not Natural': Freud's 'Uncanny' and O’Connor's Wise Blood." The Southern Literary Journal 29, no. 1 (Fall 1996): 56-68. 
Greenberg, Martin. “Modern Man as Jew.” Commentary (January 1948): 86-7.

Griffin, Roger, Modernism and Fascism: The Sense of a Beginning under Mussolini and Hitler. Basingstoke: Palgrave Macmillan, 2007.

Griffith, Robert. The Politics of Fear: Joseph R. McCarthy and the Senate. $2^{\text {nd }}$ ed. Amherst: University of Massachusetts Press, 1970.

Grixti, Joseph. Terrors of Uncertainty: The Cultural Contexts of Horror Fiction. London and New York: Routledge, 1989.

Grotjahn, Martin. Beyond Laughter: Humor and the Subconscious. New York: McGraw-Hill, 1957.

Hale, Nathan G. Jr. The Rise and Crisis of Psychoanalysis in the United States: Freud and the Americans, 1917-1985. Vol 2. New York: Oxford UP, 1995.

Halliwell, Martin. American Culture in the 1950s. Edinburgh: Edinburgh UP, 2007.

Halpern, Daniel. “An Interview with Paul Bowles (1970).” The Authorized Paul Bowles Web Site (September 2, 2009): http://www.paulbowles.org/danielhalpern.html.

Hansberry, Lorraine. A Raisin in the Sun: A Drama in Three Acts. New York: Random House, 1959.

Hardin, Michael. “Ralph Ellison’s Invisible Man: Invisibility, Race, and Homoeroticism from Fredrick Douglass to E. Lyn Harris.” The Southern Literary Journal 37, no. 1 (2004): 96-120.

Heidegger, Martin. Basic Writings from 'Being and Time' (1927) to 'The Task of Thinking' (1964). Ed. David Farrell Krell. London: Routledge and Kegan Paul, 1978.

- - - The Concept of Time. Trans. William McNeil. Oxford and Cambridge, Mass.: Blackwell, 1992. 
Heinlein, Robert. The Puppet Masters. New York: Doubleday, 1951.

Heller, Joseph. Catch-22. New York: Dell, 1972.

Hemingway. Ernest. A Farewell to Arms. London: Jonathon Cape, 1957.

Hendershot, Cynthia. Paranoia, the Bomb, and 1950s Science Fiction Films. Bowling Green, OH: Bowling Green State University Popular Press, 1999.

Henriksen, Margot A. Dr. Strangelove's America: Society and Culture in the Atomic Age. Berkeley and Los Angeles: University of California Press, 1997.

Herr, Michael. Dispatches. New York: Knopf, 1977.

Hersey, John. “A Completion of Personality: A Talk with Ralph Ellison.” Ralph Ellison: A Collection of Critical Essays. Ed. John Hersey. Englewood Cliffs, NJ: Prentice-Hall, 1974: 1-20.

- - - "Hiroshima." Harmondsworth: Penguin, 1946.

Hewitt, Avid and Robert Donahoo, ed. Flannery O'Connor in the Age of Terrorism: Essays on Violence and Grace. Knoxville: University of Tennessee Press, 2010.

Hibbard, Allen. Paul Bowles: A Study of the Short Fiction. New York: Twayne, 1993. Hienger. Jörg. "The Uncanny and Science Fiction.” Science Fiction Studies 18, no. 6 (July 18, 1979): http://www.depauw.edu/sfs/backissues/18/hienger18art.htm.

Hoberek, Andrew. "Race Man, Organization Man, Invisible Man.” Modern Language Quarterly 56, no. 1 (March 1998): 99-120.

- - - The Twilight of the Middle Class: Post-World War II American Fiction and White-Collar Work. Princeton and Oxford: Princeton UP, 2005.

Hobson, Christopher Z. "Invisible Man and African American Radicalism in World War II." African American Review 39, no. 3 (Fall 2005): 355-76.

Hobson, Laura Z. Gentleman's Agreement. New York: Simon and Schuster, 1947. 
Hoffmann, E.T.A. The Devils Elixir. Edinburgh: Blackwood, 1824.

- - - "The Sandman.” The Golden Pot and Other Tales. Trans. Ritchie Robertson. Oxford: Oxford UP, 1992.

Holmes, John Clellon. Letter to Jack Kerouac. 3 Jul. 1949. Transcript in Berg Collection, New York Public Library, New York.

- - - Letter to Jack Kerouac. 3 Feb. 1950. Transcript in the Berg Collection, New York Public Library, New York.

- - - Letter to Jack Kerouac. 26 Apr. 1950. Transcript in Berg Collection, New York Public Library, New York.

Horner, Avril and Sue Zlosnik. Gothic and the Comic Turn. New York: Palgrave Macmillan, 2005.

Howe, Irving. "Black Boys and Native Sons.” Dissent 10 (Autumn 1963): 353-68.

- - - "Odysseus Flat on his Back.” Review of Herzog, by Saul Bellow. New Republic, September 19, 1964, 21-6.

- - - "Man Underground." Review of Invisible Man, by Ralph Ellison. The Nation 174, no. 19 (May 10, 1952): 454.

- - - "Writing and the Holocaust." Writing and the Holocaust. Ed. Berel Lang. New York: 1988: 175-200.

Huyssen, Andreas. After the Great Divide: Modernism, Mass Culture, Postmodernism. Bloomington: Indiana UP, 1986.

Insdorf, Annette. Indelible Shadows: Film and the Holocaust. Cambridge: Cambridge UP, 2003.

Iser, Wolfgang. The Act of Reading. London: Routledge \& Kegan Paul, 1978.

I Was a Communist for the FBI. Film. Directed by Gordon Douglas. Warner Brothers, 1951. 
Jackson, Anna. "Uncanny Hauntings, Canny Children.” The Gothic in Children's Literature: Haunting the Borders. Ed. Anna Jackson, Karen Coats, and Roderick McGillis. New York and London: Routledge, 2008: 157-76. Jackson, Charles. "On the Seamier Side." Review of The Delicate Prey and Other Stories, by Paul Bowles. New York Times, December 3, 1950, 6.

Jackson, Rosemary. Fantasy: The Literature of Subversion. London: Methuen \& Co, 1981.

Jackson, Shirley. The Haunting of Hill House. London: Constable \& Robinson, 1999. Jacobs, Harriet. Incidents in the Life of a Slave Girl. New York: Oxford UP, 1990. Jancovich, Mark. Rational Fears: American Horror in the 1950s. Manchester and New York: Manchester UP, 1996.

Jentsch, Ernst. "On the Psychology of the Uncanny.” Trans. Roy Sellars. Angelaki 2, no. 1 (1995): 7-16.

Jones, James. From Here to Eternity. London: Hodder \& Stoughton, 1998.

Jones, Peter G. War and the Novelist: Appraising the American War Novel. Columbia and London: University of Missouri Press, 1976.

Jordan, Michael M. "Flannery O’Connor's Writings: A Guide for the Perplexed." Modern Age 47, no. 1 (Winter 2005): 48-57.

Kahane, Claire. “The Re-vision of Rage: Flannery O’Connor and Me.” Massachusetts Review 46, no. 3 (Fall 2005): 439-63.

Kaiser, Ernest. “A Critical Look at Ellison's Fiction and at Social and Literary Criticism by and about the Author." The Literature and Culture of the American 1950s. University of Pennsylvania Center for Programs in Contemporary Writing. http://www.writing.upenn.edu/ afilreis/50s/ kaiser-on-ellison.html. 
Kakutani, Michiko. "40 Years after, Artists Still Struggle with the Holocaust." New York Times, December 5, 1982, 1.

Karski, Jan. "Polish Death Camp.” Colliers, October 14, 1944, 18-19, 60-61.

Ka-Tzetnik. The House of Dolls. New York: Simon and Schuster, 1955.

Kazin, Alfred, ed. Writers at Work: The Paris Review Interviews. Third Series. London: Secker \& Warburg, 1967.

Kerouac, Jack. Letter to Alfred Kazin. February, 20 1951. Transcript in the Berg Collection, New York Public Library, New York.

- - - $\quad$ Letter to Alfred Kazin. October, 27, 1954. Transcript in Berg Collection, New York Public Library, New York.

- - - Letter to Neal Cassady. January 3, 1951. Transcript in the Berg Collection, New York Public Library, New York.

- - L Letter to Neal Cassady. December 3, 1951. Transcript in the Berg Collection, New York Public Library, New York.

- - - Letter to Neal Cassady. Undated 1953. Transcript in Berg Collection, New York Public Library, New York.

- - - On the Road. New York: Penguin, 1991.

- - - Selected Letters, 1940-1956. Ed. Ann Charters. London: Viking Press, 1995.

- - - The Town and the City. New York. Harcourt Brace, 1950.

- - Vanity of Duluoz: An Adventurous Education 1935-1946. New York: Paragon, 1979.

King, Stephen. Danse Macabre. New York: Everest House, 1981.

Klarman, Michael J. From Jim Crow to Civil Rights: The Supreme Court and the Struggle forRacial Equality. New York and Oxford: Oxford UP, 2004.

Klein, Marcus, ed. After Alienation: American Novels in the Mid-Century. Chicago: 
University of Chicago Press, 1964.

- - - The American Novel Since World War II. New York: Fawcett World Library, 1969.

Kovic, Ron. Born of the Fourth of July. New York: McGraw-Hill, 1976.

Krell, David Farrell. "Das Unheimlich: Architectural Sections of Heidegger and Freud." Research in Phenomenology 22 (1992): 43-61.

Kremer, S. Lillian. Witness Through The Imagination: Jewish American Holocaust Literature. Detroit: Wayne State UP, 1989.

Kristeva. Julia. Powers of Horror: An Essay on Abjection. Trans. Leon S. Roudiez. New York: Columbia UP, 1982.

- - - Strangers to Ourselves. Trans. L.S. Roudiez. New York: Columbia UP, 1991.

Krupat, Arnold. Ethno-Criticism: Ethnography, History, Literature. Berkeley: University of California Press, 1992.

Lake, Christina Bieber. The Incarnational Art of Flannery O'Connor. Macon, GA.: Mercer UP, 2005.

Lamb, Lady Caroline. Glenarvon. London: Routledge, 1995.

Lawrence, D.H. Studies in Classic American Literature. London: William Heinemann, 1933.

Leab, Dan. "I was a Communist for the FBI.” History Today 46, no. 12 (1996): 42-7. Leave it to Beaver. Television. CBS/ABC. Los Angeles. October 4, 1957 - June 20, 1963.

LeDrew, Stephen. "Jokes and their Relation to the Uncanny: The Comic, the Horrific, and Pleasure in Audition and Romero's Dead Films." PSYART: An Online Journal for the Psychological Study of the Arts. (2006): http://www.clas.ufl.edu/ ipsa/journal/2006_ledrew01.shtml\#ledrew01. 
Lee, Jason C. "Criticism and the Terror of Nothingness." Philosophy and Literature 27, no. 1 (April 2003): 211-23.

Leff, Laurel. Buried by the Times: The Holocaust and America's Most Important Newspaper. New York: Cambridge UP, 2005.

Levi, Primo. If This is a Man. New York: Orion, 1959.

Lewis, M. G. The Monk: A Romance. Ed. Howard Anderson. London: Oxford UP, 1973.

Lewis, R. W. B. "Recent Fiction: Picaro and Pilgrim.” A Time of Harvest: American Literature 1910-1960. Ed. Robert E. Spiller. New York: Hill and Wang, 1962: 144-53.

Liebman, Joshua. Peace of Mind. New York: Simon \& Schuster, 1947.

Lifton, Robert Jay and Greg Mitchell. Hiroshima in America: Fifty Years of Denial. New York: Putnam's Sons, 1995.

Linville, Susan E. History Films, Women, and Freud's Uncanny. Austin: University of Texas Press, 2004.

Lipstadt, Deborah E. "America and the Memory of the Holocaust: 1950-1965." Modern Judaism 16, no. 3 (1996): 195-214.

Loehr, Franklin. The Power of Prayer on Plants. Garden City, NY: Doubleday, 1959.

Loshitzky, Yosefa. "Orientalist Representations: Palestinians and Arabs in Some Postcolonial Film and Literature" Cultural Encounters: Representing Otherness. Ed. Elizabeth Hallam and Brian V. Street. London and New York: Routledge, 2000: 51-71.

- - - "The Tourist/Traveler Gaze: Bertolucci and Bowles's The Sheltering Sky." East-West Film Journal 7, no. 2 (1993): 110-32.

Luft, Joseph and W.M. Wheeler. "Reaction to John Hersey's 'Hiroshima." Journal 
of Social Psychology 28 (August 1948): 135-40.

Lukács, György. "Realism in the Balance." The Norton Anthology of Theory and Criticism. Ed. Vincent B. Leitch. New York: Norton, 2001: 1033-58.

Macdonald, Dwight. Against the American Grain. London: Victor Gollancz, 1963.

Macdonald, Ross. The Galton Case. New York: Knopf, 1959.

Magee, Rosemary, ed. Conversations with Flannery O'Connor. Jackson: UP of Mississippi, 1987.

Maher, Paul and David Amram. Kerouac: The Definitive Biography. Lanham, MD: Rowman and Littlefield, 2004.

Mailer, Norman. Advertisements For Myself. Cambridge, Mass: Harvard UP, 1992.

- - - Barbary Shore. New York: Rinehart, 1951.

- - - Letter to Alfred Kazin. May 11, 1959. Transcript in the Berg Collection, New York Public Library, New York.

- - - The Naked and the Dead. New York: Picador, 1998.

Mann, Thomas. Doctor Faustus. Trans. H. T. Lowe-Porter. London: Secker and Warburg, 1959.

Marcus, S. Freud and the Culture of Psychoanalysis. Boston: George Allen and Unwin, 1984.

Marcus, Steven. Interview with Norman Mailer. "The Art of Fiction No. 32.” Paris Review 31 (Winter-Spring 1964): 1-37.

Marquand, John P. Point of No Return. Boston: Little, Brown and Co., 1949.

Mart, Martin E. Modern American Religion. Chicago: University of Chicago Press, 1986.

Matheson, Richard. I Am Legend. New York: Orb, 1997.

Maturin, Charles Robert. Melmoth the Wanderer. Oxford and New York: Oxford 
UP, 1989.

May, Elaine Tyler. Homeward Bound: American Families in the Cold War Era. New York: Basic Books, 1999.

McGrady, Mike. "Why We Are Interviewing Norman Mailer." Conversations with Norman Mailer. Ed. Michael J. Lennon. Jackson and London: UP of Mississippi, 1988: 108-15.

Melville, Herman. Moby Dick. Ed. Harold Bloom. New York: Bloom’s Literary Criticism: Chelsea House, 2007.

Metalious, Grace. Peyton Place. New York: Buccaneer Books, 1954.

Meyerowitz, Joanne Jay. Not June Cleaver: Women and Gender in Postwar America 1945-1965. Philadelphia: Temple UP, 1994.

Miller, Arthur. Death of a Salesman. New York: Viking, 1949.

- - $\quad$ Timebends: A Life. London: Methuen, 1999.

Miller, T. Douglas and Marion Nowak. The Fifties: The Way We Really Were. New York: Doubleday, 1977.

Mills, C. Wright. White Collar: The American Middle Classes. New York: Oxford UP, 2002.

Millstein, Gilbert. Review of On the Road, by Jack Kerouac. New York Times, September 5, 1957, 27.

Mitgang, Herbert. "Invisible Man: As Vivid Today as in 1952.” New York Times, March 1, 1982, 13.

Moers, Ellen. Literary Women. London: The Women's Press, 1980.

Molloy. Maureen. "Death and the Maiden: The Feminine and the Nation in Recent New Zealand Films.” Signs 25, no. 1 (1999): 153-70.

Moore, Robert Laurence. Selling God: American Religion in the Marketplace of 
Culture. New York and Oxford: Oxford UP, 1995.

Mulvey-Roberts, Marie, ed. The Handbook to Gothic Literature. New York: New York UP, 1998.

Mumford, Lewis. "Irrational Elements in Art and Politics." Literature and Liberalism: An Anthology of Sixty Years of The New Republic. Ed. Edward Zwick. Washington: The New Republic Book Company, 1976: 169-74.

Murphy, R.C. “Think Right: Reverend Peale’s Panacea.” The Nation, May 7, 1955, 398-400.

Murrow, Edward R. Keynote Speech. The Radio-Television News Directors Association, RTNDA Convention, Chicago, IL. October 15, 1958.

Nabokov, Vladimir. Pnin. Garden City, NJ: Doubleday, 1957.

Nadel, Alan. Invisible Criticism: Ralph Ellison and the American Canon. Iowa City: University of Iowa Press, 1988.

Nilsen, Helge N. “Anti-Semitism and Persecution Complex: A Comment of Saul Bellow's The Victim." English Studies 60, no. 2 (1979): 183-91.

Ninkovich, Frank A. "The New Criticism and Cold War America." Southern Quarterly 20 (Fall 1981): 1-24.

Norris, Margot. Writing War in the Twentieth Century. Charlottesville and London: University of Virginia Press, 2000.

O’Brian, Kenneth Paul and Lynn H. Parson. The Home-Front War: World War II and American Society. Westport: Greenwood, 1995.

O’Connor, Flannery. The Habit of Being. Ed. Sally Fitzgerald. New York: Farrar, Strauss, Giroux, 1979.

- - $\quad$ Mystery and Manners. Sally and Robert Fitzgerald, eds. New York: Farrar, 1969. 
- - - Three by Flannery O'Connor: Wise Blood, The Violent Bear it Away, Everything that Rises Must Converge. New York: Penguin, 1983.

- - - The Violent Bear It Away. New York: Farrar, Strauss \& Giroux, 1955.

- - $\quad$ Wise Blood. New York: Farrar, Straus, and Giroux, 1962.

O'Hara, James E. John Cheever: A Study of the Short Fiction. Boston: Twayne, 1989.

O’Meally, Robert, ed. New Essays on Invisible Man. Cambridge: Cambridge UP, 1988.

Ostendorf, Berndt. "Ralph Waldo Emerson: Anthropology, Modernism, and Jazz." New Essays on Invisible Man. Ed. Robert O’Meally. Cambridge: Cambridge UP, 1988: 95-121.

Our Country and Our Culture. New York: Partisan Review, 1952.

Oursler, Fulton. The Greatest Story Ever Told. New York: Doubleday, 1949.

Patterson, Kathy Davis. "Echoes of Dracula: Racial Politics and the Failure of Segregated Spaces in Richard Matheson's I Am Legend." Journal of Dracula Studies 7 (2005): 19-27.

Patterson, Richard F. “Tangier Days: Talking with Paul Bowles, 1984-1988.” Web Conjunctions. Bard College (November 28, 1998): http://www.conjunctions.com/webcon/bowles.htm.

Peale, Norman Vincent. The Art of Living. New York: Abingdon, 1937.

- - $\quad$ Faith is the Answer: A Pastor and a Psychiatrist Discuss Your Problems. New York: Prentice-Hall, 1950.

Pells, Richard H. The Liberal Mind in a Conservative Age: American Intellectuals in the 1940s and 1950s. New York: Harper Row, 1985.

Pifer, Ellen. Saul Bellow: Against the Grain. Philadelphia: Pennsylvania UP, 1990. Pleasantville. Film. Directed by Gary Ross. New Line Cinema, 1998. 
Podhoretz, Norman. "The Language of Life." Commentary 16 (1953): 378-80.

Poe, Edgar Allan. Poe's Tales of Mystery and Imagination. London: J.M. Dent \& Sons, 1908.

Prown, Katherine Hemple. Revising Flannery O'Connor: Southern Literary Culture and the Problem of Female Authorship. Charlottesville: University of Virginia Press, 2001.

Psychoanalysis. EC Comics, 1955.

Punter, David, ed. Companion to the Gothic. Oxford: Blackwell Publishing, 2000.

- - - and Elisabeth Bronfen. "Gothic: Violence, Trauma and the Ethical." The Gothic. Ed. Fred Botting. Cambridge: D.S. Brewer, 2001: 7-23.

- - - The Literature of Terror: A History of Gothic Fictions from 1765 to the Present Day. London and New York: Longmans, 1980.

Purcell, D. “The People are Afraid.” Time, July 15, 1946, http://www.time.com/time/ magazine/ article/ 0,9171,803812,00.html.

Purple Heart. Film. Directed by Lewis Milestone. Twentieth Century Fox, 1944.

Raglan, Lord. The Hero: A Study in Tradition, Myth, and Drama. Westport, Conn: Greenwood Press, 1975.

Rahv, Philip. “Self-Definition in American Literature.” The Commentary Reader: Two Decades of Articles and Stories. Ed. Norman Podhoretz. London: Rupert Hart-Davis, 1968: 556-66.

Rainwater, Catherine. “'Sinister Overtones,' 'Terrible Phrases': Poe’s Influence on the Writing of Paul Bowles." Essays in Literature 2 (Fall 1984): 253-66.

Ramey, Philip. “A Talk with Paul Bowles,” The Authorized Paul Bowles Website. http://www.paulbowles.org/talk.html.

Reeve, Clara. The Old English Baron: A Gothic Story. Ed. James Trainer. London and 
New York: Oxford UP, 1967.

Reisman, David. The Lonely Crowd. New Haven and London: Yale UP, 1950.

Remarque, Erich Maria. All Quiet on the Western Front. Trans. A. W. Wheen. London: Putnam, 1954.

Rexroth, Kenneth. "The Students Take Over." World Outside the Window: The Selected Essays of Kenneth Rexroth. Ed. Bradford Murrow. New York: New Directions, 1987: 113-26.

Richardson, Mark. "Peasant Dreams: Reading On the Road." Texas Studies in Literature and Language 43, no. 2 (Summer 2001): 218-45.

Robinson, Henry Morton. The Cardinal. New York: Simon and Schuster, 1950.

Rogin, Michael Paul. The Intellectuals and McCarthy: The Radical Specter. Cambridge, Mass: Massachusetts Institute of Technology Press, 1967.

Rostan, Kimberly. "Reading Traumatically and Representing the Real in Collective Suffering." College Literature 33, no. 2 (Spring 2006): 172-84.

Roth, Philip. Reading Myself and Others. New York: Penguin, 1985.

- - - "Writing American Fiction." The American Novel Since World War II. Ed. Marcus Klein. New York: Fawcett World Library, 1969: 142-58.

Royle, Nicholas. The Uncanny. Manchester: Manchester UP, 2003.

Salinger, J.D. The Catcher in the Rye. Boston: Little, Brown \& Co, 1951.

Saroyan, William. The Adventures of Wesley Jackson. New York: Harcourt Brace, 1946.

Sassoon, Siegfried. Counter-Attack and Other Poems. London: W. Heinemann, 1918.

- - - The Old Huntsman and Other Poems. New York: Dutton, 1920.

- - - The War Poems of Siegfried Sassoon. London: W. Heinemann, 1973.

Schaub, Thomas Hill. American Fiction in the Cold War. Madison, Wisconsin: 
University of Wisconsin Press, 1991.

Schneider, Irving. "The Psychiatrist in the Movies: The First Fifty Years." The

Psychoanalytic Study of Literature. Joseph Reppen and Maurice Charney, eds. Hillsdale, NJ: The Analytic Press, 1985: 53- 67.

Schreker, Ellen. "McCarthyism: Political Repression and the Fear of Communism." Social Research 71, no. 4 (Winter 2004): 1041-86.

Scott, Lawrence P. and William M. Womack. Double V: The Civil Rights Struggle of the Tuskagee Airmen. East Lansing: Michigan State UP, 1994.

“See It Now.” Television. CBS-TV. March 9, 1954.

Semarne, Veda. “The Snake Pit: A Woman's Serpentine Journey Toward (W)holeness." Literature/Film Quarterly 22, no. 3 (1994): 144-50.

“Sex and Sand.” Review of The Sheltering Sky, by Paul Bowles. Time, December 5, 1949, http:// www.time.com/time/ magazine/ article/0,9171,805263,00.html. Seyama, Jun'ichiro and Ruth S. Nagayama. "The Uncanny Valley: Effect of Realism on the Impression of Artificial Human Faces.” Presence 16, no. 4 (August 2007): 337-53.

Shapiro, Herbert. White Violence and Black Response: From Reconstruction to Montgomery. Amherst: University of Massachusetts Press, 1988.

Shaw, Irwin. The Young Lions. London: Jonathon Cape, 1949.

- - - “The Art of Fiction No. 4.” Interviewed by Lucas Matthiessen, Willie Morris and John Marquand. Paris Review 4 (Winter 1953): 1-26.

Shedd, Charlie W. Pray Your Weight Away. Philadelphia: Lippincott, 1957.

Sheen, Fulton. Peace of Soul. New York: McGraw-Hill, 1949.

- - - Way to Happiness. Garden City, NY: Garden City Books, 1954.

Shellabarger, Samuel. Lord Vanity. Boston: Little, Brown \& Co, 1953. 
Shelley, Mary. Frankenstein. London: Dent, 1959.

Shepherd, M. Sherlock Holmes and the Case of Dr Freud. London: Tavistock, 1985.

Simpson, Caroline Chung. An Absent Presence: Japanese Americans in Postwar American Culture 1945-1960. Durham: Duke UP, 2001.

Slethaug, Gordon. The Play of the Double in Postmodern American Fiction. Carbondale: Southern Illinois UP, 1993.

Smith, Allan Lloyd. American Gothic Fiction: An Introduction. New York: Continuum, 2004.

Smith. Martha. "Georgian Pens Wise Blood, A First Novel.” Atlanta Journal and Constitution, May 18, 1952, F7.

The Snake Pit. Film. Directed by Anatole Litvak. Twentieth Century Fox, 1948. Spellbound. Film. Directed by Alfred Hitchcock. Selznick International Pictures, 1945.

Spillane, Mickey. One Lonely Night. New York: Signet, 1951.

Srigley, Susan. Flannery O'Connor's Sacramental Art. Notre Dame, Ind.: University of Notre Dame Press, 2004.

Stephens, Elizabeth. “America, Israel and the Six Day War.” History Today 57, no. 6 (June 2007): 12-20.

Stern, Daniel. Who Shall Live, Who Shall Die. New York: Crown, 1963.

Stevenson, R.L. The Strange Case of Dr Jekyll and Mr Hyde. Oxford: Oxford UP, 2007.

Steward, Douglas. "The Illusions of Phallic Agency: Invisible Man, Totem and Taboo, and the Santa Claus Surprise." Callaloo 26, no. 2 (Spring 2003): 52235.

Stewart, Maria W. Productions of Mrs Maria W. Stewart. New York: Oxford 
UP, 1988.

Stoker, Bram. The Essential Dracula: Including the Complete Novel by Bram Stoker. Ed. Leonard Wolf. New York: Plume, 1993.

Streeter, Edward. Father of the Bride. New York: Simon and Schuster, 1949.

Styron, William. Sophie's Choice. New York: Random House, 1979.

“Survival: Are Shelters the Answer?” Newsweek, November 6, 1961, 19.

Survival Under Atomic Attack. Washington: United States Government Printing Office, 1950.

Suspicion. Film. Directed by Alfred Hitchcock. RKO Radio Pictures, 1941.

Swados, Harvey. "The Image in the Mirror." The Living Novel: A Symposium. Ed. Granville Hicks. New York: Macmillan, 1957: 165-93.

Taussing, John. Personal letter (April 29, 1945). “The Mental Toll,” Perilous Fight: America's World War II in Color. http://www.pbs.org/perilousfight/ psychology/the_mental_toll/letters/.

Theado, Matt. The Beats: A Literary Reference. New York: Carroll and Graf, 2003. Them! Film. Directed by Gordon Douglas. Warner Bros, 1954.

Thigpen, Corbett H. and Hervey M. Cleckley. The Three Faces of Eve. New York: McGraw Hill, 1957.

Thomson, Irene Taviss. "Individualism and Conformity in the 1950s vs. the 1980s." Sociological Forum 7, no. 3 (September 1992): 497-516.

The Three Faces of Eve. Film. Directed by Nunnally Johnson. Twentieth Century Fox, 1957.

Todd, Jean-Marie, “The Veiled Woman in Freud's Das Unheimlich.” Signs 11, no. 3 (Spring 1986): 519-28.

Todorov, Tzvetan. The Fantastic: A Structural Approach to a Literary Genre. 
Cleveland: Press of Case Western Reserve University, 1973.

Torgovnick, Marianna. The War Complex: World War II in Our Time. Chicago: Chicago UP, 2005.

Trachtenberg, Stanley, ed. Critical Essays on Saul Bellow. Boston: G.K. Hall and Co., 1979.

Treat, John Whittier. Writing Ground Zero: Japanese Literature and the Atomic Bomb. Chicago and London: Chicago UP, 1995.

Trilling, Diana. "Fiction in Review.” Nation, January 3, 1948, 24-5.

Trilling, Lionel. The Opposing Self. London: Secker and Warburg, 1955.

"Truman Capote, In Cold Blood." Portfolio: The Journalism of Ideas. New York University, http://journalism.nyu.edu/portfolio/books/book140.html.

Truman, Harry S. Memoirs of Harry S. Truman. Garden City: Doubleday, 1987.

Tuttle, William. Daddy's Gone to War: The Second World War in the Lives of America's Children. New York: Oxford UP, 1995.

Twain, Mark. The Adventures of Huckleberry Finn. New York: Bantam, 1981.

"Vancouver is Best Place to Live." BBC News, October 4, 2005, ttp://news.bbc.co.uk/ 2/hi/business/4306936.stm.

Van Ells, Mark David. To Hear Only Thunder Again: America's World War II Veterans Come Home. Lanham, Md.: Lexington Books, 2001.

“The Veterans.” Life, August 5, 1946, 36.

Vidler, Anthony. The Architectural Uncanny: Essays in the Modern Unhomely. Cambridge: Massachusetts Institute of Technology Press, 1994.

Vonnegut, Kurt. Slaughterhouse-Five or the Children's Crusade: A Duty-Dance with Death. New York: Dell, 1971.

Wakeman, Frederic. The Hucksters. Harmondsworth, Middlesex: Penguin, 1954. 
Wald, Priscilla. Contagious: Cultures, Carriers, and the Outbreak Narrative. Durham and London: Duke UP, 2008.

Walker, David. Appeal, in Four Articles; Together with a Preamble, to the Colored Citizens of the World. New York: Hill and Wang, 1965.

Wallant, Edward Lewis. The Pawnbroker. New York: Harcourt, Brace \& World, 1961.

Walpole, Horace. The Castle of Otranto. Ed. W. S. Lewis. London: Oxford UP, 1964.

Waltari, Mika. The Egyptian. Trans. Naomi Walford. New York: G.P. Putnam, 1949.

Ward, Mary Jane. The Snake Pit. New York: Random House, 1946.

Warren, Robert Penn. “The Unity of Experience.” Commentary 39, no. 5 (1965): 916.

Washington, Booker T. Up from Slavery. Garden City: Doubleday, 1963.

Watts, Ian. The Rise of the Novel: Studies in Defoe, Richardson and Fielding. Berkeley and Los Angeles: University of California Press, 1957.

Weatherford, Doris. American Women and World War II. Edison, NJ.: Castle Books, 2008.

Webber, Andrew J. The Doppelganger: Double Visions in German Literature. Oxford: Clarendon Press, 1996.

Weis, Jessica. To Have and to Hold: Marriage, the Baby Boom and Social Change. Chicago: University of Chicago Press, 2000.

Wertham, Fredric. Seduction of the Innocent. London: Museum Press, 1955.

Wheatley, Phyllis. Complete Writings. New York: Penguin, 2001.

White, Sarah Gleeson. “A Peculiarly Southern Form of Ugliness: Eudora Welty, Carson McCullers, and Flannery O’Connor.” The Southern Literary Journal 36, no. 1 (2003): 46- 57. 
Whitfield, Stephen J. The Culture of the Cold War. $2^{\text {nd }}$ Ed. Baltimore: John Hopkins UP, 1996.

Whyte, William. The Organization Man. New York: Simon and Schuster, 1956.

Wiesel, Elie. "The Holocaust as Literary Inspiration.” Dimensions of the Holocaust. Ed. Elliot Lefkowirtz. Evanston: Northwestern UP, 1977: 4-19.

Wilde, Oscar. The Picture of Dorian Gray. Ed. Isobel Murray. Oxford: Oxford UP, 1981.

Wilhite, Keith. “John Cheever's Shady Hill, or: How I Learned to Stop Worrying and Love the Suburbs." Studies in American Fiction 34, no. 2 (Autumn 2006): 215-40.

Williams, Anne. Art of Darkness: A Poetics of Gothic. Chicago: Chicago UP, 1995. Williams, Tennessee. "An Allegory of Man and his Sahara.” Review of The Sheltering Sky, by Paul Bowles. New York Times, December 4, 1949, http://www.nytimes.com/books/ 98/05/ 17/specials/bowles-sheltering.html.

- - $\quad$ A Streetcar Named Desire. New York: New Directions, 1947.

Wilson, Edmund. Classics and Commercials. New York: Farrar Strauss and Co, 1950.

Wilson, Sloan. The Man in the Gray Flannel Suit. New York: Simon and Schuster, 1955.

Winkler, Allan M. Life under a Cloud: American Anxiety about the Atom. New York: Oxford UP, 1993.

Wolf, Arnold Jacob. "Saul Bellow, Jew.” Judaism 50, no. 2 (Spring 2001): 241-47.

Wood, Ralph C. Flannery O'Connor and the Christ-Haunted South. Grand Rapids, Michigan: William B. Eerdmans Publishing, 2004.

Wouk, Herman. The Caine Mutiny. New York: Doubleday, 1951. 
- - $\quad$ Marjorie Morningstar. New York: Doubleday, 1955.

Wright, Bradford W. Comic Book Nation: The Transformation of Youth Culture in America. Baltimore: John Hopkins UP, 2001.

Wright, Richard. Black Boy. New York: Harper Perennial, 1993.

- - - Native Son. New York: New American Library, 1964.

Wyman, David S. The Abandonment of the Jews: America and the Holocaust 19411945. New York: Pantheon Books, 1984.

Yerby, Frank. A Woman Called Fancy. New York: Dial Press, 1951.

Yôko, Ôta. "City of Corpses.” Hiroshima: Three Witnesses. Ed. Richard H. Minear. Princeton, N.J.: Princeton UP, 1990. 